\author{
UNIVERSIDADE DE SÃO PAULO \\ ESCOLA DE ENGENHARIA DE SÃO CARLOS \\ DEPARTAMENTO DE ENGENHARIA DE ESTRUTURAS
}

\title{
Cisalhamento na interface entre concreto pré-moldado e concreto moldado no local em elementos submetidos à flexão
}

\author{
Daniel de Lima Araújo
}

Dissertação apresentada à Escola de Engenharia de São Carlos da Universidade de São Paulo como parte dos requisitos para obtenção do título de Mestre em Engenharia de Estruturas.

Orientador: Prof ${ }^{\circ}$. Dr. Mounir Khalil El Debs

São Carlos 
Class. TESE

Cuts.

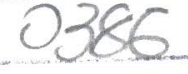

Tombo 137197

t 0934244

Ficha catalográfica preparada pela Seção de Tratamento da Informação do Serviço de Biblioteca - EESC-USP

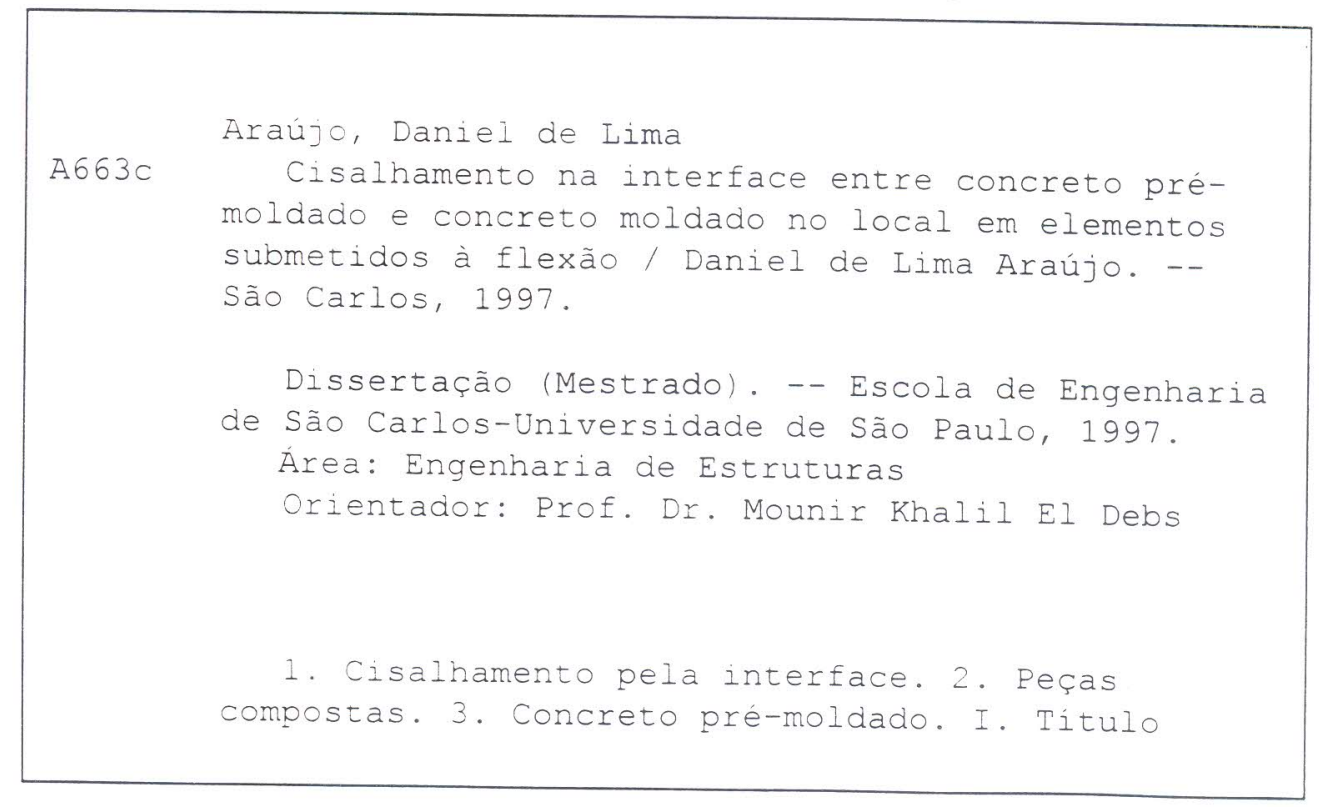


"Se aceitares as minhas palavras e esconderes contigo os meus mandamentos para fazeres atento a sabedoria o teu ouvido e para inclinares o teu coração ao entendimento, e se clamares por inteligência e por entendimento alçares a voz, se buscares a sabedoria como a prata e como a tesouros escondidos a procurares, então entenderás o temor do Senhor e acharás o conhecimento de Deus. Porque o Senhor dá a sabedoria, e da sua boca vem a inteligência e o entendimento. Ele reserva a verdadeira sabedoria para os retos; é escudo para os que caminham na sinceridade, guarda as veredas do juízo e conserva o caminho dos seus santos." (Provérbios 2:1-8)

Dedico esse trabalho ao meu Senhor e Salvador Jesus Cristo, aos meus pais, Odair e Safira, e à minha avó Áurea (em memória), aos quais devo o que sou. 


\section{AGRADECIMENTOS}

Ao prof ${ }^{0}$. Mounir Khalil El Debs pela orientação segura e incentivo, sem os quais este trabalho não existiria.

Aos professores José Samuel Giongo e Maximiliano Malite pelas sugestões feitas ao trabalho no exame de qualificação.

Ao técnicos do laboratório, Luíz Vicente Vareda, Amaury Ignácio da Silva, Jorge Luis Rodrigues Brabo, Valdir Carlos D'Lucca, Mauri Sérgio Dias Guillen e Mário Botelho pela dedicação na realização dos ensaios.

À Maria Nadir Minatel pela orientação no trabalho de referências bibliográficas.

Aos colegas e companheiros do Departamento de Engenharia de Estruturas, mas em especial à amiga Ana Elisabeth pelo auxílio nos ensaios e às amigas Leila e Cristina pela amizade e atenção dispensadas nesses últimos anos.

À Universidade Federal de Goiás pela formação acadêmica.

Aos meus pais e irmãs pelo incentivo e carinho em todos os momentos.

Ao amigo Orlando Gomes e sua esposa Rosa pelo carinho, atenção e calorosa recepção que ajudaram-me no processo de adaptação à cidade de São Carlos.

Ao meu eterno amor Roberta pelo apoio, carinho e atenção dispensados durante a realização deste trabalho.

À FAPESP e à CAPES pelo apoio financeiro, sem o qual este trabalho não poderia ter sido realizado. 


\section{ÍNDICE}

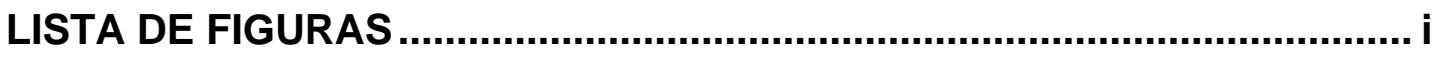

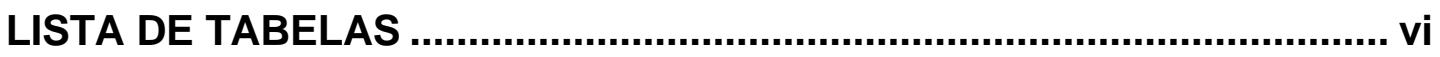

LISTA DE SÍMBOLOS.......................................................................... viii

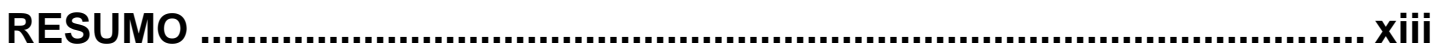

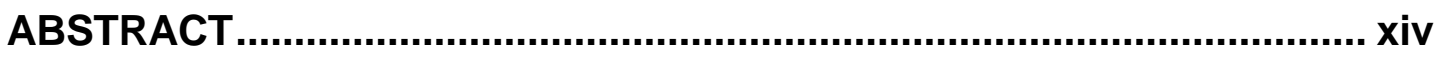

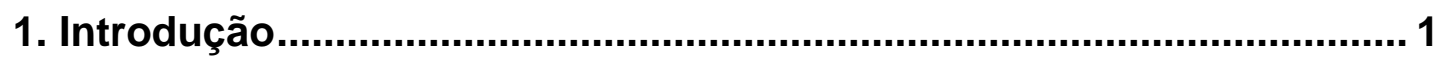

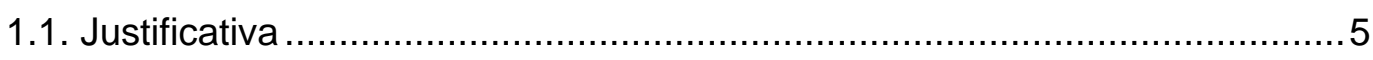

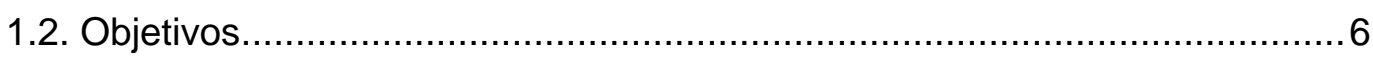

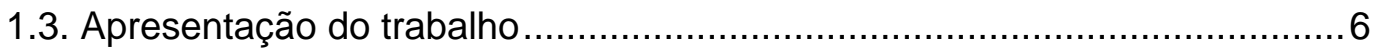

2. Transferência de tensões de cisalhamento em interfaces de concreto8

2.1. Descrição do fenômeno ................................................................. 8

2.1.1. Transferência pela superfície de contato ..................................... 9

2.1.2. Transferência pela armadura transversal à interface .......................13

2.2. Principais fatores que influenciam a resistência da interface .................... 14

2.3. Ensaios para avaliação da resistência ao cisalhamento ........................... 15

2.3.1. Ensaios de cisalhamento direto ............................................... 15

2.3.2. Ensaios em vigas ................................................................. 16

2.3.3. Comparação entre os ensaios em vigas e ensaios de cisalhamento

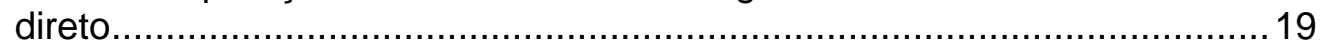

2.4. Ruptura por cisalhamento horizontal em vigas compostas .......................20

2.5. Modelos analíticos de transferência de esforços de cisalhamento.............. 25

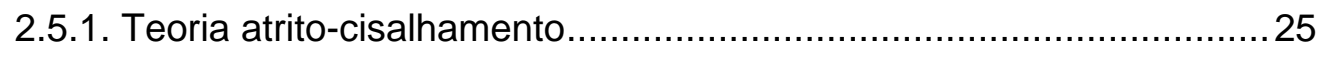

2.5.2. Modelo de Tsoukantas e Tassios............................................... 28

2.5.3. Modelo de Tassios e Vintzeleou....................................................... 35

2.5.4. Exemplo de aplicação dos modelos de Tsoukantas \& Tassios e Tassios \& Vintzeleou ....................................................................... 38

2.5.5. Modelo de Hsu, Mau e Chen........................................................ 39

2.5.5.1. Equações básicas .......................................................... 42 
2.6. Modelos empíricos de transferência de esforços de cisalhamento ............51

3. Indicações de normas e regulamentos .............................................61

3.1. Avaliação da tensão solicitante .........................................................61

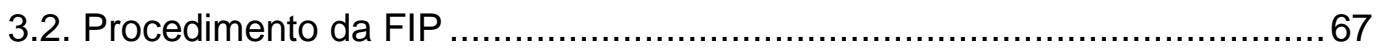

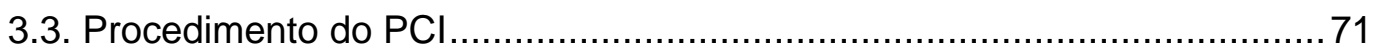

3.4. Procedimento da norma brasileira - NBR-9062 …................................ 75

3.5. Procedimento da norma espanhola - EF-88 ..................................... 77

3.6. Outros Procedimentos .................................................................... 82

3.6.1. Procedimento da norma canadense - CAN3-A23.3-M84 ................. 82

3.6.2. Procedimento da norma japonesa - JSCE:SP1 ............................ 83

3.6.3. Procedimento da norma britânica - BS8110 ................................... 83

3.6.4. Procedimento da norma dinamarquesa - DS411 ......................... 84

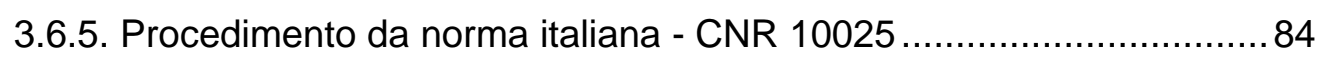

3.7. Comparação entre os procedimentos .................................................. 84

3.8. Disposições construtivas e recomendações para projeto .......................... 88

4. Análise numérica e comparação com resultados experimentais......98 98

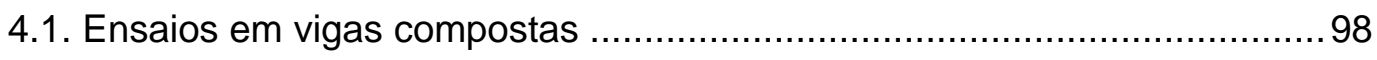

4.1.1. Análise por modelos analíticos.................................................. 98

4.1.2. Análise por modelos empíricos ................................................. 104

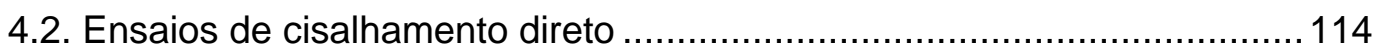

4.2.1. Instrumentação e procedimentos de ensaio.................................... 118

4.2.2. Resultados dos ensaios e discussão ......................................... 122

5. Programa experimental desenvolvido............................................ 129

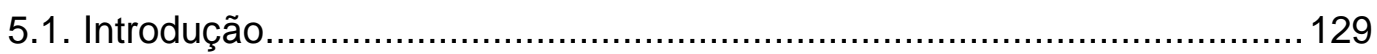

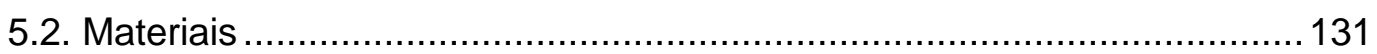

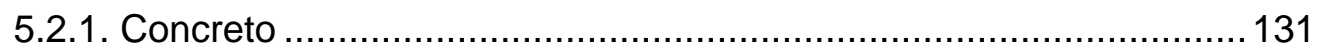

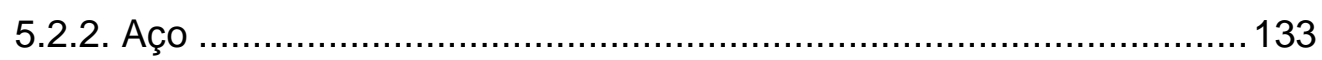

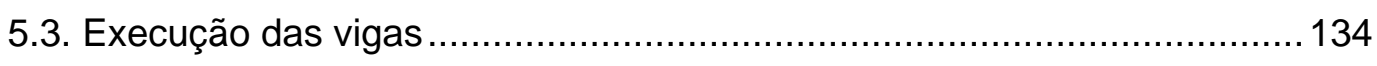

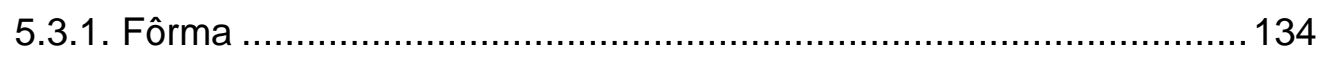

5.3.2. Armadura das vigas ........................................................ 135

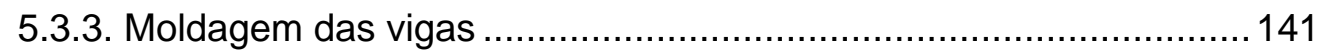

5.4. Instrumentação e execução dos ensaios ................................................ 145 
5.5. Resultados dos ensaios 153

5.5.1. Tensão de cisalhamento na interface 153

5.5.2. Configuração das fissuras e forma de ruptura das vigas 155

5.5.3. Deslizamento relativo da interface 160

5.5.4. Deformações da armadura de costura da interface 169

5.6. Comparação entre os resultados dos ensaios e os modelos analíticos e empíricos.

5.7. Verificação das vigas pelos procedimentos de normas e regulamentos .. 183

5.8. Considerações finais 185

6. Considerações finais e conclusão 186

6.1. Conclusões 187

6.2. Recomendações para trabalhos futuros 190

Referências bibliográficas. 192

Anexo A : Coeficientes de minoração a serem aplicados aos modelos.195

Apêndice I: Complementação dos resultados do programa experimental desenvolvido 


\section{LISTA DE FIGURAS}

Figura 1.1 - Aplicações com elementos pré-moldados tipo viga............................

Figura 1.2 - Aplicações com elementos pré-moldados tipo laje.............................

Figura 1.3 - Aplicações com elementos pré-moldados e blocos cerâmicos ou de concreto.

Figura 1.4 - Desenvolvimento de tensões de cisalhamento horizontal em vigas compostas

Figura 2.1 - Mecanismo de transferência de esforços de cisalhamento numa interface de concreto com superfície rugosa.

Figura 2.2 - Mecanismo de transferência de esforços de cisalhamento em uma junta rugosa (DIVAKAR; FAFITIS (1992)).

Figura 2.3 - Ruptura prematura da argamassa de cimento (TASSIOS; VINTZELEOU (1987))

Figura 2.4 - Formas e dimensões básicas dos modelos para ensaios de transferência de esforços por cisalhamento direto.....................................17

Figura 2.5 - Detalhes das vigas ensaiadas por Patnaik (PATNAIK (1992)). 18

Figura 2.6 - Tensões de cisalhamento em vigas ensaiadas para diferentes níveis de deslizamento

Figura 2.7 - Teoria atrito-cisalhamento (PATNAIK (1992)) ..................................26

Figura 2.8 - Cobrimento de concreto da armadura ............................................. 31

Figura 2.9 - Aplicação de força transversal à armadura ...................................... 31

Figura 2.10 - Posição da armadura na seção transversal para estimativa do coeficiente $\delta$

Figura 2.11 - Barras constituintes do mecanismo resistente em função de sua posição 33

Figura 2.12 - Modelo para ensaio de arrancamento de barra 35

Figura 2.13 - Tensões de aderência e tensões de tração em uma barra com comprimento de ancoragem insuficiente (TASSIOS; VINTZELEOU (1990))37 
Figura 2.14 - Tensões de aderência e tensões de tração em uma barra com comprimento de ancoragem maior que o necessário para alcançar a resistência de escoamento (TASSIOS; VINTZELEOU (1990)) .................... 38

Figura 2.15 - Resistência ao cisalhamento da ligação entre duas colunas prémoldadas

Figura 2.16 - Modelos para ensaio de cisalhamento direto

Figura 2.17 - Tensões em um elemento de concreto armado 43

Figura 2.18 - Relações tensão - deformação do concreto 45

Figura 2.19 - Modelo para ensaio de cisalhamento direto 47

Figura 2.20 - Cálculo da tensão de cisalhamento resistente pelo modelo de Hsu, et al. numa peça utilizada em ensaios de cisalhamento direto com interface não pré-fissurada. 51

Figura 2.21 - Armadura inclinada com relação à interface. .55

Figura 3.1 - Avaliação da tensão de cisalhamento horizontal na interface 63

Figura 3.2 - Avaliação da tensão na interface por equilíbrio de forças 65

Figura 3.3 - Trechos para avaliação da tensão de cisalhamento horizontal média.66

Figura 3.4 - Alguns casos típicos de lajes compostas com lajes pré-moldadas e capa de concreto (FIP (1982)). 78

Figura 3.5 - Alguns casos típicos de lajes compostas com nervuras pré-moldadas, blocos vazados e capa de concreto (FIP (1982)).

Figura 3.6 - Seção transversal de laje composta formada por nervuras e blocos vazados (EF-88 (1988)).

Figura 3.7 - Valores do coeficiente $\beta$ e do perímetro de contato $(p)$ entre a nervura e o concreto moldado no local (EF-88 (1988)).

Figura 3.8 - Comparação entre os procedimentos. (continua). 86

Figura 3.9 - Ancoragem de estribos em vigas compostas 90

Figura 3.10 - Viga T invertida com pequena espessura da camada de concreto moldado no local (MATTOCK (1987)) ... .91

Figura 3.11 - Dimensões mínimas de estribos (ACI 318-89) 91

Figura 3.12 - laje alveolar pré-moldada com capa de concreto 92

Figura 3.13 - Detalhe da armadura de retração em vigas compostas (CNR-10025 (1984)). 
Figura 3.14 - Região de distribuição das tensões de cisalhamento devido à retração diferencial na extremidade dos vãos (FIP (1982))...

Figura 4.1 - Aplicação do modelo de Tassios e Vintzeleou às vigas ensaidas por Patnaik.

Figura 4.2 - Comparação entre os modelos analíticos e os resultados dos ensaios de Patnaik. 102

Figura 4.3(a) - Comparação entre os modelos empíricos e os resultados dos ensaios de Patnaik $\left(f_{c}=20 \mathrm{MPa}\right)$. - continua 105

Figura 4.3(b) - Comparação entre os modelos empíricos e os resultados dos ensaios de Patnaik $\left(f_{c}=25 \mathrm{MPa}\right)$. - continua 107

Figura 4.3(c) - Comparação entre os modelos empíricos e os resultados dos ensaios de Patnaik $\left(f_{c}=35 \mathrm{MPa}\right)$. - continua . 109

Figura 4.4 - Viga e laje pré-moldada ligadas por conectores. 115

Figura 4.5 - Dimensões do modelo utilizado nos ensaios de ligação por conector.116

Figura 4.6 - Armadura dos corpos-de-prova utilizados nos ensaios de ligação por conector.... 117

Figura 4.7(a) - Numeração dos transdutores de deslocamento. 118

Figura 4.7(b) - Fixação dos transdutores e esquema geral do ensaio 119

Figura 4.7(c) - Estrutura de reação e corpo-de-prova posicionado para ensaio ... 120

Figura 4.8 - Ruptura do corpo-de-prova CP4 e aspecto da superfície do concreto121

Figura 4.9 - Aplicação do modelo de Tassios; Vintzeleou aos corpos-de-prova considerando superfície lisa e rugosa.... 122

Figura 4.10 - Resultados dos ensaios da ligação por conector (continua)..... 123

Figura 5.1 - Dimensões das vigas compostas ensaiadas. 131

Figura 5.2 - Diagrama tensão-deformação do aço utilizado nas vigas. 134

Figura 5.3 - Vista geral da fôrma e principais dimensões (cm). 135

Figura 5.4(a) - Detalhamento da viga 1 136

Figura 5.4(b) - Detalhamento da viga 2. 137

Figura 5.4(c) - Detalhamento da viga 3 138

Figura 5.5(a) - Vista da armadura da alma da viga 1 139 
Figura 5.5(b) - Vista da armadura da alma da viga 2 ...................................... 139

Figura 5.5(c) - Vista da armadura da alma da viga 3........................................ 140

Figura 5.6 - Detalhe da ancoragem da armadura longitudinal no apoio................ 141

Figura 5.7 - Cronograma de moldagem de uma viga composta........................ 141

Figura 5.8 - Aspecto final da superfície da interface............................................ 143

Figura 5.9 - Detalhe da interface da viga 3..................................................... 144

Figura 5.10 - Posição de ensaio das vigas e esquema de carregamento.............. 145

Figura 5.11(a) - Detalhe da instrumentação da armadura de costura da interface com extensômetros elétricos de resistência............................................. 146

Figura 5.11(b) - Instrumentação da viga 1: numeração dos extensômetros na armadura e no concreto.

Figura 5.11(c) - Instrumentação da viga 2: numeração dos extensômetros na armadura e no concreto.

Figura 5.11(d) - Instrumentação da viga 3: numeração dos extensômetros na armadura e no concreto.

Figura 5.11(e) - Instrumentação da viga 1: numeração dos transdutores para medição do deslizamento da interface e deslocamentos verticais. 150

Figura 5.11(f) - Instrumentação das vigas 2 e 3: numeração dos transdutores para medição do deslizamento da interface e deslocamentos verticais. 151

Figura 5.11(g) - Detalhe da fixação dos transdutores para medição do deslizamento relativo entre a mesa e a alma. 152

Figura 5.12(a) - Forma de ruptura da viga 1..................................................... 156

Figura 5.12(b) - Forma de ruptura da viga 2 ................................................. 156

Figura 5.12(c) - Detalhe da biela de compressão, junto ao apoio, formada na ruptura da viga 2 ......................................................................... 157

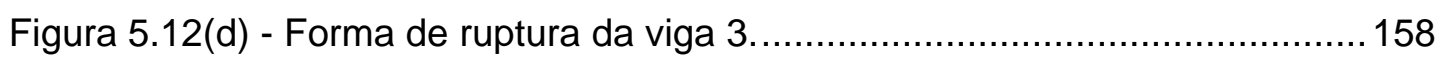

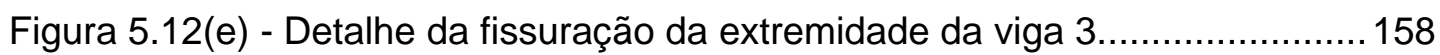

Figura 5.12(f) - Separação entre a mesa e a alma na extremidade da viga 3. ..... 159

Figura 5.13(a) - Deslizamento relativo da interface da viga 1 .............................. 161

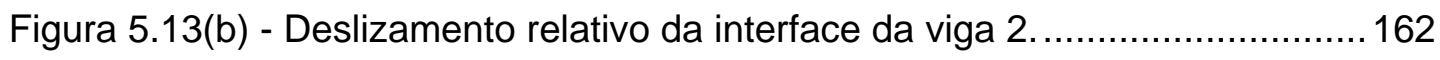


Figura 5.13(c) - Deslizamento relativo da interface da viga 3. 163

Figura 5.14 - Deslizamento relativo típico entre a mesa e a alma das vigas ensaiadas. 164

Figura 5.15 - Deslizamento da interface ao longo do vão das vigas ensaiadas. (continua)...... 165

Figura 5.16 - Máximo deslizamento da interface nas vigas ensaiadas. 166

Figura 5.17 - Deformação da armadura de costura da interface em função do deslizamento relativo. (continua). 167

Figura 5.18(a) - Deformação da armadura de costura ao nível da interface da viga 1. 170

Figura 5.18(b) - Deformação da armadura de costura ao nível da interface da viga 2. 171

Figura 5.18(c) - Deformação da armadura de costura ao nível da interface da viga 3. 172

Figura 5.19 - Comparação, entre as vigas ensaiadas, da deformação da armadura de costura ao nível da interface. (continua) 173

Figura 5.20(a) - Deformação ao longo da armadura de costura da interface da viga 1. 176

Figura 5.20(b) - Deformação ao longo da armadura de costura da interface da viga 2. 177

Figura 5.20(c) - Deformação ao longo da armadura de costura da interface da viga 3. 178

Figura 5.21 - Comparação, entre as vigas, da deformação ao longo da armadura de costura da interface. (continua). 179

Figura 5.22 - Mecanismo de transferência de tensões em interface de vigas compostas (BRUGGELING; HUYGHE (1991)). 181

Figura A.1 - Curva normal de distribuição de freqüências. 196

Figura A.2 - Comparação entre as curvas dos modelos analíticos e as curvas dos procedimentos de normas e regulamentos. (continua). 198 


\section{LISTA DE TABELAS}

Tabela 2.1 - Resultados dos ensaios de vigas compostas que romperam por cisalhamento horizontal (Interface rugosa) (PATNAIK (1992) )...................22

Tabela 2.2 - Avaliação do coeficiente $\delta$ do modelo de Tsoukantas e Tassios .........32

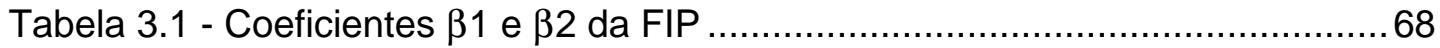

Tabela 3.2 - coeficiente $\beta 1$ proposto por Santos. ............................................ 71

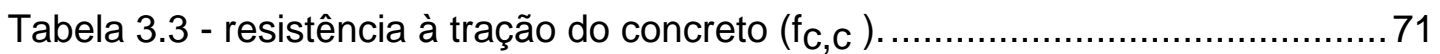

Tabela 3.4 - Coeficiente atrito-cisalhamento .................................................. 75

Tabela 3.5 - Coeficientes $\beta_{\mathrm{S}}$ e $\beta_{\mathrm{C}}$ da NBR-9062.......................................... 77

Tabela 4.1 - Aplicação dos modelos analíticos às vigas de Patnaik. .................... 101

Tabela 4.2 - Modelos empíricos utilizados na avaliação da resistência da interface de vigas compostas. 104

Tabela 4.3 - Resultado do emprego dos modelos empíricos às vigas ensaiadas por Patnaik.

Tabela 4.4 - Aplicação dos modelos empíricos à ligação por conector 128

Tabela 5.1 - Resumo das principais características das vigas ensaiadas e variáveis estudadas. 130

Tabela 5.2 - Quantidade de material para preparação de um metro cúbico de concreto. 132

Tabela 5.3 - Principais características dos agregados. 132

Tabela 5.4 - Resistência média do concreto utilizado nas vigas ensaiadas. 133

Tabela 5.5 - Características geométricas da seção fissurada das vigas ensaiadas.154

Tabela 5.6 - Tensões de cisalhamento na interface das vigas ensaiadas. 154

Tabela 5.7 - Avaliação da tensão de cisalhamento na interface por diferentes expressões. 155

Tabela 5.8(a) - Avaliação da resistência ao cisalhamento da interface das vigas ensaiadas pelos modelos analíticos. 181 
Tabela 5.8(b) - Avaliação da resistência ao cisalhamento da interface das vigas ensaiadas pelos modelos empíricos. 182

Tabela 5.9 - Avaliação da interface das vigas pelas normas e regulamentos....... 184

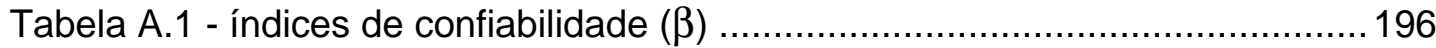

Tabela A.2 - Coeficientes de minoração dos modelos analíticos e empíricos........201 


\section{LISTA DE SÍMBOLOS}

\section{- Letras romanas maiúsculas}

$A_{s}$ : área da seção transversal da armadura longitudinal tracionada.

$A_{p}$ : área da seção transversal da armadura protendida.

$\mathrm{A}_{\mathrm{sw}}$ : área da seção transversal das barras da armadura transversal à interface.

C : coeficiente.

$\mathrm{E}_{\mathrm{c}}$ : módulo de deformação longitudinal (elástico) do concreto.

$E_{s}$ : módulo de deformação longitudinal (elástico) do aço.

F : força externa concentrada; força solicitante; força resistente.

I : momento de inércia.

$\mathrm{I}_{\mathrm{s}}:$ momento de inércia da armadura.

$\mathrm{K}$ : coeficiente.

$\mathrm{L}$ : comprimento.

$M$ : momento fletor.

$M_{d}:$ momento fletor de cálculo.

$\mathrm{N}$ : força normal.

$R_{c c}$ : resultante de tensões de compressão no concreto.

$R_{d}$ : resultante de tensões.

$\mathrm{R}_{\mathrm{s}}$ : resistência da armadura à ação de corte transversal (ação de pino).

$\mathrm{R}_{\mathrm{st}}$ : resultante das tensões de tração na armadura longitudinal.

$R_{u}$ : resultante das tensões de cisalhamento últimas na interface.

S : momento estático.

V : esforço cortante; força externa aplicada na interface. 


\section{- Letras romanas minúsculas}

$a_{v}$ : distância sobre a qual são transferidas tensões pela interface.

b : largura da interface; largura da viga.

$\mathrm{b}_{\mathrm{w}}$ : largura da alma de vigas de seção $\mathrm{T}$.

c : cobrimento da armadura.

d : altura útil de uma viga, medida da resultante das tensões de tração na armadura longitudinal ao ponto de maior encurtamento da seção transversal, medida normalmente à linha neutra.

e : excentricidade de uma força.

f : resistência.

$\mathrm{f}_{\mathrm{c}}$ : resistência à compressão do concreto medida em corpos-de-prova cilíndricos.

$\mathrm{f}_{\mathrm{cd}}$ : resistência de cálculo do concreto à compressão.

$\mathrm{f}_{\mathrm{ck}}$ : resistência característica do concreto à compressão medida em corpos-deprova cilíndricos.

$\mathrm{f}_{\mathrm{ck,c}, \mathrm{c}}$ : resistência característica do concreto à compressão medida em corposde-prova cúbicos.

$\mathrm{f}_{\mathrm{t}}$ : resistência à tração do concreto medida em corpos-de-prova cilíndricos.

$f_{\text {td,c }}$ : resistência de cálculo do concreto à tração medida em corpos-de-prova cúbicos.

$\mathrm{f}_{\mathrm{y}}$ : resistência de escoamento do aço à tração.

$\mathrm{f}_{\mathrm{yd}}$ : resistência de cálculo do aço à tração.

$\mathrm{f}_{\mathrm{yk}}$ : resistência característica de escoamento do aço à tração.

h : altura da seção.

$\ell$ : comprimento de ancoragem da armadura.

$\ell_{\mathrm{b}}$ : comprimento da armadura sobre o qual são transferidos as tensões de aderência.

$\mathrm{m}$ : média de uma amostra. 
$\mathrm{p}_{\mathrm{f}}$ : probabilidade de falha de um evento.

$r$ : raio.

s : deslizamento relativo entre duas superfícies em contato; espaçamento de armadura; desvio padrão de uma amostra.

$\mathrm{s}_{\mathrm{s}}$ : deslocamento da extremidade da armadura por ação de uma força transversal.

$\mathrm{s}_{\mathrm{u}}$ : deslizamento relativo último entre duas superfícies em contato.

w : abertura de fissura; separação transversal entre duas superfícies em contato.

z : distância entre as resultantes de tração e compressão na seção transversal.

\section{- Letras gregas maiúsculas}

$\Delta \ell:$ variação de comprimento.

$\Phi_{\mathrm{s}} ; \#$ : diâmetro da barra da armadura.

\section{- Letras gregas minúsculas}

$\alpha$ : ângulo.

$\beta$ : coeficiente; índice de confiabilidade.

$\delta$ : coeficiente; coeficiente de variação de uma amostra.

$\varepsilon$ : deformação específica.

$\varepsilon_{\mathrm{c}}:$ deformação específica de compressão no concreto.

$\varepsilon_{\mathrm{cs}}:$ deformação específica do concreto por retração.

$\varepsilon_{t}$ : deformação específica de tração no concreto.

$\varepsilon_{y}$ : deformação específica de escoamento do aço, deformação específica na direção y.

$\phi$ :coeficiente 
$\gamma$ :peso específico do material; coeficiente.

$\gamma_{c}$ : coeficiente de minoração da resistência do concreto.

$\gamma_{\mathrm{rd}}$ : coeficiente de minoração devido à dispersão de resultados experimentais.

$\gamma_{\mathrm{s}}$ : coeficiente de minoração da resistência do aço.

$\eta$ : coeficiente.

$\varphi$ : coeficiente de deformação lenta do concreto.

$\lambda$ : coeficiente.

$\mu$ : coeficiente de atrito.

$\mu_{\mathrm{e}}:$ coeficiente de atrito efetivo.

$\theta$ : ângulo.

$\rho$ : taxa geométrica de armadura.

$\tau$ : tensão de cisalhamento ou tensão tangencial.

$\tau_{\text {rd }}$ :tensão de cisalhamento resistida pela interface (valor de cálculo).

$\tau_{u}:$ tensão de cisalhamento última na interface.

$\sigma:$ tensão normal.

$\sigma_{\mathrm{c}}:$ tensão de compressão no concreto.

$\sigma_{\mathrm{n}}$ : tensão normal à interface entre duas superfícies.

$\sigma_{\mathrm{pd}}$ : tensão de tração de cálculo na armadura protendida.

$\sigma_{\mathrm{s}}$ : tensão normal de tração na armadura.

$\sigma_{t}:$ tensão de tração no concreto.

$\xi$ : relação entre a tensão normal de tração na armadura e sua resistência de escoamento.

\section{- sub-índices gerais}

agr : agregado.

c : concreto; compressão. 
cr : crítico.

d : de cálculo.

k : característico.

lim : limite.

$\mathrm{m}$ : mesa de viga $\mathrm{T}$.

max : máximo.

min : mínimo.

$r$ : resistente.

s : aço; barra da armadura.

$\mathrm{t}$ : tração.

u : último.

v : viga pré-moldada.

- abreviaturas

EESC : Escola de Engenharia de São Carlos.

FIP : Federation Internationale de la Precontrainte.

$\mathrm{PCl}$ : Prestressed / Precast Concrete Institute.

USP : Universidade de São Paulo. 


\section{RESUMO}

ARAÚJO, D.L. (1997). Cisalhamento na interface entre concreto prémoldado e concreto moldado no local em elementos submetidos à flexão. São Carlos, 201p. Dissertação (Mestrado). Escola de Engenharia de São Carlos, Universidade de São Paulo.

Neste trabalho é abordado o cisalhamento pela interface entre concreto prémoldado e concreto moldado no local em vigas e lajes compostas. São apresentados os modelos analíticos e empíricos empregados na avaliação da resistência ao cisalhamento pela interface entre duas superfícies de concreto atravessadas por armadura. Esses modelos são utilizados para avaliar a resistência ao cisalhamento pela interface de vigas compostas, disponíveis na literatura, sendo indicados os que melhor representaram os resultados experimentais. São apresentadas também as indicações das principais normas sobre o assunto e algumas indicações de detalhes construtivos para peças compostas. Na seqüência são apresentados os resultados de ensaios de cisalhamento direto e ensaios em vigas compostas realizados com o objetivo de avaliar de forma qualitativa a resistência da interface. Algumas das principais conclusões foram: a) existem divergências significativas entre os valores recomendados pelas normas; b) observou-se boa aproximação entre os modelos analíticos e alguns modelos empíricos, obtidos de ensaios de cisalhamento direto, com os resultados de ensaios de vigas compostas obtidos da literatura; c) é recomendável a inclusão de um limite máximo na expressão fornecida pela norma brasileira (NBR-9062) para avaliação da resistência da interface de peças compostas.

Palavras-chave: cisalhamento pela interface, peças compostas, concreto pré-moldado. 


\begin{abstract}
ARAÚJO, D.L. (1997). Shear at interface between precast and cast-in-place concrete in composite elements. São Carlos, 201p. Dissertação (Mestrado). Escola de Engenharia de São Carlos, Universidade de São Paulo.

This work deals with the shear at interface between precast and cast-inplace concrete in composite beams and slabs. Analytical and empirical models to predict the shear strength of interface with steel cross the transversal section are showed. These models are used to predict the shear strength at interface in composite beams and are pointed the models that presented better approximation with experimental results. The main codes and some constructive details of the composite elements are showed. Push-out tests and tests in simply supported composite beams were carried on during this research and results are included in this work. Some of the main conclusions are: a) there are significant discrepancy among codes indication; b) the experimental results of composite beam showed a good agreement with the analytical models and some empirical models originate to push-out tests; c) it is recommended to define an upper limit in the expression indicated by Brazilian Code (NBR-9062) for estimation of the shear strength at interface in composite elements.
\end{abstract}

Keywords: shear at interface, composite elements, precast concrete. 


\section{Introdução}

A associação de elementos pré-moldados com concreto moldado no local é uma das aplicações mais comuns da pré-moldagem. Essa associação recebe normalmente as denominações de elementos compostos, peças compostas ou estruturas compostas. Cabe ressaltar que estas denominações se aplicariam mais adequadamente às estruturas formadas por dois materiais diferentes como, por exemplo, viga metálica e laje de concreto, também bastante empregadas na construção civil. Mas, devido à similaridade das associações, estas denominações também podem ser usadas para representar as estruturas formadas pela associação de elementos pré-moldados de concreto com concreto moldado no local.

Esse tipo de associação tem sido utilizado com sucesso em construções de pontes e pavimentos de edifícios de concreto. Nas figuras de 1.1 a 1.3 estão ilustradas algumas dessas aplicações.

Nestes casos, o elemento pré-moldado serve de fôrma para o concreto moldado no local, eliminando ou reduzindo drasticamente a utilização de fôrmas e cimbramentos. A seção resistente do elemento pré-moldado será ampliada após o endurecimento do concreto moldado no local, o qual passará a absorver parte dos esforços atuantes na estrutura, desde que garantida a transferência de esforços através da interface entre o concreto pré-moldado e o concreto moldado no local. 

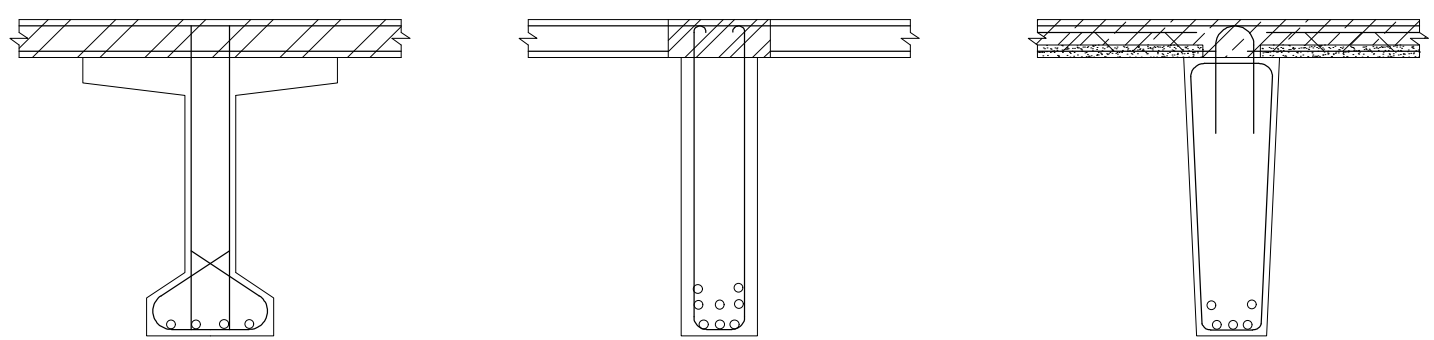

Figura 1.1 - Aplicações com elementos pré-moldados tipo viga.
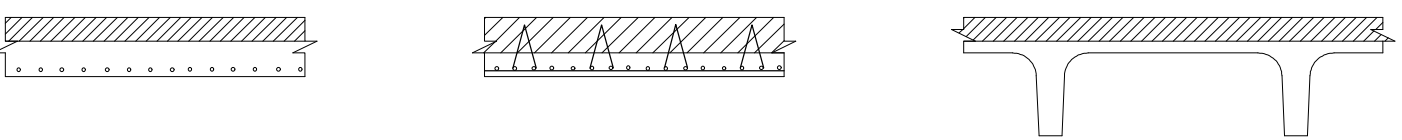

Figura 1.2 - Aplicações com elementos pré-moldados tipo laje.
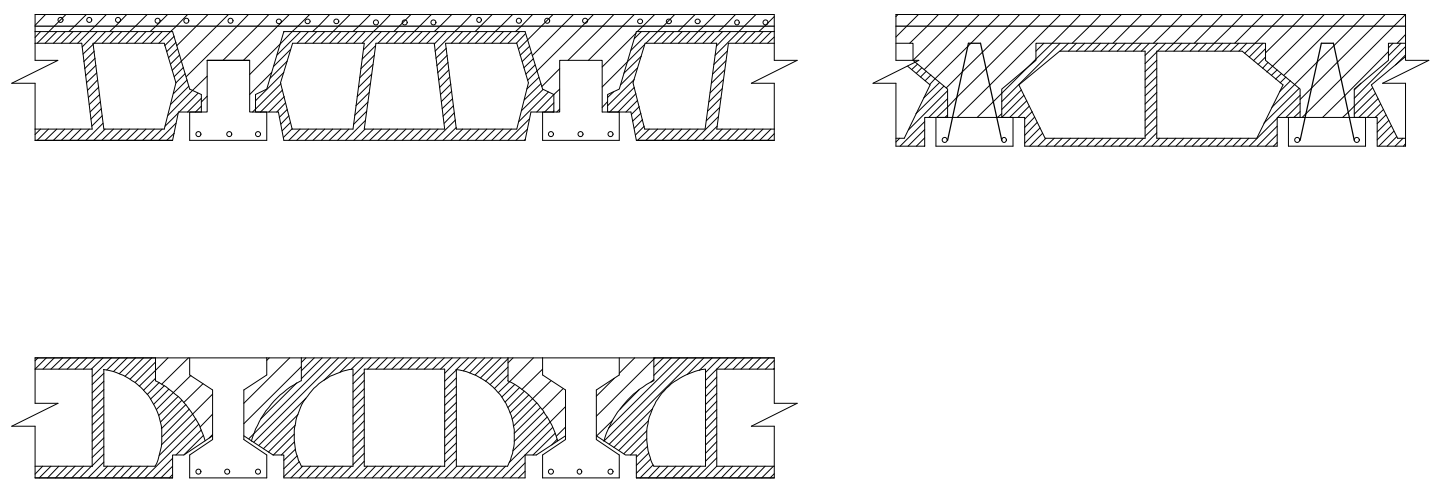

Figura 1.3 - Aplicações com elementos pré-moldados e blocos cerâmicos ou de concreto. 
Com o emprego de peças compostas é possível beneficiar-se de grande parte das vantagens da pré-moldagem, como, por exemplo, a facilidade de execução dos elementos em fábricas e a rápida montagem na obra, e, também, das vantagens da solução em concreto moldado no local, sem a utilização de fôrmas e cimbramentos. Algumas das vantagens mais significativas do uso de peças compostas são:

- redução do peso próprio dos elementos pré-moldados, o que resulta na utilização de equipamentos mais leves para o transporte e montagem da estrutura;

- comparado com a solução exclusivamente em elementos pré-moldados, as peças compostas apresentam menores dificuldades para a realização da ligação entre os elementos pré-moldados, pois a continuidade entre elas é garantida pelo concreto moldado no local;

- o concreto moldado no local garante maior monolitismo à estrutura e aumenta a resistência aos esforços horizontais. Por essa razão, essas estruturas também são denominadas estruturas monolíticas formadas por elementos pré-moldados;

- facilita a utilização do sistema aberto, o que fornece maior flexibilidade à construção. Esse sistema caracteriza-se pela utilização na construção de elementos pré-moldados provenientes de vários fabricantes.

Entretanto, ao projetar peças compostas, deve-se analisar a resistência ao cisalhamento da interface entre o concreto pré-moldado e o concreto moldado no local, o que pode acarretar uma colaboração completa ou parcial da parte moldada no local quando a peça é solicitada.

A existência de tensões de cisalhamento horizontais em peças compostas pode ser observada em uma viga formada por duas barras retangulares iguais de altura h, como observado na figura 1.4. Colocando-as juntas, sobre apoios simples, e solicitando-as à flexão por meio de uma carga concentrada $P$, se não houver tensões cisalhantes entre as barras, a flexão de uma será independente da outra, ou seja, cada uma sofrerá compressão nas fibras longitudinais superiores e tração nas inferiores (figura 1.4(b)). As fibras longitudinais inferiores da barra superior 
deslizarão em relação às fibras superiores da barra inferior. Numa barra única, de altura $2 \mathrm{~h}$, haverá tensões de cisalhamento ao longo do plano neutro, em magnitude capaz de impedir este deslizamento. Devido a essa resistência ao deslizamento, a barra única de altura $2 \mathrm{~h}$ possui maior resistência à flexão do que duas barras separadas. Estudo mais detalhado pode ser encontrado em outras publicações como, por exemplo, TIMOSHENKO; GERE (1983). No caso de peças compostas, este comportamento de peça monolítica pode ser alcançado desde que existam tensões de cisalhamento entre as peças que impeçam o completo deslizamento entre elas.

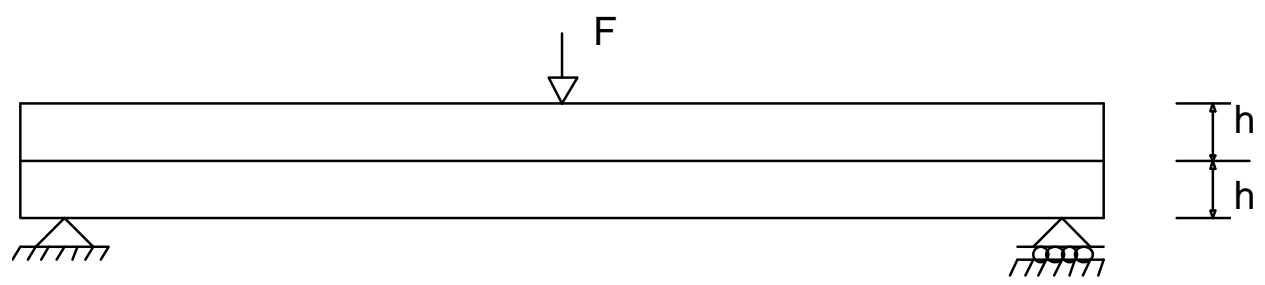

(a) viga formada por duas barras

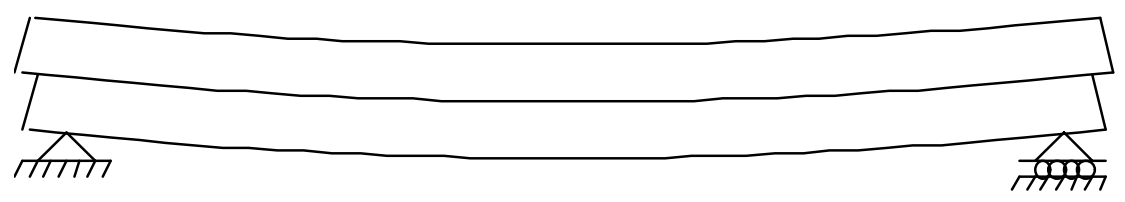

(b) barras com interface sem tensões de cisalhamento

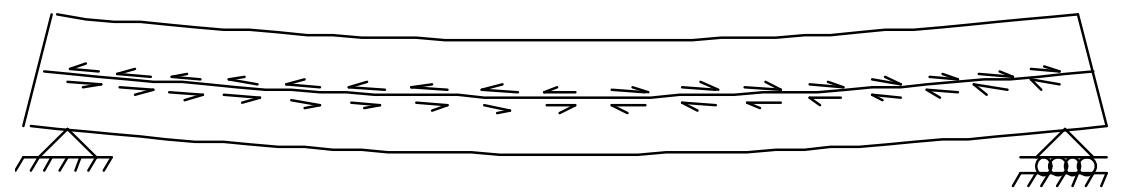

(c) barras com transferência integral de tensões de cisalhamento

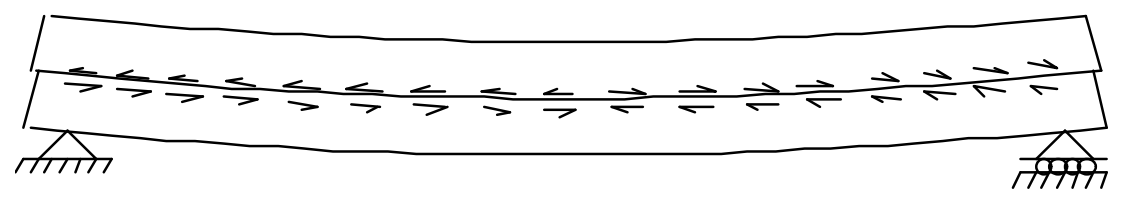

(d) barras com transferência parcial de tensões de cisalhamento

Figura 1.4 - Desenvolvimento de tensões de cisalhamento horizontal em vigas compostas 
O dimensionamento pode, portanto, ser feito considerando a colaboração completa da seção no estado limite último ou apenas a colaboração parcial. Para possibilitar a colaboração completa é necessário garantir a transferência total de esforços através da interface. Ao garantir-se a colaboração completa no estado limite último automaticamente tem-se, também, colaboração completa no estado de utilização. Pode-se também garantir a colaboração completa no estado de utilização e colaboração parcial no estado limite último. Nesse caso deve-se garantir a transferência de esforços apenas para o estado de utilização.

Outro problema nas peças compostas é a dificuldade de avaliar o comportamento da estrutura ao longo do tempo devido a utilização de materiais com idades e características diferentes. $O$ efeito da retração diferenciada dos dois concretos e a consideração de materiais com módulo de deformação diferentes devem ser analisados com cuidado. Deve-se analisar, também, o efeito da alteração do sistema estrutural sobre o elemento quando é estabelecida a continuidade de vãos simplesmente apoiados.

\subsection{Justificativa}

Diversas pesquisas visando avaliar a resistência da interface de juntas de concreto foram realizadas ao longo das últimas décadas, sendo que as primeiras pesquisas significativas sobre o assunto datam de 1960 e os primeiros ensaios em vigas compostas datam de 1964. Contudo, ainda restam diversas dúvidas sobre a transferência de esforços de cisalhamento pela interface de vigas compostas. O assunto também é abordado por diversas organizações normativas, apresentando, entretanto, algumas divergências.

Com este trabalho pretende-se contribuir no estudo da avaliação da resistência ao cisalhamento na interface entre concreto pré-moldado e concreto moldado no local. Deverão ser abordados dois tipos de ligação: com armadura de costura atravessando a interface, situação típica de vigas, conforme mostrado na figura 1.1 e sem armadura de costura, situação que ocorre em lajes, conforme mostrado na figura 1.2. Neste trabalho a ênfase maior será dada à ligação entre concreto pré-moldado e concreto moldado no local com armadura de costura atravessando a interface. 


\subsection{Objetivos}

Os principais objetivos deste trabalho são:

a) apresentar os modelos analíticos e empíricos, disponíveis na literatura, utilizados para avaliação da resistência ao cisalhamento de juntas de concreto e, através da aplicação sistemática destes modelos em ensaios experimentais encontrados na literatura, verificar os modelos que melhor representam o comportamento da interface de vigas compostas com armadura transversal;

a) efetuar um levantamento de procedimentos e recomendações para avaliação da resistência ao cisalhamento da interface entre concreto pré-moldado e concreto moldado no local em peças fletidas;

a) realizar alguns ensaios em vigas compostas de forma a obter uma avaliação qualitativa do comportamento da interface de peças compostas submetidas à flexão;

a) fornecer recomendações para a avaliação da resistência ao cisalhamento da interface, bem como detalhes construtivos para ligações entre concreto prémoldado e concreto moldado no local em peças fletidas.

\subsection{Apresentação do trabalho}

No capítulo 2 deste trabalho é apresentado o mecanismo de transferência de esforços de cisalhamento através de juntas de concreto de forma geral. Alguns ensaios encontrados na literatura para avaliação da resistência da interface de peças compostas também são apresentados. Na seqüência são estudados dois modelos analíticos, baseados nesse mecanismo, e um terceiro modelo baseado na teoria de bielas e tirantes. Ao final do capítulo são apresentados vários modelos empíricos encontrados na literatura.

No terceiro capítulo são apresentados alguns critérios de projeto e algumas indicações de normas para o dimensionamento da interface de vigas e lajes compostas submetidas à flexão, com e sem armadura transversal. Na seqüência são apresentadas algumas recomendações para execução das peças compostas. 
No capítulo 4 os modelos analíticos e empíricos, apresentados no capítulo 2, são utilizados para avaliar a resistência da interface de vigas compostas ensaiadas por outros autores e disponíveis na literatura. Esses modelos também são utilizados para avaliar a resistência da ligação de peças pré-moldadas através de conectores formados por barras dobradas em laço. Ao final do capítulo são indicados os modelos que mais aproximam-se dos resultados dos ensaios das vigas compostas e das peças ligadas por conector.

No capítulo 5 são apresentados o detalhamento e os resultados dos ensaios de três vigas compostas biapoiadas realizados no Laboratório de Estruturas da EESC. O objetivo desses ensaios foi obter resultados próprios que proporcionassem uma maior sensibilidade na análise dos resultados experimentais disponíveis na literatura. Nestas vigas foi variada a forma da armadura transversal à interface de forma a observar a influência do arranjo da armadura na resistência da interface das vigas aos esforços de cisalhamento horizontal.

No capítulo 6 são feitas as considerações finais e apresentadas as conclusões deste trabalho, sendo propostos alguns temas para outros trabalhos de pesquisa.

Em anexo são sugeridos coeficientes de minoração a serem aplicados aos modelos estudados de forma a possibilitar a utilização desses modelos em projetos de estruturas compostas. Em apêndice, conforme diretrizes da EESC (UNIVERSIDADE DE SÃO PAULO (1997)), são apresentados os resultados do programa experimental desenvolvido que não foram analisados no decorrer do texto. 


\section{Transferência de tensões de cisalhamento em interfaces de concreto}

Neste capítulo é abordado o fenômeno de transferência de esforços de cisalhamento entre duas superfícies de concreto atravessadas por armadura transversal. Alguns ensaios encontrados na literatura para avaliação da resistência da interface de peças compostas também são apresentados. Na seqüência são estudados dois modelos analíticos, baseados na teoria atrito-cisalhamento, e um terceiro modelo baseado na teoria de bielas e tirantes. Ao final do capítulo são apresentados vários modelos empíricos encontrados na literatura.

\subsection{Descrição do fenômeno}

Quando tensões de cisalhamento são transferidas ao longo de uma junta formada pela ligação de concretos com idades diferentes, são desenvolvidas tensões contrárias que tendem a equilibrar as ações. Esta junta pode ser formada pela ligação de uma peça pré-moldada com concreto moldado no local ou pela ruptura de uma peça monolítica para formação de um plano de cisalhamento. Ao ser submetido à esforços de cisalhamento, ocorre uma tendência de deslizamento na interface resultando num movimento de translação entre as duas superfícies. Se a superfície da interface é rugosa, o movimento de translação é acompanhado de um afastamento das peças. Neste caso, são mobilizados dois mecanismos de transferência de esforços (figura 2.1) :

- transferência pela superfície de contato

- transferência pela armadura transversal à interface 


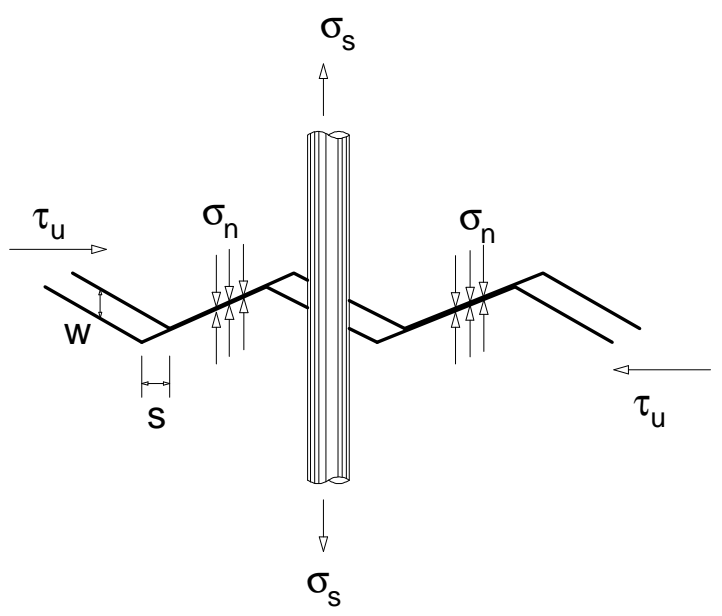

Figura 2.1 - Mecanismo de transferência de esforços de cisalhamento numa interface de concreto com superfície rugosa.

\subsubsection{Transferência pela superfície de contato}

O mecanismo de transferência de esforços de cisalhamento pela superfície de contato é semelhante à transferência de esforços de barras de aço para o concreto por tensões de aderência (LEONHARDT (1977)). Ele pode ser dividido em três parcelas:

a) Transferência por adesão ou aderência

Esse é o primeiro mecanismo mobilizado ao aplicar-se esforços de cisalhamento em uma interface de concreto. Para baixas solicitações, os esforços são resistidos pela adesão entre as partículas internas do aglomerante. Esse efeito, isoladamente, não é suficiente para uma boa transferência pois é destruído no caso de pequenos deslocamentos.

b) Transferência por atrito

Uma vez rompida a adesão, para o menor deslizamento relativo, aparece uma resistência por atrito entre as superfícies em contato, desde que existam tensões normais à interface. Essas tensões podem surgir pela aplicação de forças externas ou pela reação da armadura normal à interface quando é solicitada à 
tração. Essa parcela de resistência possui um importante papel na transferência dos esforços de cisalhamento após ocorrer o deslizamento entre as partes em contato, sendo diretamente influenciada pela rugosidade da superfície.

c) Transferência por ação mecânica

Através do engrenamento mecânico, do tipo de encaixe, entre as duas superfícies em contato formam-se "dentes de concreto" que são solicitados ao corte quando ocorre o deslizamento relativo entre as superfícies. $O$ tipo de ligação mais representativa dessa forma de transferência é a ligação por chave de cisalhamento. Entretanto, em superfícies rugosas, essa forma de transferência pode ser garantida pelo agregado graúdo atravessando a interface de deslizamento, uma vez que ocorre um engrenamento entre os agregados fixados em lados opostos da interface.

Nas juntas de concreto formadas pela ligação de concretos com idades diferentes, a primeira parcela de resistência é fornecida pela aderência entre as superfícies em contato. Com o aumento dos esforços de cisalhamento surgem fissuras na interface e posterior deslizamento entre as duas partes em contato. Neste momento não existe a parcela da aderência e a transferência de esforços é garantida pelo atrito e pela ação mecânica. Nas juntas formadas pela ruptura de uma peça monolítica para formação do plano de cisalhamento não existe a contribuição da aderência sendo os esforços transmitidos pelas outras parcelas.

A formação de fissuras no concreto foi estudada por Hsu em 1963 (HSU (1963) apud DIVAKAR; FAFITIS (1992)) ${ }^{1}$. Em seus estudos, o autor concluiu que a interface entre o aglomerante (argamassa de cimento) e as partículas inativas (agregado graúdo) forma uma região fraca onde sempre existem microfissuras mesmo antes da aplicação de qualquer carregamento. Estas microfissuras surgem devido à retração, diferencial de temperatura, segregação, etc. , e são orientadas aleatoriamente. Aplicando um carregamento externo há um aumento destas microfissuras. Algumas delas permanecem restritas à ligação entre o agregado e a argamassa de cimento enquanto outras propagam-se ao longo da peça na direção

\footnotetext{
${ }^{1}$ HSU, T.T.C. (1963). Mathematical analysis of shrinkage stresses in a model of hardened concrete, apud DIVAKAR, M.P.; FAFITIS, A. (1992). Micromechanics based constitutive model for interface shear. Journal of Engineering Mechanics, v.118, n.7, p.1317-1337.
} 
das tensões solicitantes. Quando o número e o tamanho das microfissuras aumentam pode ocorrer a ligação entre elas resultando no surgimento de uma zona fraturada. Esta zona fraturada possui alta concentração de microfissuras, sendo comumente chamada plano fissurado. Uma junta é rugosa quando existem agregados graúdos atravessando a interface e interagindo entre si, sendo capaz de transmitir significativos esforços de cisalhamento antes que ocorra uma total separação entre as partes.

Um modelo para transferência de esforços de cisalhamento em interfaces rugosas de concreto sem armadura de costura, baseado na interação entre os agregados, foi proposto por DIVAKAR; FAFITIS (1992). Eles dividiram o mecanismo de transferência de esforços em quatro componentes: atrito, engrenamento dos agregados graúdos, separação transversal entre as partes e ruptura da argamassa e do agregado. Na figura 2.2 é ilustrada uma superfície rugosa e também é mostrado, esquematicamente, o funcionamento de cada mecanismo. O engrenamento dos agregados é garantido por sua forma irregular. Num movimento transversal à junta, um prende-se ao outro impedindo a separação entre as partes. O movimento de translação entre as duas partes é impedido pela rugosidade da superfície. Devido à existência de agregados atravessando a interface, para que este movimento ocorra é necessário haver um deslizamento entre os agregados na direção transversal que resulte na ruptura do agregado e da argamassa de cimento na direção do deslizamento.

A parcela de cada componente na resistência final ao cisalhamento depende de vários fatores: intensidade da força normal à interface; natureza da rugosidade da interface; dimensões do agregado; valor do deslizamento da interface. A avaliação e a quantificação da influência de cada fator sobre o mecanismo resistente é muito trabalhoso. Usualmente são propostas simplificações que simulam o comportamento de uma junta rugosa quando submetida à tensão de cisalhamento. Uma destas simplificações é a consideração de que o acréscimo da intensidade da força normal à interface proporciona um acréscimo na resistência final ao cisalhamento, uma vez que o mecanismo resistente está baseado na força de atrito entre as partes em contato. Entretanto, como observado em TASSIOS;VINTZELEOU (1987), este acréscimo não é proporcional, ou seja, quando têm-se elevados valores de força normal à interface obtém-se pequeno 
acréscimo na tensão resistente ao incrementar a tensão normal. Isto acontece porque, para elevados valores de tensão normal, ocorre uma diminuição da rugosidade devido ao "achatamento" dos agregados. Também pode ocorrer uma ruptura na argamassa de cimento antes que seja atingido o valor da tensão de cisalhamento que proporciona o deslizamento entre os agregados no sentido transversal à interface (figura 2.3). Esta ruptura ocorre devido às elevadas tensões de cisalhamento que surgem na interface, em função da alta tensão normal, as quais são maiores que a resistência da argamassa. Desta forma, ocorre uma ruptura prematura antes que o mecanismo resistente seja acionado.

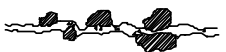

a) interface rugosa

sentido do deslizamento<smiles>CCCCC#Cc1cc(CC)ccc1C</smiles>

c) separação transversal sentido do deslizamento

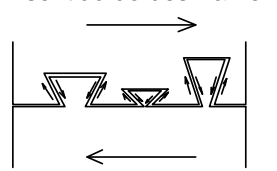

b ) engrenamento dos agregados

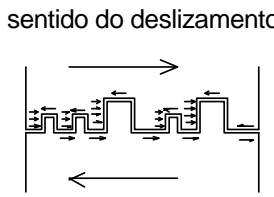

d) ruptura

Figura 2.2 - Mecanismo de transferência de esforços de cisalhamento em uma junta rugosa (DIVAKAR; FAFITIS (1992))

O modelo proposto por Divakar e Fafitis possui parcelas resistentes devido ao atrito e à ação mecânica. De seus estudos eles concluíram que uma parte significativa dos esforços são transmitidos pela ação mecânica. Entretanto, esse modelo é de difícil aplicação. Outros modelos, baseados na transferência apenas por atrito e pela ação de pino da armadura, foram propostos por diversos autores. Esses modelos são de fácil aplicação e apresentam excelentes resultados quando comparados com resultados experimentais. 


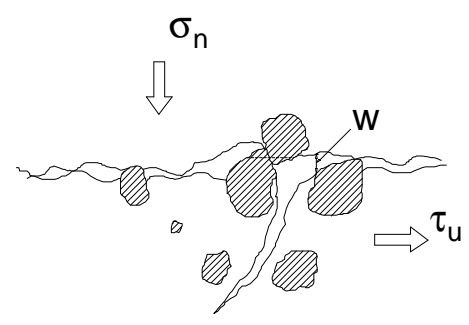

Figura 2.3 - Ruptura prematura da argamassa de cimento (TASSIOS; VINTZELEOU (1987))

\subsubsection{Transferência pela armadura transversal à interface}

Ao solicitar-se uma junta de concreto por esforços de cisalhamento, ocorre um deslizamento entre as duas partes. Se existir armadura atravessando a interface, este movimento tenderá a "cortá-la “. Esta, por sua vez, fornecerá uma resistência ao corte que será somada à resistência fornecida pela superfície de contato. A este efeito dá-se o nome de ação de pino da armadura.

A força transmitida pela ação de pino quando uma junta de concreto é solicitada por um deslizamento depende de vários parâmetros, entre os quais o cobrimento da armadura, o diâmetro da barra e seu comprimento de ancoragem, a qualidade do concreto, a forma de carregamento, etc. ( TSOUKANTAS; TASSIOS (1989) e TASSIOS; VINTZELEOU (1990) ).

No caso de juntas rugosas a armadura transversal também contribui garantindo a força normal à interface necessária para uma efetiva transferência por atrito entre as superfícies em contato. 


\subsection{Principais fatores que influenciam a resistência da interface}

Os principais fatores que influenciam a resistência da interface aos esforços de cisalhamento são:

a) resistência do concreto

A resistência ao cisalhamento aumenta com a resistência dos concretos em contato. No caso de peças compostas com concretos de resistências diferentes, a resistência ao cisalhamento é controlada pelo concreto de menor resistência.

b) Aderência da superfície de contato

Os elementos com superfície de contato aderente apresentam, inicialmente, comportamento idêntico ao dos elementos monolíticos. Por outro lado, no caso de não haver aderência, o deslizamento e a separação são muito significativos desde o início e a resistência última sofre uma redução significativa.

c) Rugosidade da superfície de contato

A resistência ao deslizamento aumenta com a rugosidade da superfície de contato. Entretanto, segundo diversos pesquisadores, a profundidade das irregularidades não parece ter influência significativa. Em termos de comportamento último o efeito da rugosidade é "somável" ao da aderência.

d) Chaves de cisalhamento

As chaves de cisalhamento têm um papel idêntico ao da rugosidade da superfície de contato, entretanto o seu efeito não é "somável". No caso de serem adotadas, deve desprezar-se o efeito da aderência e da rugosidade e devem ser feitas no elemento pré-moldado.

e) Armadura transversal

Para pequenos valores de deslizamento a quantidade de armadura transversal tem pouca influência na resistência da ligação. Assim, se a ruptura da ligação for definida pela condição de limitação do valor do deslizamento na superfície de contato, por exemplo, $\mathrm{s}=0,1 \mathrm{~mm}$, a contribuição da armadura terá 
pouca influência na resistência. Entretanto, no estado limite último, a resistência já é bastante influenciada pela quantidade e resistência da armadura transversal. Nesse caso, ela apresenta uma dupla função pois, com o deslizamento da superfície de contato, por um lado resiste diretamente ao esforço de corte (efeito de pino) e, por outro, aumenta a resistência por atrito devido às tensões normais que são aplicadas à interface.

\subsection{Ensaios para avaliação da resistência ao cisalhamento}

Ao longo dos anos inúmeras pesquisas foram realizadas visando determinar a resistência ao cisalhamento de interfaces de concreto. Nessas pesquisas eram empregados dois tipos de ensaios: ensaios de cisalhamento direto e ensaios em vigas biapoiadas. Os ensaios de cisalhamento direto eram realizados em modelos com interface previamente fissurada ou em modelos monolíticos. Em cada um desses ensaios, diferentes tipos de formas, dimensões e condições de carregamento foram empregados.

\subsubsection{Ensaios de cisalhamento direto}

Os modelos para ensaios de cisalhamento direto usados por Anderson, Hanson e Mast são mostrados na figura 2.4. Nos ensaios realizados por Anderson e Hanson, uma das partes foi moldada e, após endurecida, a segunda parte moldada sobre ela. Os ensaios executados por Mast consistiam de duas peças prémoldadas ligadas por uma junta de concreto moldada após a soldagem da armadura transversal de ambas as peças. Nestes ensaios, a superfície de contato da interface foi preparada manualmente antes da nova concretagem (BIRKELAND; BIRKELAND (1966)).

Nos ensaios realizados por Mattock na Universidade de Washington foi usado o modelo mostrado na figura $2.4(\mathrm{e})$. Cada modelo foi moldado na posição horizontal em uma única concretagem. Alguns modelos foram pré-fissurados para formação de uma junta de cisalhamento e outros não. A fissura ao longo do plano de cisalhamento foi feita colocando o modelo na posição horizontal e aplicando forças concentradas, em faces opostas, ao longo de seu plano de cisalhamento. A intensidade dessas forças foi aumentada até ocorrer a ruptura do concreto ao 
longo do plano de cisalhamento sem haver deslizamento entre as duas partes. ensaio de cisalhamento foi realizado colocando o modelo na posição vertical e aplicando forças concentradas sobre o plano pré-fissurado (HOFBECK; et al. (1969)).

Walraven, em ensaios realizados na Delft University of Technology, adotou modelos similares em forma e tamanho aos usados na Universidade de Washington, conforme ilustrado na figura 2.4(d). Esses modelos foram rompidos ao longo de seu plano de cisalhamento aplicando forças concentradas em entalhes de ambos os lados (PATNAIK (1992)).

\subsubsection{Ensaios em vigas}

Nesses ensaios, diferentes tipos de seção transversal, vão, carregamento e vinculação de apoio foram adotadas por diversos pesquisadores. SAEMANN; WASHA (1964) analisaram o comportamento de 42 vigas compostas à flexão. Essas vigas eram formadas por uma alma pré-moldada sobre a qual era moldada a mesa. As variáveis estudadas nos ensaios foram a rugosidade da superfície de contato entre a alma e a mesa, a posição da interface com relação à linha neutra, o comprimento do vão (biapoiado), a porcentagem de armadura atravessando a interface e a resistência à compressão do concreto. Os resultados obtidos indicaram uma relação complexa entre a rugosidade da superfície, a porcentagem de armadura transversal à interface e o comprimento do vão.

Em ensaios realizados na Universidade de Calgary, Canadá, Patnaik (PATNAIK (1992)) ensaiou 16 vigas biapoiadas de seção "T “. Essas vigas eram semelhantes às ensaiadas por Saemann e Washa, com exceção do comprimento da mesa que, em algumas vigas, era inferior ao comprimento do vão (figura 2.5). As variáveis estudadas foram a resistência à compressão do concreto e a porcentagem de armadura transversal. A superfície da interface era rugosa, sendo obtida pela exposição dos agregados graúdos através da rápida vibração da última camada de concreto quando da fabricação da alma pré-moldada. 


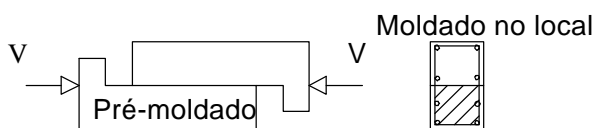

(a) Anderson (1960)

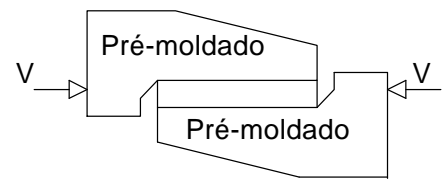

(c) Mast
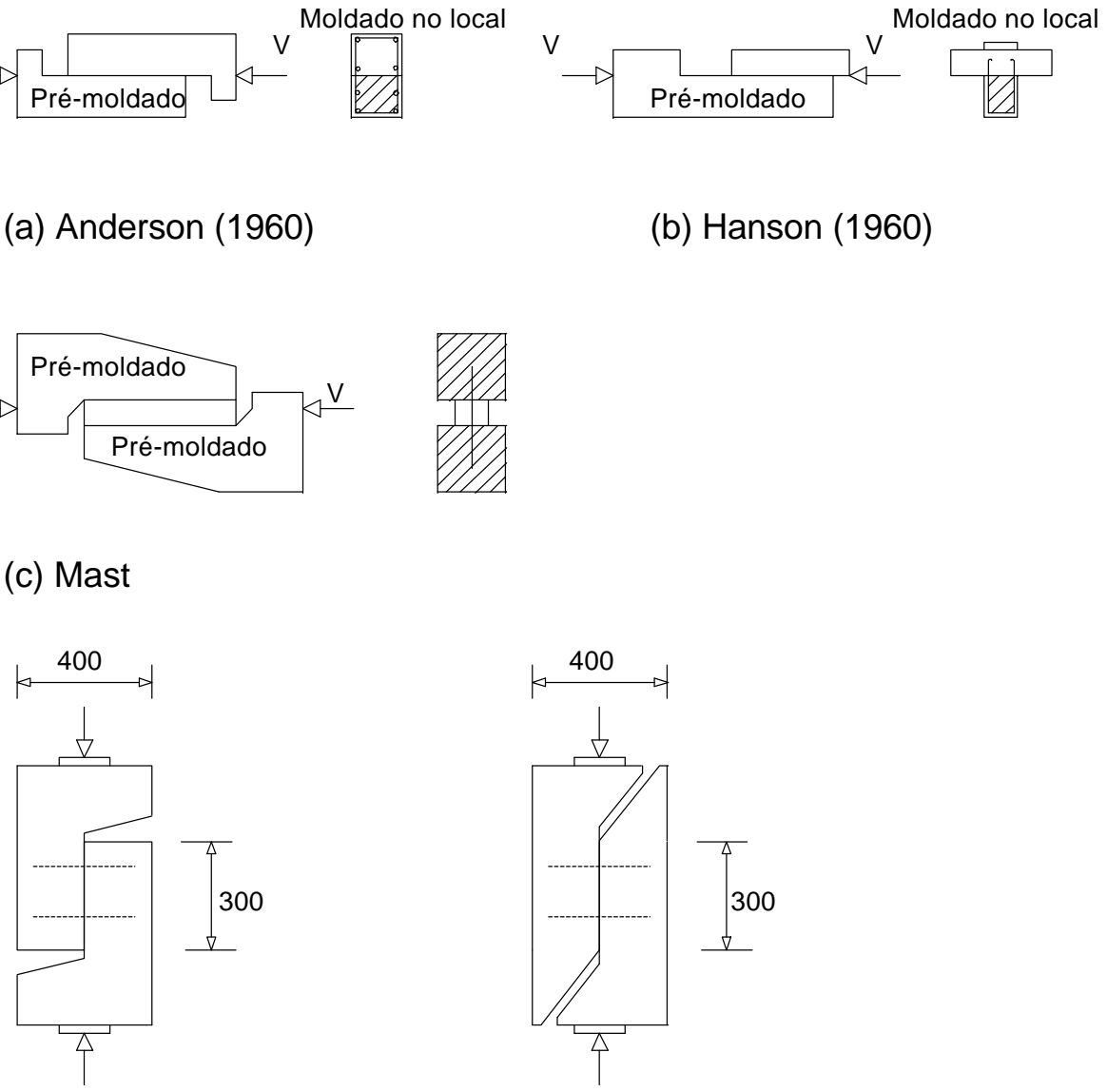

(b) Hanson (1960)

(d) Ensaios realizados na Delft University of Technology

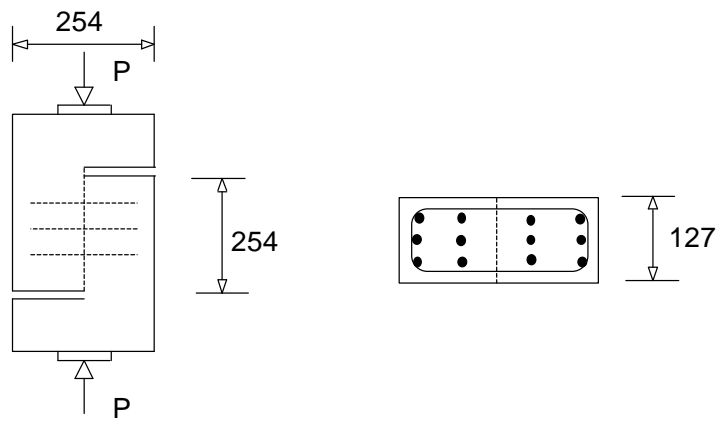

(e) Ensaios realizados na Universidade de Washington

Figura 2.4 - Formas e dimensões básicas dos modelos para ensaios de transferência de esforços por cisalhamento direto. 


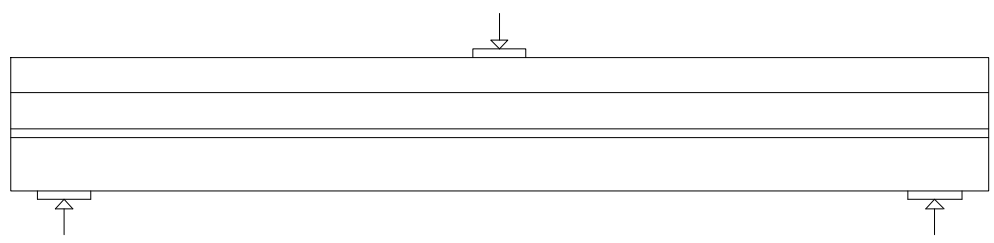

Viga ensaiada com mesa sobre todo o vão

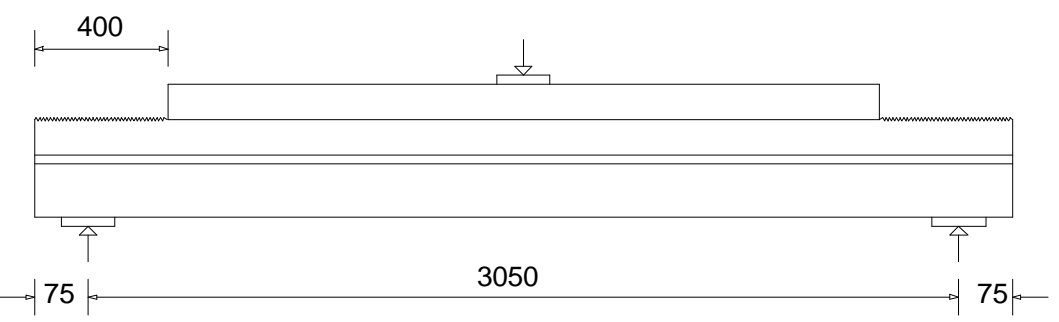

Viga ensaiada com mesa menor que o vão

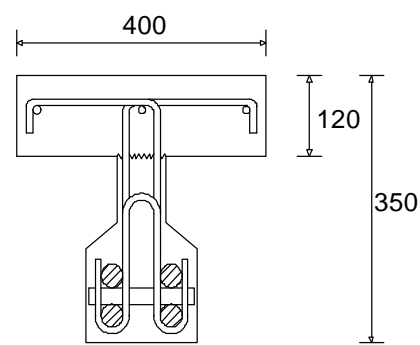

p 150

seção de viga com alma fina

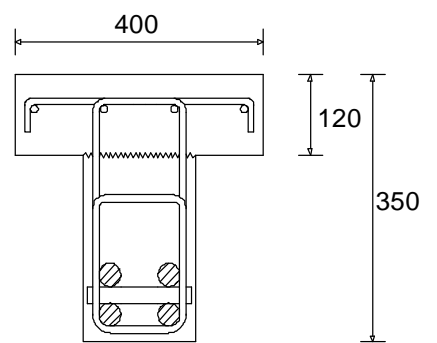

150

seção de viga com alma de largura uniforme

Todas as dimensões estão em mm

\section{Seção típica das vigas ensaiadas}

Figura 2.5 - Detalhes das vigas ensaiadas por Patnaik (PATNAIK (1992)). 


\subsubsection{Comparação entre os ensaios em vigas e ensaios de cisalhamento direto}

Vários ensaios foram realizados visando correlacionar os resultados dos ensaios de cisalhamento direto com os ensaios em vigas. Pela análise da relação força de cisalhamento - deslizamento da interface nos dois tipos de ensaio, concluiu-se que os ensaios de cisalhamento direto representam o comportamento dos ensaios em vigas quando a superfície da interface é rugosa e existe uma parcela de resistência por aderência (PATNAIK (1992)). Entretanto, quando os modelos para ensaios de cisalhamento direto são rompidos com antecedência para formação do plano de cisalhamento nem sempre representam o comportamento da interface das vigas compostas. A formação da junta pela ruptura do concreto antes do ensaio muda o comportamento da interface dos modelos. Esse tipo de junta não representa bem o comportamento da interface de vigas compostas de concreto não sendo possível aplicar os conhecimentos adquiridos ao dimensionamento destas vigas.

As características físicas e o estado de tensão da interface de vigas compostas são diferentes das características da interface dos modelos usados nos ensaios de cisalhamento direto. Quando a concretagem é feita em duas etapas, a superfície da interface é tornada rugosa manualmente, enquanto, se a interface é formada pela fissuração do concreto, a ruptura ao longo do plano de cisalhamento ocorre nas regiões de menor resistência. O comportamento de transferência dos esforços de cisalhamento pela interface de vigas compostas está compreendido entre o comportamento dos modelos de ensaios de cisalhamento direto com plano de cisalhamento pré-fissurado e dos modelos monolíticos. O deslizamento relativo nos ensaios de cisalhamento direto não era limitado enquanto nos ensaios em vigas a limitação do deslizamento é um critério de definição do carregamento último. Os resultados dos ensaios de cisalhamento direto têm sido tratados, por alguns pesquisadores, apenas como indicativos do comportamento da interface de vigas compostas (HAWKINS (1969) apud PATNAIK (1992) )².

\footnotetext{
${ }^{2}$ HAWKINS, N.M. (1969). Comments of "Auxiliary reinforcement in concrete connections". ASCE Journal, p.508-512. /paper by R.F. Mast, ASCE Journal, v.94, n.ST6, p.1485-1504, June, apud PATNAIK, A.H. (1992). Horizontal shear strength of composite concrete beams with a rough interface. Ph.D Thesis, University of Calgary, Calgary, Canadá.
} 


\subsection{Ruptura por cisalhamento horizontal em vigas compostas}

Numa viga composta com interface rugosa é considerado atingido o estado limite de ruptura por cisalhamento horizontal se a mesa sofrer deslizamentos significativos com relação à alma e, também, se ocorrer um afastamento significativo entre elas antes da viga atingir o estado limite último por flexão ou cisalhamento vertical (esforço cortante).

Em 1960, Hanson considerou que a máxima tensão de cisalhamento transferida pela interface de vigas compostas era atingida quando ocorria um deslizamento relativo de $0,13 \mathrm{~mm}$ entre a parte pré-moldada e a parte moldada no local (PATNAIK (1992)). A mesma idéia foi adotada mais tarde por Saemann \& Washa (SAEMANN; WASHA (1964)). Entretanto, grandes resistências ao cisalhamento são obtidas somente se grandes deslizamentos forem permitidos. Se o máximo deslizamento relativo permitido for de $0,5 \mathrm{~mm}$, a resistência ao cisalhamento das vigas ensaiadas por Hanson, Saemann \& Washa e outros autores seria bem maior (figura 2.6). Pode-se observar dessa figura que, em média, este aumento é de $50 \%$ para algumas vigas quando o deslizamento máximo é de $0,5 \mathrm{~mm}$.

Apenas poucas vigas ensaiadas por diversos pesquisadores romperam por cisalhamento horizontal. Um lista dos resultados de várias vigas compostas que romperam por cisalhamento horizontal é apresentado na tabela 2.1. Esta lista apresenta os resultados de ensaios em vigas com superfície rugosa. São apresentados também a resistência do concreto e a resistência ao cisalhamento horizontal correspondentes aos deslizamentos relativos de $0,13 \mathrm{~mm}, 0,5 \mathrm{~mm}$ e na ruptura. A tabela inclui também resultados de vigas com interface "medianamente rugosa" dos estudos de Saemann \& Washa pois estas superfícies eram preparadas de maneira que podiam ser classificadas como possuindo interface rugosa.

Em estudo recente, Patnaik concluiu que o uso da teoria atrito-cisalhamento e a limitação do deslizamento relativo em $0,13 \mathrm{~mm}$ são incompatíveis. Nos ensaios realizados a armadura transversal atingiu a resistência de escoamento para valores de deslizamento próximos a $0,5 \mathrm{~mm}$, sendo, portanto, este valor recomendado para obter o carregamento que define a resistência última de vigas compostas (PATNAIK (1992)). 
Patnaik observou também em seus ensaios que o máximo deslizamento da interface atingiu valores superiores a $2 \mathrm{~mm}$ na maioria dos casos. Formou-se, na ruptura, uma fissura na interface entre a mesa e a alma que estendeu-se da região de aplicação da força até a distância do apoio igual à altura útil da viga. Surgiu, então, uma grande fissura diagonal ligando o apoio à interface, o que provocou a rotação da extremidade da viga. Patnaik concluiu que este trecho de comprimento d à partir da seção do apoio (onde d é a altura útil da viga) não contribui na resistência final da viga ao cisalhamento horizontal.

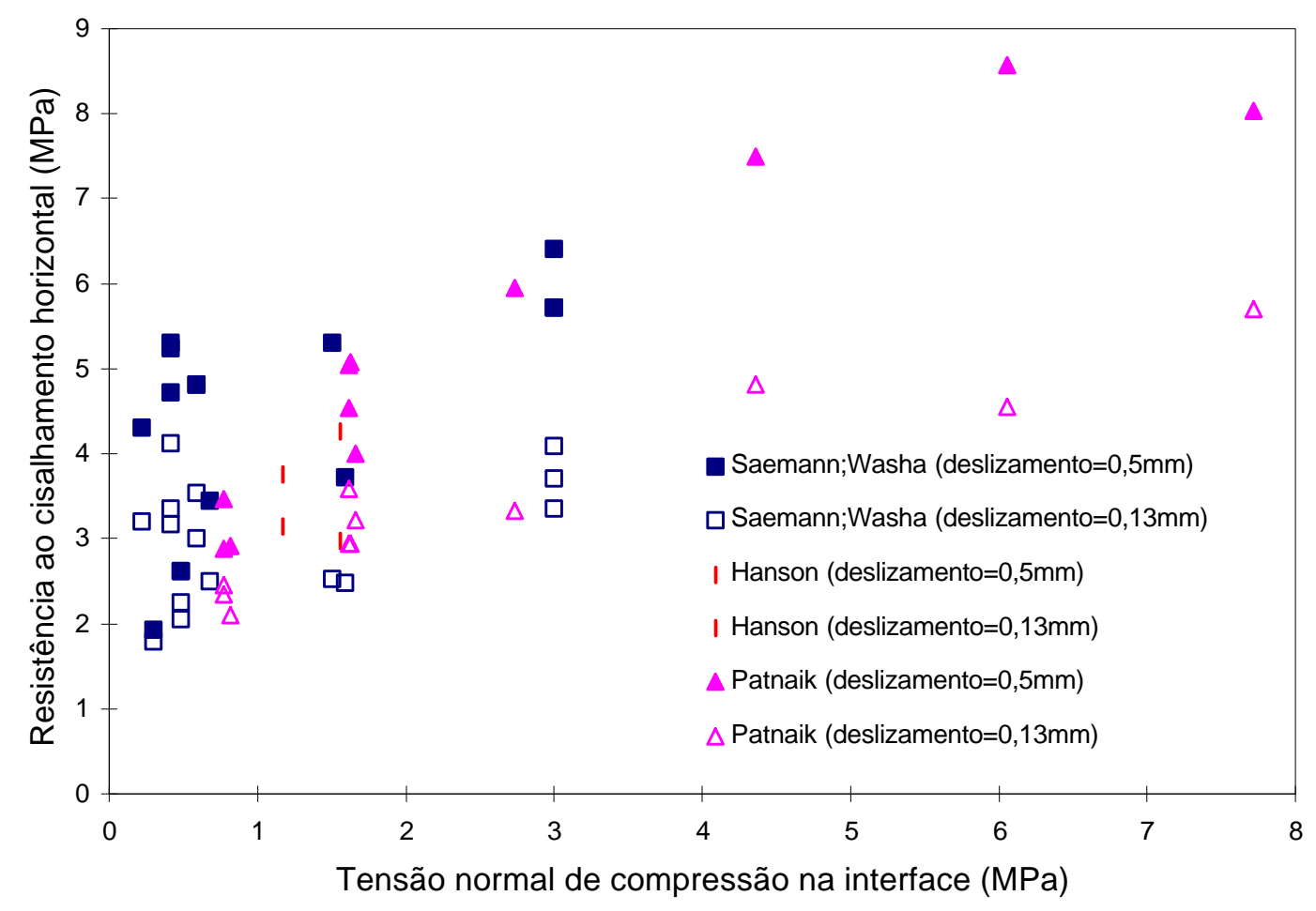

Figura 2.6 - Tensões de cisalhamento em vigas ensaiadas para diferentes níveis de deslizamento 
Tabela 2.1 - Resultados dos ensaios de vigas compostas que romperam por cisalhamento horizontal (Interface rugosa) (PATNAIK (1992) )

\begin{tabular}{|c|c|c|c|c|c|c|}
\hline \multirow[t]{2}{*}{ Viga } & \multicolumn{2}{|c|}{$\begin{array}{c}\text { Resistência do } \\
\text { concreto }\left(\mathrm{f}_{\mathrm{ck}}\right) \mathrm{MPa}\end{array}$} & \multirow{2}{*}{$\begin{array}{c}\text { tensão } \\
\text { normal de } \\
\text { compressão } \\
\left(\rho . \mathrm{f}_{\mathrm{yk}}\right) \mathrm{MPa}\end{array}$} & \multicolumn{3}{|c|}{$\begin{array}{c}\text { Resistência ao cisalhamento horizontal } \\
(\tau) \mathrm{MPa}\end{array}$} \\
\hline & Viga & Mesa & & $\begin{array}{l}\text { deslizamento } \\
\text { de } 0,13 \mathrm{~mm}\end{array}$ & $\begin{array}{c}\text { deslizamento } \\
\text { de } 0,5 \mathrm{~mm}\end{array}$ & ruptura \\
\hline \multicolumn{7}{|c|}{ Hanson } \\
\hline BRS-I & 30,9 & 21,5 & 1,56 & 2,97 & 4,27 & $\mathrm{DNF}^{*}$ \\
\hline BRS-II & 34,0 & 17,2 & 1,17 & 3,14 & 3,76 & DNF \\
\hline \multicolumn{7}{|c|}{ Mattock e Kaar } \\
\hline S11 & 43,2 & 24,1 & 0,58 & DNF & DNF & 2,75 \\
\hline S12 & 45,4 & 22,9 & 0,58 & DNF & DNF & 2,40 \\
\hline S13 & 44,5 & 23,1 & 0,58 & DNF & DNF & 2,72 \\
\hline S22 & 45,5 & 21,4 & 0,58 & DNF & DNF & 2,32 \\
\hline \multicolumn{7}{|c|}{ Saemann e Washa } \\
\hline $14 \mathrm{C}$ & 21,6 & 19,8 & 0,22 & 3,21 & 4,31 & 4,99 \\
\hline $13 C$ & 25,7 & 23,6 & 0,30 & 1,80 & 1,93 & 2,90 \\
\hline $12 \mathrm{C}$ & 20,5 & 23,9 & 0,41 & 3,17 & 4,72 & 5,55 \\
\hline $8 D$ & 31,8 & 32,5 & 0,41 & 3,36 & 5,24 & 6,07 \\
\hline 9D & 37,4 & 33,8 & 0,41 & 4,12 & 5,31 & 6,31 \\
\hline $11 \mathrm{C}$ & 20,3 & 19,8 & 0,48 & 2,05 & 2,62 & 2,73 \\
\hline $2 \mathrm{D}$ & 25,8 & 24,5 & 0,48 & 2,26 & 2,62 & 3,78 \\
\hline
\end{tabular}


Tabela 2.1 - Resultado dos ensaios de vigas compostas que romperam por cisalhamento horizontal (Interface rugosa) (PATNAIK (1992)) - continuação.

\begin{tabular}{|c|c|c|c|c|c|c|}
\hline \multirow[t]{2}{*}{ Viga } & \multicolumn{2}{|c|}{$\begin{array}{l}\text { Resistência do } \\
\text { concreto }\left(f_{\mathrm{ck}}\right) \mathrm{MPa}\end{array}$} & \multirow{2}{*}{$\begin{array}{c}\text { tensão } \\
\text { normal de } \\
\text { compressão } \\
\left(\rho . f_{\mathrm{yk}}\right) \mathrm{MPa}\end{array}$} & \multicolumn{3}{|c|}{$\begin{array}{l}\text { Resistência ao cisalhamento horizontal } \\
(\tau) \mathrm{MPa}\end{array}$} \\
\hline & Viga & Mesa & & $\begin{array}{l}\text { deslizamento } \\
\text { de } 0,13 \mathrm{~mm}\end{array}$ & $\begin{array}{c}\text { deslizamento } \\
\text { de } 0,5 \mathrm{~mm}\end{array}$ & ruptura \\
\hline \multicolumn{7}{|c|}{ Saemann e Washa (Continuação) } \\
\hline $5 \mathrm{D}$ & 23,4 & 24,7 & 0,59 & 3,00 & 4,82 & 6,14 \\
\hline $6 \mathrm{D}$ & 25,4 & 26,7 & 0,59 & 3,54 & 4,82 & 6,10 \\
\hline $8 \mathrm{C}$ & 19,2 & 20,5 & 0,68 & 2,50 & 3,45 & 3,78 \\
\hline $5 \mathrm{C}$ & 20,8 & 22,5 & 1,50 & 2,53 & 5,31 & 6,44 \\
\hline $3 \mathrm{C}$ & 21,2 & 21,2 & 1,59 & 2,48 & 3,72 & 4,10 \\
\hline $7 A$ & 19,9 & 21,0 & 3,00 & 3,36 & 5,72 & 6,04 \\
\hline $15 B$ & 22,6 & 22,3 & 3,00 & 3,57 & DNF & 7,78 \\
\hline $10 \mathrm{~A}$ & 21,1 & 19,8 & 3,00 & 3,71 & 5,72 & 6,44 \\
\hline $6 \mathrm{~A}$ & 20,0 & 24,9 & 3,00 & 4,10 & 6,41 & 6,57 \\
\hline \multicolumn{7}{|c|}{ Evans e Chung (concreto leve) } \\
\hline 2 & 59,8 & 35,9 & 0,38 & DNF & DNF & 3,17 \\
\hline 3 & 61,9 & 35,6 & 0,50 & DNF & DNF & 3,55 \\
\hline 4 & 62,4 & 35,3 & 0,75 & DNF & DNF & 3,79 \\
\hline \multicolumn{7}{|c|}{ Nosseir e Murtha } \\
\hline $\mathrm{R} 0.3$ & 31,7 & 23,0 & 0,51 & DNF & DNF & 4,19 \\
\hline $\mathrm{R} 0.7$ & 33,7 & 27,5 & 1,21 & DNF & DNF & 4,63 \\
\hline
\end{tabular}


Tabela 2.1 - Resultados dos ensaios de vigas compostas que romperam por cisalhamento horizontal (Interface rugosa) (PATNAIK (1992) ) - continuação.

\begin{tabular}{|c|c|c|c|c|c|c|}
\hline \multirow[t]{2}{*}{ Viga } & \multicolumn{2}{|c|}{$\begin{array}{c}\text { Resistência do } \\
\text { concreto }\left(f_{c k}\right) \mathrm{MPa}\end{array}$} & \multirow{2}{*}{$\begin{array}{c}\text { tensão } \\
\text { normal de } \\
\text { compressão } \\
\left(\rho . f_{\mathrm{yk}}\right) \mathrm{MPa}\end{array}$} & \multicolumn{3}{|c|}{$\begin{array}{l}\text { Resistência ao cisalhamento horizontal } \\
(\tau) \mathrm{MPa}\end{array}$} \\
\hline & Viga & Mesa & & $\begin{array}{l}\text { deslizamento } \\
\text { de } 0,13 \mathrm{~mm}\end{array}$ & $\begin{array}{c}\text { deslizamento } \\
\text { de } 0,5 \mathrm{~mm}\end{array}$ & ruptura \\
\hline \multicolumn{7}{|c|}{ Patnaik } \\
\hline 8 & 38,0 & 35,6 & 0,77 & 2,35 & 2,89 & 3,12 \\
\hline 10 & 37,6 & 38,7 & 0,77 & 2,46 & 3,46 & 3,46 \\
\hline 13 & 23,7 & 19,2 & 0,82 & 2,10 & 2,92 & 2,92 \\
\hline 6 & 40,4 & 37,1 & 1,62 & 2,95 & 5,04 & 5,25 \\
\hline 9 & 37,6 & 37,1 & 1,62 & 3,59 & 4,54 & 4,64 \\
\hline 5 & 42,6 & 34,8 & 1,63 & 2,95 & 5,08 & 5,54 \\
\hline 2 & 39,2 & 34,9 & 1,66 & 3,22 & 4,00 & 4,27 \\
\hline 3 & 40,2 & 30,5 & 2,73 & 3,32 & 5,95 & 6,82 \\
\hline 1 & 42,7 & 37,4 & 4,36 & 4,81 & 7,50 & 7,76 \\
\hline 7 & 38,0 & 35,8 & 6,06 & 4,55 & 8,57 & 9,25 \\
\hline 12 & 36,2 & 34,6 & 7,72 & 5,71 & 8,04 & 9,20 \\
\hline
\end{tabular}

* Dados Não Fornecidos 


\subsection{Modelos analíticos de transferência de esforços de cisalhamento}

\subsubsection{Teoria atrito-cisalhamento}

Um modelo simplificado para avaliação da resistência ao cisalhamento em interfaces rugosas é fornecido pela teoria atrito-cisalhamento (BIRKELAND; BIRKELAND (1966) e MAST (1968)). Nesse modelo, a interface rugosa é substituída por uma série de pequenos dentes sem atrito inclinados de tg $\phi$ (figura 2.7). Ao aplicar-se uma força horizontal, uma parte deslizará sobre a outra. Entretanto, devido aos pequenos dentes, elas também separar-se-ão tracionando a armadura transversal, a qual aplicará uma força $\mathrm{F}$ à interface. Do equilíbrio de forças horizontais da figura temos $F \cdot \operatorname{tg} \phi=\mu . N$. $O$ efeito da força $F$ sobre a interface é equivalente à uma força normal externa de compressão N. Assumindo que a armadura transversal à interface alcance sua resistência de escoamento $\mathrm{f}_{\mathrm{y}}$, a tensão normal de compressão à interface é igual ao produto da taxa de armadura pela resistência de escoamento do aço ( $\left.\rho . f_{y}\right)$. A força de cisalhamento que provoca a ruptura da interface é adotada como aquela que leva toda a armadura transversal ao escoamento. Dessa forma, a equação que representa a resistência ao cisalhamento da interface pode ser escrita como:

$$
\begin{aligned}
& R=F \cdot \operatorname{tg} \phi=A_{s w} \cdot f_{y} \cdot \operatorname{tg} \phi \\
& \text { ou } \\
& \tau=\rho \cdot f_{y} \cdot \operatorname{tg} \phi
\end{aligned}
$$

$$
\begin{aligned}
& \operatorname{tg} \phi=\mu \text { : coeficiente de atrito } \\
& R \text { : força de cisalhamento resistente; } \\
& \tau \text { : tensão de cisalhamento resistente }\left(\tau_{u} \leq 5,5 \mathrm{MPa}\right) ; \\
& \rho \text { : taxa geométrica de armadura transversal à interface }(\rho \leq 0,015) \text {; }
\end{aligned}
$$$$
\mathrm{R} \text { : força de cisalhamento resistente; }
$$ 
A tensão normal à interface pode ser originada da armadura transversal ou da ação de forças externas. Logo a eq.(2.1.b) pode ser generalizada como:

$$
\tau=\left(\rho . f_{y}+\sigma_{n}\right) \cdot \operatorname{tg} \phi
$$

$\sigma_{\mathrm{n}}$ : tensão de compressão devido às forças externas aplicadas perpendicularmente ao plano de ruptura da interface.
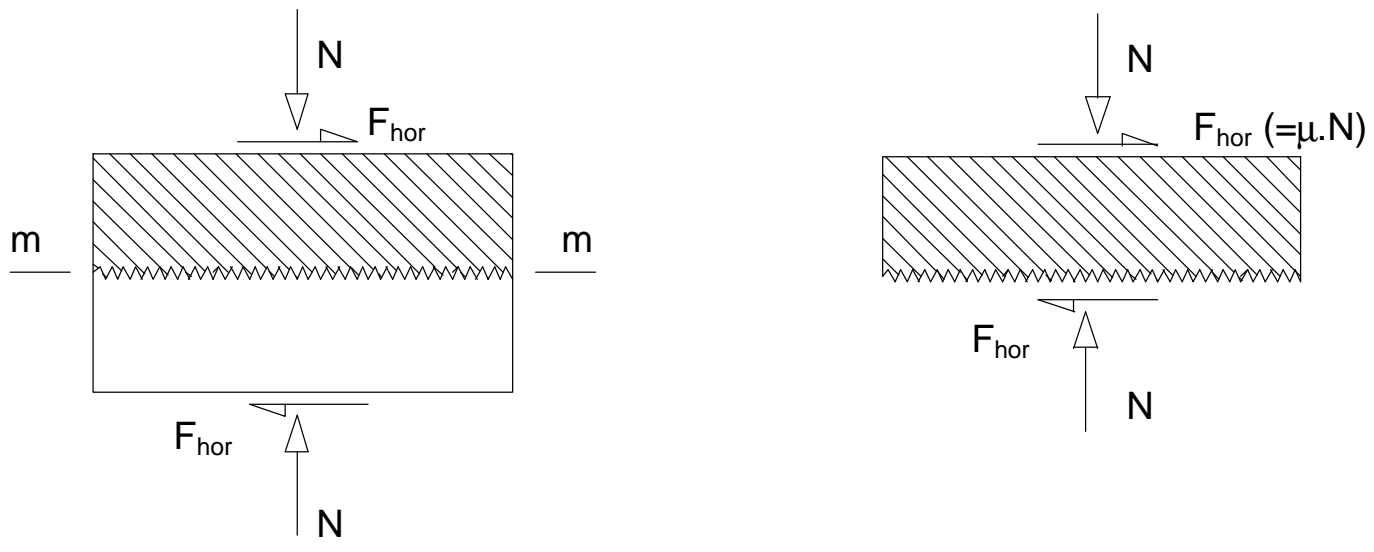

(a) força de atrito entre duas superfícies em contato
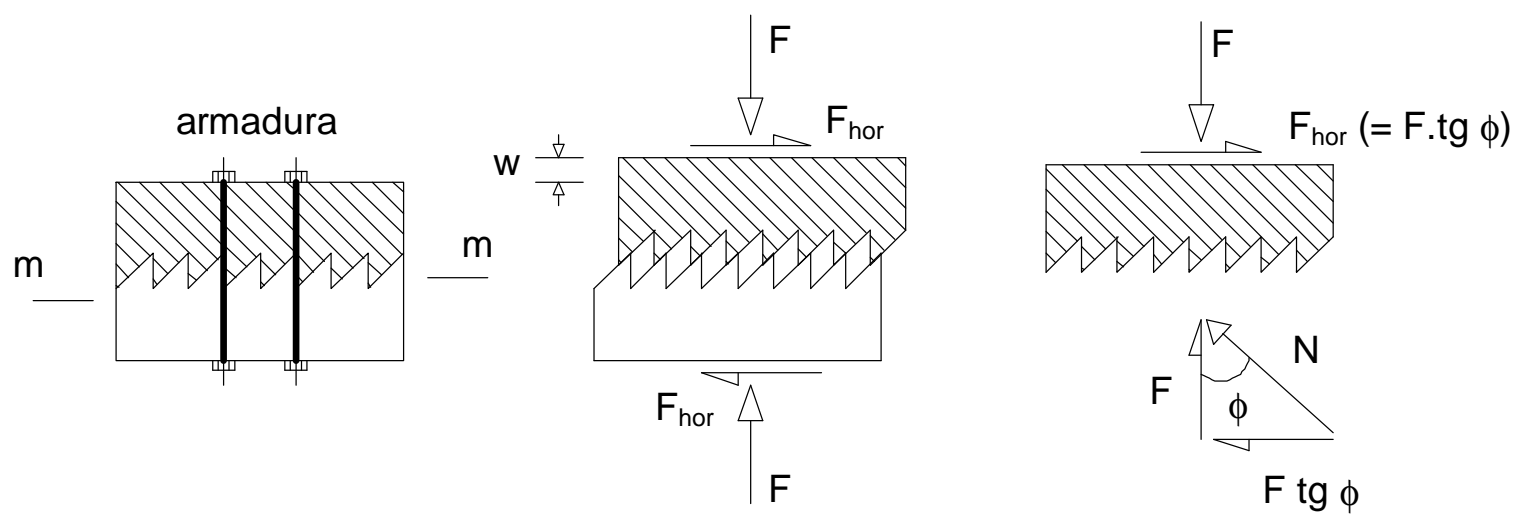

(b) aplicação pela armadura de força normal à interface

Figura 2.7 - Teoria atrito-cisalhamento (PATNAIK (1992)) 
Na formulação da eq.(2.2) foram feitas algumas hipóteses e simplificações:

a) a armadura transversal à interface está devidamente ancorada em ambos os lados da junta de forma que ela atinge a resistência de escoamento;

a) é admissível um deslizamento relativo entre as duas superfícies em contato;

a) a resistência ao deslizamento é proporcionada pelo atrito e não pela aderência;

a) o concreto da região da junta é bem confinado através de cintamento;

a) a superfície da interface é livre de impurezas ou detritos;

a) a resistência ao cisalhamento é definida para carregamento estático, não sendo válida a equação quando a fadiga ou o deslizamento entre as duas superfícies forem critérios de ruptura;

a) o diâmetro das barras da armadura transversal é limitado a $19 \mathrm{~mm}$ e sua resistência de escoamento $\left(f_{y}\right)$ a $420 \mathrm{MPa}$;

a) a equação é válida para concreto de densidade normal;

a) o valor do coeficiente de atrito independe da resistência do concreto e do nível de tensão a que está submetido;

a) o coeficiente de atrito é "aparente" e aplicável apenas a baixos níveis de tensão;

a) a tensão normal de compressão $\left(\rho . f_{y}+\sigma_{n}\right)$ é limitada a $0,15 . f_{c}$,onde $f_{c}$ é a resistência do concreto medida em corpos-de-prova cilíndricos, sendo $\mathrm{f}_{\mathrm{c}} \geq 27 \mathrm{MPa}$.

Algumas dessas limitações são devidas ao pequeno número de variáveis estudadas nos ensaios. Esse modelo ignora o efeito da aderência mas compensa usando um ângulo de atrito interno maior que o real, sendo válido apenas para baixos níveis de tensão. A teoria atrito-cisalhamento é utilizada como base por muitas normas e regulamentos para avaliação da tensão resistente em vigas compostas. 


\subsubsection{Modelo de Tsoukantas e Tassios}

Um extensivo estudo baseado em ensaios de painéis pré-moldados foi desenvolvido, alguns anos atrás, na National Technical University, em Atenas com o objetivo de definir um modelo que simulasse o mecanismo de transferência de tensões de cisalhamento (TSOUKANTAS; TASSIOS (1989)). Esse modelo é baseado nas contribuições da resistência por atrito e da resistência por ação de pino da armadura transversal.

No caso de interfaces com superfície naturalmente rugosa e concreto com resistência inferior a $56 \mathrm{MPa}$, os ensaios mostraram que a relação entre o deslizamento da interface e a separação transversal entre as partes é independente de parâmetros como diâmetro máximo do agregado, tensão normal à interface, resistência do concreto, etc.. Convencionalmente, uma superfície de concreto é classificada como lisa quando produzida em fôrmas metálicas, como, por exemplo, pré-moldados de concreto. Interfaces de concreto produzidas pela ruptura de uma peça monolítica (modelos com plano de cisalhamento préfissurado) ou superfícies lisas tornadas rugosas como ,por exemplo, pelo jateamento de areia são classificadas como rugosas. A separação transversal (w) pode ser avaliada, em função do deslizamento da interface (s), por:

$$
\begin{array}{ll}
\text { interfaces lisas } & : \mathrm{w}=0,05 . \mathrm{s} \\
\text { interfaces rugosas } & : \mathrm{w}=0,6 \cdot \mathrm{s}^{2 / 3} \leq 1,4 \mathrm{~mm}
\end{array}
$$

Estas equações empíricas são válidas para valores de deslizamento inferiores a $2 \mathrm{~mm}$ em interfaces com superfície lisa e 2,5 $\mathrm{mm}$ com superfície rugosa. Esses valores foram obtidos de ensaios de cisalhamento direto em modelos monolíticos com plano de cisalhamento pré-fissurado. A interface lisa foi obtida moldando blocos de concreto separadamente, os quais foram colocados juntos durante o ensaio. Não havia armadura transversal à interface, sendo a tensão normal garantida por forças externas. A resistência última ao cisalhamento para superfície lisa é dada, em função da tensão normal $\sigma_{n}$, por:

$$
\tau_{u}=0,4 . \sigma_{n} \quad(\mathrm{MPa})
$$


A relação entre a resistência ao cisalhamento e o deslizamento da interface é expressa por:

$$
\tau=\tau_{\mathrm{u}} \cdot \frac{\mathrm{s}}{\mathrm{s}_{\mathrm{u}}} \quad(\mathrm{MPa})
$$

sendo:

$$
\begin{aligned}
\mathrm{s}_{\mathrm{u}} & =0,15 \cdot \sqrt{\sigma_{\mathrm{n}}}: \text { deslizamento correspondente à máxima capacidade } \\
& \text { resistente da interface }\left(\mathrm{s}_{\mathrm{u}} \text { em } \mathrm{mm} \text { e } \sigma_{\mathrm{n}} \text { em MPa }\right) ; \\
\tau_{\mathrm{u}} & \text { : resistência última da interface dada pela eq.(2.4). }
\end{aligned}
$$

Nos ensaios com superfície rugosa, a resistência última ao cisalhamento foi alcançada para um deslizamento $\left(\mathrm{s}_{\mathrm{u}}\right)$ da ordem de $2 \mathrm{~mm}$, independente do valor da tensão normal. Seu valor, em função da tensão normal $\sigma_{n}$, é dada por:

$$
\tau_{\mathrm{u}}=0,5 \cdot \sqrt[3]{\mathrm{f}_{\mathrm{c}}{ }^{2} \cdot \sigma_{\mathrm{n}}} \quad(\mathrm{MPa})
$$

A relação entre a resistência ao cisalhamento $(\tau)$ e o deslizamento da interface é expressa por:

$$
\begin{aligned}
& \mathrm{s} \leq 0,05 \mathrm{~s}_{\mathrm{u}}, \tau=10 \cdot \tau_{\mathrm{u}} \cdot \frac{\mathrm{s}}{\mathrm{s}_{\mathrm{u}}} \quad(\mathrm{MPa}) \\
& 0,05 \mathrm{~s}_{\mathrm{u}} \leq \mathrm{s} \leq \mathrm{s}_{\mathrm{u}}, \frac{\mathrm{s}}{\mathrm{s}_{\mathrm{u}}}=1,7 \cdot\left[\left(\frac{\tau}{\tau_{\mathrm{u}}}\right)^{4}-0,5 \cdot\left(\frac{\tau}{\tau_{\mathrm{u}}}\right)^{3}\right]+0,05 \quad(\mathrm{MPa})(2 \cdot 7 \cdot \mathrm{b})
\end{aligned}
$$

sendo:

$$
\begin{aligned}
& \mathrm{S}_{\mathrm{u}}=2 \mathrm{~mm} \text { : deslizamento correspondente à máxima capacidade } \\
& \text { resistente da interface } \\
& \tau_{\mathrm{u}} \text { : resistência última da interface dada pela eq.(2.6) }
\end{aligned}
$$

Aplicando uma força horizontal na interface, ocorrerá um deslizamento entre as duas partes em contato. Conhecido este deslizamento é possível calcular o valor 
da separação transversal entre as partes, o qual será transmitido à armadura transversal. Esta, por sua vez, aplicará uma tensão normal à interface $\left(\sigma_{\mathrm{n}}=\rho . \sigma_{\mathrm{s}}\right)$ e, através das equações anteriores, pode-se calcular a resistência oferecida pela interface. Se a armadura estiver devidamente ancorada em ambas as partes, na ruptura ela poderá alcançar a resistência de escoamento e, neste caso, $\sigma_{s}=f_{y}$. Esta situação representa a completa utilização do mecanismo resistente por atrito e deve, sempre que possível, ser empregada. Para tanto, atenção especial deve ser dada à ancoragem da armadura em ambas as partes de concreto.

A armadura transversal à interface fornecerá também uma parcela de resistência devido à ação de pino. Se existir um cobrimento de concreto da armadura adequado (figura 2.8), devido ao deslizamento da interface a armadura atinge sua resistência ao escoamento e o concreto à sua volta sofre esmagamento. Admite-se que a partir deste instante não há mais contribuição da armadura por efeito de pino. A relação entre a força na armadura $\left(R_{s}\right)$ e seu deslocamento transversal $\left(\mathrm{s}_{\mathrm{s}}\right)$ é expressa por (figura 2.9 ):

$$
\begin{aligned}
& \mathrm{s}_{\mathrm{s}} \leq \mathrm{s}_{\mathrm{s}, \mathrm{lim}}, \mathrm{R}_{\mathrm{s}}=0,5 \cdot \frac{\mathrm{R}_{\mathrm{s}, \mathrm{u}}}{\mathrm{s}_{\mathrm{s}, \mathrm{im}}} \cdot \mathrm{s}_{\mathrm{s}}(\mathrm{N}) \\
& \mathrm{s}_{\mathrm{s}, \lim } \leq \mathrm{s}_{\mathrm{s}} \leq \mathrm{s}_{\mathrm{s}, \mathrm{u}}, \mathrm{s}_{\mathrm{s}}=\mathrm{s}_{\mathrm{s}, \mathrm{lim}}+1,15 \cdot \mathrm{s}_{\mathrm{s}, \mathrm{u}} \cdot\left[\left(\frac{\mathrm{R}_{\mathrm{s}}}{\mathrm{R}_{\mathrm{s}, \mathrm{u}}}\right)^{4}-0,5 \cdot\left(\frac{\mathrm{R}_{\mathrm{s}}}{\mathrm{R}_{\mathrm{s}, \mathrm{u}}}\right)^{3}\right]
\end{aligned}
$$

sendo :

$\mathrm{R}_{\mathrm{s}, \mathrm{u}}$ : resistência última da armadura à ação de pino em $\mathrm{N}$;

$$
\mathrm{s}_{\mathrm{s}, \mathrm{im}}=\frac{2 \cdot \mathrm{R}_{\mathrm{s}, \mathrm{u}} \cdot \beta \cdot(\mathrm{e} \cdot \beta+1)}{\mathrm{E}_{\mathrm{c}}}
$$

onde:

$$
\begin{aligned}
& \beta=\left(\frac{E_{c}}{8 \cdot E_{s} \cdot I_{s}}\right)^{1 / 4} \\
& E_{c}: \text { módulo de elasticidade longitudinal do concreto; } \\
& E_{s}: \text { módulo de elasticidade longitudinal do aço; }
\end{aligned}
$$


$I_{s}$ : momento de inércia da seção transversal da barra;

e : excentricidade do carregamento;

$\mathrm{s}_{\mathrm{s}, \mathrm{u}} \cong 0,05 \Phi_{\mathrm{s}}$ : deslocamento transversal da armadura correspondente à máxima capacidade resistente;

Фs : diâmetro da barra.

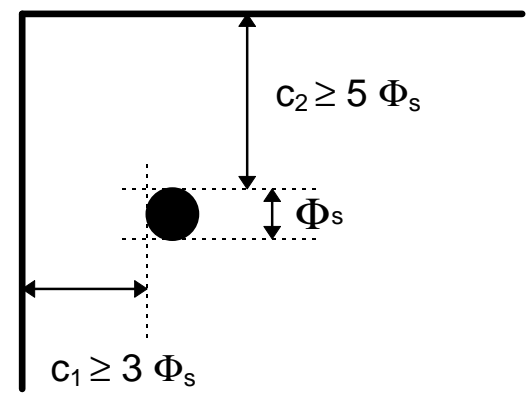

Figura 2.8 - Cobrimento de concreto da armadura

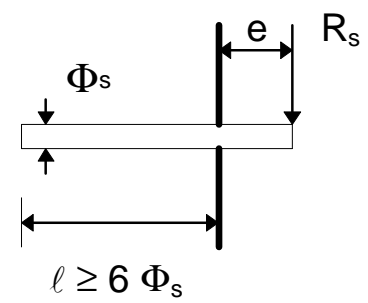

Figura 2.9 - Aplicação de força transversal à armadura

A resistência última fornecida pela armadura pode ser avaliada pela seguinte expressão:

$$
R_{s, u}{ }^{2}+\left(10 \cdot f_{c} \cdot \Phi_{s} \cdot e\right) \cdot R_{s, u}-\delta^{2} \cdot \Phi_{s}{ }^{4} \cdot f_{c} \cdot f_{y} \cdot\left(1-\xi^{2}\right)=0
$$

onde as unidades são dadas em mm, $\mathrm{N}$ e MPa. 
O coeficiente $\delta(\delta \leq 1,3)$ depende do cobrimento de concreto da armadura e da direção da força de cisalhamento. Seu valor pode ser obtido da tabela $2.2 \mathrm{com}$ a ajuda da figura 2.10. O coeficiente $\xi=\sigma_{\mathrm{s}} / \mathrm{f}_{\mathrm{y}}$ é usado para avaliar a diminuição da resistência por ação de pino em função das tensões de tração na armadura.

Tabela 2.2 - Avaliação do coeficiente $\delta$ do modelo de Tsoukantas e Tassios

\begin{tabular}{|c|c|}
\hline $\begin{array}{c}\text { Região em que está localizada a } \\
\text { armadura transversal }\end{array}$ & valor de $\delta$ \\
\hline I & $0,6+\frac{\mathrm{C}_{1}}{\Phi_{\mathrm{s}}}\left(0,027 \frac{\mathrm{c}_{2}}{\Phi_{\mathrm{s}}}+0,1\right)$ \\
\hline II & $0,9+0,03 \frac{\mathrm{c}_{2}}{\Phi_{\mathrm{s}}}$ \\
\hline III & $0,6+0,233 \frac{\mathrm{c}_{1}}{\Phi_{\mathrm{s}}}$ \\
\hline IV & 1,3 \\
\hline
\end{tabular}

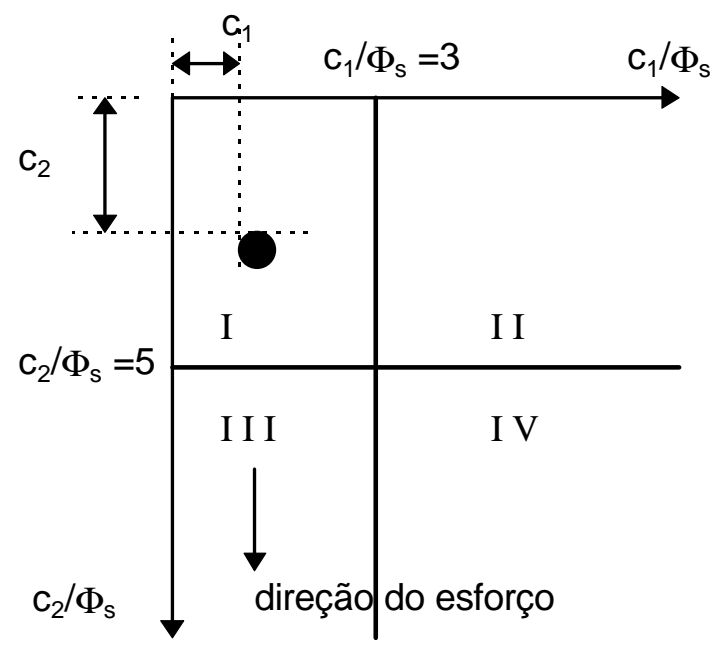

Figura 2.10 - Posição da armadura na seção transversal para estimativa do coeficiente $\delta$ 
Apenas as barras que possuírem cobrimento maior que 5 vezes seu diâmetro $\left(c \geq 5 \Phi_{\mathrm{s}}\right)$ na direção da força de cisalhamento deverão ser consideradas para avaliação da resistência (figura 2.11).

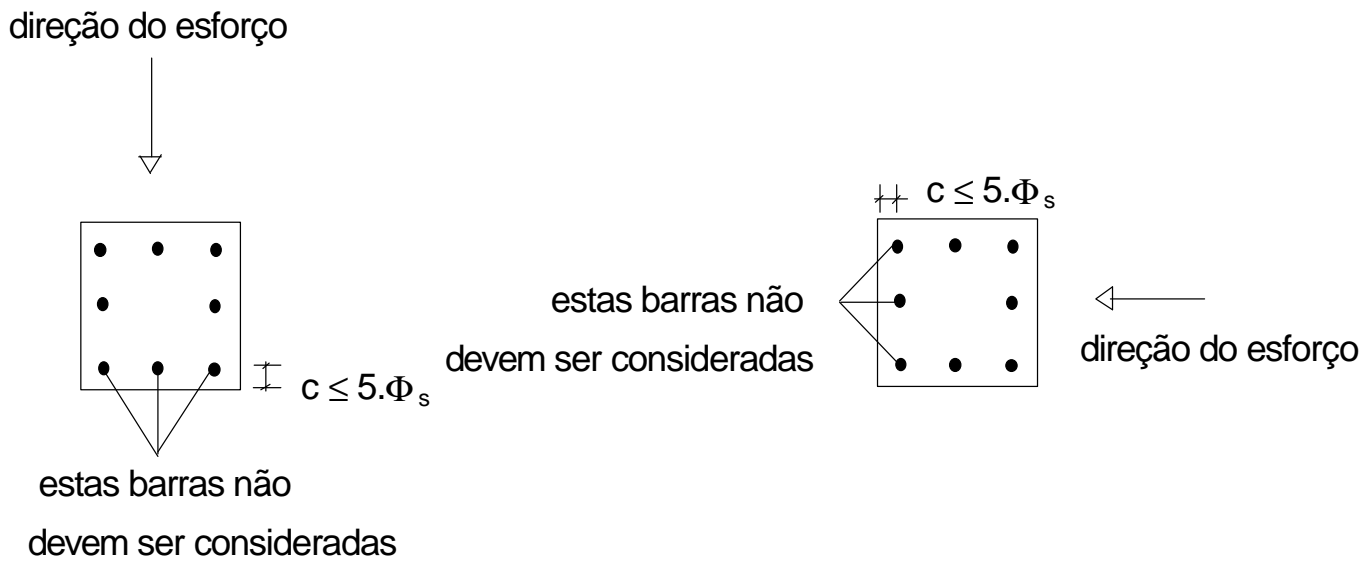

Figura 2.11 - Barras constituintes do mecanismo resistente em função de sua posição

No caso de interfaces de concreto a excentricidade do carregamento é nula. As expressões anteriores podem ser simplificadas e a resistência fornecida pelo modelo, desde que o deslizamento da interface (s) seja maior que $\mathrm{s}_{\mathrm{s}, \mathrm{u}}$,vale:

$$
R_{s, u d}=\frac{1}{\gamma_{r d}} \cdot \delta \cdot \Phi_{s}{ }^{2} \cdot \sqrt{\frac{f_{c}}{\gamma_{c}} \cdot \frac{f_{y}}{\gamma_{s}} \cdot\left(1-\xi^{2}\right)}
$$

sendo:

$$
\begin{aligned}
& \gamma_{\mathrm{rd}}=\frac{4}{3} \quad: \text { coeficiente devido à dispersão dos resultados dos } \\
& \text { ensaios; } \\
& \gamma_{c}, \gamma_{\mathrm{s}}: \text { coeficientes de minoração da resistência do concreto e do } \\
& \text { aço, respectivamente. }
\end{aligned}
$$


Para valores de $\mathrm{s}<\mathrm{s}_{\mathrm{s}, \mathrm{u}}$, a resistência da armadura pode ser avaliada pela eq.(2.8.a) ou eq.(2.8.b), adotando-se $R_{s, u d}$ fornecido pela eq.(2.10) e e= 0 .

Para o completo aproveitamento do mecanismo de transferência de tensões de cisalhamento através de juntas de concreto com armadura transversal é fundamental que a armadura esteja bem ancorada em ambas as partes, de modo que ela possa alcançar sua resistência de escoamento. Dessa forma, segundo a teoria atrito-cisalhamento, será mobilizada a máxima resistência por atrito entre as superfícies de concreto. A relação força de arrancamento - deslocamento é obtida de ensaios de arrancamento de barras imersas em blocos de concreto sendo expressa por:

$$
\sigma_{\mathrm{s}}=15 \cdot \Phi_{\mathrm{s}}^{-1 / 2} \cdot \ell \cdot\left(\frac{\mathrm{f}_{\mathrm{c}}}{16}\right)^{1 / 4} \cdot \Delta \ell^{1 / 3} \leq \mathrm{f}_{\mathrm{y}} \quad(\mathrm{MPa})
$$

sendo:

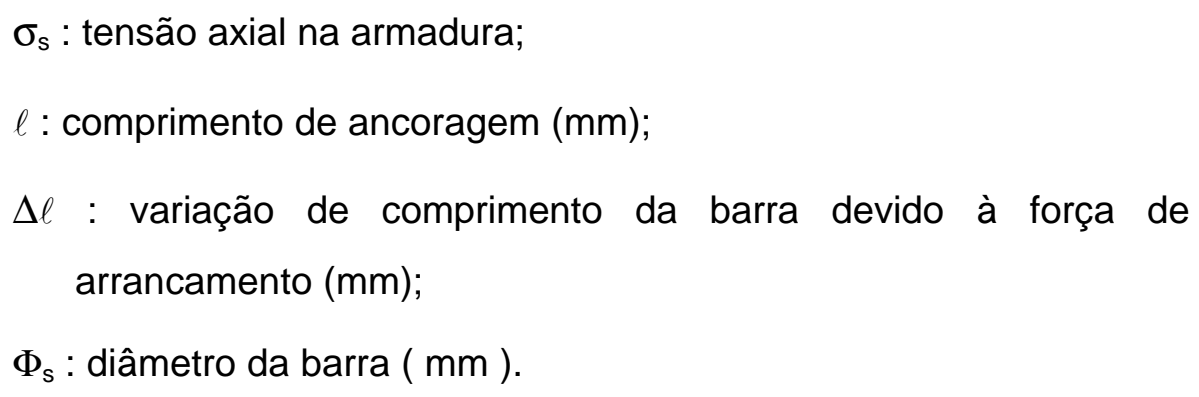

Nesta equação, a variação de comprimento $\Delta \ell$ na extremidade da barra representa a resultante de deformações ocorridas na barra na região ancorada (figura 2.12). O comprimento de ancoragem deve estar no intervalo $2 \Phi_{\mathrm{s}} \leq \ell \leq 12 \Phi_{\mathrm{s}}$. Em grande parte das aplicações práticas, o comprimento de ancoragem das barras atravessando a interface é muito maior que $12 \Phi_{\mathrm{s}}$. Neste caso, visando facilitar a aplicação do modelo, a eq.(2.12) pode ser usada para calcular a tensão na barra fornecendo, entretanto, valores conservadores. Fazendo $\ell=12 \Phi_{\mathrm{s}}$ na eq.(2.11) e aplicando um coeficiente de incerteza devido à dispersão dos resultados experimentais $\left(\gamma_{\mathrm{rd}}=2 / 3\right)$, obtêm-se a seguinte expressão: 


$$
\sigma_{\mathrm{s}, \mathrm{d}}=60 \cdot \sqrt{\Phi_{\mathrm{s}}} \cdot \mathrm{f}_{\mathrm{cd}}{ }^{1 / 4} \cdot \Delta \ell^{1 / 3} \leq \mathrm{f}_{\mathrm{y}} \quad(\mathrm{MPa}), \ell \geq 12 \Phi_{\mathrm{s}}
$$

sendo $\Delta \ell=\frac{\mathrm{w}}{2}$ e as unidades em $\mathrm{mm}$ e MPa.

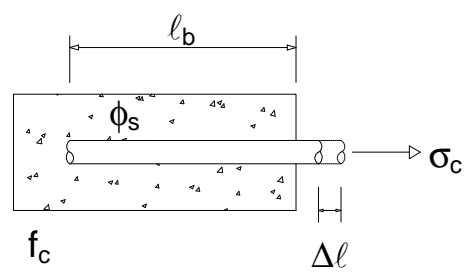

Figura 2.12 - Modelo para ensaio de arrancamento de barra

\subsubsection{Modelo de Tassios e Vintzeleou}

Baseados nos mesmos estudos realizados na National Technical University, em Atenas, TASSIOS; VINTZELEOU (1990) simplificaram o modelo anterior e aplicaram-no a modelos de ensaios de cisalhamento direto.

A resistência última ao cisalhamento em interfaces rugosas submetidas à tensão normal constante $\left(\sigma_{n}\right)$ pode ser avaliada por:

$$
\tau_{\mathrm{u}}=0,44 \cdot \sqrt[3]{\mathrm{f}_{\mathrm{c}}^{2} \cdot \sigma_{\mathrm{n}}} \quad(\mathrm{MPa})
$$

Nesta expressão, a tensão normal é garantida por forças externas atuando sobre a interface. Nos ensaios, realizados sob tensão normal constante, observouse que a máxima resistência da ligação aos esforços de cisalhamento foi obtida para valores de deslizamento da ordem de $2 \mathrm{~mm}$. A equação que representa a resistência ao cisalhamento em função do deslizamento, para $\sigma_{\mathrm{n}}$ constante, é :

$$
\tau=0,5 \cdot \sqrt[3]{f_{\mathrm{c}}{ }^{2} \cdot \sigma_{\mathrm{n}} \cdot \frac{\mathrm{s}}{\mathrm{s}_{\mathrm{u}}}} \quad(\mathrm{MPa}) \quad, \mathrm{s}_{\mathrm{u}} \cong 2 \mathrm{~mm}
$$

A resistência devido à ação de pino da armadura pode ser avaliada por: 


$$
\begin{aligned}
& \mathrm{s}_{\mathrm{s}} \leq 0,1 \mathrm{~s}_{\mathrm{s}, \mathrm{u}}, \mathrm{R}_{\mathrm{s}}=5 \cdot \frac{\mathrm{R}_{\mathrm{s}, \mathrm{u}}}{\mathrm{s}_{\mathrm{s}, \mathrm{u}}} \cdot \mathrm{s}_{\mathrm{s}} \\
& 0,1 \mathrm{~s}_{\mathrm{s}, \mathrm{u}} \leq \mathrm{s}_{\mathrm{s}} \leq \mathrm{s}_{\mathrm{s}, \mathrm{u}}, \mathrm{s}_{\mathrm{s}}=0,10+1,15 \cdot\left[\left(\frac{\mathrm{R}_{\mathrm{s}}}{\mathrm{R}_{\mathrm{s}, \mathrm{u}}}\right)^{4}-0,5 \cdot\left(\frac{\mathrm{R}_{\mathrm{s}}}{\mathrm{R}_{\mathrm{s}, \mathrm{u}}}\right)^{3}\right] \cdot \mathrm{s}_{\mathrm{s}, \mathrm{u}}
\end{aligned}
$$

sendo:

$$
\begin{aligned}
& \mathrm{s}_{\mathrm{s}, \mathrm{u}}=0,05 \Phi_{\mathrm{s}} \quad(\mathrm{mm}) \\
& \mathrm{R}_{\mathrm{s}, \mathrm{u}}=1,3 \cdot \Phi_{\mathrm{s}}^{2} \cdot \sqrt{\mathrm{f}_{\mathrm{c}} \cdot \mathrm{f}_{\mathrm{y}} \cdot\left(1-\xi^{2}\right)}
\end{aligned}
$$

A relação força de arrancamento - deslocamento de uma barra imersa em uma região de concreto com resistência à tração $f_{t}$ pode ser obtida conhecendo-se a distribuição de tensões axiais e tensões de aderência nesta barra, conforme ilustrado na figura 2.13. Nesta figura, a barra possui comprimento insuficiente para que a tensão axial alcance a resistência de escoamento do aço. Neste caso a barra é arrancada do bloco de concreto com tensão axial $\sigma_{\mathrm{s}}$ inferior à resistência de escoamento $f_{y}$. Do equilíbrio entre forças externas e tensões de aderência obtêmse:

$$
\begin{aligned}
& \sigma_{\mathrm{s}}=7 \cdot \frac{\ell_{\mathrm{b}}}{\Phi_{\mathrm{s}}} \cdot \mathrm{f}_{\mathrm{t}} \leq \mathrm{f}_{\mathrm{y}} \\
& \Delta \ell=3,5 \cdot \frac{\mathrm{f}_{\mathrm{t}}}{\mathrm{E}_{\mathrm{s}}} \cdot \frac{\ell_{\mathrm{b}}{ }^{2}}{\Phi_{\mathrm{s}}}=\frac{w}{2}
\end{aligned}
$$

sendo as unidades em $\mathrm{mm}$ e $\mathrm{MPa}, \ell_{\mathrm{b}}$ o comprimento sobre o qual são desenvolvidas as tensões de aderência para transferência de esforços da barra para o concreto e $\Delta \ell$ a variação de comprimento da barra.

Da eq.(2.16) é possível determinar o mínimo comprimento de ancoragem de uma barra para que ela seja arrancada com $\sigma_{s}=f_{y}$, ou seja: 


$$
\ell_{\min }=\frac{1}{7} \cdot \frac{\Phi_{\mathrm{s}} \cdot \mathrm{f}_{\mathrm{y}}}{\mathrm{f}_{\mathrm{t}}} \quad(\mathrm{mm})
$$

Se a barra possuir comprimento de ancoragem maior que $\ell_{\min }$, ela alcançara a resistência de escoamento $\left(\sigma_{s}=f_{y}\right)$ e a sua variação de comprimento será dada por (figura 2.14):

$$
\Delta \ell=\left(\ell-\frac{1}{7} \cdot \frac{f_{y}}{f_{t}} \cdot \Phi_{s}\right) \cdot\left(\frac{f_{y}}{E_{s}}+0,029\right)+\frac{1}{14} \cdot \frac{f_{y}}{E_{s}} \cdot \frac{f_{y}}{f_{t}} \cdot \Phi_{s}
$$

Este valor deve ser inferior ao correspondente à deformação de ruptura do aço empregado.

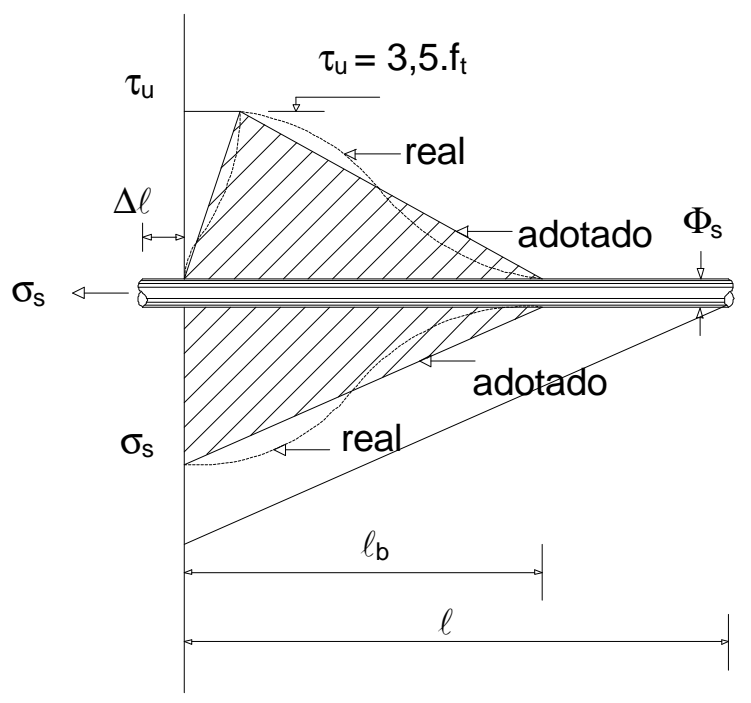

Figura 2.13 - Tensões de aderência e tensões de tração em uma barra com comprimento de ancoragem insuficiente (TASSIOS; VINTZELEOU (1990)) 


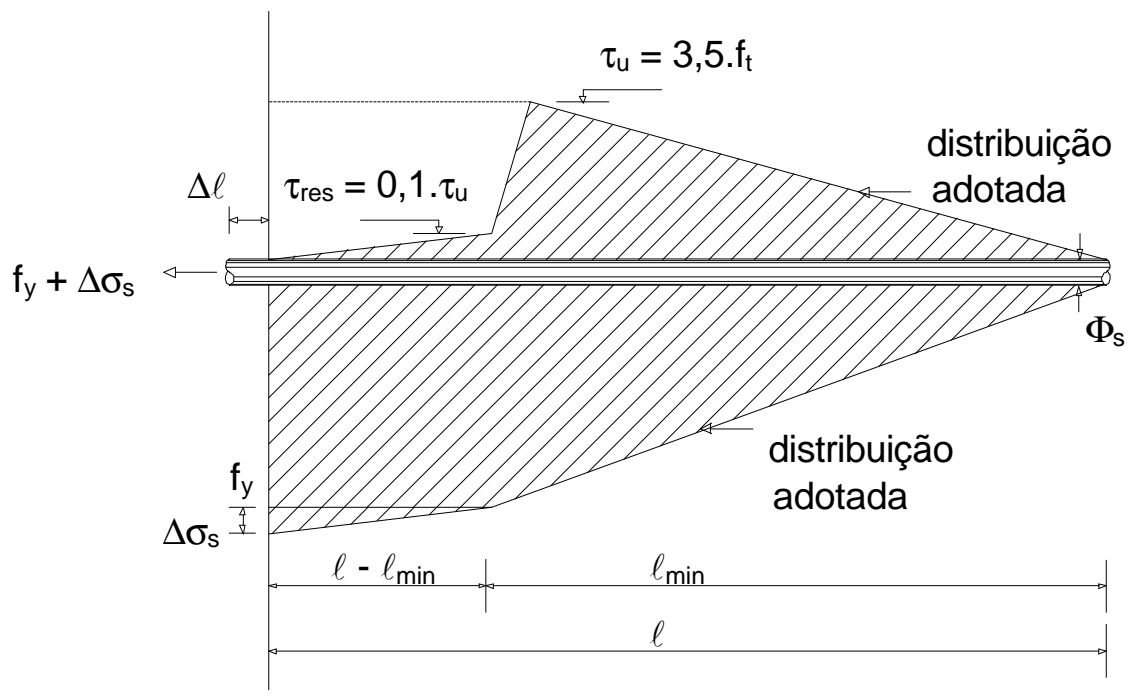

Figura 2.14 - Tensões de aderência e tensões de tração em uma barra com comprimento de ancoragem maior que o necessário para alcançar a resistência de escoamento (TASSIOS; VINTZELEOU (1990))

\subsubsection{Exemplo de aplicação dos modelos de Tsoukantas \& Tassios e Tassios \& Vintzeleou}

A título de ilustração, foi desenvolvido um exemplo de aplicação dos modelos apresentados. Trata-se da ligação entre duas colunas pré-moldadas, para a qual será traçada a curva que relaciona a resistência da interface com seu respectivo deslizamento (figura 2.15). A seção transversal é de $35 \mathrm{~cm} \times 35 \mathrm{~cm}$ e possui 8 barras de $20 \mathrm{~mm}$ de aço CA-50A ( $\left.\mathrm{f}_{\mathrm{yk}}=500 \mathrm{MPa}\right)$. A superfície da interface é suposta rugosa e ambas as peças possuem concreto com resistência de $16 \mathrm{MPa}$ ou de $40 \mathrm{MPa}$. A força normal nas colunas vale $400 \mathrm{kN}$.

De acordo com os modelos, a resistência ao cisalhamento é fornecida pela soma das parcelas de resistência devido ao atrito e à ação de pino da armadura transversal à interface. Conhecido o valor do deslizamento da interface é possível calcular o valor da abertura das fissuras utilizando a eq.(2.3.a) ou eq.(2.3.b). A armadura transversal é, então, tracionada e aplica uma força normal à interface. Essa força pode ser calculada pela eq.(2.12) ou eq.(2.16), onde $\Delta \ell$ deve ser tomado igual à metade do valor da abertura das fissuras. A tensão normal à superfície $\left(\sigma_{n}\right)$ é obtida multiplicando a tensão na armadura $\left(\sigma_{\mathrm{s}}\right)$ pela taxa geométrica de armadura transversal. Utilizando a eq.(2.7.a), eq.(2.7.b) ou eq.(2.14) 
calcula-se a resistência por atrito da interface sujeita à tensão normal constante $\sigma_{n}$. A resistência devido à ação de pino da armadura é calculada pela eq.(2.8.a), eq.(2.8.b) ou eq.(2.15.a), eq.(2.15.b) $c o m s_{s}=s / 2$, sendo somada à resistência por atrito para fornecer a resistência final da interface ao cisalhamento para um valor de deslizamento conhecido. Variando o deslizamento, obtêm-se a curva que relaciona o deslizamento da interface com a resistência ao cisalhamento. Esta curva possui um ponto de máximo que fornece a resistência última da interface de concreto.

Seguindo esse procedimento, traçou-se as curvas mostradas na figura 2.15. Estas curvas mostram que as equações propostas por Tsoukantas \& Tassios e Tassios \& Vintzeleou fornecem, aproximadamente, os mesmos valores de resistência. A resistência última, para $\mathrm{f}_{\mathrm{ck}}=16 \mathrm{MPa}$, foi obtida para o deslizamento de $2 \mathrm{~mm}$ pois, devido ao baixo valor da resistência do concreto, a armadura não atingiu sua resistência de escoamento, sendo a ruptura definida pelo deslizamento excessivo. Para $\mathrm{f}_{\mathrm{ck}}=40 \mathrm{MPa}$, devido ao maior valor de resistência do concreto, a armadura alcançou sua resistência de escoamento e a ruptura ocorreu para um deslizamento de 1,3 mm. Desse exemplo observa-se que os dois modelos propostos fornecem, aproximadamente, o mesmo resultado sendo que as equações propostas por Tassios e Vintzeleou são mais fáceis de usar e fornecem resultados mais conservadores.

\subsubsection{Modelo de Hsu, Mau e Chen}

Existem, basicamente, dois comportamentos distintos para os problemas de transferência de tensões de cisalhamento: transferência através de um plano previamente fissurado e através de um plano não fissurado. O comportamento para o primeiro caso é determinado pela relação entre tensão de cisalhamento e deslizamento do plano fissurado. O engrenamento dos agregados, a ação de pino e a tensão normal ao plano de cisalhamento afetam a resistência da interface. A ruptura ocorre ao longo da fissura existente com pequeno ou nenhum aumento da abertura exceto quando há grande porcentagem de armadura atravessando a interface. A resistência final da interface é avaliada pela teoria atrito-cisalhamento. 


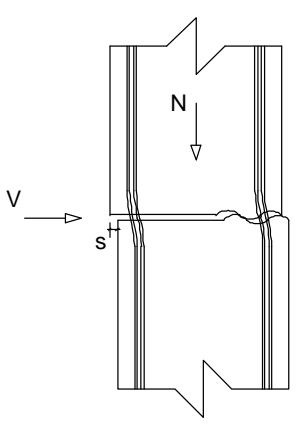

elevação

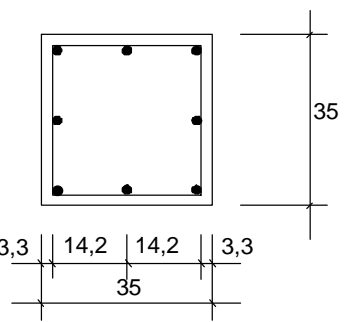

seção transversal

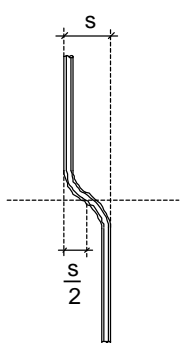

efeito de pino

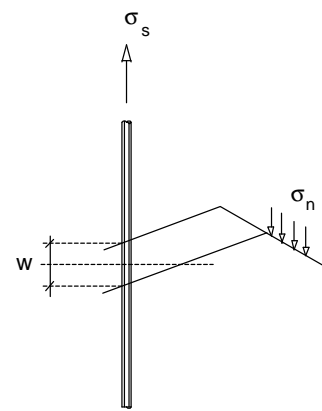

atrito

$$
\begin{aligned}
& 8 \text { barras de } 20 \mathrm{~mm} \\
& \mathrm{f}_{\mathrm{ck}}=16 \mathrm{MPa} \text { ou } \mathrm{f}_{\mathrm{ck}}=40 \mathrm{MPa} \\
& \mathrm{f}_{\mathrm{yk}}=500 \mathrm{MPa}
\end{aligned}
$$

diâmetro do estribo : $8 \mathrm{~mm}$

Curva deslizamento da interface $\mathrm{x}$ resistência ao cisalhamento

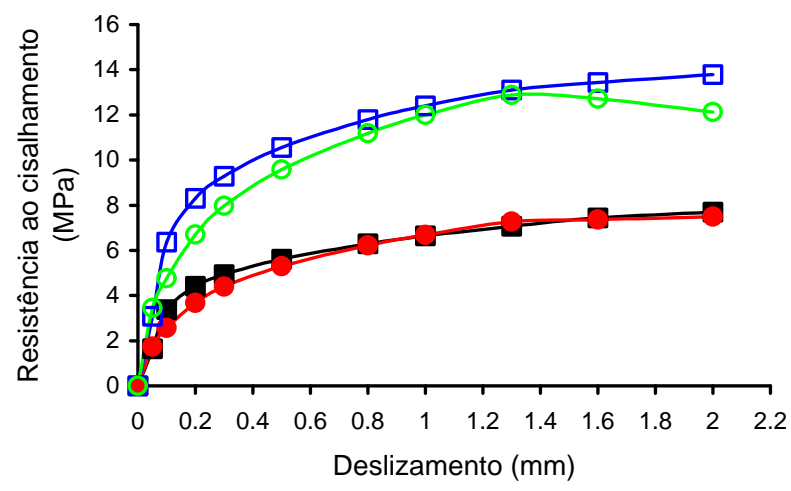

$\begin{array}{ll}\rightarrow \text {-TSOUKANTAS;TASSIOS (fck=16 MPa) } & - \text {-TASSIOS;VINTZELEOU (fck=16 MPa } \\ \rightarrow \text { —TSOUKANTAS;TASSIOS (fck=40 MPa) } & - \text {-TASSIOS;VINTZELEOU (fck=40 MPa }\end{array}$

Figura 2.15 - Resistência ao cisalhamento da ligação entre duas colunas prémoldadas 
Por outro lado, a ruptura por cisalhamento em um plano não fissurado ocorre pela formação de inúmeras fissuras inclinadas em relação ao plano de cisalhamento (figura 2.16). Neste caso, a ruptura ocorre pelo esmagamento das bielas comprimidas de concreto formadas, aproximadamente, paralelas às fissuras. A compressão nas bielas e a tração nas armaduras paralelas e normais ao plano de cisalhamento formam uma treliça que resiste às forças aplicadas no plano de cisalhamento.

A transferência de esforços de cisalhamento através de um plano não fissurado foi estudado por Hsu, et al. (HSU, et al. (1987)) que sugeriram um procedimento para o traçado da curva tensão-deformação do plano de cisalhamento. Eles sugeriram um modelo baseado na teoria de biela e tirante para representar as fissuras e também adotaram uma curva tensão-deformação para o concreto das bielas comprimidas que apresentava um ramo descendente após atingido a resistência máxima do concreto. Foi definida uma região crítica, ao longo do plano de cisalhamento, onde a distribuição de tensões foi considerada aproximadamente uniforme após a formação das fissuras, e foram deduzidas equações para representar a relação tensão-deformação dessa região.

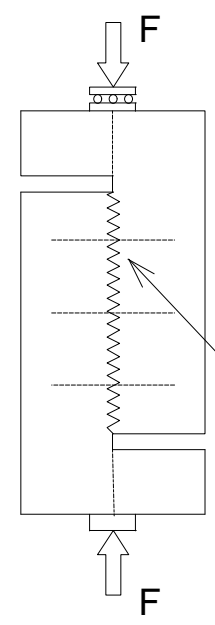

(a) modelo pré-fissurado

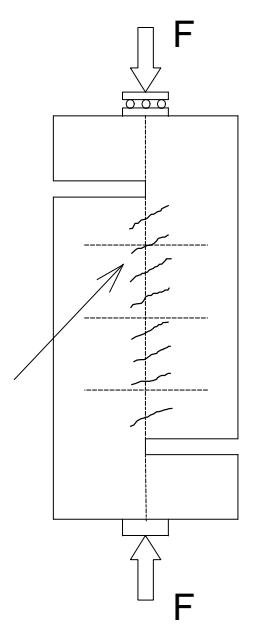

(b) modelo não pré-fissurado

Figura 2.16 - Modelos para ensaio de cisalhamento direto 


\subsubsection{Equações básicas}

- Equação de equilíbrio

Seja um elemento de concreto com armadura nas duas direções ortogonais $x$ e y (figura 2.17). Ele está submetido às tensões normais $\left(\sigma_{x}\right.$ e $\left.\sigma_{y}\right)$ e tensões de cisalhamento $\left(\tau_{x y}\right)$ constantes ao longo de cada plano. Após a fissuração, surgem várias bielas comprimidas e inclinadas de um ângulo $\alpha$ que, junto com a armadura, formam uma treliça resistente aos esforços de cisalhamento. Esta direção é assumida como a direção da tensão principal de compressão no concreto $\left(\sigma_{c}\right)$, sendo a direção da tensão principal de tração $\left(\sigma_{t}\right)$ ortogonal a ela. As tensões $\sigma_{x}$, $\sigma_{y}$ e $\tau_{x y}$, atuantes no elemento de concreto armado, são resistidas pelo concreto e pela armadura, sendo que as tensões resistidas apenas pelo concreto são designadas por $\sigma_{\mathrm{x}, \mathrm{c}}, \sigma_{\mathrm{y}, \mathrm{c}}$ e $\tau_{\mathrm{xy}, \mathrm{c}}$. Elas podem ser escritas em função das tensões principais através de uma transformação de coordenadas, ou seja:

$$
\begin{aligned}
& \sigma_{x, c}=\sigma_{c} \cdot \cos ^{2} \alpha+\sigma_{t} \cdot \operatorname{sen}^{2} \alpha \\
& \sigma_{y, c}=\sigma_{c} \cdot \operatorname{sen}^{2} \alpha+\sigma_{t} \cdot \cos ^{2} \alpha \\
& \tau_{x y, c}=\left(\sigma_{c}-\sigma_{t}\right) \cdot \operatorname{sen} \alpha \cdot \cos \alpha
\end{aligned}
$$

A armadura resiste apenas às tensões normais e sua contribuição pode ser avaliada como:

$$
\begin{aligned}
& \sigma_{x, s}=\rho_{x} \cdot f_{s, x} \\
& \sigma_{y, s}=\rho_{y} \cdot f_{s, y}
\end{aligned}
$$

$f_{s, x}$ e $f_{s, y}$ : resistência da armadura nas direções $x$ e y respectivamente.

A tensão total no elemento de concreto armado é obtida pela soma da parcela resistida pelo concreto com a parcela resistida pela armadura.

$$
\sigma_{\mathrm{x}}=\sigma_{\mathrm{c}} \cdot \cos ^{2} \alpha+\sigma_{\mathrm{t}} \cdot \operatorname{sen}^{2} \alpha+\rho_{\mathrm{x}} \cdot \mathrm{f}_{\mathrm{s}, \mathrm{x}}
$$




$$
\begin{aligned}
& \sigma_{y}=\sigma_{c} \cdot \operatorname{sen}^{2} \alpha+\sigma_{t} \cdot \cos ^{2} \alpha+\rho_{y} \cdot f_{s, y} \\
& \tau_{x y}=\left(\sigma_{c}-\sigma_{t}\right) \cdot \operatorname{sen} \alpha \cdot \cos \alpha
\end{aligned}
$$

- Equação de compatibilidade

Assumindo que as deformações são uniformemente distribuídas no elemento de concreto, elas podem ser avaliadas pelas seguintes equações:

$$
\begin{aligned}
& \varepsilon_{x}=\varepsilon_{c} \cdot \cos ^{2} \alpha+\varepsilon_{t} \cdot \operatorname{sen}^{2} \alpha \\
& \varepsilon_{y}=\varepsilon_{c} \cdot \operatorname{sen}^{2} \alpha+\varepsilon_{t} \cdot \cos ^{2} \alpha \\
& \gamma_{x y}=2\left(\varepsilon_{c}-\varepsilon_{t}\right) \cdot \operatorname{sen} \alpha \cdot \cos \alpha
\end{aligned}
$$

$\varepsilon_{\mathrm{x}}, \varepsilon_{\mathrm{y}}$ : deformações normais nas direções $\mathrm{x}$ e y respectivamente;

$\gamma_{x y}:$ deformação angular;

$\varepsilon_{\mathrm{c}}, \varepsilon_{\mathrm{t}}$ : deformações principais de compressão e tração respectivamente.

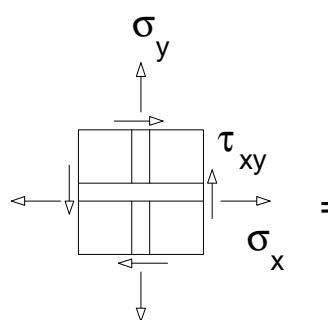

concreto armado

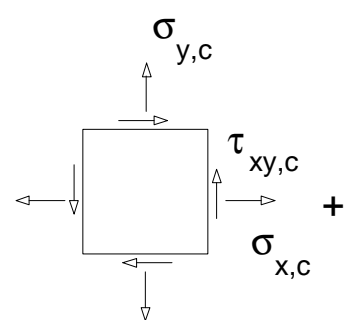

concreto

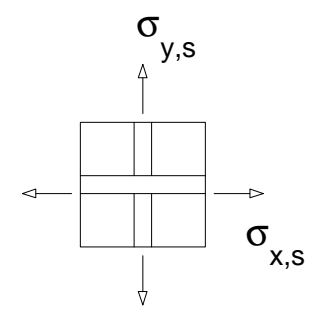

armadura
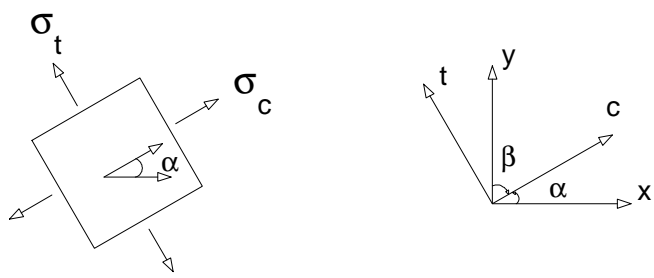

concreto

Figura 2.17 - Tensões em um elemento de concreto armado 
- Equação constitutiva

A relação tensão-deformação nas bielas comprimidas de concreto é representada pelas seguintes equações (figura 2.18(a)):

ramo ascendente

$$
\sigma_{\mathrm{c}}=-\mathrm{f}_{\mathrm{c}} \cdot\left[2 \frac{\varepsilon_{\mathrm{c}}}{\varepsilon_{0}}-\lambda \cdot\left(\frac{\varepsilon_{\mathrm{c}}}{\varepsilon_{0}}\right)^{2}\right] \quad \text { se }\left|\varepsilon_{\mathrm{c}}\right| \leq\left|\frac{\varepsilon_{0}}{\lambda}\right|
$$

ramo descendente

$$
\sigma_{\mathrm{c}}=-\frac{\mathrm{f}_{\mathrm{c}}}{\lambda} \cdot\left[1-\left(\frac{\frac{\varepsilon_{\mathrm{c}}}{\varepsilon_{0}}-\frac{1}{\lambda}}{2-\frac{1}{\lambda}}\right)^{2}\right] \text { se }\left|\varepsilon_{\mathrm{c}}\right|>\left|\frac{\varepsilon_{0}}{\lambda}\right|
$$

sendo $\frac{\varepsilon_{0}}{\lambda}$ a deformação correspondente à máxima tensão de compressão na biela de concreto e $\varepsilon_{0}=-0,002$ a deformação correspondente à resistência do concreto $\left(f_{c}\right)$ medida em corpos-de-prova cilíndricos. O coeficiente $\lambda$ é definido para avaliar o fenômeno de encruamento negativo ("softening") do concreto, sendo expresso por:

$$
\lambda=\sqrt{0,7-\frac{\varepsilon_{\mathrm{t}}}{\varepsilon_{\mathrm{c}}}}
$$

A relação tensão-deformação do concreto submetido à tração é mostrado na figura 2.18(b) sendo representada pelas seguintes equações:

$$
\begin{gathered}
\sigma_{\mathrm{t}}=\mathrm{E}_{\mathrm{c}} \cdot \varepsilon_{\mathrm{t}} \quad \text { se } \varepsilon_{\mathrm{t}} \leq \varepsilon_{\mathrm{cr}} \\
\sigma_{\mathrm{t}}=\frac{\mathrm{f}_{\mathrm{t}}}{1+\sqrt{\frac{\varepsilon_{\mathrm{t}}-\varepsilon_{\mathrm{cr}}}{0,005}}} \text { se } \varepsilon_{\mathrm{t}}>\varepsilon_{\mathrm{cr}} \\
\mathrm{E}_{\mathrm{c}}=-\frac{2 \cdot \mathrm{f}_{\mathrm{c}}}{\varepsilon_{0}}: \text { módulo de elasticidade do concreto }
\end{gathered}
$$


$\mathrm{f}_{\mathrm{t}}=0,331 \cdot \sqrt{\mathrm{f}_{\mathrm{c}}}$ : tensão de tração do concreto $(\mathrm{MPa})$

$\varepsilon_{c r}=\frac{f_{t}}{E_{c}}:$ deformação correspondente à tensão que inicia a fissuração do concreto

Nas expressões anteriores a tensão e a deformação de tração são tomadas com sinal positivo enquanto a tensão e a deformação de compressão são tomadas com sinal negativo. Vale ressaltar que estas relações representam 0 comportamento das bielas de concreto num estado plano de tensões, nada tendo haver com a relação tensão - deformação do concreto obtida através corpos-deprova.

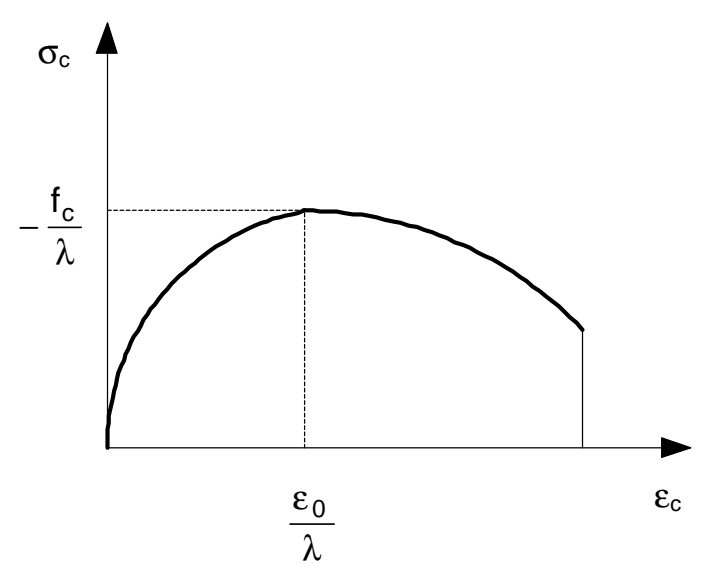

(a) curva tensão de compressão-deformação

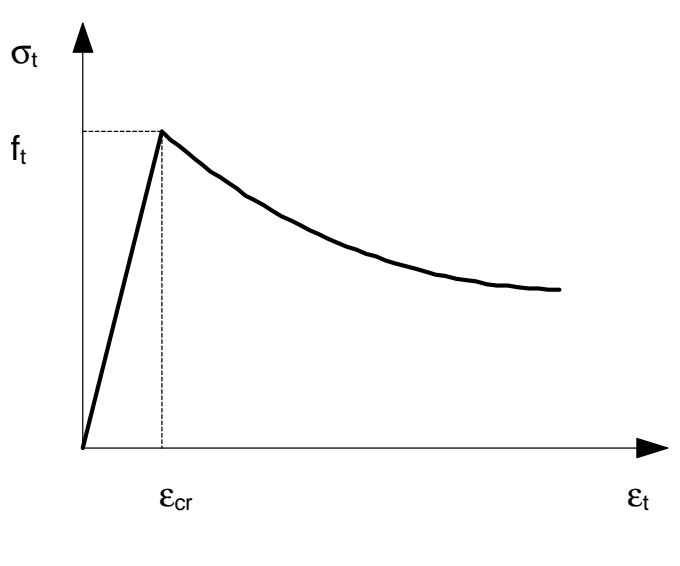

(b) curva tensão de tração-deformação

Figura 2.18 - Relações tensão - deformação do concreto

\subsubsection{Procedimento de resolução}

Seja o modelo para ensaio de cisalhamento direto com plano de cisalhamento não pré-fissurado mostrado na figura 2.19. Assumindo que as tensões normais ao plano de cisalhamento devido às ações externas sejam conhecidas, as outras tensões podem ser obtidas em função da força $F$ por: 


$$
\begin{aligned}
\sigma_{y} & =K_{\sigma} \frac{F}{b \cdot h} \\
\tau_{x y} & =K_{\tau} \frac{F}{b \cdot \ell}
\end{aligned}
$$

$\mathrm{K}_{\sigma}$ : coeficiente para avaliação da distribuição não uniforme de $\sigma_{\mathrm{y}}$

$\mathrm{K}_{\tau}$ : coeficiente para avaliação da distribuição não uniforme de $\tau_{x y}$;

Se as tensões forem uniformemente distribuídas ao longo da peça, os coeficientes $\mathrm{K}_{\sigma}$ e $\mathrm{K}_{\tau}$ são iguais à unidade. Combinando a eq.(2.27.a) e eq.(2.27.b), obtêm-se uma relação entre $\sigma_{y}$ e $\tau_{x y}$ :

$$
\sigma_{y}=K \cdot \tau_{x y} \quad, \quad K=\frac{\ell}{h}
$$

Segundo a teoria da elasticidade, as tensões não são uniformes na região crítica do modelo da figura 2.19. Antes da fissuração do concreto a tensão $\tau_{x y}$ é maior próxima às extremidades onde há uma concentração de tensões devido à aplicação da força concentrada. De igual forma a tensão $\sigma_{y}$ também é maior nas extremidades enquanto a tensão normal ao plano de cisalhamento $\sigma_{\mathrm{x}}$ é muito pequena, podendo ser desconsiderada. Com o aumento do carregamento ocorre a formação de fissuras inclinadas na região próxima ao plano de cisalhamento. Essa região é chamada de região crítica e está hachurada na figura 2.19. Em ensaios realizados em modelos com largura (h) de $254 \mathrm{~mm}$, observou-se que a região crítica possuía largura $\left(h_{c r}\right)$ de 50,8 mm a 76,2 mm. Nessa região, a intensa fissuração do concreto possibilita a redistribuição das tensões $\sigma_{x}, \sigma_{y}$ e $\tau_{x y}$ ao longo do plano de cisalhamento, diminuindo a rigidez dessa região em comparação com outras partes da peça. Dessa forma, as tensões podem ser consideradas uniformes na região crítica e a teoria exposta pode ser aplicada. No modelo apresentado na figura $2.19, \tau_{x y}$ foi tomado como a tensão média no plano de cisalhamento, $\sigma_{y}$ como a tensão média paralela ao plano de cisalhamento e $\sigma_{x}$ igual a zero, uma vez que não há tensões externas na direção $x$. 
A taxa de armadura $\rho_{x}$ foi obtida dividindo a área total de armadura na direção x pela área do plano de cisalhamento e $\rho_{\mathrm{y}}$ foi obtida dividindo a área total de armadura na direção y pela seção transversal do modelo. A avaliação de $\rho_{y}$ desta forma é válida para o modelo da figura, uma vez que a armadura está distribuída de forma simétrica na seção transversal. No caso de vigas submetidas à flexão, onde a maior parte da armadura está concentrada distante da interface, $\rho_{y}$ deve ser calculada dividindo a área de armadura próxima à interface pela área da região crítica.

Vale lembrar que este modelo é válido para regiões fissuradas, não representando bem o comportamento da região antes de ocorrer a fissuração do concreto. Logo, apresenta boa aproximação para avaliação da tensão última resistente em planos de cisalhamento após ocorrido a fissuração do concreto.

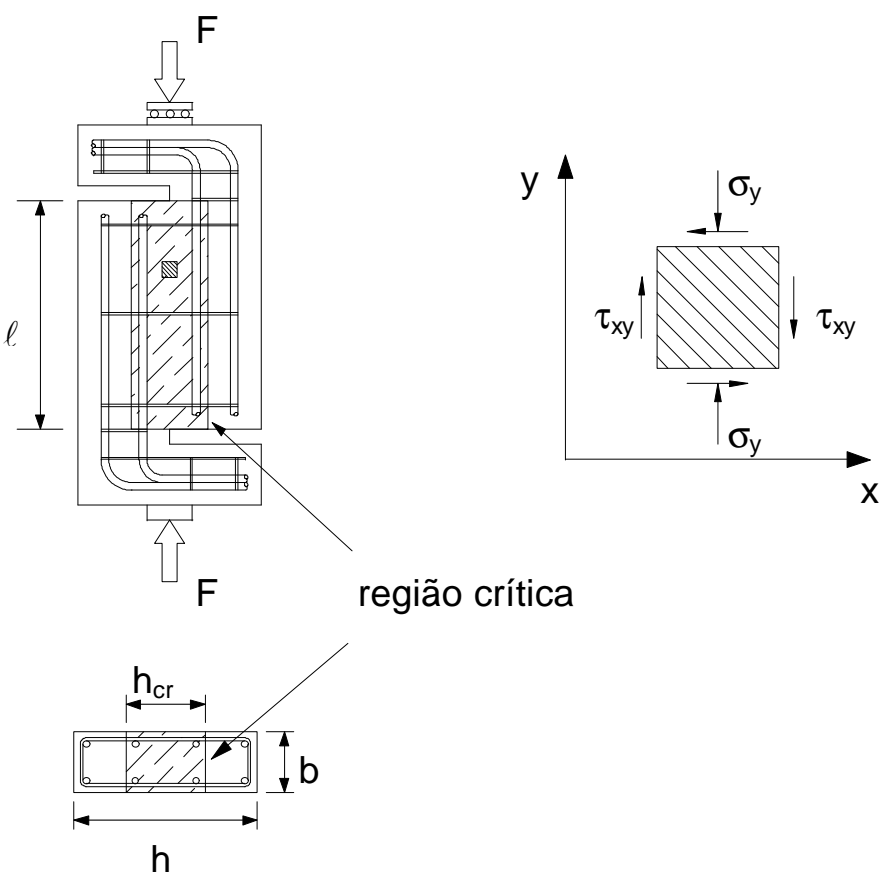

Figura 2.19 - Modelo para ensaio de cisalhamento direto

Combinando as equações já definidas e lembrando que $f_{s, x}$ e $f_{s, y}$ são iguais à $\mathrm{f}_{\mathrm{y}}$ quando a armadura atinge a deformação de escoamento $\left(\varepsilon_{\mathrm{y}, \mathrm{s}}\right)$, obtém-se das eq.(2.22) e eq.(2.23) : 


$$
\begin{gathered}
\varepsilon_{x} \geq \varepsilon_{y, s} \quad \sigma_{x}=\sigma_{c} \cdot \cos ^{2} \alpha+\sigma_{t} \cdot \operatorname{sen}^{2} \alpha+\rho_{x} \cdot f_{y} \\
\varepsilon_{x}<\varepsilon_{y, s} \quad \sigma_{x}=\sigma_{c} \cdot \cos ^{2} \alpha+\sigma_{t} \cdot \operatorname{sen}^{2} \alpha+ \\
\\
\quad \rho_{x} \cdot E_{s} \cdot\left(\varepsilon_{c} \cdot \cos ^{2} \alpha+\varepsilon_{t} \cdot \operatorname{sen}^{2} \alpha\right)
\end{gathered}
$$

Combinando a eq.(2.22.b) e eq.(2.22.c) com a eq.(2.28), obtém-se:

$$
\mathrm{K} \cdot\left(\sigma_{\mathrm{c}}-\sigma_{\mathrm{t}}\right) \cdot \operatorname{sen} \alpha \cdot \cos \alpha=\sigma_{\mathrm{c}} \cdot \operatorname{sen}^{2} \alpha+\sigma_{\mathrm{t}} \cdot \cos ^{2} \alpha+\rho_{\mathrm{y}} \cdot \mathrm{f}_{\mathrm{s}, \mathrm{y}}
$$

Substituindo o valor de $f_{s, y}$ e utilizando a eq.(2.23.b), tem-se:

$$
\begin{aligned}
& \begin{array}{l}
\varepsilon_{y} \geq \varepsilon_{y, s} \quad K \cdot\left(\sigma_{c}-\sigma_{t}\right) \cdot \operatorname{sen} \alpha \cdot \cos \alpha= \\
\quad=\sigma_{c} \cdot \operatorname{sen}^{2} \alpha+\sigma_{t} \cdot \cos ^{2} \alpha+\rho_{y} \cdot f_{y}
\end{array} \\
& \begin{aligned}
\varepsilon_{y}< & \varepsilon_{y, s} \quad K \cdot\left(\sigma_{c}-\sigma_{t}\right) \cdot \operatorname{sen} \alpha \cdot \cos \alpha= \\
= & \sigma_{c} \cdot \operatorname{sen}^{2} \alpha+\sigma_{t} \cdot \cos ^{2} \alpha+\rho_{y} \cdot E_{s} \cdot\left(\varepsilon_{c} \cdot \operatorname{sen}^{2} \alpha+\varepsilon_{t} \cdot \cos ^{2} \alpha\right)
\end{aligned}
\end{aligned}
$$

A eq.(2.29.a), eq.(2.29.b), eq.(2.31.a) e eq.(2.31.b) são escritas em função de 6 variáveis. Adotando um valor para $\varepsilon_{\mathrm{c}}$, as outras variáveis $\sigma_{\mathrm{c}}, \sigma_{\mathrm{t}}, \varepsilon_{\mathrm{t}}, \alpha$ e $\lambda$ podem ser obtidas da eq.(2.24), eq.(2.25), eq.(2.26), eq.(2.29) e eq.(2.31). A variável $\varepsilon_{\mathrm{c}}$ foi escolhida porque espera-se que a deformação das bielas aumente com o acréscimo do carregamento.

Um procedimento iterativo para resolução simultânea das cinco equações não lineares é o seguinte:

1. Adotar um valor (negativo) para $\varepsilon_{\mathrm{c}}$

1. Adotar um valor (positivo) para $\sigma_{t}$

1. Calcular $\varepsilon_{\mathrm{t}}$ pela curva tensão-deformação do concreto

$$
\varepsilon_{\mathrm{t}} \geq \varepsilon_{\mathrm{cr}} \quad \varepsilon_{\mathrm{t}}=\left[0,005 \cdot\left(\frac{\mathrm{f}_{\mathrm{t}}}{\sigma_{\mathrm{t}}}-1\right)^{2}+\varepsilon_{\mathrm{cri}}\right]
$$




$$
\varepsilon_{\mathrm{t}}<\varepsilon_{\mathrm{cr}} \quad \varepsilon_{\mathrm{t}}=\frac{\sigma_{\mathrm{t}}}{\mathrm{E}_{\mathrm{c}}}
$$

4. Calcular $\lambda$

$$
\lambda=\sqrt{0,7-\frac{\varepsilon_{\mathrm{t}}}{\varepsilon_{\mathrm{c}}}}
$$

5. Calcular $\sigma_{c}$

$$
\begin{aligned}
& \left|\varepsilon_{\mathrm{c}}\right| \leq\left|\frac{\varepsilon_{0}}{\lambda}\right| \quad \sigma_{\mathrm{c}}=-\mathrm{f}_{\mathrm{c} \cdot} \cdot\left[2 \cdot \frac{\varepsilon_{\mathrm{c}}}{\varepsilon_{0}}-\lambda \cdot\left(\frac{\varepsilon_{\mathrm{c}}}{\varepsilon_{0}}\right)^{2}\right] \\
& \left|\varepsilon_{\mathrm{c}}\right|>\left|\frac{\varepsilon_{0}}{\lambda}\right| \quad \sigma_{\mathrm{c}}=-\frac{\mathrm{f}_{\mathrm{c}}}{\lambda} \cdot\left[1-\left(\frac{\frac{\varepsilon_{\mathrm{c}}}{\varepsilon_{0}}-\frac{1}{\lambda}}{2-\frac{1}{\lambda}}\right)^{2}\right]
\end{aligned}
$$

6. Calcular $\alpha$

$$
\begin{aligned}
& \varepsilon_{x} \geq \varepsilon_{y, s} \quad \cos ^{2} \alpha=\frac{\sigma_{x}-\sigma_{t}-\rho_{x} \cdot f_{y}}{\sigma_{c}-\sigma_{t}} \\
& \varepsilon_{x}<\varepsilon_{y, s} \quad \cos ^{2} \alpha=\frac{\sigma_{x}-\sigma_{t}-\rho_{x} \cdot E_{s} \cdot \varepsilon_{t}}{\sigma_{c}-\sigma_{t}+\rho_{x} \cdot E_{s} \cdot\left(\varepsilon_{c}-\varepsilon_{t}\right)}
\end{aligned}
$$

7. Calcular $\sigma_{t}$

$$
\begin{aligned}
& \varepsilon_{y} \geq \varepsilon_{y, s} \quad \sigma_{t}=\frac{\sigma_{c} \cdot\left(K \cdot \operatorname{sen} \alpha \cdot \cos \alpha-\operatorname{sen}^{2} \alpha\right)-\rho_{y} \cdot f_{y}}{K \cdot \operatorname{sen} \alpha \cdot \cos \alpha+\cos ^{2} \alpha} \\
& \varepsilon_{y}<\varepsilon_{y, s} \quad \sigma_{t}=\frac{\sigma_{c} \cdot\left(K \cdot \operatorname{sen} \alpha \cdot \cos \alpha-\operatorname{sen}^{2} \alpha\right)-\rho_{y} \cdot E_{s} \cdot\left(\varepsilon_{c} \cdot \operatorname{sen}^{2} \alpha+\varepsilon_{t} \cdot \cos ^{2} \alpha\right)}{K \cdot \operatorname{sen} \alpha \cdot \cos \alpha+\cos ^{2} \alpha}
\end{aligned}
$$


8. Se o valor calculado para $\sigma_{\mathrm{t}}$ estiver próximo do valor inicialmente adotado, $\sigma_{\mathrm{c}}, \sigma_{\mathrm{t}}, \varepsilon_{\mathrm{t}}, \alpha$ e $\lambda$ são a solução para o valor de $\varepsilon_{\mathrm{c}}$ adotado. Caso contrário, deve-se adotar outro valor para $\sigma_{\mathrm{t}}$ e repetir os passos de 2 a 7 .

4. Adotar um novo valor para $\varepsilon_{\mathrm{c}}$ e repetir os passos de 1 a 8 .

4. Os valores de $\sigma_{x}$, $\tau_{x y}$ e $\gamma_{x y}$ podem ser calculados pela eq.(2.22.b), eq.(2.22.c) e eq.(2.23.c), respectivamente, para cada valor de $\varepsilon_{\mathrm{c}}$ adotado.

A tensão de cisalhamento última resistente $\left(\tau_{u}\right)$ pode ser obtida do ponto de máximo absoluto da curva que relaciona $\tau_{x y} \operatorname{com} \gamma_{x y}($ figura 2.20).

O modelo proposto por Hsu, et al. foi comparado com resultados de ensaios de cisalhamento direto em planos não pré-fissurados realizados por Hofbeck, et al. fornecendo bons resultados. Os autores concluíram que a redução da resistência do concreto das bielas após a fissuração é um importante fator que influencia a resistência final da interface aos esforços de cisalhamento. Tanto a quantidade da armadura normal ao plano de cisalhamento quanto da armadura paralela a ele são importantes fatores que também influenciam na resistência final da interface. A armadura normal ao plano de cisalhamento influencia mais na resistência do que a armadura paralela ao mesmo. Entretanto, utilizando baixas porcentagens de armadura paralela ao plano de cisalhamento ocorre uma redução significativa na resistência final. Os modelos baseados na teoria atrito-cisalhamento não levam em consideração esta armadura, sendo função apenas da armadura normal à interface e da resistência à compressão do concreto. Eles foram obtidos, em geral, de ensaios de cisalhamento direto com alta porcentagem de armadura paralela à interface sendo, portanto, contrários à segurança nos casos em que existem baixa porcentagem de armadura. 

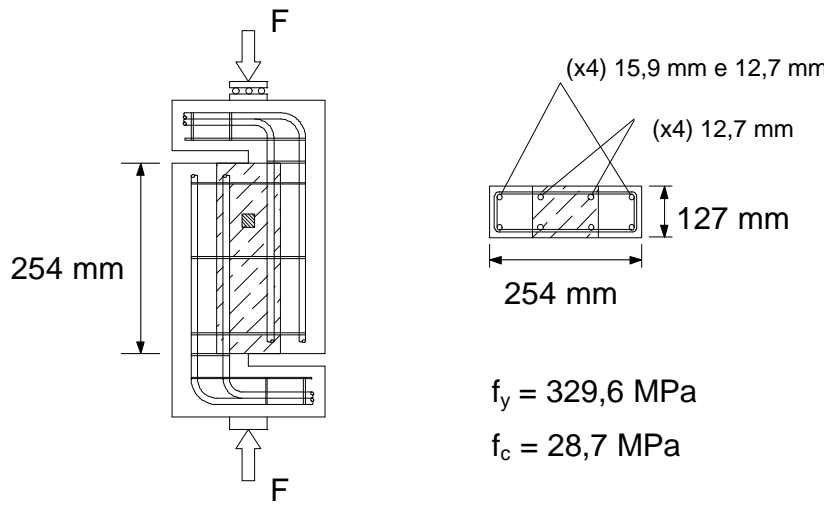

$\mathrm{f}_{\mathrm{y}}=329,6 \mathrm{MPa}$

$\mathrm{f}_{\mathrm{c}}=28,7 \mathrm{MPa}$

(a) modelo ensaiado por HOFBECK (1969)

Resistência ao cisalhamento de um modelo não pré-fissurado

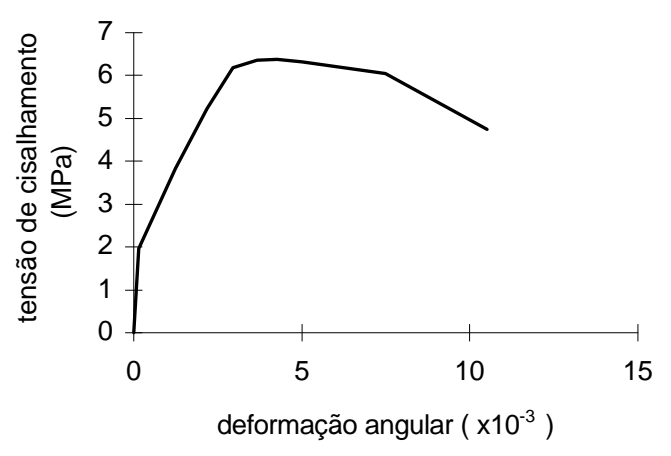

$\tau_{\mathrm{u}, \text { calculado }}=6,385 \mathrm{MPa}$

$\tau_{\mathrm{u}, \text { experimental }}=6,730 \mathrm{MPa}$

(b) curva tensão de cisalhamento - deformação angular

Figura 2.20 - Cálculo da tensão de cisalhamento resistente pelo modelo de Hsu, et al. numa peça utilizada em ensaios de cisalhamento direto com interface não préfissurada.

\subsection{Modelos empíricos de transferência de esforços de cisalhamento}

À seguir são apresentadas algumas equações empíricas para a avaliação da resistência última ao cisalhamento em interfaces de concreto obtidas de ensaios de cisalhamento direto e de ensaios em vigas (PATNAIK (1992)). 
- A.R. Anderson, 1960

A relação entre a resistência última ao cisalhamento e a taxa de armadura transversal à interface proposta por Anderson é:

$$
\tau_{\mathrm{u}}=\tau_{0}+\mathrm{K} . \rho
$$

sendo

$$
\begin{aligned}
\tau_{0} & =4,41 \mathrm{MPa} \text { e } \mathrm{K}=229 \mathrm{MPa} \text { para } \mathrm{f}_{\mathrm{c}}=20,7 \mathrm{MPa} \\
\tau_{0} & =5,52 \mathrm{MPa} \text { e } \mathrm{K}=276 \mathrm{MPa} \text { para } \mathrm{f}_{\mathrm{c}}=51,7 \mathrm{MPa}
\end{aligned}
$$

Os valores de $\tau_{0}$ e $\mathrm{K}$ foram obtidos de ensaios de cisalhamento direto realizados por Anderson. As duas partes dos modelos eram moldados em idades diferentes de modo a formar uma junta de concretagem.

- N.W. Hanson, 1960

Baseado em ensaios de cisalhamento direto e ensaios em vigas, Hanson sugeriu a seguinte equação para interfaces rugosas:

$$
\tau_{\mathrm{u}}=3,45+121 . \rho \quad(\mathrm{MPa})
$$

- J.C. Saemann e G.W. Washa, 1964

Baseado em ensaios realizados em vigas compostas biapoiadas os autores sugeriram a seguinte equação para avaliação da resistência (SAEMANN; WASHA (1964)):

$$
\tau_{u}=\frac{18,6}{x+5}+207 \cdot \rho \cdot \frac{33-x}{x^{2}+6 x+5} \quad(\mathrm{MPa})
$$

sendo $x$ a relação entre o vão de cisalhamento (comprimento com esforço cortante constante) e a altura útil da viga (M/V.d).

Na formulação desta equação não foi feita distinção entre resistência última ao cisalhamento horizontal e tensão de cisalhamento para força de ruptura, ou seja, nos ensaios mediu-se a força concentrada que provocava a ruptura da viga, sendo posteriormente calculada a tensão de cisalhamento horizontal pela equação 
fornecida pela resistência dos materiais. A influência da armadura transversal não foi considerada na formulação da equação.

- J.R. Gaston e L.B. Kriz, 1964

Baseado em resultados experimentais, o coeficiente de atrito para 0 concreto pré-moldado foi estimado e a seguinte equação sugerida para avaliar a resistência última ao cisalhamento:

superfícies lisas com as partes apenas apoiadas

$$
\tau_{\mathrm{u}}=0,30+0,78 \sigma_{\mathrm{n}} \quad(\mathrm{MPa})
$$

superfícies lisas com as partes ligadas

$$
\tau_{\mathrm{u}}=0,76+0,70 \sigma_{\mathrm{n}} \quad(\mathrm{MPa})
$$

sendo $\sigma_{\mathrm{n}}$ a tensão normal à interface devido às forças externas.

- P.W. Birkeland e H.W. Birkeland, 1966

Nesse artigo o coeficiente de atrito $\mu(=\operatorname{tg} \phi)$ para a equação da teoria atrito-cisalhamento foi pela primeira vez apresentado, ou seja (BIRKELAND; BIRKELAND (1966)):

$$
\tau_{\mathrm{u}}=\rho \cdot \mathrm{f}_{\mathrm{y}} \cdot \operatorname{tg} \phi \leq 5,52(\mathrm{MPa})
$$

$\operatorname{tg} \phi=1,7$ para peças de concreto monolítica;

$\operatorname{tg} \phi=1,4$ para interface com superfície intencionalmente rugosa;

$\operatorname{tg} \phi=0,8$ a 1,0 para interface não rugosa e interface entre concreto e aço.

Foram feitas as seguintes limitações:

$\rho \geq 0,015$ e $_{\mathrm{c}} \geq 27,6 \mathrm{MPa}$

- H.W. Birkeland, 1968

Birkeland foi o primeiro autor a introduzir uma função parabólica entre a taxa de armadura transversal à interface e a resistência última ao cisalhamento. $A$ 
equação é válida para peças compostas onde as partes tenham sido moldadas em datas diferentes:

$$
\tau_{\mathrm{u}}=2,78 \sqrt{\rho . \mathrm{f}_{\mathrm{y}}} \quad(\mathrm{MPa})
$$

- R.F.Mast, 1968

A equação proposta por Mast (MAST (1968)) é semelhante à proposta por Birkeland em 1966, sendo, entretanto, recomendado um valor diferente para o limite da resistência da interface bem como valores ligeiramente diferentes para o coeficiente de atrito.

$$
\tau_{\mathrm{u}}=\rho \cdot \mathrm{f}_{\mathrm{y}} \cdot \operatorname{tg} \phi \leq 0,15 \mathrm{f}_{\mathrm{c}} \cdot \operatorname{tg} \phi
$$

$\operatorname{tg} \phi=1,4$ para ligação de concreto com concreto e interface rugosa;

$\operatorname{tg} \phi=1,0$ para ligação de concreto com aço em vigas compostas;

$\operatorname{tg} \phi=0,7$ para ligação de concreto com aço e conectores metálicos soldados;

$\operatorname{tg} \phi=0,7$ para ligação de concreto com concreto e interface lisa.

HOFBECK; et al.(1969) sugeriram um limite absoluto de 4,14 MPa para a tensão normal de compressão $\left(\rho \cdot f_{y} \cdot \operatorname{tg} \phi \leq 4,14 \cdot \operatorname{tg} \phi \mathrm{MPa}\right)$.

- A.H. Mattock e N.M. Hawkins, 1972

Baseado em vários ensaios de cisalhamento direto em modelos préfissurados, os autores sugeriram uma equação similar à de Anderson.

$$
\tau_{\mathrm{u}}=1,38+0,8\left(\rho . \mathrm{f}_{\mathrm{y}}+\sigma_{\mathrm{n}}\right) \quad(\mathrm{MPa})
$$

sendo $\tau_{u} \leq 0,3 \mathrm{f}_{\mathrm{c}}$ ou 10,34 MPa, adotando-se o menor valor, $\mathrm{e}$ $\rho . f_{y}+\sigma_{n} \geq 1,38 \mathrm{MPa}$.

Esta equação foi formulada assumindo que a resistência ao cisalhamento é composta por uma parcela devido à aderência e outra devido ao atrito, quando a 
tensão normal está compreendida entre $1,38 \mathrm{MPa}$ e $0,3 \mathrm{f}_{\mathrm{c}}$.O primeiro termo representa a resistência ao corte dos agregados localizados no plano de cisalhamento e a resistência devido à ação de pino da armadura. O segundo termo a resistência por atrito para um coeficiente de atrito da superfície igual a 0,8 multiplicado por forças normais de compressão resultantes do escoamento da armadura transversal à interface e de forças externas.

- A.H. Mattock, 1974

A eq.(2.41) foi formulada com poucos resultados experimentais. Mais tarde ela foi modificada de forma a representar os resultados dos ensaios.

$$
\tau_{u}=2,76+0,8 \cdot \rho \cdot f_{y} \leq 0,3 \cdot f_{c} \quad(M P a)
$$

sendo $\rho . f_{y} \geq 1,38 \mathrm{MPa}$.

Quando a armadura atravessa a interface segundo um ângulo $\theta$ (figura 2.21), a equação anterior modifica-se para:

$$
\begin{gathered}
\tau_{u}=2,76 \cdot \operatorname{sen}^{2} \theta+\rho \cdot \sigma_{s}\left(0,8 \cdot \operatorname{sen}^{2} \theta-0,5 \cdot \operatorname{sen} 2 \theta\right) \leq 0,3 f_{c}(M P a) \\
\text { sendo } \sigma_{s}=0 \text { para } 0 \leq \theta \leq 51,3^{0} \\
\sigma_{s}=-1,6 \cdot f_{y} \cdot \cos (\theta+38,7) \text { para } 51,3^{\circ} \leq \theta \leq 90^{\circ} \\
\sigma_{s}=f_{y} \text { para } 90^{\circ} \leq \theta \leq 180^{\circ}
\end{gathered}
$$

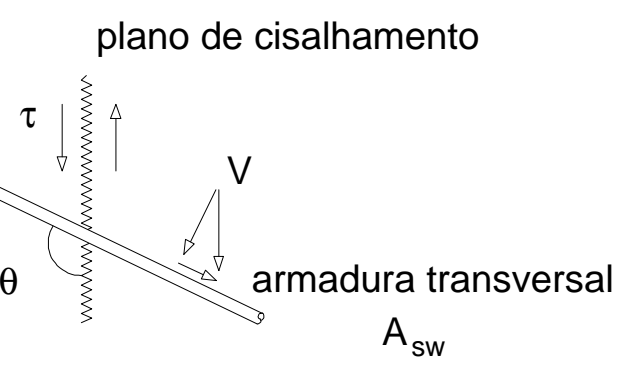

Figura 2.21 - Armadura inclinada com relação à interface 
- B.R. Hermansen e J. Cowan, 1974 e J. Cowan e A.F. Cruden, 1975

Baseado em resultados de ensaios em consolos curtos (HERMANSEN; COWAN (1974)), os autores sugeriram uma equação semelhante à equação proposta por Mattock (eq.(2.42)). Ela representa o comportamento dos consolos quando a ruptura se dá por cisalhamento na interface entre o pilar e o consolo, sendo, portanto, válida para analisar o comportamento de peças monolíticas.

$$
\tau_{\mathrm{u}}=4,0+0,8 \cdot \rho \cdot \mathrm{f}_{\mathrm{y}} \quad(\mathrm{MPa})
$$

Os autores sugeriram que o valor da coesão do concreto e do ângulo de atrito interno fossem dependentes da resistência do concreto, entretanto não sugeriram nenhuma relação.

- C.H. Raths, 1977

A equação sugerida pelo autor é válida para interfaces de peças monolíticas.

$$
\tau_{\mathrm{u}}=\mathrm{C}_{\mathrm{s}} \cdot 3,11 \cdot \sqrt{\rho \cdot \mathrm{f}_{\mathrm{y}}} \quad(\mathrm{MPa})
$$

sendo $\mathrm{C}_{\mathrm{s}}$ uma constante definida em função da densidade do concreto. Para concretos com densidade normal $\mathrm{C}_{\mathrm{s}}=1,0$.

- R.E. Loov, 1978

Loov foi o primeiro autor a incorporar a influência da resistência do concreto na expressão da resistência ao cisalhamento horizontal. A resistência última ao cisalhamento é dada por:

$$
\frac{\tau_{u}}{f_{c}}=K \cdot \sqrt{\frac{\rho \cdot f_{y}+\sigma_{n}}{f_{c}}}
$$

A resistência do concreto para a maior parte dos ensaios realizados até 1978 era de $27,6 \mathrm{MPa}$. Loov sugeriu, então, $\mathrm{K}=0,5$ para interfaces não pré- 
fissuradas. Se substituirmos estes valores de $K$ e $f_{c}$ na eq.(2.46) e considerarmos que não existam tensões externas atuando na interface $\left(\sigma_{n}=0\right)$, esta equação torna-se semelhante à equação proposta por Birkeland (eq.(2.39)).

- A.F. Shaikh, 1978

Baseado na equação de Raths (eq.(2.45)), o autor sugeriu a seguinte expressão para avaliação da resistência:

$$
\begin{aligned}
& \rho=\frac{\tau_{u}}{\phi \cdot f_{y} \cdot \mu_{e}} \\
& \phi=0,85 \text { : coeficiente de redução da resistência; } \\
& \mu_{\mathrm{e}} \text { : coeficiente de atrito efetivo; } \\
& \mu_{\mathrm{e}}=\frac{6,90 \mathrm{C}_{\mathrm{s}}^{2} \cdot \mu}{\tau_{\mathrm{u}}} \quad(\mathrm{MPa}) \\
& \mu=1, .4 \text { para ligação monolítica de concreto; } \\
& \mu=1,0 \text { para ligação de concretos com idades diferentes } \mathrm{e} \\
& \text { rugosidade de 6,4 } \mathrm{mm} \text {; } \\
& \mu=0,4 \text { para ligação entre concretos com interface rugosa; } \\
& \mu=0,6 \text { para ligação entre concreto e aço; } \\
& \mathrm{C}_{\mathrm{s}}=1 \text { para concreto com densidade normal. }
\end{aligned}
$$

Esta expressão foi posteriormente incorporada às recomendações do Precast / Prestressed Concrete Institute (PCI).

- F.J. Vecchio e M.P. Collins, 1986

Baseado em trabalhos desenvolvidos por Walraven e em ensaios de elementos de membrana em concreto armado, os autores sugeriram a seguinte expressão para avaliação da resistência ao cisalhamento da interface de concreto sujeita à tensões normais (VECCHIO; COLLINS (1986)):

$$
\tau_{\mathrm{u}}=0,18 \cdot \tau_{\mathrm{s}, \max }+1,64 \cdot \sigma_{\mathrm{c}}-0,82 \cdot \frac{\sigma_{\mathrm{c}}{ }^{2}}{\tau_{\mathrm{s}, \max }} \quad(\mathrm{MPa})
$$




$$
\begin{aligned}
& \tau_{\mathrm{s}, \max }=\frac{\sqrt{\mathrm{f}_{\mathrm{c}}}}{0,31+\frac{24 \mathrm{w}}{\Phi_{\mathrm{agr}}+16}} \quad(\mathrm{MPa}) \\
& \Phi_{\mathrm{agr}} \text { : diâmetro máximo do agregado }(\mathrm{mm}) ; \\
& \tau_{\mathrm{s}, \text { max }} \text { : máxima tensão de cisalhamento, com fissuras controladas, } \\
& \quad \text { que a seção pode resistir; } \\
& \mathrm{w}: \text { abertura média das fissuras na interface }(\mathrm{mm}) ; \\
& \sigma_{\mathrm{c}}=\rho . \mathrm{f}_{\mathrm{y}}+\sigma_{\mathrm{n}} \text { : tensão normal de compressão, com valor positivo } \\
& \quad(\mathrm{MPa}) .
\end{aligned}
$$

Nesta equação, duas novas variáveis foram incluídas $\left(\Phi_{\text {agr }} \mathrm{e}\right.$ w). A determinação do valor da abertura das fissuras é difícil. Elas diminuem com o aumento da porcentagem de armadura sendo sua influência importante apenas para pequenas taxas de armadura. Observa-se também que não foi especificado um limite máximo para a resistência ao cisalhamento.

- J. Walraven, J. Frénay e A. Pruijssers, 1987

Uma extensiva análise estatística foi realizada pelos autores em 88 ensaios de cisalhamento direto com interfaces pré-fissuradas sendo sugerida a seguinte equação (WALRAVEN, et al. (1987)):

$$
\tau_{u}=C_{1} \cdot\left(\rho \cdot f_{y}\right)^{C_{2}} \quad(M P a)
$$

sendo $C_{1}=0,878 \cdot f_{c}^{0,406}$ e $C_{2}=0,167 \cdot f_{c}{ }^{0,303}$

- A.H. Mattock, 1988

Comentando sobre o artigo de WALRAVEN, et al. (1987), Mattock incluiu o efeito da resistência do concreto sugerindo uma nova equação (MATTOCK (1988)):

$$
\tau_{\mathrm{u}}=0,467 \mathrm{f}_{\mathrm{c}}^{0,545}+0,8 \cdot\left(\rho \cdot \mathrm{f}_{\mathrm{y}}+\sigma_{\mathrm{n}}\right) \leq 0,3 \cdot \mathrm{f}_{\mathrm{c}} \quad(\mathrm{MPa})
$$


O primeiro termo representa a resistência devido à aderência e o segundo termo devido ao atrito entre os agregados.

- S.T.Mau e T.T.C. Hsu, 1988

Comentando sobre o artigo de WALRAVEN, et al. (1987), os autores (MAU; HSU (1988)) sugeriram uma equação semelhante à equação de Loov (eq.(2.46)):

$$
\frac{\tau_{u}}{f_{c}}=0,66 \cdot \sqrt{\frac{\rho \cdot f_{y}}{f_{c}}}<0,3
$$

Entretanto, eles adotaram o mesmo coeficiente 0,66 tanto para interfaces em modelos com plano de cisalhamento pré-fissurado quanto para interfaces em modelos monolíticos, apesar delas apresentarem comportamentos diferentes na ruptura.

- S.G. Tsoukantas e T.P. Tassios, 1989

Os autores sugeriram a seguinte equação (TSOUKANTAS; TASSIOS (1989)):

$$
\begin{aligned}
& \text { para superfícies lisas : } \tau_{\mathrm{u}}=0,40 \cdot \sigma_{\mathrm{n}} \quad(\mathrm{MPa}) \\
& \text { para superfícies rugosas }: \tau_{\mathrm{u}}=0,5 \cdot \sqrt[3]{\mathrm{f}_{\mathrm{c}}{ }^{2} \cdot \sigma_{\mathrm{n}}} \quad(\mathrm{MPa})
\end{aligned}
$$

sendo $\sigma_{\mathrm{n}}$ a tensão normal à interface devido às ações externas e à armadura transversal.

Alguns trabalhos mais recentes que tratam sobre o assunto são apresentados a seguir.

- A.K. Patnaik, 1992

Baseado em resultados de ensaios em 16 vigas biapoiadas, Patnaik sugeriu a seguinte equação para avaliação da resistência última ao cisalhamento (PATNAIK (1992) ): 


$$
\tau_{u}=0,6 \cdot \sqrt{\left(0,1+\rho \cdot f_{y}\right) \cdot f_{c}} \leq 0,25 \cdot f_{c} \quad(M P a)
$$

sendo $\mathrm{f}_{\mathrm{y}} \leq 440 \mathrm{MPa}$. A equação anterior é válida para concretos moldados em idades diferentes e interface rugosa. Ela possui uma parcela de resistência devido à aderência e outra devido ao atrito na superfície de contato. Para situações com plano de cisalhamento pré-fissurado, o autor sugere outra equação (PATNAIK; LOOV (1994)):

$$
\tau_{\mathrm{u}}=0,5 \cdot \sqrt{\rho \cdot \mathrm{f}_{\mathrm{y}} \cdot \mathrm{f}_{\mathrm{c}}} \quad(\mathrm{MPa})
$$

- A.H. Mattock, 1994

Comentando o artigo de Patnaik, Mattock sugeriu que a resistência da interface não era proporcional $a f_{c}^{0,5}$. Assim sugeriu as seguintes equações (MATTOCK (1994)):

- peças monolíticas com plano de cisalhamento não pré-fissurado:

$$
\tau_{u}=\frac{\sqrt{\rho \cdot f_{y}} \cdot f_{c}^{0,73}}{3,820} \leq 0,3 \cdot f_{c} \quad(M P a)
$$

- peças monolíticas com plano de cisalhamento pré-fissurado:

$$
\tau_{u}=\frac{\sqrt{\rho \cdot f_{y}} \cdot f_{c}^{0,73}}{4,536} \leq 0,3 \cdot f_{c} \quad(M P a)
$$

- peças onde as partes são moldadas em idades diferentes:

$$
\tau_{u}=\frac{\sqrt{\rho \cdot f_{y}} \cdot f_{c}^{0,73}}{3,820}-0,02 \cdot f_{c} \leq 0,3 \cdot f_{c} \quad(M P a)
$$

sendo adotado para a resistência do concreto o valor médio da resistência das duas partes. 


\section{Indicações de normas e regulamentos}

No capítulo 2 foi estudada a transferência de esforços de cisalhamento entre duas superfícies de concreto de forma geral, sendo apresentados alguns modelos analíticos e empíricos para avaliação da resistência de interfaces de concreto aos esforços de cisalhamento atuando no seu plano. Neste capítulo são apresentadas algumas indicações de normas e regulamentos para 0 dimensionamento de vigas e lajes compostas submetidas à flexão. Ao final são apresentadas algumas disposições construtivas e recomendações para projetos de peças compostas.

\subsection{Avaliação da tensão solicitante}

O projeto de estruturas consiste, basicamente, em conhecido as ações dimensionar as peças estruturais de forma a resistir, com segurança, às solicitações. Normalmente as solicitações são provenientes de forças externas, peso próprio e, em alguns casos, efeitos de temperatura, retração, recalque, etc.. No caso do dimensionamento da interface de peças compostas é necessário obter as solicitações na interface de forma que ela seja adequadamente dimensionada para oferecer uma resistência maior que a solicitação.

Uma das maneiras de avaliar a tensão solicitante na interface é através da expressão da resistência dos materiais:

$$
\tau=\frac{\text { V.S }}{\text { l.b }}
$$

V : esforço cortante na seção; 
S : momento estático da área acima da fibra em estudo com relação ao centróide da seção transversal;

I : momento de inércia da seção transversal;

b: largura da seção transversal na fibra em estudo.

Esta expressão é válida apenas para materiais no regime elástico linear, entretanto pode ser utilizada para o concreto fissurado. Neste caso, as propriedades geométricas da seção devem ser obtidas da seção fissurada desprezando a região tracionada do concreto.

No estado limite último, a tensão de cisalhamento horizontal na interface também pode ser avaliada conforme ilustrado na figura 3.1. Nesta figura, a interface MN é formada por uma peça pré-moldada e por outra moldada no local. Chamando de $M_{d} O$ momento de cálculo numa seção transversal e $V_{d} O$ esforço cortante de cálculo, a força transmitida pela interface entre as duas peças, por unidade de comprimento, pode ser obtida pela variação do esforço normal de compressão na peça moldada no local.

$$
R_{d} \cdot d s=d R_{c c}=\frac{d M_{d}}{z}
$$

Logo:

$$
\mathrm{R}_{\mathrm{d}}=\frac{1}{\mathrm{z}} \cdot \frac{\mathrm{dM}_{\mathrm{d}}}{\mathrm{ds}}=\frac{1}{\mathrm{z}} \cdot \mathrm{V}_{\mathrm{d}}
$$

A tensão de cisalhamento na interface é obtida dividindo o fluxo de cisalhamento pela largura da interface.

$$
\tau_{d}=\frac{V_{d}}{\text { b.z }}
$$

Normalmente, o braço de alavanca entre as resultantes de tração e compressão na seção é tomado igual a 0,9.d , sendo d a altura útil. Logo: 


$$
\tau_{d}=\frac{V_{d}}{0,9 \cdot b \cdot d}
$$

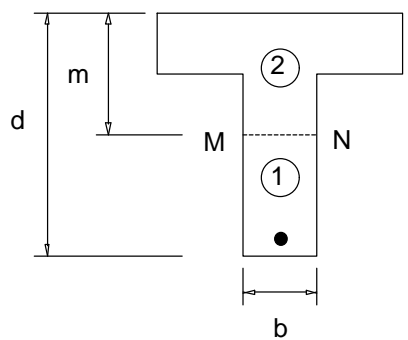

a)

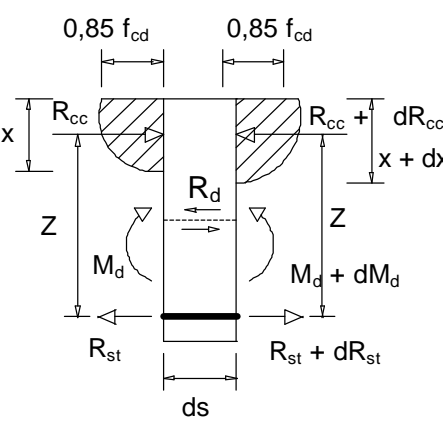

b)

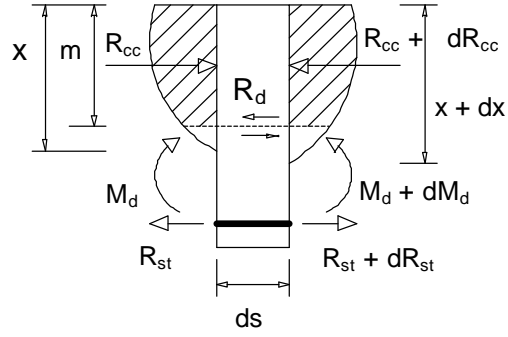

C)

Figura 3.1 - Avaliação da tensão de cisalhamento horizontal na interface

$\mathrm{Na}$ avaliação da força transmitida pela interface foi suposto que o acréscimo no esforço normal de compressão é igual ao acréscimo no esforço de tração na armadura, ou seja, $d R_{c c}=d R_{s t}$. Entretanto, no estado limite último, esta afirmação é verdadeira apenas quando toda a região comprimida da seção está acima da interface, ou seja, a linha neutra está acima da interface. Quando a linha neutra da seção está abaixo da interface (figura 3.1(c)), a força transmitida por ela é menor que a resultante de compressão na seção composta. Neste caso a eq.(3.3) não é válida pois conduz a valores superiores à tensão real atuante na interface. Contudo, a tensão pode ser avaliada de forma simplificada multiplicando a eq.(3.3) pela relação entre a força de compressão no concreto moldado no local $R_{c c 2}$ e a resultante de compressão da seção composta $R_{c c}$.

$$
\tau_{d}=\frac{V_{d}}{\text { 0,9.b.d }} \frac{R_{c c 2}}{R_{c c}}
$$

As expressões anteriores avaliam a tensão de cisalhamento horizontal para cada seção em função do esforço cortante atuante. Neste caso, a distribuição das tensões de cisalhamento horizontal da interface ao longo do vão da viga é proporcional à variação do esforço cortante. 
Outra forma de avaliar a tensão na interface é computar as forças de compressão ou de tração em um trecho da viga e prover sua transferência através de forças de cisalhamento horizontais. Sabendo que $V_{d}=\frac{d M_{d}}{d s}$, a eq.(3.2) pode ser rescrita da seguinte forma:

$$
\begin{aligned}
\tau_{d} & =\frac{d M_{d}}{d s} \cdot \frac{1}{b \cdot z}=\frac{d M_{d}}{z} \cdot \frac{1}{b \cdot d s} \\
\tau_{d} & =\frac{d R_{c c}}{b . d s}
\end{aligned}
$$

Nesta equação, o valor da tensão de cisalhamento horizontal é função da variação do esforço normal de compressão no trecho ds. Também neste caso foi admitido que a linha neutra da seção está acima da interface de modo que a resultante de compressão transmitida à interface é igual à resultante de tração na armadura. Quando a linha neutra está abaixo da interface, apenas a componente de compressão do concreto moldado no local é transferido para a interface. Substituindo o diagrama parábola-retângulo que representa a relação tensão de compressão - deformação do concreto por um diagrama retangular equivalente, pode-se, de forma simplificada, calcular a resultante de compressão na seção. Multiplicando a área de concreto moldado no local pela tensão de plastificação do concreto, obtêm-se a força de compressão na parte moldada no local. Sabendo que na flexão sempre existirá equilíbrio entre as resultantes de tração e de compressão, pode-se determinar a força transmitida pela interface, conforme ilustrado na figura 3.2. Inicialmente calcula-se a força de compressão no concreto moldado no local supondo que a linha neutra seja coincidente com a interface. Compara-se este valor com a resultante de compressão na seção submetida à um momento de cálculo $M_{d}$. Se for menor, a linha neutra está abaixo da interface e a força transmitida pela interface é igual à força de compressão na área de concreto moldado no local. Se for maior, a linha neutra está acima da interface e a força transmitida pela interface é igual à resultante de compressão ou à resultante de tração da seção, uma vez que, por equilíbrio, sabe-se que elas são iguais. 
Seção submetida a momento positivo

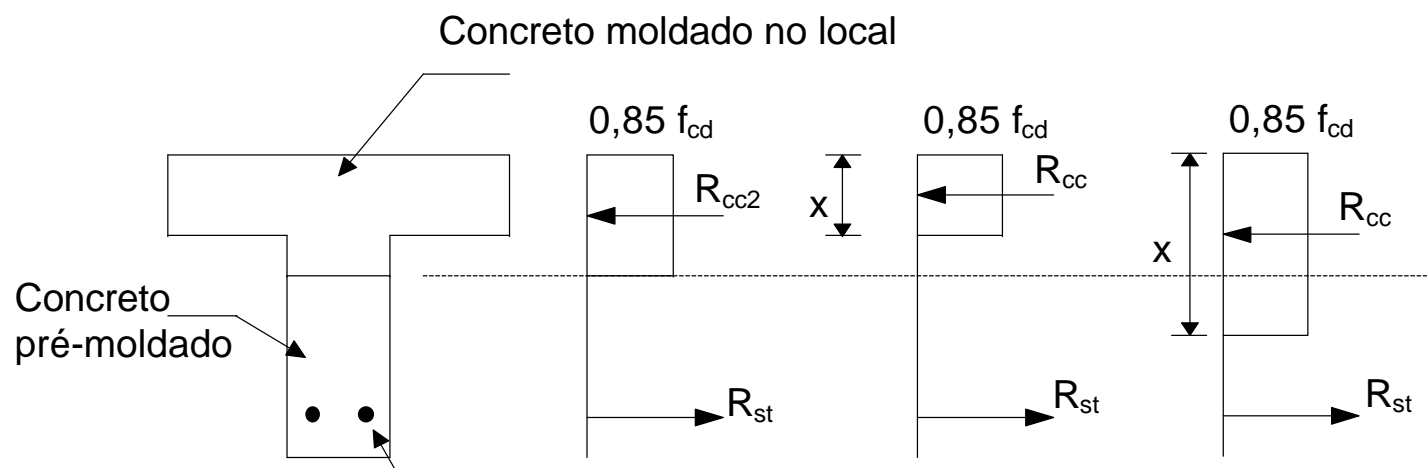

$A_{s}$ ou $A_{p}$

Caso 1

Caso 2

$\mathrm{A}_{\mathrm{c} 2}$ : área da seção de concreto moldado no local

$\mathrm{R}_{\mathrm{cc2}}$ : força de compressão no concreto moldado no local

$$
R_{c c 2}=0,85 \cdot f_{c d} \cdot A_{c 2}
$$

$\mathrm{R}_{\mathrm{cc}}$ : força total de compressão na seção composta

$\mathrm{R}_{\mathrm{st}}$ : força total de tração

$\mathrm{f}_{\mathrm{cd}}$ : resistência de cálculo do concreto à compressão

$R_{d}$ : força atuante na interface

$A_{s}$ : área de armadura passiva

$A_{p}$ : área de armadura de protensão

Seção submetida a momento negativo

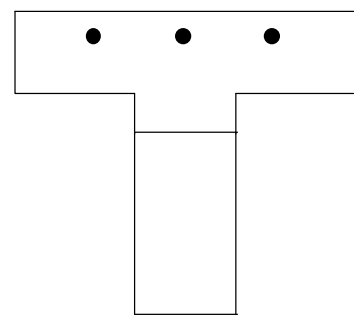

$$
\mathrm{R}_{\mathrm{d}}=\mathrm{R}_{\mathrm{cc}}=\mathrm{R}_{\mathrm{st}}
$$

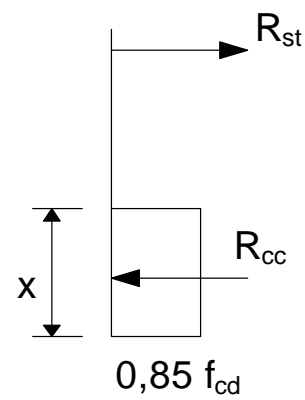

Figura 3.2 - Avaliação da tensão na interface por equilíbrio de forças 
A tensão de cisalhamento horizontal média é avaliada entre as seções de momento máximo positivo ou negativo e momento nulo. Neste trecho a tensão de cisalhamento na interface é igual à resultante de compressão na seção de momento máximo, uma vez que na seção de momento nulo a resultante de compressão é nula. Na figura 3.3 estão ilustrados os trechos onde a tensão média deve ser calculada. A eq.(3.5) pode, portanto, ser escrita como:

$$
\tau_{d}=\frac{R_{c c 2}}{b \cdot a_{v}}=\frac{A_{c 2} \cdot 0,85 \cdot f_{c d}}{b \cdot a_{v}} \leq \frac{A_{s} \cdot f_{y d}+A_{p} \cdot \sigma_{p d}}{b \cdot a_{v}}
$$

b : largura da interface;

$a_{v}$ : comprimento sobre o qual são transferidas as tensões de cisalhamento horizontais. É a distância entre os pontos de momento máximo e momento nulo;

$\sigma_{\mathrm{pd}}:$ tensão na armadura de protensão;

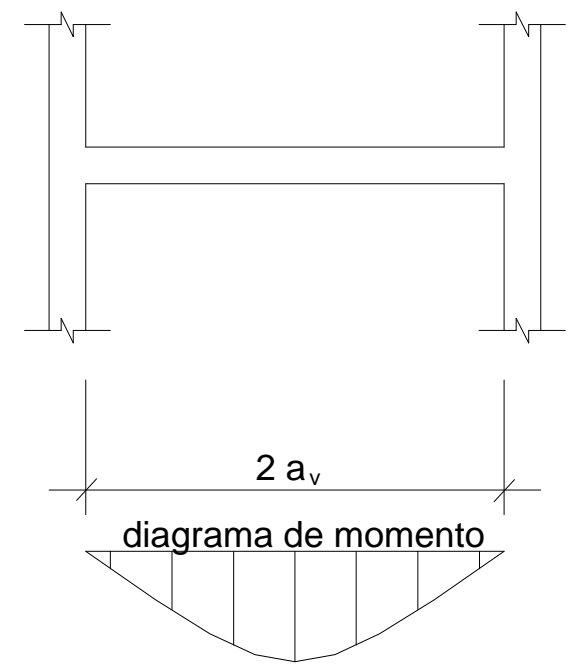

viga simplesmente apoiada
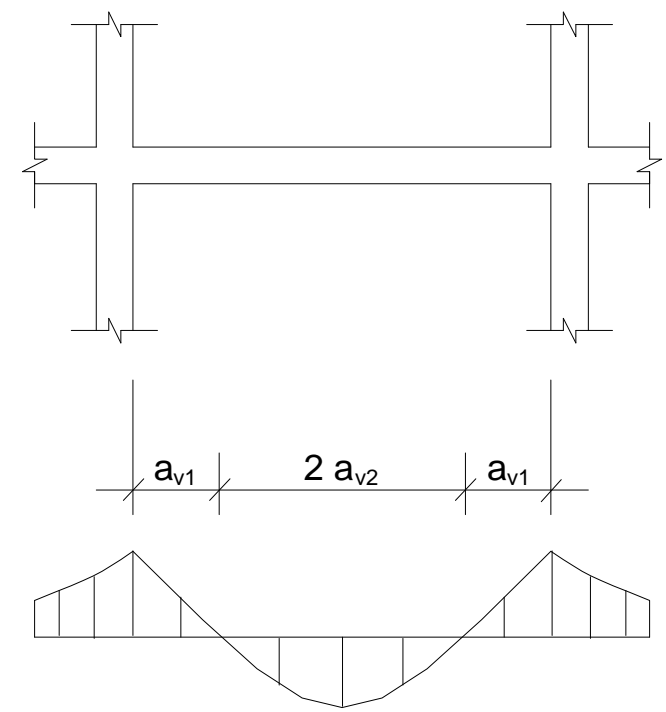

viga contínua

Figura 3.3 - Trechos para avaliação da tensão de cisalhamento horizontal média

Caso exista armadura de compressão, deverá ser somada à força de compressão no concreto a força resistida pela armadura. Vale também observar 
que a eq.(3.6) é válida para seções submetidas à flexão simples nos domínios 2 e 3 , onde a armadura de tração atinge o escoando.

A tensão de cisalhamento horizontal atuante na interface pode ser avaliada pelas eq.(3.1), eq.(3.4) e eq.(3.6). A escolha da equação a ser utilizada depende do procedimento adotado para avaliação da resistência, como será visto a seguir.

\subsection{Procedimento da FIP}

Este procedimento é aplicado a peças simplesmente apoiadas. As expressões permitem o dimensionamento no estado limite último garantindo o funcionamento como seção composta tanto no estado limite último quanto no estado de utilização.

As fórmulas apresentadas para o cálculo da resistência ao cisalhamento são baseadas em dados experimentais obtidos nos últimos 20 anos em mais de 100 testes em vigas e lajes de seção composta. Os valores de projeto foram obtidos pela multiplicação dos valores médios dos ensaios por 0,7, o que leva em conta a dispersão dos resultados e fornece um valor característico (5\%) da resistência ao cisalhamento. Tendo-se em conta que os ensaios foram realizados em boas condições de laboratório, o valor característico da resistência é multiplicado por 0,5. Este coeficiente de segurança está baseado em vários testes realizados no Reino Unido, Suécia e Finlândia.

A tensão solicitante de cálculo (ou tensão de referência) no estado limite último deve ser avaliada por:

$$
\tau_{d}=\frac{V_{d}}{\text { b.d }}
$$

Esta expressão, em certos casos, fornece valores conservadores, especialmente quando a interface está situada na região comprimida da seção no estado limite último. 
Para o dimensionamento de vigas compostas (situações de alta solicitação, ou seja, pequena largura de contato da interface), a resistência de cálculo da interface ao cisalhamento horizontal pode ser estimada por:

$$
\tau_{\mathrm{rd}}=\beta_{1} \cdot \rho \cdot \mathrm{f}_{\mathrm{yd}}+\beta_{2} \cdot \mathrm{f}_{\mathrm{td}, \mathrm{c}} \leq 0,25 \mathrm{f}_{\mathrm{ck}, \mathrm{c}}
$$

$$
\rho=\frac{A_{s w}}{s \cdot b}
$$

$\rho$ : taxa geométrica de armadura que atravessa a interface $(\geq 0,001)$;

$\mathrm{A}_{\mathrm{sw}}$ : área de armadura transversal à interface e totalmente ancorada nos elementos;

s : espaçamento da armadura transversal;

b : largura ou comprimento transversal à interface;

$f_{y d}$ : resistência de cálculo do aço (MPa);

$\mathrm{f}_{\mathrm{ck}, \mathrm{c}}$ : resistência característica do concreto medida em corpos-de-prova cúbicos (MPa);

$\mathrm{f}_{\mathrm{td}, \mathrm{c}}=0,25 \cdot \sqrt{\mathrm{f}_{\mathrm{ck}, \mathrm{c}}}$ : resistência de cálculo do concreto à tração (MPa);

$\beta_{1}$ e $\beta_{2}$ : coeficientes multiplicadores da resistência fornecida pela armadura e pela superfície de contato, obtidos na tabela 3.1.

Tabela 3.1 - Coeficientes $\beta 1$ e $\beta 2$ da FIP

\begin{tabular}{|c|c|c|}
\hline \multirow{2}{*}{ coeficiente } & \multicolumn{2}{|c|}{ categoria da superfície } \\
\cline { 2 - 3 } & 1 & 2 \\
\hline$\beta_{1}$ & 0,6 & 0,9 \\
\hline$\beta_{2}$ & $0,2^{*}$ & 0,4 \\
\hline
\end{tabular}

* Para superfícies lisas é recomendado utilizar $\beta_{2}=0,1$

Categoria 1 : São as superfícies obtidas naturalmente durante a produção dos elementos pré-moldados. A amplitude das irregularidades da superfície 
geralmente são menores que $1 \mathrm{~mm}$ de acordo com "Swedish Standard SIS 8120 $05 "$.

Categoria 2 : A superfície dos elementos pré-moldados são deliberadamente tornadas rugosas durante a fabricação.

A armadura de costura deve ser efetivamente ancorada de cada lado da interface e não deve resistir a outros esforços. Contudo, ela pode ser somada à quantidade de armadura transversal proveniente do dimensionamento ao esforço cortante, de forma que a mesma armadura resista tanto ao cisalhamento horizontal na interface quanto ao esforço cortante.

Para o dimensionamento de lajes compostas (situações de baixa solicitação, ou seja, grande largura de contato da interface), a resistência de cálculo da interface ao cisalhamento horizontal pode ser estimada por:

$$
\tau_{\mathrm{rd}}=\beta_{2} \cdot f_{\mathrm{td}, \mathrm{c}}
$$

Se a tensão de referência for inferior a este valor não é necessário armadura transversal. Contudo, se ela for maior, a resistência da interface pode ser avaliada de forma mais precisa pela eq.(3.10), sendo o acréscimo de resistência em relação à equação anterior limitado a $50 \%$. Se a tensão de referência ainda for maior que este valor, então é necessário a colocação de armadura transversal avaliada pela eq.(3.8).

$$
\begin{aligned}
& \tau_{\mathrm{rd}}=\mathrm{K}_{1} \cdot \mathrm{K}_{2} \cdot \mathrm{K}_{3} \cdot \beta_{2} \cdot \mathrm{f}_{\mathrm{td}, \mathrm{c}} \leq 1,5 \beta_{2} \cdot \mathrm{f}_{\mathrm{td}, \mathrm{c}} \\
& \mathrm{K}_{1}=0,7 \cdot \frac{\mathrm{x}}{\mathrm{e}}+0,3 \leq 1,0 \\
& \mathrm{x} \quad \text { : distância da fibra mais tracionada à interface; } \\
& \mathrm{e} \quad \text { : distância da fibra mais tracionada ao centro de gravidade da seção não } \\
& \quad \text { fissurada; } \\
& \mathrm{K}_{2}=2-0.4 \cdot \frac{\mathrm{M}}{\mathrm{V} \cdot \mathrm{d}} \geq 1.0 \\
& \mathrm{M} \quad: \text { momento fletor na seção; }
\end{aligned}
$$


V : esforço cortante na seção;

d : altura útil da seção;

$K_{3}=\frac{0,3}{b \cdot d^{2}} \cdot\left(f_{t d, c} \cdot W_{u}+0,16 \cdot M_{0}\right)+0,8 \geq 1,0$

$M_{0}$ : momento fletor necessário para produzir tensão nula na fibra mais tracionada (MN.m);

$\mathrm{W}_{\mathrm{u}}=\frac{\mathrm{l}}{\mathrm{e}} \quad\left(\mathrm{m}^{3}\right)$

I : momento de inércia da seção de concreto não fissurada $\left(\mathrm{m}^{4}\right)$;

$\mathrm{f}_{\mathrm{td}, \mathrm{c}}$ : resistência de cálculo do concreto à tração $(\mathrm{MPa})$.

Para carregamentos repetidos (fadiga), os valores obtidos pela eq.(3.9) devem ser reduzidos em $50 \%$.

Baseado em ensaios de cisalhamento direto realizados por Mattock, SANTOS (1985) propôs uma alteração no procedimento da FIP através da modificação dos coeficientes envolvidos na resistência da ligação.

$$
\tau_{\mathrm{rd}}=0,8 \frac{A_{\mathrm{sw}}}{\mathrm{s} \cdot \mathrm{b}} \cdot \mathrm{f}_{\mathrm{yd}} \cdot(1+\operatorname{cotg} \alpha) \cdot \operatorname{sen} \alpha+\beta_{1} \cdot \mathrm{f}_{\mathrm{t}, \mathrm{c}}
$$

$\mathrm{A}_{\mathrm{sw}}$ : área de armadura transversal à interface e totalmente ancorada nos elementos;

$\mathrm{f}_{\mathrm{yd}}$ : resistência de cálculo da armadura $(\mathrm{MPa})$;

s : espaçamento da armadura transversal;

b : largura ou comprimento transversal à interface;

$\alpha$ : ângulo da armadura transversal com a superfície de contato;

$f_{t, c}$ : resistência de cálculo à tração do concreto menos resistente em contato medida em corpos-de-prova cúbicos (tabela 3.3);

$\beta_{1}$ : coeficiente função das condições de rugosidade da superfície do elemento pré-moldado e do modo de atuação dos esforços (com ou sem inversão) e ainda da existência ou não de armadura transversal. 
Nesta expressão o coeficiente que considera a contribuição da armadura transversal na resistência da interface é tomado constante e igual a 0,8. Para as situações correntes de superfície aderente com armadura transversal o coeficiente $\beta 1$ terá os valores indicados na tabela 3.2. No caso de superfícies sem armadura transversal os valores da tabela 3.2 devem ser multiplicados por 0,8 . Considera-se que uma superfície tenha armadura transversal quando é atravessada por armaduras, devidamente ancoradas nos dois elementos, com uma porcentagem mínima de $0,2 \%$ ( $\rho \geq 0,002$ ). No caso de peças compostas em que as tensões normais atuantes na interface puderem ser de tração, o coeficiente $\beta_{1}$ deverá ser tomado igual a 0.

Tabela 3.2 - coeficiente $\beta_{1}$ proposto por Santos.

\begin{tabular}{|c|c|c|c|}
\hline$\beta_{1}$ & superfície lisa & $\begin{array}{c}\text { superfície } \\
\text { naturalmente } \\
\text { rugosa }\end{array}$ & $\begin{array}{c}\text { superfície } \\
\text { intencionalmente } \\
\text { rugosa }\end{array}$ \\
\hline $\begin{array}{c}\text { sem inversão } \\
\text { de esforços }\end{array}$ & 0,3 & 0,7 & 1,0 \\
\hline $\begin{array}{c}\text { com inversão } \\
\text { de esforços }\end{array}$ & 0 & 0,3 & 0,5 \\
\hline
\end{tabular}

Tabela 3.3 - resistência à tração do concreto $\left(\mathfrak{f}_{t, c}\right)$.

\begin{tabular}{|c|c|c|c|c|c|c|}
\hline $\begin{array}{c}\text { resistência do } \\
\text { concreto à } \\
\text { compressão (MPa ) }\end{array}$ & 20 & 25 & 30 & 35 & 40 & 45 \\
\hline $\mathrm{f}_{\mathrm{t}, \mathrm{c}}(\mathrm{MPa})$ & 0,60 & 0,65 & 0,75 & 0,85 & 0,90 & 1,00 \\
\hline
\end{tabular}

\subsection{Procedimento do PCI}

O procedimento aqui apresentado é baseado no item 17.5.3 do ACI 318-89. Ele está baseado na teoria atrito-cisalhamento entre duas superfícies em contato sujeitas à força normal. No caso da ligação entre concreto pré-moldado e concreto 
moldado no local sem atuação de forças normais à superfície, o atrito é garantido pela força introduzida pela armadura transversal. Entretanto, enquanto não ocorrer a fissuração, a força externa é resistida apenas pela aderência entre as duas superfícies em contato.

A tensão de cisalhamento solicitante é avaliada pela eq.(3.6) a qual é baseada no equilíbrio de forças transmitidas pela interface no trecho entre as seções de momento nulo e momento máximo. A tensão resistente depende das características da superfície de contato e da existência ou não de armadura transversal, sendo uniformemente distribuída na interface entre as seções de momento máximo e momento nulo. Para superfícies intencionalmente rugosas sem armadura transversal ou superfícies não rugosas com armadura transversal mínima, a força resistente, após as conversões de unidades, vale:

$$
\begin{aligned}
& F_{r d}=\phi \cdot 552 \cdot b \cdot a_{v} \\
& \tau_{r d}=\phi \cdot 0,552
\end{aligned}
$$

$\mathrm{F}_{\mathrm{rd}}$ : força resistente ao cisalhamento na interface $(\mathrm{kN})$;

$\tau_{\mathrm{rd}}$ : tensão resistente ao cisalhamento na interface $(\mathrm{MPa})$;

$\phi=0,85$ : coeficiente de minoração da resistência;

b : largura ou comprimento transversal da interface $(m)$;

$a_{v}$ : distância entre os pontos de momento máximo e nulo $(\mathrm{m})$.

Para elementos pré-moldados com superfície sem tratamento visando o aumento de rugosidade e sem armadura transversal, a força resistente vale:

$$
\begin{aligned}
& \mathrm{F}_{\mathrm{rd}}=\phi \cdot 276 \cdot b \cdot \mathrm{a}_{\mathrm{v}} \\
& \tau_{\mathrm{rd}}=\phi \cdot 0,276
\end{aligned}
$$

Para elementos pré-moldados com superfície intencionalmente rugosa e armadura transversal mínima, a força resistente vale: 


$$
\begin{aligned}
& F_{r d}=\phi \cdot 2416 \cdot b \cdot a_{v} \\
& \tau_{r d}=\phi \cdot 2,416
\end{aligned}
$$

A área de armadura transversal mínima é especificada pelo ACI 318-89 no item 11.5.5.3

$$
A_{s w, \min }=\frac{0,343 \cdot \text { b.s }}{f_{y}}
$$

b : largura da seção;

s : espaçamento da armadura;

$\mathrm{f}_{\mathrm{y}}$ : resistência de escoamento à tração da armadura em $\mathrm{MPa}$ $\left(f_{y} \leq 412 \mathrm{MPa}\right)$

Utilizando o aço CA 50-A, a taxa mínima de armadura é de 0,08 \%. KRAUTHAMMER (1992), entretanto, sugere um aumento na taxa mínima de armadura para $0,13 \%$.

Caso a força atuante na interface seja maior que os valores de $F_{r d}$ apresentados anteriormente, deve-se colocar armadura transversal estimada por:

$$
A_{s w}=\frac{1000 \cdot F_{s d}}{\phi \cdot\left(\mu_{e} \cdot \operatorname{sen} \alpha+\cos \alpha\right) \cdot f_{y}}
$$

$F_{s d}:$ força de cálculo atuante na interface $(k N)$;

$\mathrm{A}_{\mathrm{sw}}$ : área de armadura transversal à interface e totalmente ancorada nos elementos $\left(\mathrm{m}^{2}\right)$;

$f_{y}$ : resistência de escoamento à tração da armadura em $\mathrm{MPa}$ $\left(f_{y} \leq 412 \mathrm{MPa}\right)$;

$\mu_{\mathrm{e}}$ : coeficiente de atrito-cisalhamento efetivo;

$\phi=0,85$ : coeficiente de minoração da resistência; 
$\alpha$ : ângulo entre a armadura transversal e a interface.

O coeficiente de atrito-cisalhamento efetivo $\mu_{\mathrm{e}}$ pode ser obtido por:

$$
\mu_{\mathrm{e}}=\frac{6904 \cdot \lambda \cdot A_{\mathrm{cr}} \cdot \mu}{\mathrm{F}_{\mathrm{d}}} \leq \text { valores da tabela } 3.4
$$

$F_{d}$ : força última paralela ao plano de fissuração $(k N)$;

$A_{c r}$ : área da superfície fissurada $\left(m^{2}\right)$;

$\mu$ : coeficiente de atrito-cisalhamento apresentado na tabela 3.4;

$\lambda=1,0$ para concreto normal;

$\lambda=\frac{1,85 . f_{c t}}{\sqrt{f_{c k}}}$ para concreto leve. Caso não seja conhecido o valor de $f_{c t}$, pode-se adotar $\lambda=0,75$;

$\mathrm{f}_{\mathrm{ct}}$ : resistência à tração do concreto leve $(\mathrm{MPa})$;

$\mathrm{f}_{\mathrm{ck}}$ : resistência característica à compressão do concreto (MPa).

Para seções compostas $\mu=1,0 \lambda$ e $A_{c r}=b . a_{v}$, logo :

$$
\mu_{e}=\frac{6904 \cdot \lambda^{2} \cdot b \cdot a_{v}}{F_{s d}} \leq 2,9
$$

O valor de $F_{\text {sd }}$ é limitado por:

$$
F_{s d}=\phi \cdot 250 \cdot \lambda^{2} \cdot f_{c k} \cdot b \cdot a_{v} \leq \phi \cdot 6904 \cdot \lambda^{2} \cdot b \cdot a_{v}
$$

Para avaliação da resistência ao cisalhamento deve-se adotar o concreto com menor $f_{c k}$ em contato na interface. 
Tabela 3.4 - Coeficiente atrito-cisalhamento

\begin{tabular}{|c|c|c|c|}
\hline $\begin{array}{c}\text { Tipo de superfície } \\
\text { de contato }\end{array}$ & $\begin{array}{c}\mu \\
\text { recomendado }\end{array}$ & $\begin{array}{c}\mu_{e} \\
\text { máximo }\end{array}$ & $F_{d}$ máximo $(k N)$ \\
\hline $\begin{array}{c}\text { concreto com } \\
\text { concreto (ligação } \\
\text { monolítica ) }\end{array}$ & $1,4 \lambda$ & 3,4 & $\phi \cdot 300 \cdot \lambda^{2} \cdot \mathrm{f}_{\mathrm{ck}} \cdot \mathrm{A}_{\mathrm{cr}} \leq \phi \cdot 6904 \cdot \lambda^{2} \cdot \mathrm{A}_{\mathrm{cr}}$ \\
\hline $\begin{array}{c}\text { concreto com } \\
\text { concreto pré- } \\
\text { moldado } \\
(\text { superfície rugosa) }\end{array}$ & $1,0 \lambda$ & 2,9 & $\phi \cdot 250 \cdot \lambda^{2} \cdot \mathrm{f}_{\mathrm{ck}} \cdot \mathrm{A}_{\mathrm{cr}} \leq \phi \cdot 6904 \cdot \lambda^{2} \cdot \mathrm{A}_{\mathrm{cr}}$ \\
\hline $\begin{array}{c}\text { concreto com } \\
\text { concreto }\end{array}$ & $0,6 \lambda$ & 2,2 & $\phi \cdot 200 \cdot \lambda^{2} \cdot \mathrm{f}_{\mathrm{ck}} \cdot \mathrm{A}_{\mathrm{cr}} \leq \phi \cdot 5523 \cdot \lambda^{2} \cdot \mathrm{A}_{\mathrm{cr}}$ \\
\hline \begin{tabular}{c} 
concreto com aço \\
\hline
\end{tabular} & $0,7 \lambda$ & 2,4 & $\phi \cdot 250 \cdot \lambda^{2} \cdot \mathrm{f}_{\mathrm{ck}} \cdot \mathrm{A}_{\mathrm{cr}} \leq \phi \cdot 6904 \cdot \lambda^{2} \cdot \mathrm{A}_{\mathrm{cr}}$ \\
\hline
\end{tabular}

* São superfícies que apresentam rugosidade mínima de 0,6 cm

\subsection{Procedimento da norma brasileira - NBR-9062}

A NBR-9062 no item 6.3 estabelece sobre o dimensionamento de peças compostas:

6.3.1 O cálculo deve levar em conta as tensões existentes na parte prémoldada da peça antes do endurecimento do concreto aplicado na segunda etapa, as propriedades mecânicas do concreto pré-moldado e do concreto moldado posteriormente, a redistribuição de esforços decorrentes da retração e da fluência e a incidência dessas ações sobre o esforço de deslizamento das superfícies em contato;

6.3.2 Permite-se considerar as condições de cálculo como peça monolítica para duas situações:

a) colaboração completa para o estado limite último;

b) colaboração parcial para os estados limites de utilização.

Nota: No caso b, o estado limite último deve ser verificado para a parte pré-moldada da peça composta. 
O dimensionamento pode, portanto, ser feito considerando a colaboração completa da seção no estado limite último ou apenas a colaboração parcial. Ao garantir-se a colaboração completa no estado limite último automaticamente temse, também, colaboração completa no estado de utilização. Pode-se também garantir a colaboração completa no estado de utilização e colaboração parcial no estado limite último. Neste caso deve-se garantir a transferência de esforços apenas para o estado de utilização

Para o cálculo da tensão de cisalhamento solicitante na interface, é recomenda a eq.(3.6) a qual é baseada no equilíbrio de forças num trecho da viga. A tensão resistente pode ser obtida por:

$$
\tau_{\mathrm{rd}}=\beta_{\mathrm{s}} \cdot \frac{\mathrm{f}_{\mathrm{yd}} \cdot \mathrm{A}_{\mathrm{sw}}}{\mathrm{b} . \mathrm{s}}+\beta_{\mathrm{c}} \cdot \mathrm{f}_{\mathrm{td}}
$$

$A_{s w}$ : área de armadura transversal à interface e totalmente ancorada nos elementos;

$f_{y d}$ : resistência de cálculo da armadura $(\mathrm{MPa})$;

S : espaçamento da armadura transversal;

b : largura ou comprimento transversal à interface;

$f_{\text {td }}$ : resistência de cálculo à tração para o concreto menos resistente em contato (MPa);

$\beta_{\mathrm{s}}$ e $\beta_{\mathrm{c}}$ : coeficientes de minoração aplicados à armadura e ao concreto, respectivamente, válidos para superfícies ásperas (rugosidade com profundidades de $0,5 \mathrm{~cm}$ a cada $3,0 \mathrm{~cm}$ nas duas direções do plano da interface), obtidos da tabela 3.5 .

Segundo a NBR-6118/78 no item 5.2.1.2, a resistência à tração do concreto pode ser estimada por:

$$
\begin{aligned}
& f_{t k}=\frac{f_{c k}}{10} \quad \text { para } f_{c k} \leq 18 \mathrm{MPa} \\
& f_{t k}=0,7+0,06 f_{c k} \quad \text { para fck }>18 \mathrm{MPa}
\end{aligned}
$$


$\mathrm{f}_{\mathrm{ck}}$ : resistência característica do concreto à compressão, medida em corpos-de-prova cilíndricos.

Tabela 3.5 - Coeficientes $\beta_{\mathrm{s}}$ e $\beta_{\mathrm{c}}$ da NBR-9062.

\begin{tabular}{|c|c|c|}
\hline$\frac{A_{s w}}{s . b}$ & $\beta_{s}$ & $\beta_{c}$ \\
\hline$<0,002$ & 0 & 0,3 \\
\hline$>0,005$ & 0,9 & 0,6 \\
\hline
\end{tabular}

Admite-se $A_{s w}=0$ e dimensionamento como peça monolítica quando $\tau_{d}<$ $\beta_{c} \cdot f_{t d}$ e forem satisfeitas, simultaneamente, as seguintes condições:

a ) a interface ocorre em região da peça onde haja predominância da largura da ligação sobre as outras dimensões da peça (normalmente lajes);

b ) a superfície da ligação satisfaça a rugosidade de $0,5 \mathrm{~cm}$ a cada $3,0 \mathrm{~cm}$ (conforme disposto no item 6.3.4 da NBR 9062);

c ) o plano da ligação não esteja submetido a esforços normais de tração nem a tensões alternadas provenientes de carregamentos repetidos;

d ) a armadura da alma resista à totalidade das forças de tração provenientes de esforços cortante, desprezada a contribuição do concreto da zona comprimida;

e ) a superfície de concreto já endurecido seja escovada para eliminar a nata de cimento superficial e abundantemente molhada e encharcada, pelo menos, com 2 horas de antecedência à nova concretagem.

\subsection{Procedimento da norma espanhola - EF-88}

Os procedimentos vistos anteriormente podem ser utilizados para avaliar a resistência da interface tanto de vigas compostas quanto de lajes compostas formadas por laje pré-moldada e capa de concreto moldado no local (figura 3.4). 


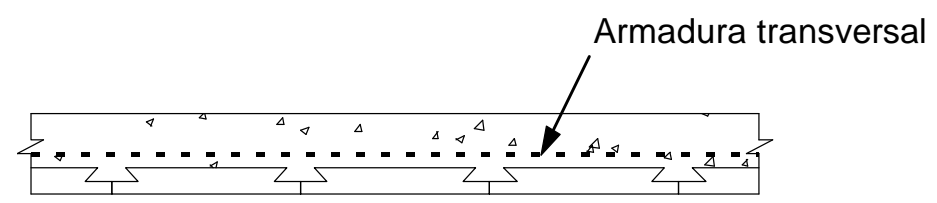

(a) pré-lajes maciças com laje moldada no local

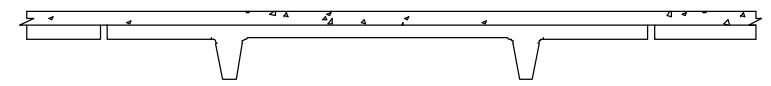

(b) laje pré-moldade em duplo T e capa de concreto

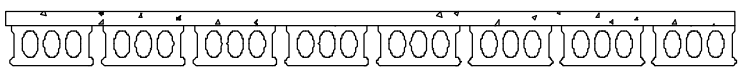

(c) lajes pré-moldadas vazadas com capa de concreto

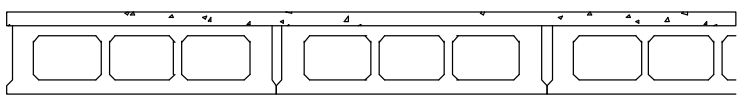

(d) lajes pré-moldadas vazadas com capa de concreto

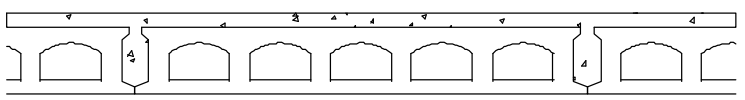

(e) lajes pré-moldadas vazadas com capa de concreto

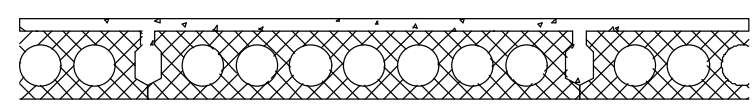

(f) lajes pré-moldadas vazadas com capa de concreto

Figura 3.4 - Alguns casos típicos de lajes compostas com lajes pré-moldadas e capa de concreto (FIP (1982)).

Esta forma construtiva é normalmente empregada em pavimentos de edifícios. A laje pré-moldada pode ter diversas formas e tamanhos, mas, o que caracteriza estas lajes compostas é o fato da capa de concreto estar uniformemente em contato com toda a superfície superior da laje pré-moldada. Em geral a tensão solicitante na interface é baixa e especial atenção deve ser dada à execução da capa de concreto bem como à preparação da superfície da peça prémoldada.

Outro tipo de laje composta é aquela formada por nervuras de concreto prémoldado e blocos vazados, de material cerâmico ou de concreto, sobre os quais é moldada uma capa de concreto (figura 3.5). 


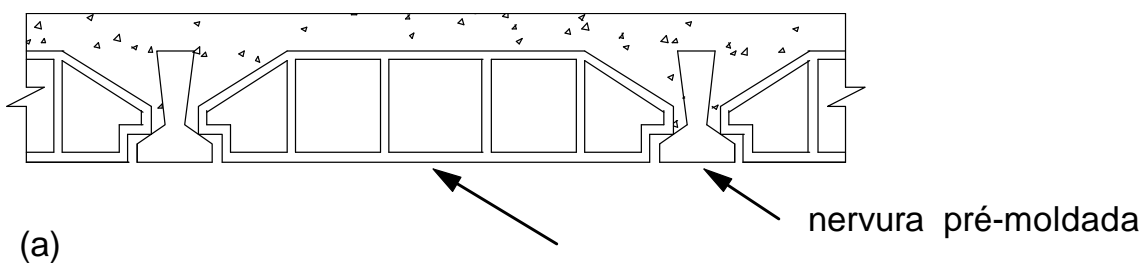

(a)

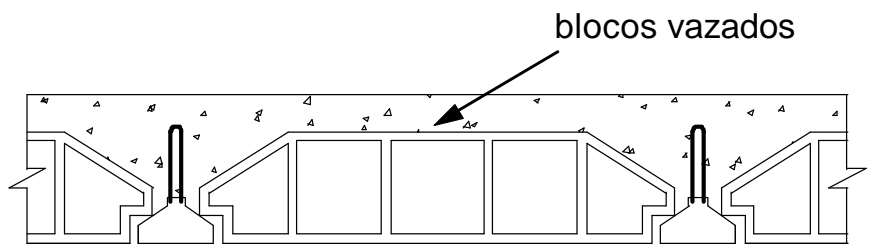

(b)

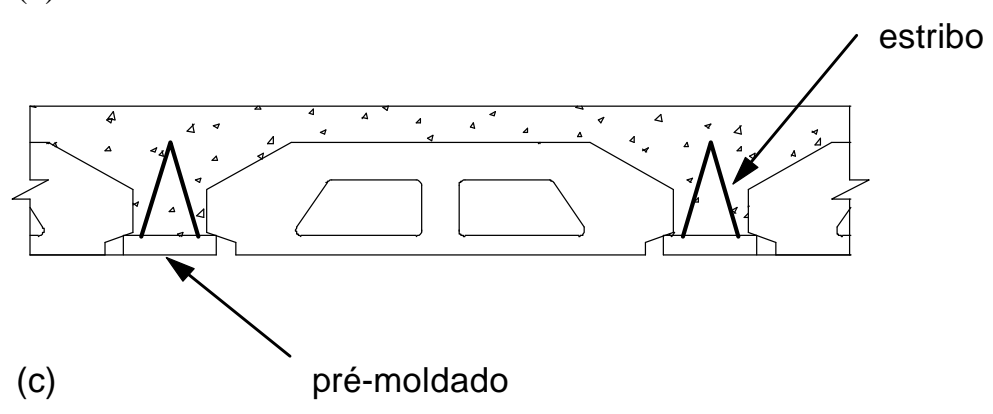

Figura 3.5 - Alguns casos típicos de lajes compostas com nervuras pré-moldadas, blocos vazados e capa de concreto (FIP (1982)).

Podem existir diversos tipos de lajes compostas em função do tipo de nervura ou do tipo de bloco utilizado. A definição do bloco a ser utilizado depende da condição de utilização da laje, do tipo de carregamento e se o bloco irá ou não contribuir na resistência final da laje. Em termos de comportamento estrutural, estas lajes são semelhantes às da figura 3.4, ou seja, apresentam baixa solicitação de cisalhamento na interface. Para as lajes ilustradas na figura 3.5(b) e figura 3.5(c) é necessário a colocação de armadura para garantir a ligação entre a peça pré-moldada e o concreto moldado no local de forma a criar as nervuras, enquanto que na figura 3.5(a) a nervura é formada por uma peça pré-moldada. A espessura mínima da capa de concreto sobre os blocos vazados e a necessidade ou não de armadura na capa são fatores que dependem do espaçamento das nervuras, do tipo de bloco usado, da forma de carregamento da laje e do esquema estrutural adotado para seu dimensionamento. 
A norma espanhola EF-88 apresenta alguns critérios para o dimensionamento destas lajes compostas (figura 3.6):

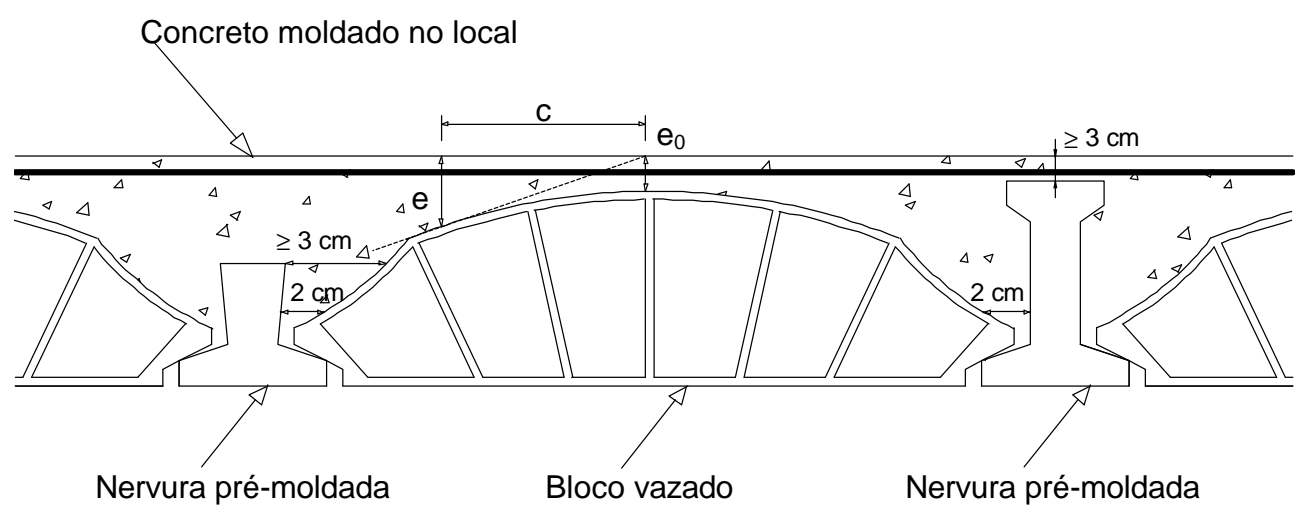

Figura 3.6 - Seção transversal de laje composta formada por nervuras e blocos vazados (EF-88 (1988)).

- A espessura mínima da camada de concreto moldado no local deve ser:

_ $3 \mathrm{~cm}$ sobre as nervuras

- $4 \mathrm{~cm}$ sobre os blocos vazados $\left(\mathrm{e}_{0}\right)$

_ $\quad 5 \mathrm{~cm}$ nos demais casos

- A seção transversal do bloco vazado deve ser de tal forma que a qualquer distância de seu eixo de simetria (c) a espessura da camada de concreto moldado no local (e) seja superior a c/8 no caso de blocos vazados que contribuam na resistência final da laje e c/6 no caso de blocos vazados sem função resistente.

- No caso de nervuras sem estribos ligando a peça pré-moldada ao concreto moldado no local (figura 3.5(a)), o espaçamento entre o bloco vazado e o topo da nervura deverá ser de no mínimo $3 \mathrm{~cm}$.

- Deve-se deixar uma distância mínima de $2 \mathrm{~cm}$, ou o diâmetro máximo do agregado, entre as faces laterais da nervura e os blocos vazados para permitir um bom adensamento da camada de concreto nesta região. 
A tensão solicitante nestas lajes deve ser avaliada por:

$$
\tau_{d}=\frac{V_{d}}{\text { p.d }}
$$

onde $\mathrm{p}$ é o perímetro de contato entre a nervura e a capa de concreto e $d$ a altura útil da laje composta. $\mathrm{Na}$ avaliação do perímetro de contato não se deve computar a região cuja distância entre a nervura e o bloco vazado seja igual ou inferior a 2 cm e/ou o diâmetro máximo do agregado. Nestes casos, o perímetro crítico deve atravessar a região de concreto moldado no local (figura 3.7).
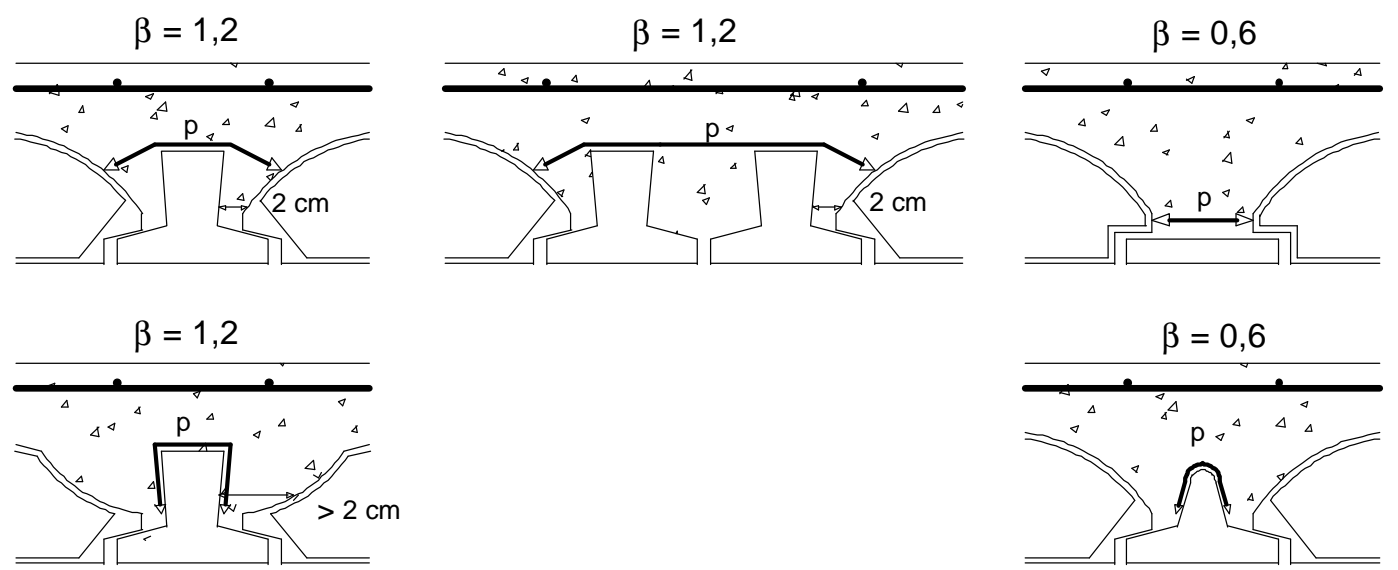

Figura 3.7 - Valores do coeficiente $\beta$ e do perímetro de contato $(p)$ entre a nervura e o concreto moldado no local (EF-88 (1988)).

A tensão solicitante em toda a superfície de contato entre as nervuras prémoldadas e concreto moldado no local deve ser limitada a:

$$
\tau_{\mathrm{d}} \leq \beta . \mathrm{f}_{\mathrm{cv}}
$$

$\mathrm{f}_{\mathrm{cv}}=0,5 \cdot \sqrt{\frac{\mathrm{f}_{\mathrm{cd}}}{1,5}}$ : resistência fictícia, de cálculo, ao esforço cortante da capa de concreto moldada no local, sendo $f_{c d}$ expresso em $\mathrm{kg} / \mathrm{cm}^{2}$ e medido em corpos-de-prova cilíndricos. 
$\beta$ : coeficiente que depende do "engastamento" da nervura no concreto moldado no local conforme a figura 3.7:

$\beta=1,2$ para nervuras com superfície rugosa e engastadas no concreto moldado no local.

$\beta=0,6$ para os demais casos e, em particular, para nervuras com superfícies lisas.

\subsection{Outros Procedimentos}

\subsubsection{Procedimento da norma canadense - CAN3-A23.3-M84}

Quando não existe armadura atravessando a interface a norma canadense permite que seja admitida uma resistência ao cisalhamento de 0,42 $\mathrm{MPa}$ se a superfície for limpa, livre de partículas soltas e intencionalmente rugosa. Esta resistência é aumentada para 1,8 $\mathrm{MPa}$ se existir armadura transversal mínima aplicando uma tensão normal $\left(\sigma=\rho . f_{y}\right)$ maior ou igual a 0,35 MPa e se a distância máxima entre as barras for menor que quatro vezes a menor dimensão da interface ou $60 \mathrm{~cm}$. Se a tensão solicitante for maior que estes valores a norma canadense sugere uma expressão, baseada na teoria atrito-cisalhamento, para avaliação da resistência ao cisalhamento da interface em função da quantidade de armadura transversal:

$$
\tau_{\mathrm{rd}}=\phi_{\mathrm{s}} \cdot \rho \cdot \mathrm{f}_{\mathrm{y}} \cdot \mu
$$

$\mu=0,5$ para concreto moldado sobre concreto com superfície não intencionalmente rugosa;

$\mu=0,9$ para concreto moldado sobre concreto com superfície intencionalmente rugosa;

$\mu=1,25$ para concreto monolítico;

$\phi_{\mathrm{s}}=\phi_{\mathrm{c}}=0,85$ : coeficientes de minoração da resistência do aço e do concreto respectivamente. 
Uma superfície é definida como intencionalmente rugosa quando possui rugosidade com profundidade superior a $5 \mathrm{~mm}$. A resistência ao cisalhamento da interface é limitada a $0,25 . \phi_{c} . f_{c}$ para concreto com resistência inferior a $26 \mathrm{MPa}$ ou 6,5. $\phi_{\mathrm{c}} \mathrm{MPa}$ para resistência superior a $26 \mathrm{MPa}$, sendo que a resistência do aço é limitada a $400 \mathrm{MPa}$.

\subsubsection{Procedimento da norma japonesa - JSCE:SP1}

Baseado em vários resultados de ensaios realizados, a norma japonesa recomenda a seguinte expressão para avaliação da resistência da interface ao cisalhamento:

$$
\begin{aligned}
& \tau_{\mathrm{rd}}=0,38 \cdot\left(\rho \cdot \mathrm{f}_{\mathrm{y}}\right) \cdot \sqrt{\mathrm{f}_{\mathrm{c}}} \text { se } \rho \cdot \mathrm{f}_{\mathrm{y}}<2,8 \mathrm{MPa} \\
& \tau_{\mathrm{rd}}=0,75 \cdot\left(\rho \cdot \mathrm{f}_{\mathrm{y}}\right)^{0,33} \cdot \sqrt{\mathrm{f}_{\mathrm{c}}} \text { se } \rho . \mathrm{f}_{\mathrm{y}} \geq 2,8 \mathrm{MPa}
\end{aligned}
$$

\subsubsection{Procedimento da norma britânica - BS8110}

A norma britânica permite considerar que para superfícies sem armadura transversal a resistência ao cisalhamento da interface é de 0,70 MPa para concreto com resistência de 21,3 MPa, 0,75 MPa para concreto com resistência de 25,5 $\mathrm{MPa}$ e 0,8 MPa para concreto com resistência igual ou superior a $34 \mathrm{MPa}$. Nestes casos, a superfície de contato deve ser limpa para remover partículas ou tratada com retardador de pega. Se for colocada armadura mínima de 0,15\% da área de contato da interface e seu espaçamento for inferior a quatro vezes a menor espessura da camada de concreto moldado no local, e também inferior a $60 \mathrm{~cm}$, a resistência ao cisalhamento é de 2,1 $\mathrm{MPa}$ para concreto de 21,3 $\mathrm{MPa}, 2,2 \mathrm{MPa}$ para concreto de 25,5 MPa e 2,5 MPa para concreto com resistência igual ou superior a $34 \mathrm{MPa}$. Se a tensão solicitante for superior a estes valores, deverá ser colocada armadura transversal e a resistência ao cisalhamento da interface é avaliada por:

$$
\tau_{\text {rd }}=\frac{\rho \cdot f_{y}}{\gamma_{s}}, \gamma_{s}=1,15
$$


Esta equação é válida para qualquer tipo de superfície de contato e independe da resistência do concreto.

\subsubsection{Procedimento da norma dinamarquesa - DS411}

Para valores de tensão normal $\left(\sigma=\rho . f_{y}+\sigma_{n}\right)$ entre $0,02 . f_{c}$ e $0,3 . f_{c}$, a norma dinamarquesa recomenda que a resistência ao cisalhamento da interface pode ser avaliada por:

$$
\tau_{r d}=0,06 \cdot f_{c}+\mu \cdot\left(\rho \cdot f_{y}+\sigma_{n}\right) \leq(0,06+\mu \cdot 0,3) \cdot f_{c}
$$

$\mu=0,7$ para superfície de contato rugosa.

Esta equação pode ser extrapolada para valores de tensão normal inferior a $0,02 . f_{c}$. O limite máximo da resistência ao cisalhamento corresponde à tensão normal de $0,3 . f_{c}$. A superfície de contato é admitida rugosa quando sua rugosidade for superior a $3 \mathrm{~mm}$.

\subsubsection{Procedimento da norma italiana - CNR 10025}

O procedimento da norma italiana para avaliação da resistência da interface de concretos é idêntica ao procedimento da NBR-9062, diferindo apenas no cálculo da tensão solicitante que deve ser feito pela tensão de referência:

$$
\tau=\frac{V_{d}}{\text { b.d }}
$$

\subsection{Comparação entre os procedimentos}

Os procedimentos apresentados neste capítulo foram utilizados para avaliar a resistência da interface de uma viga de seção T com concreto de $35 \mathrm{MPa}$ de resistência e aço com resistência de escoamento de $400 \mathrm{MPa}$. As dimensões desta viga eram idênticas às da viga de alma com largura uniforme mostrada na figura 2.5 (PATNAIK (1992)). As curvas foram traçadas sem a utilização de coeficientes de minoração na resistência dos materiais ou na resistência final da viga composta. Também foram indicados os resultados dos ensaios de PATNAIK (1992) e 
SAEMANN;WASHA (1964) de forma a possibilitar a comparação destes procedimentos com resultados experimentais.

Observa-se da figura 3.8 que a norma canadense CAN-A23.3-M84 forneceu os resultados mais conservadores e a norma japonesa JSCE:SP1 os resultados mais próximos dos obtidos em ensaios. Os demais procedimentos forneceram resultados conservadores.

Alguns procedimentos (NBR 9062, JSCE:SP1, BS8110) não apresentam um limite máximo para a resistência ao cisalhamento e, aparentemente, forneceram resultados contrários à segurança para valores da tensão normal superiores a $8 \mathrm{MPa}$. O limite proposto pela FIP de $0,25 . \mathrm{f}_{\mathrm{c}}$ parece ser $\mathrm{o}$ mais adequado quando comparado com os resultados dos ensaios.

Para baixas taxas de armadura os procedimentos apresentaram mudanças bruscas nos valores da resistência sem nenhuma justificativa. Isto deve-se ao fato da resistência final da viga ser muito influenciada pela aderência entre as superfícies de concreto quando há baixa taxa de armadura de costura atravessando a interface. Para $\rho . f_{y} \cong 1 \mathrm{MPa}$ os procedimentos que melhor representaram os resultados dos ensaios de Patnaik foram o $\mathrm{PCl}$, a $\mathrm{BS} 8110$ e a DS411. Observou-se grande discrepância dos resultados dos ensaios de SAEMANN;WASHA (1964) na região de baixos valores de tensão normal.

O procedimento do $\mathrm{PCl}$ parece ser mais adequado para utilização em projetos de vigas compostas com armadura de costura em forma de estribo, uma vez que ele forneceu resultados mais próximos aos obtidos dos ensaios. Contudo, ele apresentou um limite superior muito baixo para a resistência ao cisalhamento. Desta forma, atingido este limite, parece razoável verificar a resistência pelo procedimento da FIP e, se encontrado valor superior ao do $\mathrm{PCl}$, adotá-lo como a resistência da interface. Deve-se observar com atenção as características mínimas requeridas por cada procedimento para a caracterização da superfície de contato como rugosa. 


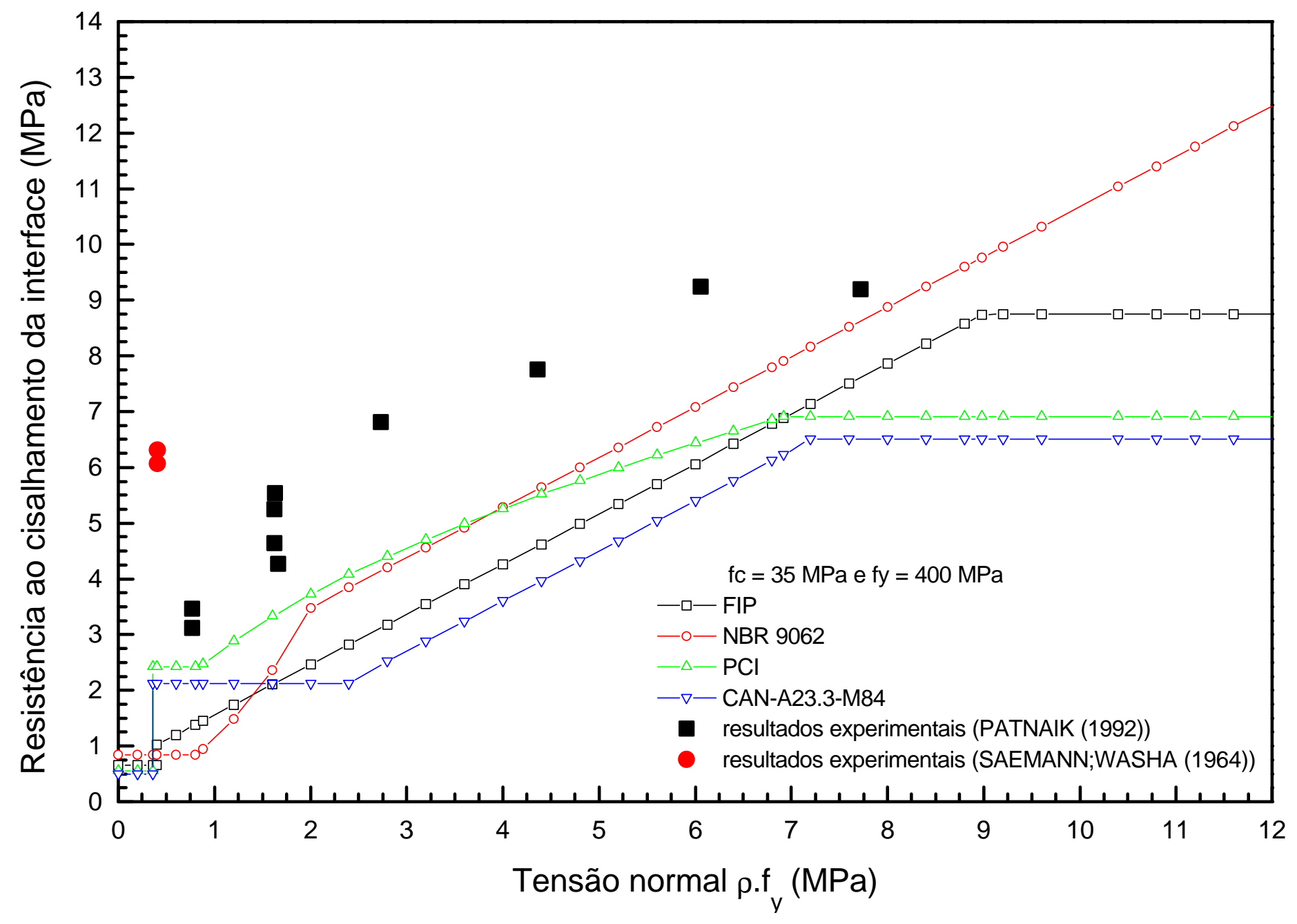

Figura 3.8 - Comparação entre os procedimentos. (continua) 


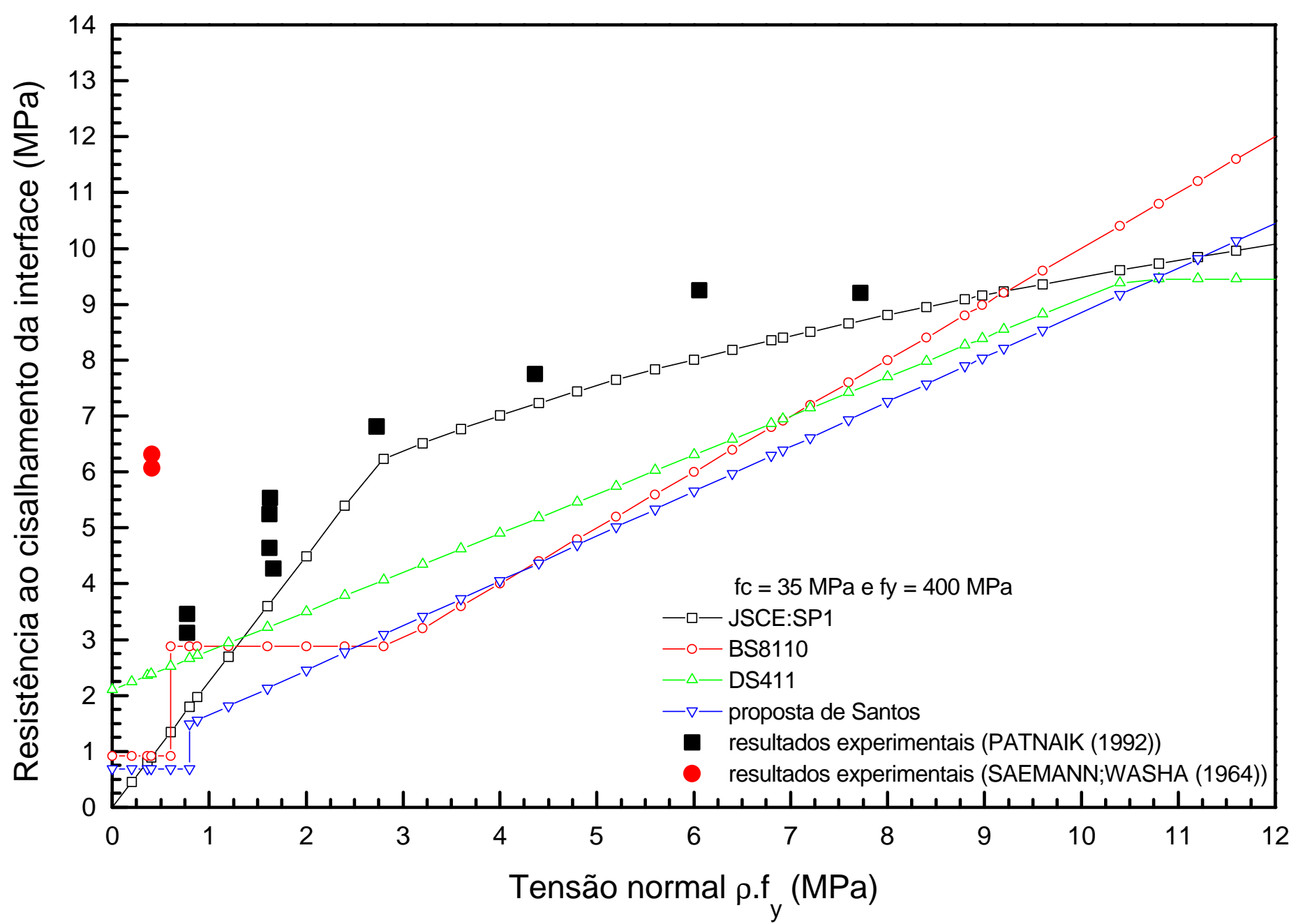

Figura 3.8 - Comparação entre os procedimentos. (continuação) 


\subsection{Disposições construtivas e recomendações para projeto}

São apresentadas a seguir algumas disposições construtivas para a execução de vigas e lajes compostas.

a) Preparação da superfície de contato

A superfície do elemento pré-moldado deve estar limpa e úmida no momento da nova concretagem. A superfície deve ser, de preferência, rugosa para aumentar a resistência ao cisalhamento. Existem diferentes maneiras de obter uma superfície rugosa. Patnaik fazia uma rápida vibração na concretagem dos últimos 5 $\mathrm{cm}$ da peça pré-moldada. Ele descrevia a superfície obtida como uma superfície bem compactada sem a intenção de torná-la lisa ou dar-Ihe qualquer textura, sendo a rugosidade formada por agregados graúdos salientes e perfeitamente fixados na peça e com superfície de contato limpa e livre de partículas soltas (PATNAIK (1992)).

A definição de uma superfície como rugosa é feita de diferentes maneiras. $\mathrm{O} \mathrm{PCl}$ define uma superfície como rugosa quando ela possui profundidades com valores mínimo de 0,6 cm; a NBR-9062 define profundidades de $0,5 \mathrm{~cm}$ a cada 3 cm nas duas direções do plano da interface; a FIP define diferentes níveis de rugosidade dos quais depende a avaliação da resistência. Estes níveis, em ordem crescente de rugosidade, são:

nível 1: superfície bastante lisa, obtida com o uso de fôrmas metálicas ou de madeira plastificada.

nível 2: superfície que foi alisada, chegando a níveis bastante próximos aos dos casos do nível 1.

nível 3: superfície que foi alisada (trazendo os finos do agregado à superfície), mas que ainda apresenta pequenas ondulações.

nível 4: superfície que foi executada com fôrmas deslizantes ou régua vibratória.

nível 5: superfície produzida por alguma forma de extrusão. 
nível 6: superfície que foi deliberadamente texturizada pelo escovamento do concreto ainda fresco.

nível 7: como em 6, com maior pronunciamento da texturização (por exemplo, o uso de tela de metal expandido presa à superfície da forma).

nível 8: superfície em que o concreto foi perfeitamente vibrado, sem a intenção de se fazer a superfície lisa, ou fazendo que os agregados graúdos fiquem expostos.

nível 9: superfície em que o concreto ainda fresco foi jateado (com água ou areia), para expor os agregados graúdos.

nível 10: superfície propositadamente rugosa

Os níveis 1 e 2 são de ocorrência esporádica. Os níveis de 3 a 6 são os mais freqüentes. Existem níveis que podem ter eficiência semelhante, como, por exemplo, os níveis 7 e 9 . Estes níveis de rugosidade são utilizados pela FIP para avaliação da resistência da interface. Ela divide as superfícies em duas categorias: categoria 1, ou seja, superfícies obtidas naturalmente durante a produção das peças pré-moldadas (níveis de 1 a 6 ) e categoria 2, ou seja, superfícies onde a rugosidade foi feita deliberadamente (níveis de 7 a 10).

A rugosidade da superfície na interface tem sido considerada como o fator principal para garantir a transferência de esforços de cisalhamento. Entretanto, trabalhos experimentais mostraram que o tratamento da interface, envolvendo aspectos como limpeza, grau de compactação do concreto e tipo de cura são tão importantes quanto a consideração da rugosidade superficial. Por esta razão, devese dar grande atenção ao tratamento da interface e ao trabalho de concretagem das capas.

b) Armadura transversal

As peças fletidas podem ser divididas em dois grupos: peças com pequena largura de interface, normalmente vigas, e peças com grande largura de interface, normalmente lajes. Via de regra, apenas as vigas necessitam de armadura transversal à interface. Esta armadura normalmente é formada por estribos que estendem-se da peça pré-moldada até o concreto moldado no local, devendo-se, 
sempre que possível, levá-las até à face superior da peça. SOLAS (1988) concluiu que levando o estribo até a face superior do concreto moldado no local eles são $35 \%$ mais resistentes a esforços horizontais que os estribos terminando muito próximos à interface (figura 3.9). Os estribos devem ser colocados de forma que seu plano seja ortogonal à direção dos esforços de cisalhamento.

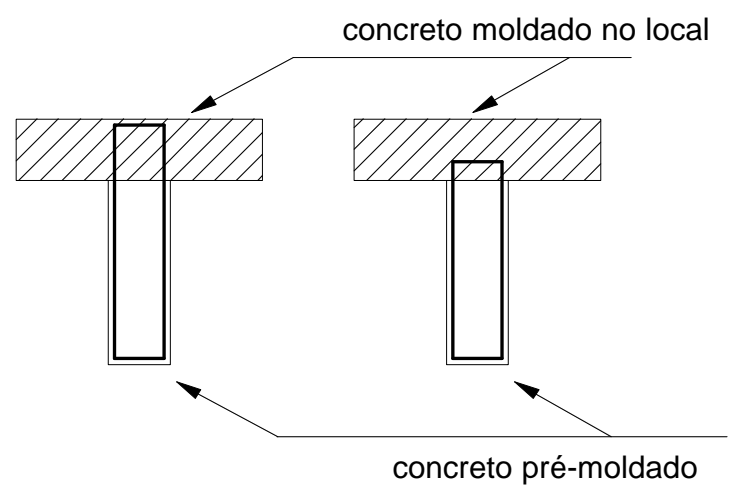

(a) estribo ancorado próximo à face superior do concreto moldado no local (b) estribo ancorado próximo à interface

Figura 3.9 - Ancoragem de estribos em vigas compostas

Em alguns casos a espessura do concreto moldado no local é muito pequena (figura 3.10). MATTOCK (1987) ensaiou estribos em forma de laço ou gancho (figura 3.11) e sugeriu algumas recomendações para o detalhamento da armadura:

- A espessura mínima da camada de concreto moldado no local para a utilização de estribos de $10 \mathrm{~mm}, 12,5 \mathrm{~mm}$ e $16 \mathrm{~mm}$ são $7,5 \mathrm{~cm}, 9,0 \mathrm{~cm}$ e $10,5 \mathrm{~cm}$ respectivamente, desde que o cobrimento da armadura no topo da camada seja de $2 \mathrm{~cm}$. Para cobrimentos maiores, a quantidade que exceder $2 \mathrm{~cm}$ deverá ser somada à espessura mínima. O concreto moldado no local deve ter $\mathrm{f}_{\mathrm{c}} \geq 20,6 \mathrm{MPa}$.

- Tanto estribos em forma de gancho quanto em forma de laço podem ser utilizados. Entretanto o laço apresenta melhor desempenho quando a ruptura ocorre pelo deslizamento entre a armadura e o concreto moldado no 
local. A ancoragem dos estribos na peça pré-moldada pode ser normal à interface ou paralela a ela, desde que o comprimento de ancoragem seja contado à partir de $12,5 \mathrm{~cm}$ da interface e seja utilizado estribos com diâmetro máximo de $16 \mathrm{~mm}$.

- Estas recomendações são válidas quando a interface está tanto na região comprimida da seção transversal quanto na região tracionada.

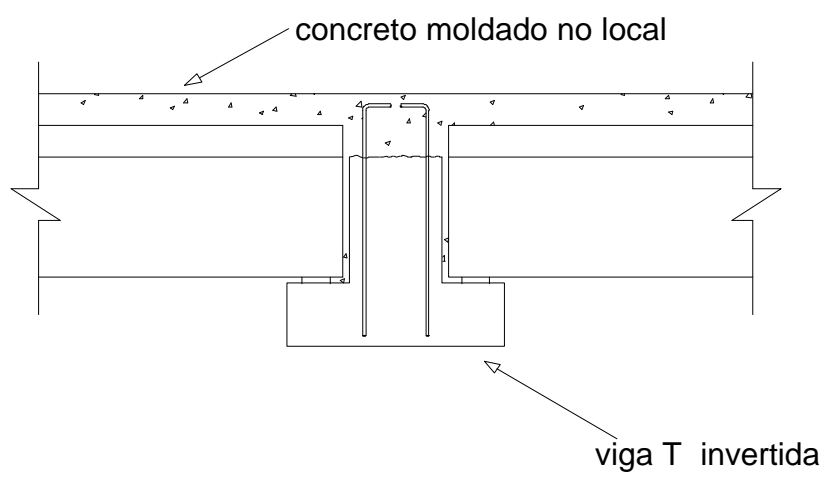

Figura 3.10 - Viga T invertida com pequena espessura da camada de concreto moldado no local (MATTOCK (1987))

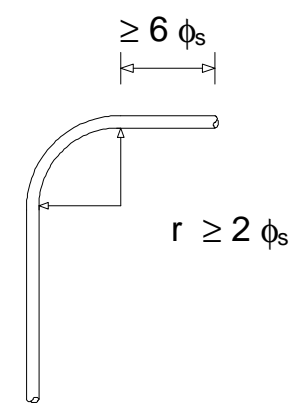

(a) gancho a $90^{\circ}$

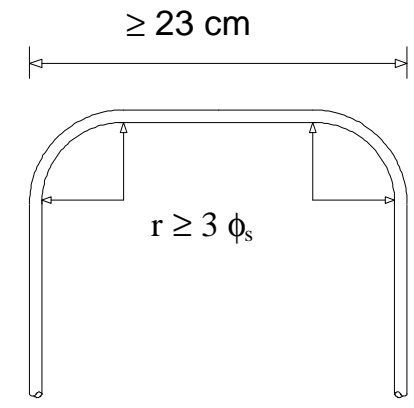

(b) laço

Figura 3.11 - Dimensões mínimas de estribos (ACI 318-89)

c) Capa de concreto

Denomina-se capa de concreto a camada de concreto moldado no local sobre uma peça pré-moldada. Normalmente é usada para designar a camada de 
concreto colocada sobre lajes pré-moldadas. Por esta razão, na maioria dos casos não possui armadura transversal. Entretanto, os cuidados dispensados para a execução da capa de concreto em lajes também devem ser seguidos para a execução de vigas compostas (FIP (1982)).

- espessura da capa

A espessura da capa de concreto deverá ser, em média, superior a $50 \mathrm{~mm}$, admitindo-se valores mínimos, em pontos localizados, de $30 \mathrm{~mm}$. Para capas com espessura inferior a $80 \mathrm{~mm}$ cuidados especiais devem ser tomados com o desvio de medidas, a perda de água excessiva e, quando existir armadura de costura, com a ancoragem das barras dessa armadura.

SERNA ROS, et al. (1994) realizaram ensaios em lajes alveolares com capa de concreto (figura 3.12). Eles sugeriram que neste tipo de laje composta seja moldada uma capa de concreto com espessura mínima de $40 \mathrm{~mm}$. Quando a interface é rugosa a força de ruptura das lajes foi $50 \%$ superior à das lajes alveolares sem a capa de concreto. Contudo, se a superfície de contato não era rugosa ou se a concretagem da capa de concreto não era executada com cuidado, o aumento de resistência devido à presença da capa era muito pequeno. Outra observação dos autores foi que a orientação da rugosidade (transversal ou longitudinal) e sua profundidade não influenciaram na resistência à ruptura da laje composta. Contudo, o aumento na profundidade das rugosidades diminuiu os deslocamentos verticais da laje para os estados limites de utilização. A presença de armadura em malha na capa de concreto possibilitou a transferência de esforços entre as lajes alveolares no estado limite de utilização garantindo, assim, o comportamento como laje monolítica destas lajes compostas.

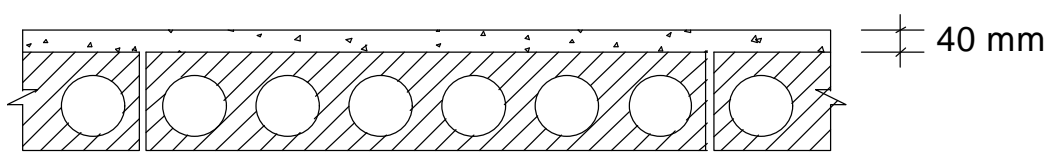

Figura 3.12 - laje alveolar pré-moldada com capa de concreto 
- execução da capa

1) limpeza: a interface deverá ser cuidadosamente inspecionada quanto à presença de pó, areia, terra, óleo e outras substâncias que possam prejudicar a adesão.

2) umedecimento da interface: em climas secos é recomendável o umedecimento da interface antes da concretagem da capa, o qual poderá estender-se por 1 dia para elementos pré-moldados com espessura inferior a $150 \mathrm{~mm}$. Para elementos com espessura superior a $150 \mathrm{~mm}$, o tratamento deve ser mais prolongado. É fundamental que a interface esteja isenta da presença de água livre na superfície no instante da concretagem. A presença de água superficial na interface, nessa ocasião, pode acarretar perdas de até $50 \%$ na resistência.

3) pré-tratamento da interface com graute: é um tratamento pouco recomendado pois nem sempre é executado corretamente. O graute deve ter traço 1:1 ou 1:2 e uma relação água-cimento inferior à utilizada no concreto da capa. Deve ser evitado em estruturas compostas com a interface armada.

- qualidade do concreto

O concreto da capa deverá ser dosado para se ter pouca retração. A consistência deve ser compatível com os equipamentos utilizados no transporte e vibração do concreto. O diâmetro máximo do agregado deverá ser no máximo igual a 1/3 da espessura da capa.

- cura da capa

Em climas secos, quentes ou com presença acentuada de ventos, a capa deve ser protegida (lonas, pequena camada de água ou areia, estopa úmida,. etc.) após a concretagem. A cura deve iniciar-se tão logo seja possível, dependendo do método empregado e deve prolongar-se até que o concreto atinja $50 \%$ da resistência de projeto. Para ambientes com temperatura média superior a $10^{\circ} \mathrm{C}$, a cura deve estender-se até 3 dias após a concretagem.

A necessidade de uma cura cuidadosa é devido ao fato que a retração diferencial entre os concretos de idades diferentes, bem como a fluência e a 
temperatura, podem causar tensões de cisalhamento e de tração na interface produzindo danos à capa.

- armadura de distribuição

Nas lajes compostas formadas por nervuras pré-moldadas e blocos vazados é recomendável o emprego de armadura de distribuição na capa de concreto. Esta armadura contribui na distribuição dos esforços entre as nervuras evitando a fissuração da face inferior da laje, distribui as fissuras devido à retração da capa, proporciona resistência aos esforços horizontais aplicados ao longo do plano da laje e garante a ligação entre a laje e o restante da estrutura.

Segundo a norma espanhola EF-88 (1988) esta armadura deve ser colocada em ambas as direções e possuir diâmetro mínimo de $4 \mathrm{~mm}$, sendo 0 espaçamento máximo entre as barras inferior a $30 \mathrm{~cm}$ na direção perpendicular às nervuras e $50 \mathrm{~cm}$ na direção paralela à nervuras. A quantidade de armadura deve ser superior a:

- direção perpendicular às nervuras:

$A_{s} \geq \frac{5000 \cdot e_{0}}{f_{y d}}\left(\mathrm{~cm}^{2}\right)$

- direção paralela às nervuras

$A_{s} \geq \frac{2500 \cdot e_{0}}{f_{y d}}\left(\mathrm{~cm}^{2}\right)$

$\mathrm{e}_{0}$ : espessura mínima da capa de concreto sobre os blocos $\operatorname{vazados}(m)$;

$\mathrm{f}_{\mathrm{yd}}$ : resistência de escoamento de cálculo do aço (MPa).

d) armadura de retração

A retração diferencial entre o concreto pré-moldado e o concreto moldado no local introduz tensões de cisalhamento na interface. Essas tensões normalmente possuem baixos valores podendo ser desprezadas. Entretanto, nas extremidades de elementos planos e lineares como, por exemplo, vigas compostas, 
essas tensões podem assumir elevados valores e provocar a fissuração da capa de concreto moldado no local. Nas peças que possuem armadura transversal à interface é possível colocar armadura suplementar nas extremidades de forma a resistir os esforços devido à retração diferencial, enquanto nas peças sem armadura transversal os esforços são resistidos pela aderência entre as duas superfícies de concreto.

A norma italiana CNR-10025 (1984) recomenda que nas extremidades de vigas compostas sejam colocadas armaduras para resistir à retração diferencial entre a viga de concreto pré-moldado e a laje de concreto moldado no local (figura 3.13). A força solicitante na extremidade do elemento vale:

$$
F_{s d}=\frac{\varepsilon_{c s}}{\frac{1}{E_{c v} \cdot A_{c v}}+\frac{e_{1}{ }^{2}}{E_{c v} \cdot I_{c v}}+\frac{1}{E_{c m} \cdot A_{c m}}}
$$

$\varepsilon_{\mathrm{cs}}:$ deformação diferencial entre os dois concretos devido à retração;

$\mathrm{E}_{\mathrm{cv}}, \mathrm{E}_{\mathrm{cm}}$ : módulo de elasticidade da viga pré-moldada e da mesa moldada no local, respectivamente;

$A_{c v}, A_{c m}$ : área da seção transversal da viga pré-moldada e da mesa moldada no local, respectivamente;

$I_{c v}:$ momento de inércia da viga pré-moldada em relação ao seu centróide;

$e_{1}$ : distância da interface ao centróide da viga pré-moldada;

A resistência de cálculo das armaduras podem ser avaliadas por:

$$
\begin{aligned}
& F_{r s n d}=c \cdot A_{s n} \sqrt{f_{c d} \cdot f_{y d}} \\
& F_{r s p d}=A_{s p} \cdot \cos \alpha_{m} \cdot f_{y d}
\end{aligned}
$$

sendo $c=1$ na ausência de determinação experimental e $\alpha_{m}$ o ângulo médio das armaduras de distribuição com o eixo da viga. 


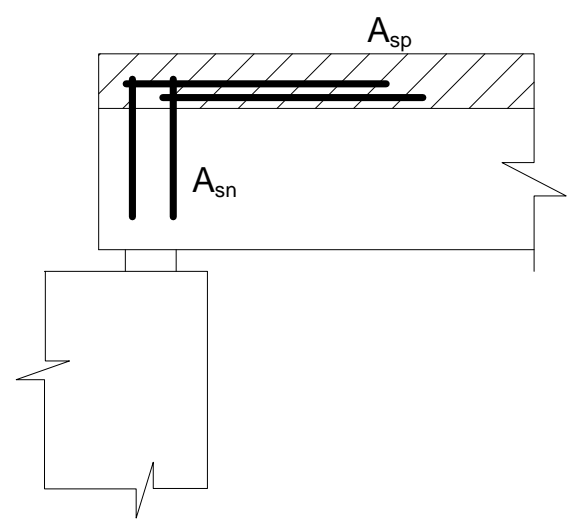

(a) elevação

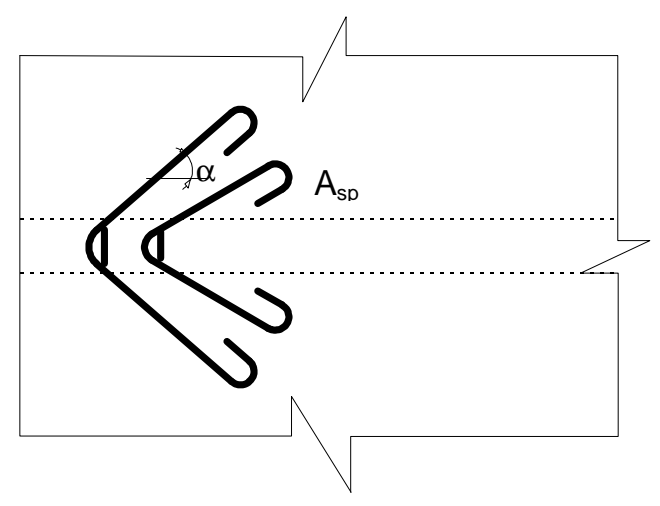

Figura 3.13 - Detalhe da armadura de retração em vigas compostas (CNR-10025 (1984)).

A FIP(1992) recomenda que a quantidade de armadura transversal à interface nas extremidades de vigas compostas seja aumentada para também resistir à retração diferencial. A força solicitante nas extremidades é avaliada por:

$$
F_{s d}=\varepsilon_{c s} \cdot E_{c m} \cdot A_{c m} \cdot\left[\frac{A_{c v}}{A_{c c}}-d_{1} \cdot \frac{S_{c c}}{I_{c c}}\right]
$$

$\mathrm{A}_{c c}$ :área da seção transversal da viga composta;

$\mathrm{S}_{\mathrm{cc}}$ :momento estático da mesa moldada no local em relação ao centróide da viga composta;

$\mathrm{I}_{\mathrm{cc}}$ :momento de inércia da seção composta;

$\mathrm{d}_{1}$ :distância do centróide da mesa ao centróide da seção composta.

Como a retração diferencial é um processo que ocorre ao longo do tempo, a FIP recomenda que a força solicitante seja reduzida multiplicando-a pelo coeficiente $\eta$ : 


$$
\eta=\frac{1-\mathrm{e}^{-\varphi}}{\varphi}
$$

onde $\varphi$ é o coeficiente de deformação lenta do concreto moldado no local.

A quantidade de armadura a ser acrescentada nas extremidades da viga é avaliada por:

$$
A_{s w}=\frac{\eta \cdot F_{s d}-\beta_{2} \cdot f_{t d} \cdot A_{i, e x t}}{f_{y d} \cdot \beta_{1}}
$$

onde $\beta_{1}, \beta_{2}$ e $f_{\text {td }}$ são valore obtidos da recomendação da FIP e $A_{i, e x t}$ é a área da interface na extremidade da viga onde a tensão de cisalhamento, devido à retração diferencial, está distribuída (figura 3.14).

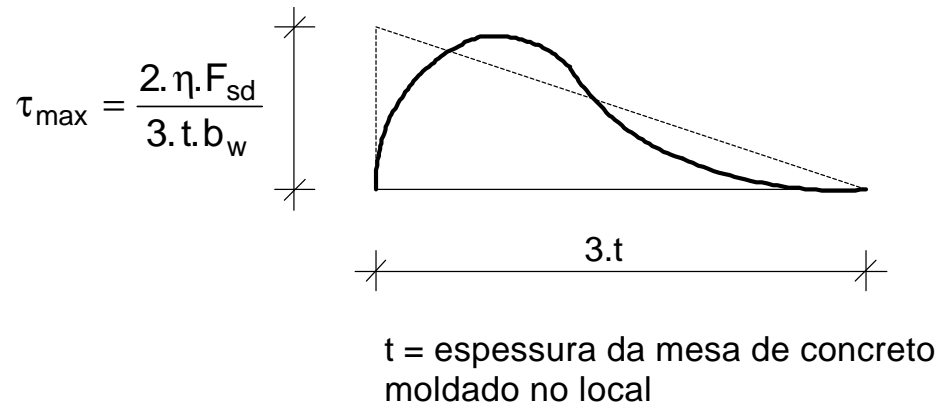

Figura 3.14 - Região de distribuição das tensões de cisalhamento devido à retração diferencial na extremidade dos vãos (FIP (1982)).

Os valores da força solicitante devido à retração fornecidos pela FIP e pela norma italiana são semelhantes. Entretanto, a norma italiana é muito conservadora na avaliação da resistência das armaduras. O procedimento indicado pela FIP é melhor elaborado pois considera a deformação lenta e a contribuição da aderência entre as superfícies de concreto na resistência ao deslizamento sendo, portanto, mais adequado para aplicação em projetos. 


\section{Análise numérica e comparação com resultados experimentais}

Neste capítulo, os modelos analíticos e empíricos estudados no capítulo 2 são empregados na avaliação da resistência da interface de vigas compostas com o objetivo de verificar os que melhor representam os resultados experimentais. São apresentados também os resultados de ensaios "push-out" realizados no Laboratório de Estruturas da EESC para verificar a capacidade de transferência de esforços de cisalhamento de conectores utilizados na ligação entre peças prémoldadas.

\subsection{Ensaios em vigas compostas}

\subsubsection{Análise por modelos analíticos}

Os modelos analíticos apresentados no capítulo 2 foram formulados para descrever o comportamento da ligação entre duas superfícies de concreto atravessadas por armadura. Alguns modelos são baseados na transferência de esforços por atrito entre as superfícies em contato e pela ação de pino da armadura, enquanto outros são baseados na teoria de bielas e tirantes. A tensão normal à interface, necessária para garantir a transferência por atrito, é garantida pela armadura transversal.

No capítulo 2 foram apresentados três modelos, contudo, apenas o modelo de Tassios \& Vintzeleou, uma simplificação do modelo de Tsoukantas \& Tassios, e o modelo de Hsu; Mau \& Chen são analisados neste capítulo. Estes modelos foram aplicados às vigas compostas ensaiadas por Patnaik (PATNAIK (1992)) de forma a obter a resistência da interface aos esforços de cisalhamento horizontal. 
O modelo de Tassios \& Vintzeleou fornece a resistência ao cisalhamento da interface em função do deslizamento relativo entre a mesa e a alma. Variando o deslizamento é possível traçar um gráfico relacionando a resistência ao cisalhamento com o deslizamento da interface, conforme ilustrado na figura 4.1 para as vigas ensaiadas por Patnaik. As principais características dessas vigas foram mostradas na tabela 2.1 .

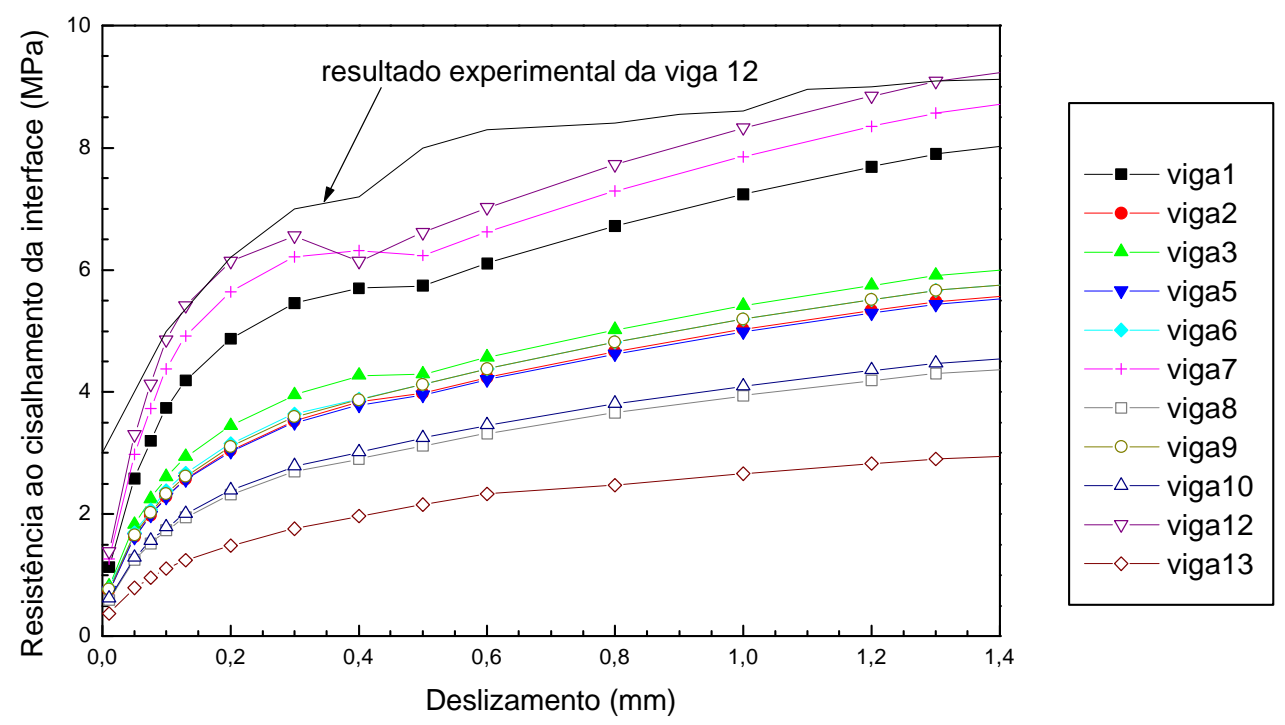

Figura 4.1 - Aplicação do modelo de Tassios e Vintzeleou às vigas ensaiadas por Patnaik.

Observa-se que as vigas com maior taxa de armadura possuem maior resistência ao cisalhamento, sendo possível identificar o valor do deslizamento para o qual a armadura atinge a resistência de escoamento, pois ele é caracterizado por uma redução na resistência. Essa redução ocorre porque quando a armadura atinge a resistência de escoamento ela não mais contribui com a resistência por ação de pino. Nas vigas com baixa taxa de armadura não ocorre essa redução, uma vez que a parcela de resistência por ação de pino da armadura pouco contribui na resistência final da viga. A resistência da interface, segundo o modelo, 
poderia ser obtida no momento em que toda a armadura atingisse a resistência de escoamento. Contudo, como nas vigas compostas há uma redistribuição de esforços para as regiões menos solicitadas e o modelo não apresenta um limite máximo para a tensão de cisalhamento, mas apenas para o deslizamento da interface, prosseguiu-se com o incremento nos deslizamentos, adotando a tensão normal à interface constante e sem contribuição do efeito de pino da armadura, até o máximo deslizamento de 1,4 mm. Em outras palavras, a resistência da interface foi calculada pela eq.(2.13) considerando que toda a armadura tenha atingido a resistência de escoamento.

Para aplicar-se o modelo de Hsu; Mau; Chen às vigas ensaiadas por Patnaik utilizou-se o procedimento iterativo apresentado no capítulo 2. Nestas vigas foi definida uma região crítica distante $7,5 \mathrm{~cm}$ acima e abaixo da interface. Dessa forma, nas vigas com largura da alma uniforme a seção critica era de $15 \mathrm{~cm} \times 15$ $\mathrm{cm}$ e nas vigas com largura da alma reduzida era de $7,5 \mathrm{~cm} \times 15 \mathrm{~cm}$. A taxa de armadura longitudinal foi obtida dividindo-se a área das barras de aço longitudinais contidas nesta região pela área da região crítica. $\mathrm{O}$ coeficiente $\mathrm{K}$, que representa a relação entre o comprimento da viga e sua altura, foi tomado igual à unidade, seguindo recomendação dos autores de que o valor deste coeficiente tem pouca influência na resistência final. Tal fato foi observado quando calculou-se a resistência de uma viga variando o coeficiente $\mathrm{K}$ e obteve-se pequena variação na resistência da viga ao cisalhamento horizontal. Algumas vigas foram calculadas desprezando a contribuição da armadura longitudinal $\left(\rho_{y}=0\right)$ e seus resultados comparados com as mesmas vigas calculadas com $\rho_{y} \neq 0$. Observou-se uma redução na resistência ao cisalhamento da interface, o que mostra a importância da armadura longitudinal no mecanismo de transferência dos esforços de cisalhamento desse modelo.

Os resultados obtidos pela aplicação dos modelos analíticos às vigas de Patnaik estão indicados na tabela 4.1 e a comparação destes com a resistência última ao cisalhamento obtida dos ensaios está mostrada na figura 4.2. 
Tabela 4.1 - Aplicação dos modelos analíticos às vigas de Patnaik.

\begin{tabular}{|c|c|c|c|c|c|c|c|}
\hline viga & $\begin{array}{c}\mathrm{f}_{\mathrm{c}} \\
(\mathrm{MPa})\end{array}$ & $\begin{array}{c}\rho . f_{y} \\
(\mathrm{MPa})\end{array}$ & $\begin{array}{c}\tau_{\text {ensaio }} \\
(\mathrm{MPa})\end{array}$ & $\begin{array}{c}\tau_{1} \\
\text { Tassios; } \\
\text { Vintzeleou } \\
\text { (MPa) }\end{array}$ & $\begin{array}{c}\tau_{2} \\
\text { Hsu et al. } \\
\text { (MPa) }\end{array}$ & $\begin{array}{c}\frac{\tau_{1}}{\tau_{\text {ensaio }}} \\
(\mathrm{MPa})\end{array}$ & $\begin{array}{c}\tau_{2} \\
\tau_{\text {ensaio }} \\
(\mathrm{MPa})\end{array}$ \\
\hline 1 & 37.4 & 4.36 & 7.76 & 8.02 & 7.40 & 1.03 & 0.95 \\
\hline 2 & 34.9 & 1.66 & 4.27 & 5.57 & 4.35 & 1.30 & 1.02 \\
\hline 3 & 30.5 & 2.73 & 6.82 & 6.00 & 5.39 & 0.88 & 0.79 \\
\hline 5 & 34.8 & 1.63 & 5.54 & 5.52 & 4.31 & 1.00 & 0.78 \\
\hline 6 & 37.1 & 1.62 & 5.25 & 5.76 & 4.33 & 1.10 & 0.82 \\
\hline 7 & 35.8 & 6.06 & 9.25 & 8.71 & 8.87 & 0.94 & 0.96 \\
\hline 8 & 35.6 & 0.77 & 3.12 & 4.37 & 3.14 & 1.40 & 1.01 \\
\hline 9 & 37.1 & 1.62 & 4.64 & 5.76 & 4.34 & 1.24 & 0.94 \\
\hline 10 & 37.6 & 0.77 & 3.46 & 4.54 & 3.20 & 1.31 & 0.92 \\
\hline 12 & 34.6 & 7.72 & 9.20 & 9.23 & 9.59 & 1.00 & 1.04 \\
\hline 13 & 19.2 & 0.82 & 2.92 & 2.95 & 2.68 & 1.01 & 0.92 \\
\hline \multicolumn{6}{|c|}{ média (m) } & 1.11 & 0.92 \\
\hline \multicolumn{6}{|c|}{ desvio padrão (s) } & 0.174 & 0.090 \\
\hline
\end{tabular}



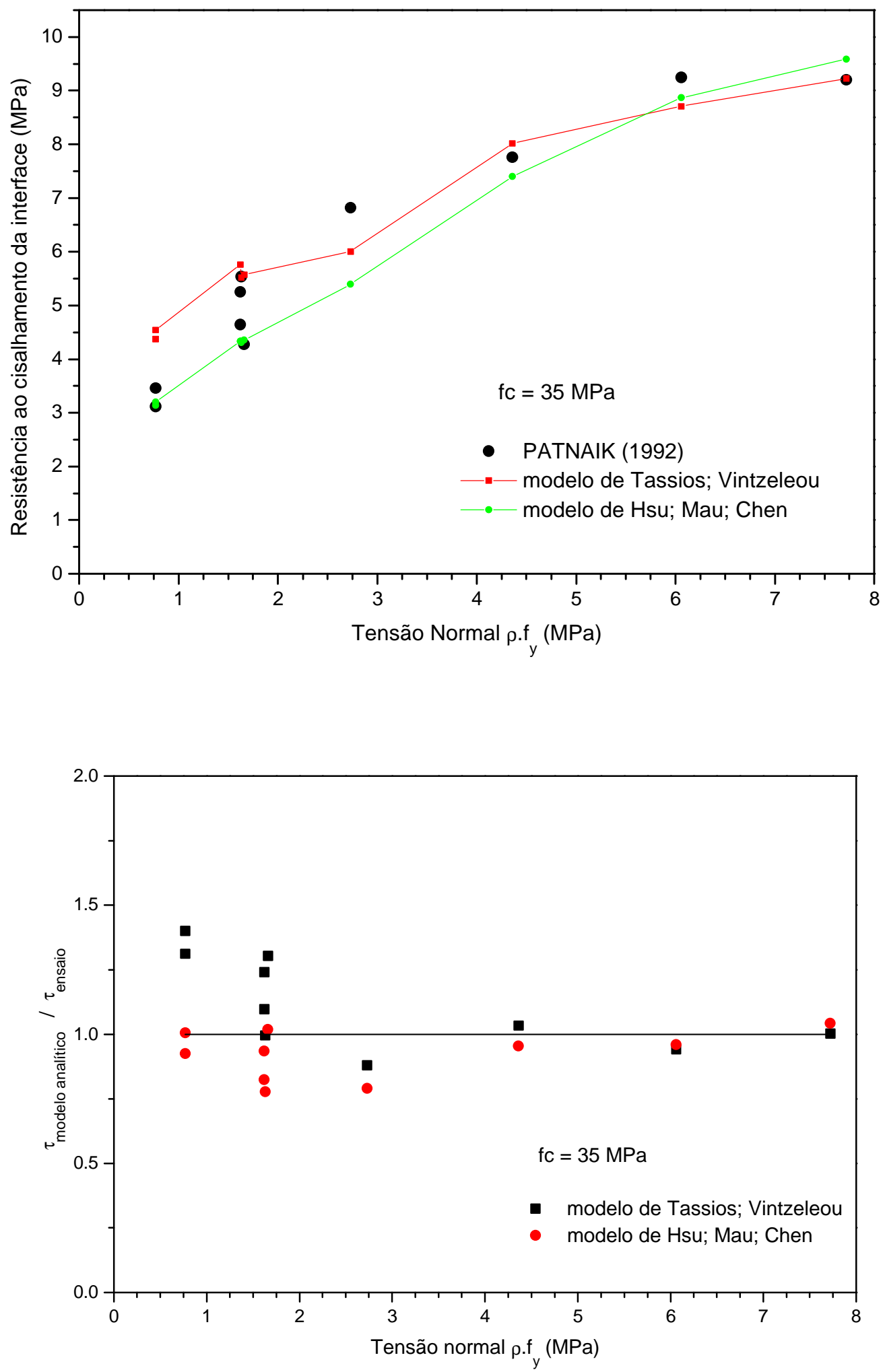

Figura 4.2 - Comparação entre os modelos analíticos e os resultados dos ensaios de Patnaik. 
Dos gráficos apresentados observa-se que há uma boa aproximação entre os resultados fornecidos pelos modelos analíticos e os resultados dos ensaios. Contudo, há uma maior divergência para baixos valores de tensão normal (ou baixa taxa de armadura), o que pode ser explicado pelo fato dos modelos não incluírem em suas expressões uma parcela de resistência devido à aderência, a qual é mais importante em baixas taxas de armadura do que em altas taxas de armadura.

Os deslizamentos relativos das vigas previstos pelo modelo de Tassios e Vintzeleou não estão de acordo com os resultados obtidos dos ensaios. Entretanto, o modelo mostrou que a armadura atinge a resistência de escoamento quando o deslizamento está próximo de $0,5 \mathrm{~mm}$. Nesse ponto a resistência fornecida pelo modelo é inferior à dos ensaios, contudo, calculando a resistência correspondente ao deslizamento de 1,4 mm, obtém-se valores próximos aos obtidos por Patnaik na ruptura de vigas com interface rugosa.

Dessa forma, a resistência última das vigas ao cisalhamento horizontal fornecida pelo modelo de Tassios e Vintzeleou independe da história de carregamento e do valor final do deslizamento. Portanto, para utilização deste modelo na avaliação da resistência da interface de vigas compostas é suficiente calcular a tensão de cisalhamento pela eq.(2.13) adotando como tensão normal aquela correspondente à toda armadura transversal escoando. Para isso é importante utilizar concreto com resistência elevada de forma a permitir que a armadura transversal realmente alcance sua resistência de escoamento.

O modelo de Hsu; Mau e Chen parece ser mais adequado para o tipo de viga ensaiada por Patnaik do que o modelo de Tassios e Vintzeleou, uma vez que fornece valores mais próximos dos resultados obtidos dos ensaios. Entretanto, ele é de difícil aplicação e fornece valores menos conservadores que o modelo de Tassios e Vintzeleou para altas taxas de armadura.

Para altos valores de tensão normal à interface, ambos os modelos tendem a fornecer resultados superiores aos obtidos em ensaios, o que indica que a tensão normal nas vigas compostas com armadura de costura atravessando a interface e com $\mathrm{f}_{\mathrm{c}}=35 \mathrm{MPa}$ seja limitada em $8 \mathrm{MPa}$. 


\subsubsection{Análise por modelos empíricos}

No capítulo 2 foram apresentados diversos modelos empíricos encontrados na literatura para avaliação da transferência de esforços de cisalhamento através de interfaces de concreto. Esses modelos foram obtidos, na sua maioria, de ensaios de cisalhamento direto e alguns de ensaios em vigas. Neste capítulo eles são empregados na avaliação da resistência da interface das vigas ensaiadas por Patnaik e das vigas ensaiadas por outros autores.

A comparação entre os resultados dos ensaios e os fornecidos pelos modelos empíricos está ilustrada na figura 4.3, e na tabela 4.3 estão indicados os resultados dos modelos que apresentaram melhor aproximação com os ensaios. Para melhor compreensão, a tabela 4.2 indica os modelos empíricos que foram utilizados e a resistência do concreto das vigas ensaiadas.

Tabela 4.2 - Modelos empíricos utilizados na avaliação da resistência da interface de vigas compostas.

\begin{tabular}{|c|c|c|}
\hline Modelos empregados & $\begin{array}{c}\text { Resistência do } \\
\text { concreto das vigas } \\
\left(f_{c}\right) \text { em MPa }\end{array}$ & Figura \\
\hline $\begin{array}{c}\text { Hanson, } 1960 \text { - Saemann; Washa, } 1964 \text { - Birkeland; } \\
\text { Birkeland, } 1966 \text { - Birkeland, } 1968 \text { - Mattock, } 1974 \text { - Raths, } \\
1977 \text { - Loov, } 1978 \text { - Shaikh, } 1978 \text { - Vecchio; Collins, } 1986 \\
\text { - Walraven, et al., } 1987 \text { - Mattock, } 1988 \text { - Mau; Hsu, } 1988 \\
\text { - Tsoukantas; Tassios, } 1989 \text { - Tassios; Vintzeleou, - } 1990 \\
\text { - Patnaik, } 1992 \text { - Mattock, } 1994 .\end{array}$ & 20 & 4.3(a) \\
\hline $\begin{array}{c}\text { Hanson, } 1960 \text { - Saemann; Washa, } 1964 \text { - Birkeland; } \\
\text { Birkeland, } 1966 \text { - Birkeland, } 1968 \text { - Mattock, } 1974 \text { - Raths, } \\
1977 \text { - Loov, } 1978 \text { - Shaikh, } 1978 \text { - Vecchio; Collins, } 1986 \\
\text { - Walraven, et al., } 1987 \text { - Mattock, } 1988 \text { - Mau; Hsu, } 1988 \\
\text { - Tsoukantas; Tassios, } 1989 \text { - Tassios; Vintzeleou, - } 1990 \\
\text { - Patnaik, } 1992 \text { - Mattock, } 1994 .\end{array}$ & 25 & $4.3(b)$ \\
\hline $\begin{array}{c}\text { Hanson, } 1960 \text { - Saemann; Washa, } 1964 \text { - Birkeland; } \\
\text { Birkeland, } 1966 \text { - Birkeland, } 1968 \text { - Mattock, } 1974 \text { - Raths, } \\
1977 \text { - Loov, } 1978 \text { - Shaikh, } 1978 \text { - Vecchio; Collins, } 1986 \\
\text { - Walraven, et al., } 1987 \text { - Mattock, } 1988 \text { - Mau; Hsu, } 1988 \\
\text { - Tsoukantas; Tassios, } 1989 \text { - Tassios; Vintzeleou, - } 1990 \\
\text { - Patnaik, } 1992 \text { - Mattock, } 1994 .\end{array}$ & 35 & 4.3(c) \\
\hline
\end{tabular}



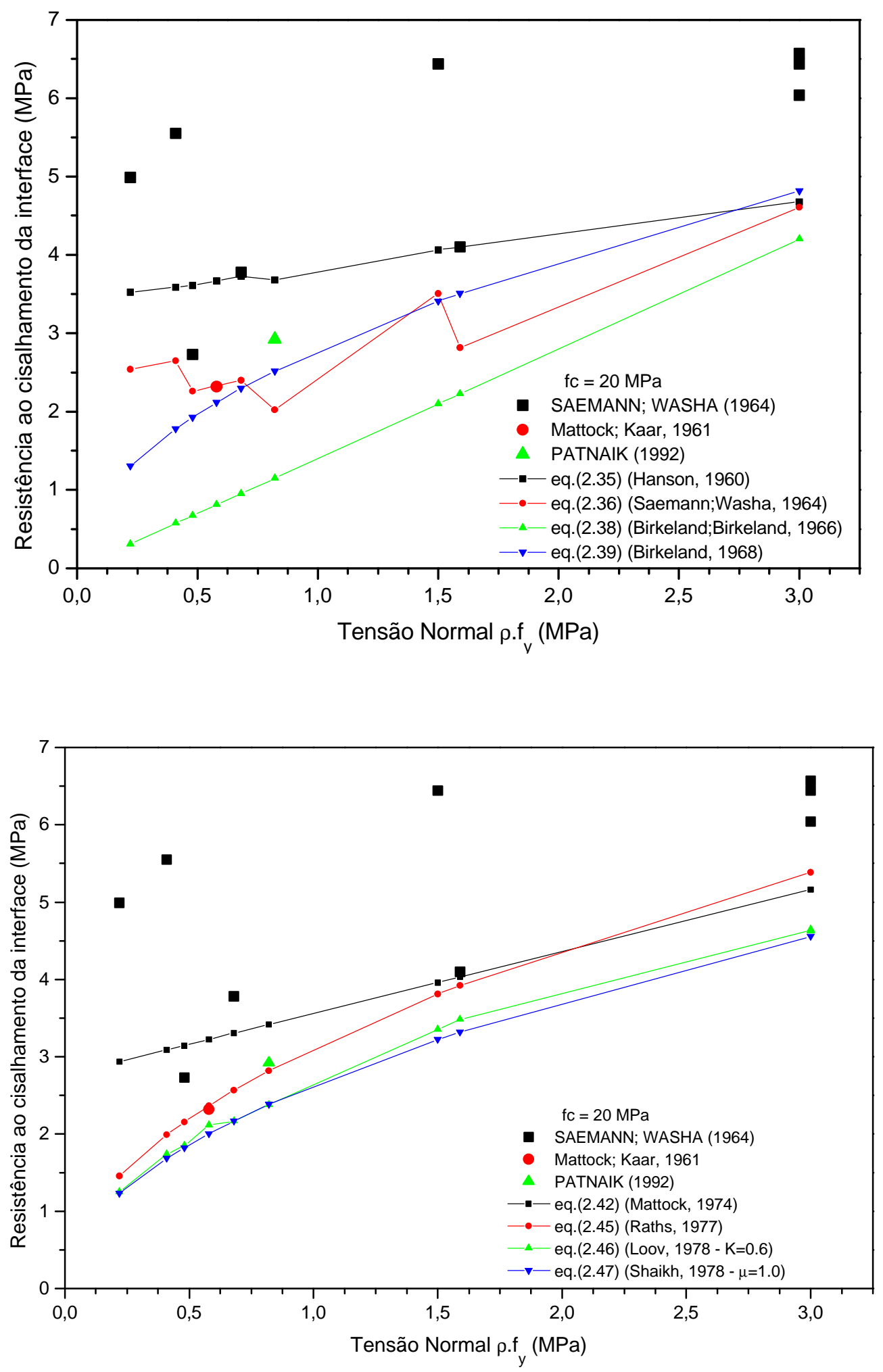

Figura 4.3(a) - Comparação entre os modelos empíricos e os resultados dos ensaios de Patnaik $\left(f_{c}=20 \mathrm{MPa}\right)$. - continua 

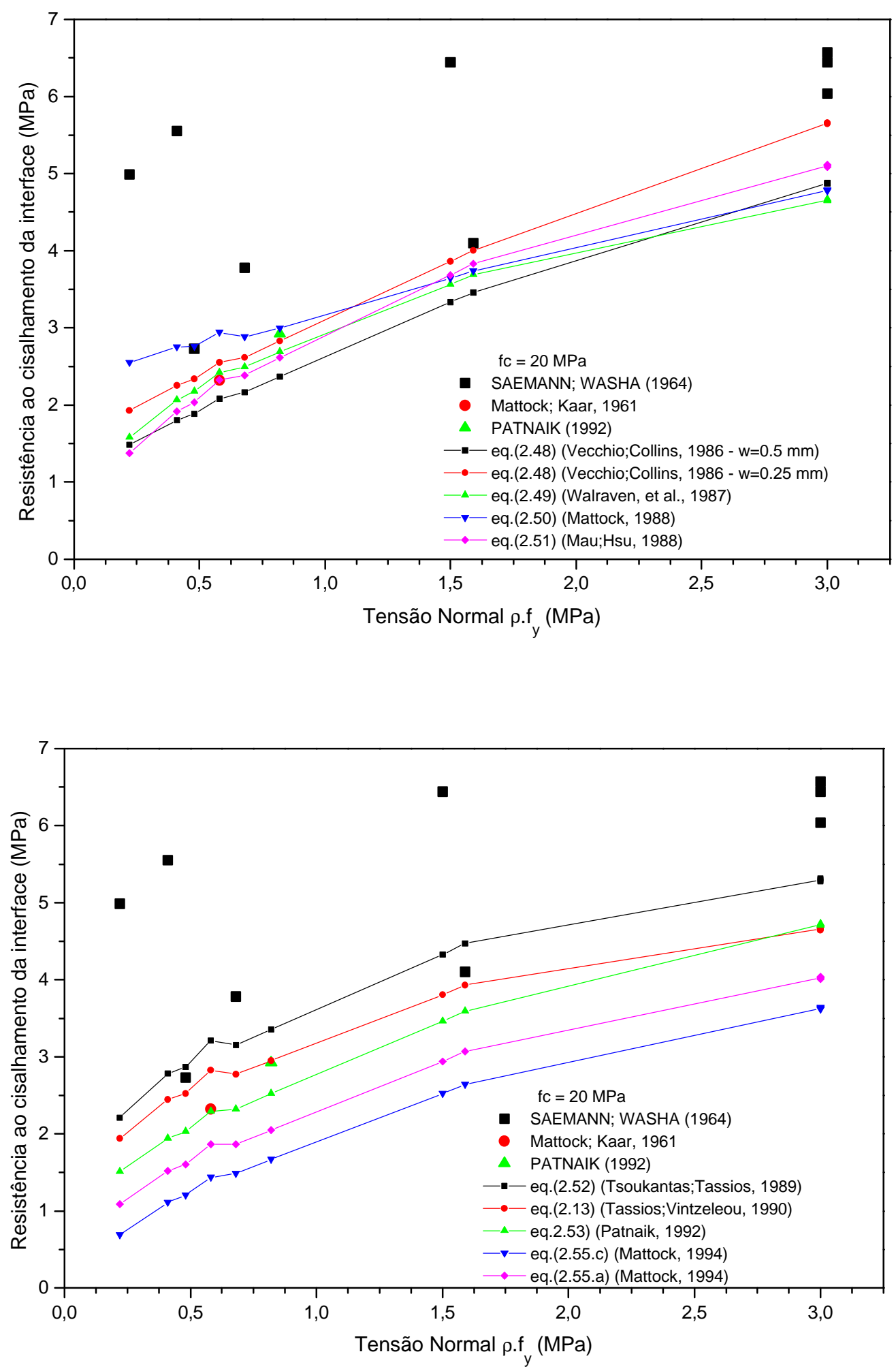

Figura 4.3(a) - Comparação entre os modelos empíricos e os resultados dos ensaios de Patnaik $\left(f_{c}=20 \mathrm{MPa}\right)$. - continuação 

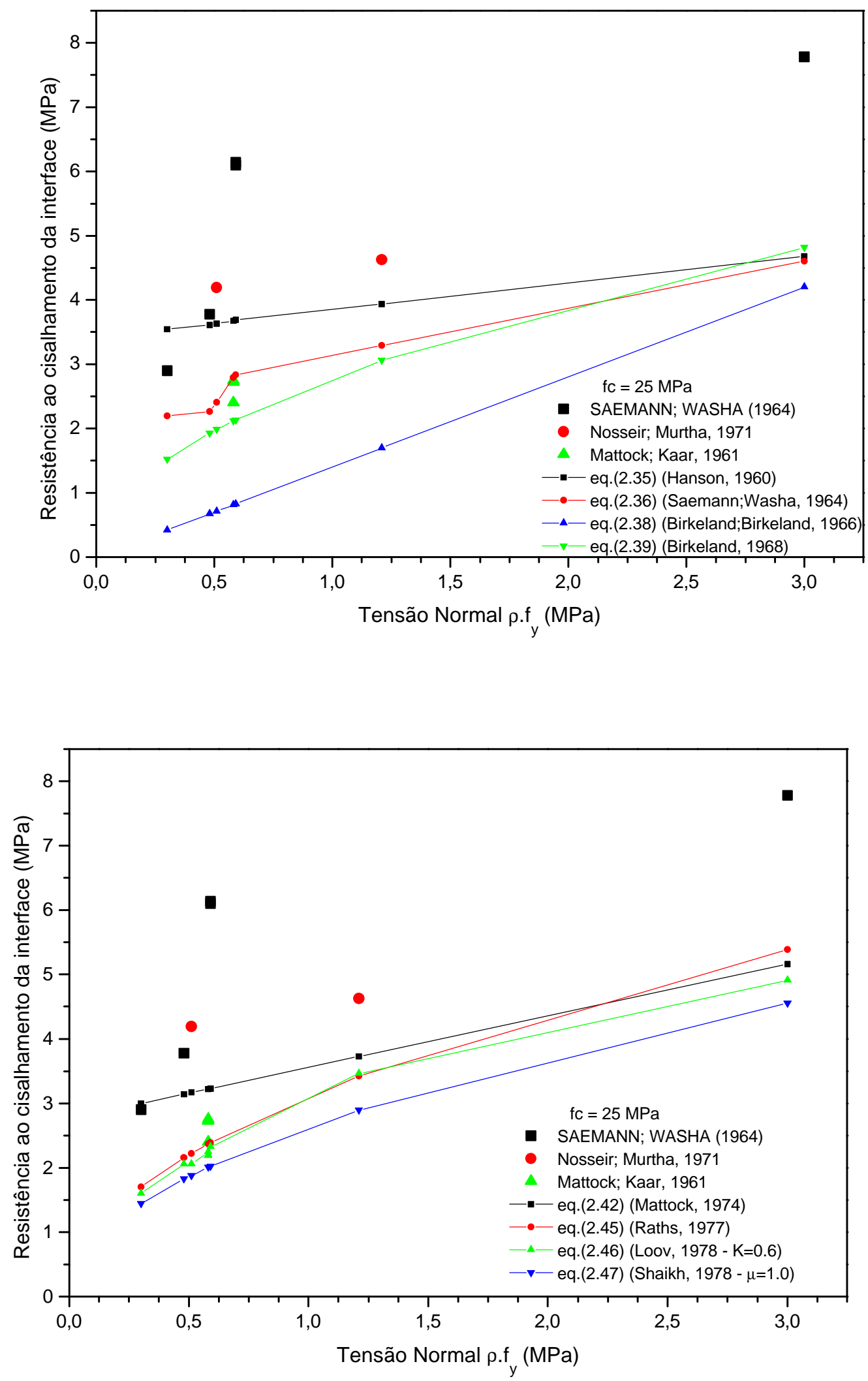

Figura 4.3(b) - Comparação entre os modelos empíricos e os resultados dos ensaios de Patnaik $\left(f_{c}=25 \mathrm{MPa}\right)$. - continua 

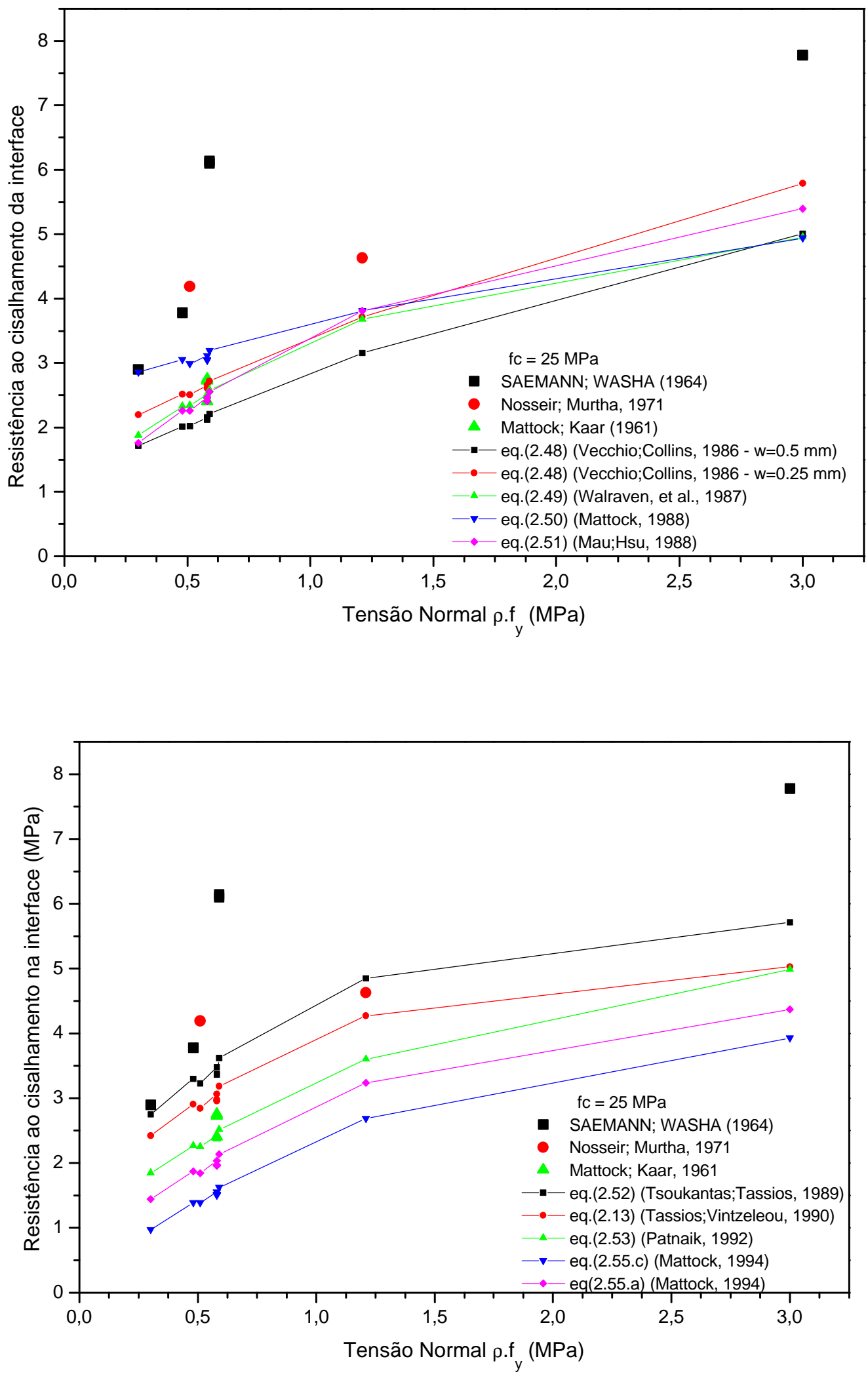

Figura 4.3(b) - Comparação entre os modelos empíricos e os resultados dos ensaios de Patnaik ( $\left.f_{c}=25 \mathrm{MPa}\right)$. - continuação 

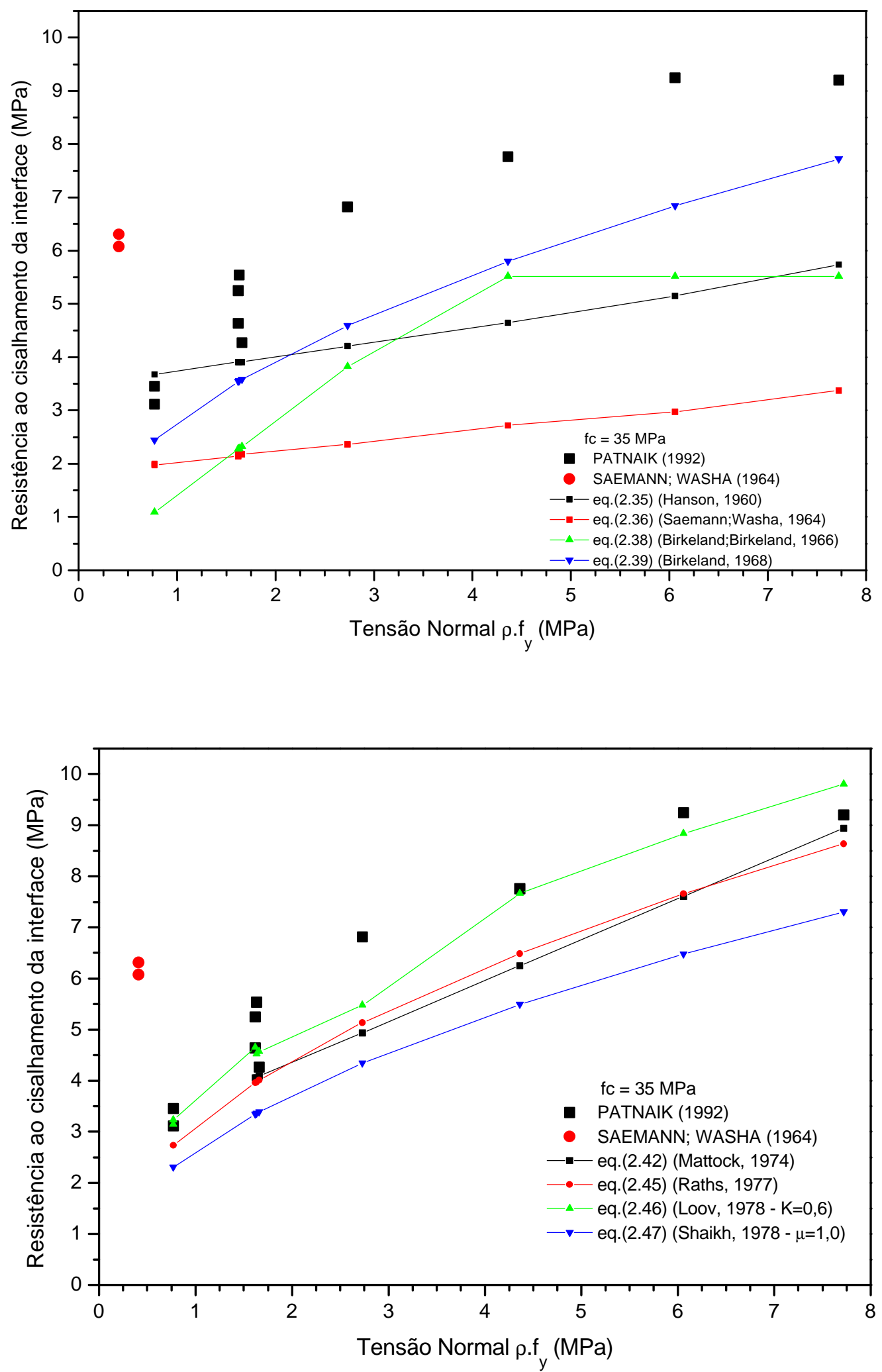

Figura 4.3(c) - Comparação entre os modelos empíricos e os resultados dos ensaios de Patnaik $\left(f_{c}=35 \mathrm{MPa}\right)$. - continua 

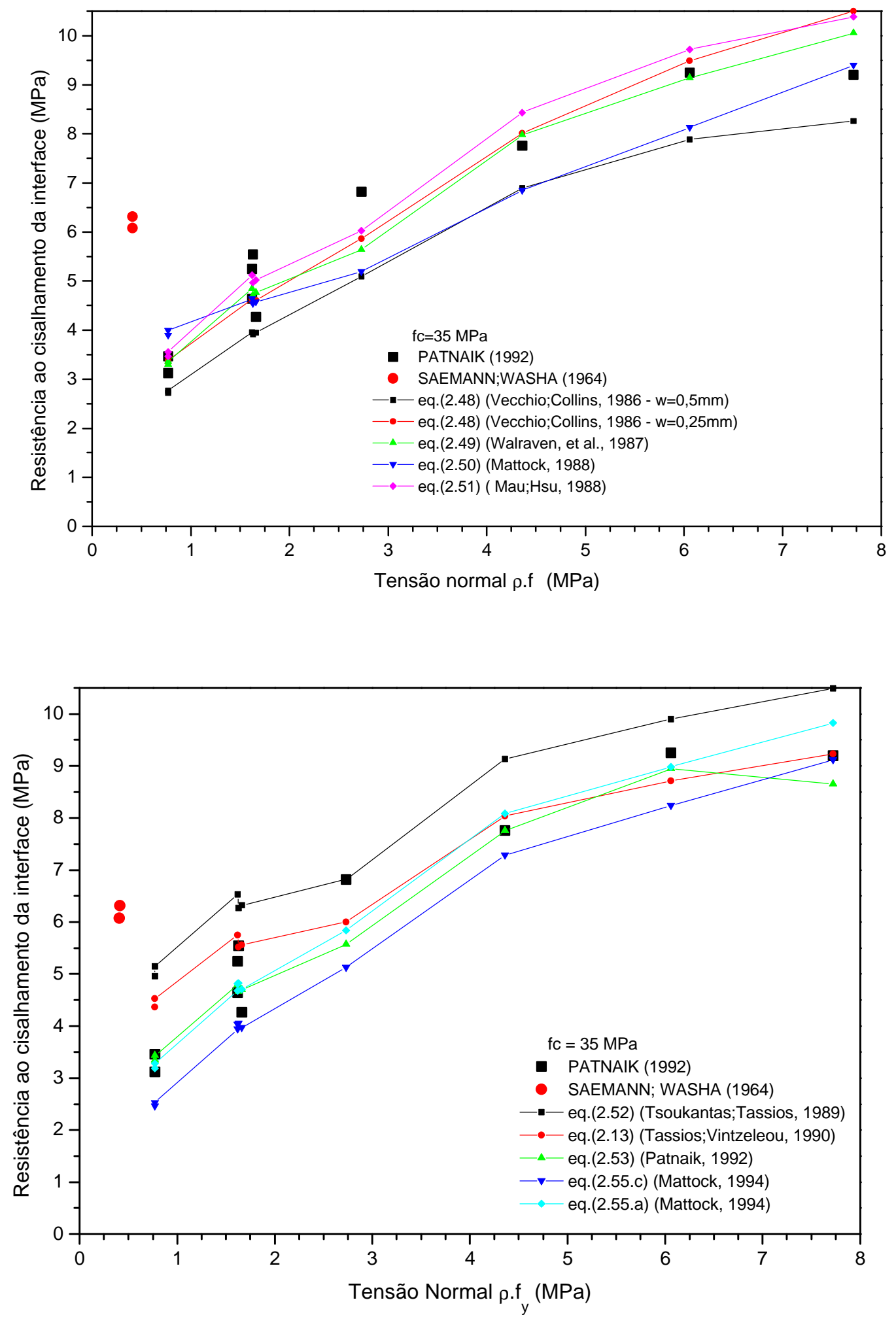

Figura 4.3(c) - Comparação entre os modelos empíricos e os resultados dos ensaios de Patnaik ( $\left.f_{c}=35 \mathrm{MPa}\right)$. - continuação 
Tabela 4.3 - Resultado do emprego dos modelos empíricos às vigas ensaiadas por Patnaik.

\begin{tabular}{|c|c|c|c|c|c|c|c|c|c|c|c|}
\hline viga & $\begin{array}{c}\mathrm{f}_{\mathrm{c}} \\
(\mathrm{MPa})\end{array}$ & $\begin{array}{c}\rho . f_{y} \\
(\mathrm{MPa})\end{array}$ & $\begin{array}{c}\tau_{\text {ensaio }} \\
(\mathrm{MPa})\end{array}$ & $\begin{array}{c}\text { Loov, } 1978 \\
-\mathrm{K}=0,6 \\
\text { eq. }(2.46)\end{array}$ & $\frac{\tau_{\text {empirico }}}{\tau_{\text {ensaio }}}$ & $\begin{array}{c}\text { Vecchio; } \\
\text { Collins, } 1986 \text { - } \\
\text { w=0,25 mm } \\
\text { eq. }(2.48)\end{array}$ & $\frac{\tau_{\text {empirico }}}{\tau_{\text {ensaio }}}$ & $\begin{array}{l}\text { Walraven, } \\
\text { et al., } 1987 \\
\text { eq. }(2.49)\end{array}$ & $\frac{\tau_{\text {empirico }}}{\tau_{\text {ensaio }}}$ & $\begin{array}{c}\text { Mattock, } \\
1988 \\
\text { eq. }(2.50)\end{array}$ & $\begin{array}{l}\frac{\tau_{\text {empirico }}}{\tau_{\text {ensaio }}} \\
\end{array}$ \\
\hline 1 & 37.4 & 4.36 & 7.76 & 7.66 & 0.99 & 8.01 & 1.03 & 7.98 & 1.03 & 6.85 & 0.88 \\
\hline 2 & 34.9 & 1.66 & 4.27 & 4.57 & 1.08 & 4.61 & 1.08 & 4.76 & 1.11 & 4.57 & 1.08 \\
\hline 3 & 30.5 & 2.73 & 6.82 & 5.47 & 0.80 & 5.86 & 0.86 & 5.64 & 0.83 & 5.19 & 0.76 \\
\hline 5 & 34.8 & 1.63 & 5.54 & 4.52 & 0.81 & 4.57 & 0.83 & 4.71 & 0.85 & 4.54 & 0.82 \\
\hline 6 & 37.1 & 1.62 & 5.25 & 4.65 & 0.88 & 4.63 & 0.88 & 4.84 & 0.93 & 4.64 & 0.88 \\
\hline 7 & 35.8 & 6.06 & 9.25 & 8.84 & 0.95 & 9.48 & 1.02 & 9.14 & 0.99 & 8.13 & 0.88 \\
\hline 8 & 35.6 & 0.77 & 3.12 & 3.14 & 1.01 & 3.33 & 1.06 & 3.29 & 1.05 & 3.89 & 1.25 \\
\hline 9 & 37.1 & 1.62 & 4.64 & 4.65 & 1.00 & 4.63 & 1.00 & 4.84 & 1.04 & 4.64 & 1.00 \\
\hline 10 & 37.6 & 0.77 & 3.46 & 3.23 & 0.93 & 3.39 & 0.98 & 3.36 & 0.97 & 3.99 & 1.15 \\
\hline 12 & 34.6 & 7.72 & 9.20 & 9.81 & 1.06 & 10.50 & 1.14 & 10.05 & 1.09 & 9.40 & 1.02 \\
\hline 13 & 19.2 & 0.82 & 2.92 & 2.38 & 0.81 & 2.83 & 0.97 & 2.69 & 0.92 & 2.99 & 1.02 \\
\hline \multicolumn{4}{|c|}{ média $(m)$} & - & 0.94 & - & 0.99 & - & 0.98 & - & 0.98 \\
\hline \multicolumn{4}{|c|}{ desvio padrão (s) } & _ & 0.10 & _ & 0.10 & _ & 0.09 & _ & 0.15 \\
\hline
\end{tabular}


Tabela 4.3 - Resultado do emprego dos modelos empíricos às vigas ensaiadas por Patnaik (continuação).

\begin{tabular}{|c|c|c|c|c|c|c|c|c|c|}
\hline viga & $\begin{array}{c}\mathrm{f}_{\mathrm{c}} \\
(\mathrm{MPa})\end{array}$ & $\begin{array}{c}\rho . f_{y} \\
(\mathrm{MPa})\end{array}$ & $\begin{array}{r}\tau_{\text {ensaio }} \\
(\mathrm{MPa})\end{array}$ & $\begin{array}{l}\text { Mau; Hsu, } 1988 \\
\text { eq. }(2.51)\end{array}$ & $\frac{\tau_{\text {empirico }}}{\tau_{\text {ensaio }}}$ & $\begin{array}{l}\text { Patnaik, } 1992 \\
\text { eq.(2.53) }\end{array}$ & $\frac{\tau_{\text {empirico }}}{\tau_{\text {ensaio }}}$ & $\begin{array}{c}\text { Mattock, } 1994 \\
\text { eq.(2.55.a ) }\end{array}$ & $\frac{\tau_{\text {empirico }}}{\tau_{\text {ensaio }}}$ \\
\hline 1 & 37.4 & 4.36 & 7.76 & 8.43 & 1.09 & 7.75 & 1.00 & 8.08 & 1.04 \\
\hline 2 & 34.9 & 1.66 & 4.27 & 5.02 & 1.18 & 4.70 & 1.10 & 4.71 & 1.10 \\
\hline 3 & 30.5 & 2.73 & 6.82 & 6.02 & 0.88 & 5.57 & 0.82 & 5.84 & 0.85 \\
\hline 5 & 34.8 & 1.63 & 5.54 & 4.97 & 0.90 & 4.66 & 0.84 & 4.82 & 0.87 \\
\hline 6 & 37.1 & 1.62 & 5.25 & 5.12 & 0.97 & 4.79 & 0.91 & 4.81 & 0.92 \\
\hline 7 & 35.8 & 6.06 & 9.25 & 9.72 & 1.05 & 8.95 & 0.97 & 8.98 & 0.97 \\
\hline 8 & 35.6 & 0.77 & 3.12 & 3.46 & 1.11 & 3.34 & 1.08 & 3.19 & 1.02 \\
\hline 9 & 37.1 & 1.62 & 4.64 & 5.12 & 1.10 & 4.79 & 1.03 & 4.68 & 1.01 \\
\hline 10 & 37.6 & 0.77 & 3.46 & 3.55 & 1.03 & 3.43 & 0.99 & 3.28 & 0.95 \\
\hline 12 & 34.6 & 7.72 & 9.20 & 10.38 & 1.12 & 8.65 & 0.94 & 9.83 & 1.06 \\
\hline 13 & 19.2 & 0.82 & 2.92 & 2.62 & 0.90 & 2.52 & 0.86 & 2.22 & 0.76 \\
\hline \multicolumn{4}{|c|}{ média (m) } & - & 1.03 & - & 0.97 & - & 0.96 \\
\hline \multicolumn{4}{|c|}{ desvio padrão (s) } & - & 0.10 & - & 0.09 & _ & 0.10 \\
\hline
\end{tabular}


De forma semelhante aos modelos analíticos, os modelos empíricos apresentaram maior divergência em relação aos resultados dos ensaios quando as vigas possuíam baixo valor de tensão normal. Porém o modelo de Mattock (eq.(2.50)), além, evidentemente, do modelo de Patnaik (eq.(2.53)), forneceu resultados mais próximos dos valores de ensaio com baixa taxa de armadura devido a existência da parcela de resistência por aderência em suas expressões. Este fato mais uma vez indica a importância da aderência quando a tensão normal à interface das vigas compostas é baixa, ou seja, a taxa de armadura transversal é baixa $\left(\sigma_{\mathrm{n}} \leq 2 \mathrm{MPa}\right)$. Os modelos que apresentaram melhor aproximação foram: Loov(eq.(2.46)), Walraven et al. (eq.(2.49)), Mattock (eq.(2.50) e eq.(2.55.a)), Mau; Hsu (eq.(2.51) e Vecchio; Collins (eq.(2.48)).

Observou-se que os modelos que não possuem a resistência do concreto em suas expressões fornecem resultados muito inferiores aos obtidos dos ensaios, o que indica a importância da resistência do concreto na resistência das vigas ao cisalhamento horizontal.

Alguns modelos não apresentam um limite máximo para a resistência ao cisalhamento, fornecendo valores superiores aos obtidos dos ensaios quando as vigas possuem altas taxas de armadura. O limite proposto por Patnaik de 0,25. $f_{c}$ parece razoável uma vez que fornece resultados seguros e coincide com o limite máximo proposto pela FIP.

Aparentemente o comportamento dos modelos é diferente quando o concreto possui resistência inferior a $35 \mathrm{MPa}$. Contudo, os dados utilizados nesta comparação foram obtidos de outros autores, sendo que não foi possível obter informações detalhadas sobre as vigas ensaiadas e sobre a metodologia de ensaio. Nos ensaios de SAEMANN; WASHA (1964) as vigas possuíam seção transversal um pouco diferente e armadura transversal inclinada em relação à interface. Também possuíam vãos variando entre 2,44 m , 3,35 m e 6,10 m. Observou-se que quando era comparada a resistência das vigas de Saemann; Washa com vão de 3,35 m com os valores obtidos por Patnaik, elas apresentaram resistência ligeiramente superior, enquanto as vigas com vão de $2,44 \mathrm{~m}$ apresentaram resistência muito superior. Tal fato sugere que as vigas com vão de 
2,44 m apresentaram um acréscimo na resistência devido ao aumento da rigidez à flexão, e não pelo aumento da resistência da interface.

O modelo de Vecchio; Collins (eq.(2.48)) apesar de fornecer bons resultados é de difícil aplicação em função da avaliação da abertura das fissuras, o que nem sempre é possível em projetos.

\subsection{Ensaios de cisalhamento direto}

Neste item são apresentados os ensaios de cisalhamento ("push-out") realizados no laboratório do Departamento de Engenharia de Estruturas da EESC. Esses ensaios são parte integrante de um trabalho de prestação de serviço apresentado à construtora MARNA para avaliação da capacidade última de transferência de esforços de cisalhamento da ligação entre vigas pré-moldadas e lajes pré-moldadas utilizadas na construção de pontes no estado de São Paulo (MALITE; TAKEYA (1996)). Na ocasião aproveitou-se os resultados dos ensaios para aplicação dos modelos analíticos e empíricos na avaliação teórica da resistência da interface de peças compostas submetidas à esforços de cisalhamento direto.

O conector era constituído por barras de aço dobradas em forma de laço e ancoradas em ambas as peças pré-moldadas. Eles eram deixados nas vigas e depois concretados em furos existentes nas lajes. A figura 4.4 ilustra esta ligação e o esquema de transferência de esforços entre a laje e a viga quando a peça é submetida à flexão.

O modelo utilizado nos ensaios para solicitar os conectores apenas a esforços de cisalhamento consistia de uma parte central (simulando a viga) e duas partes laterais (simulando a laje). Cada conector era formado por uma barra de 10 $\mathrm{mm}$ mais uma barra de $8 \mathrm{~mm}$ dobradas em forma de laço. A ligação entre a peça central e as peças laterais era feita pelos conectores através da concretagem dos furos existentes nas peças laterais. Nas figuras 4.5 e 4.6 estão ilustradas as dimensões e a armação do modelo utilizado no ensaio, o qual é recomendado pela norma britânica BS5400 part 5 - "steel, concrete and composite bridges: code of practice for design of composite bridges", 1979. 


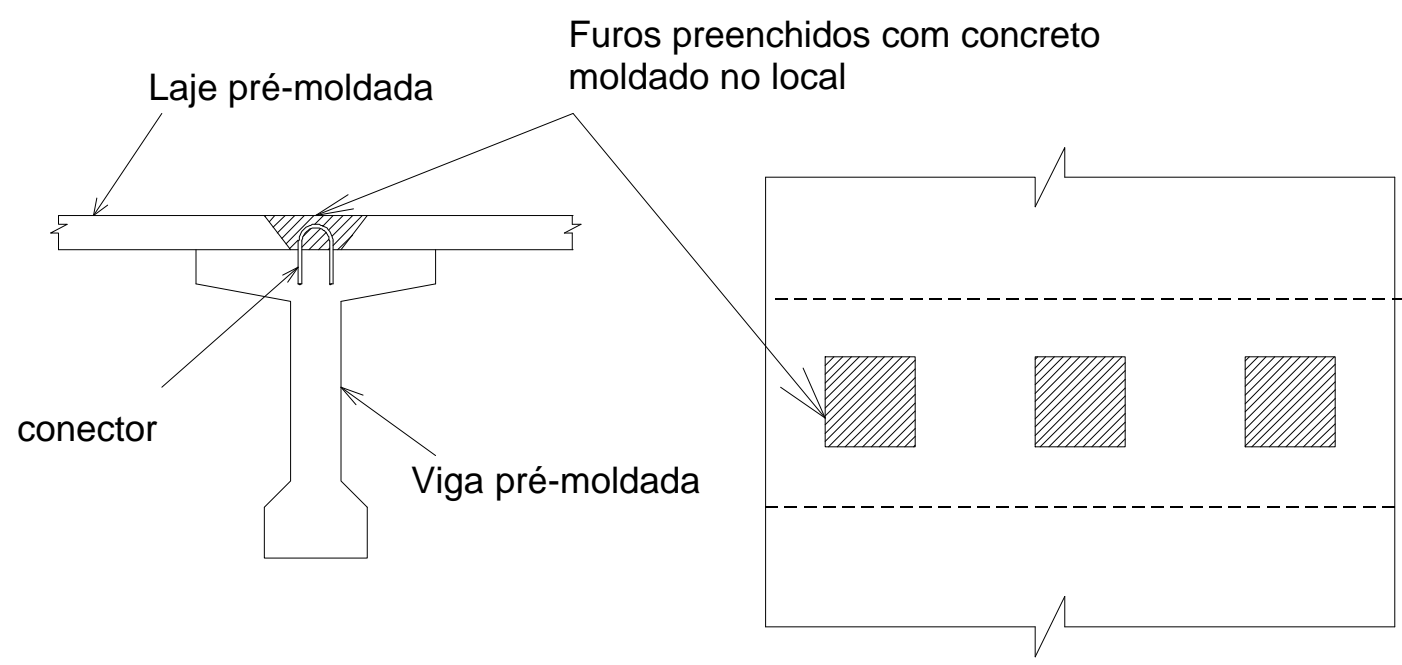

$\begin{array}{ll}\text { a) seção transversal } & \text { b) vista superior }\end{array}$

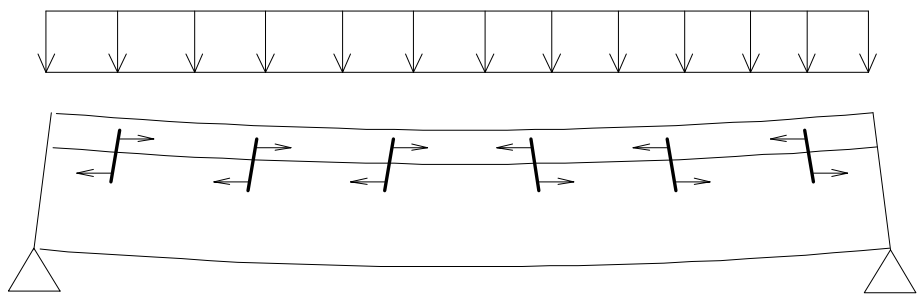

c) transferência de esforços entre a viga e a laje

Figura 4.4 - Viga e laje pré-moldada ligadas por conectores 


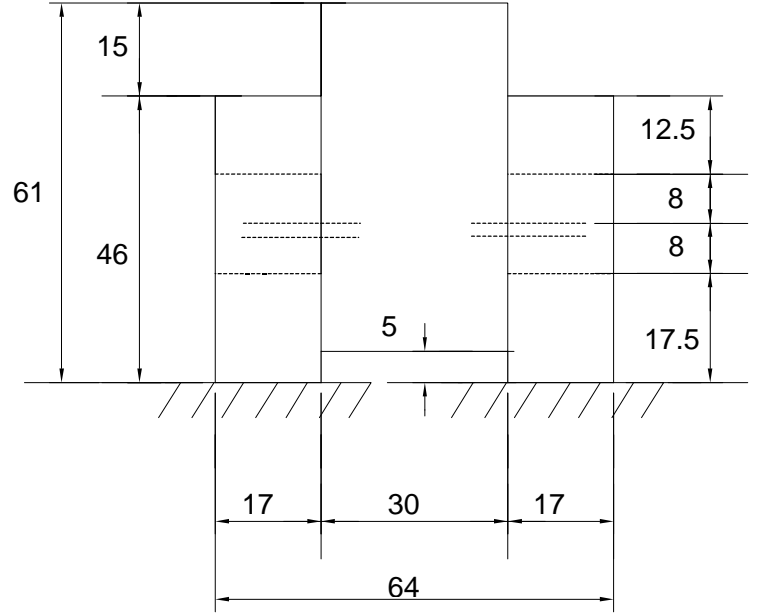

Elevação frontal

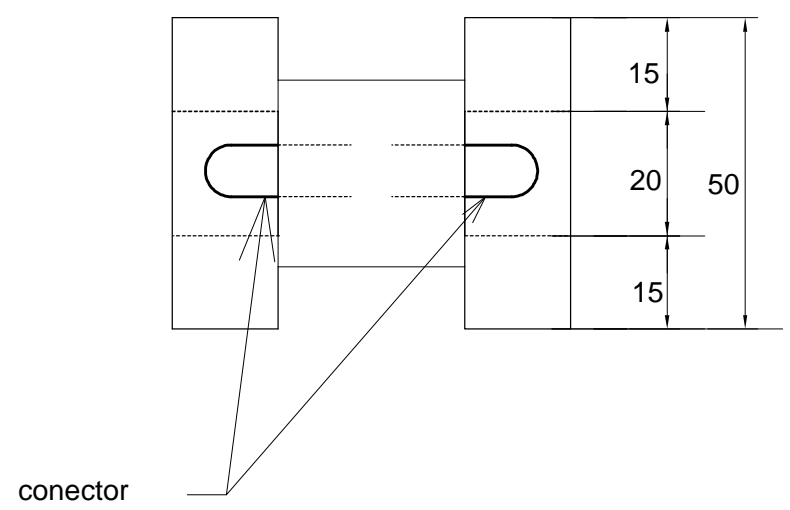

Planta

Nota: dimensões em centímetros

Figura 4.5 - Dimensões do modelo utilizado nos ensaios de ligação por conector.

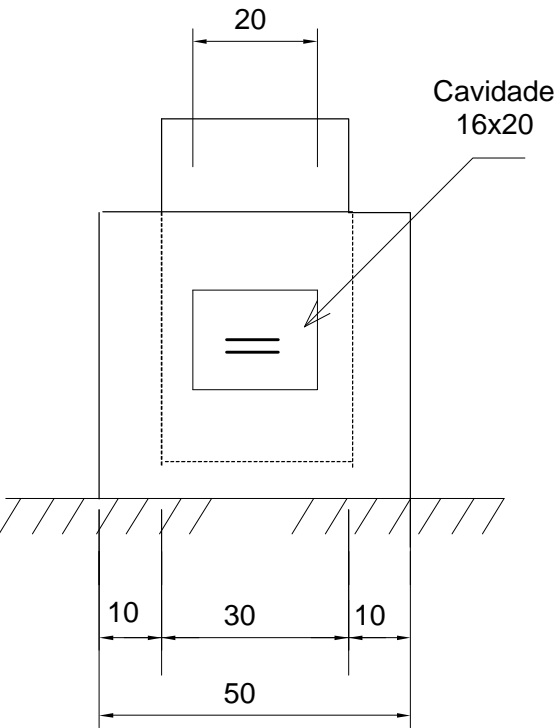

Elevação lateral
Nota: dimensöes em centimetros 

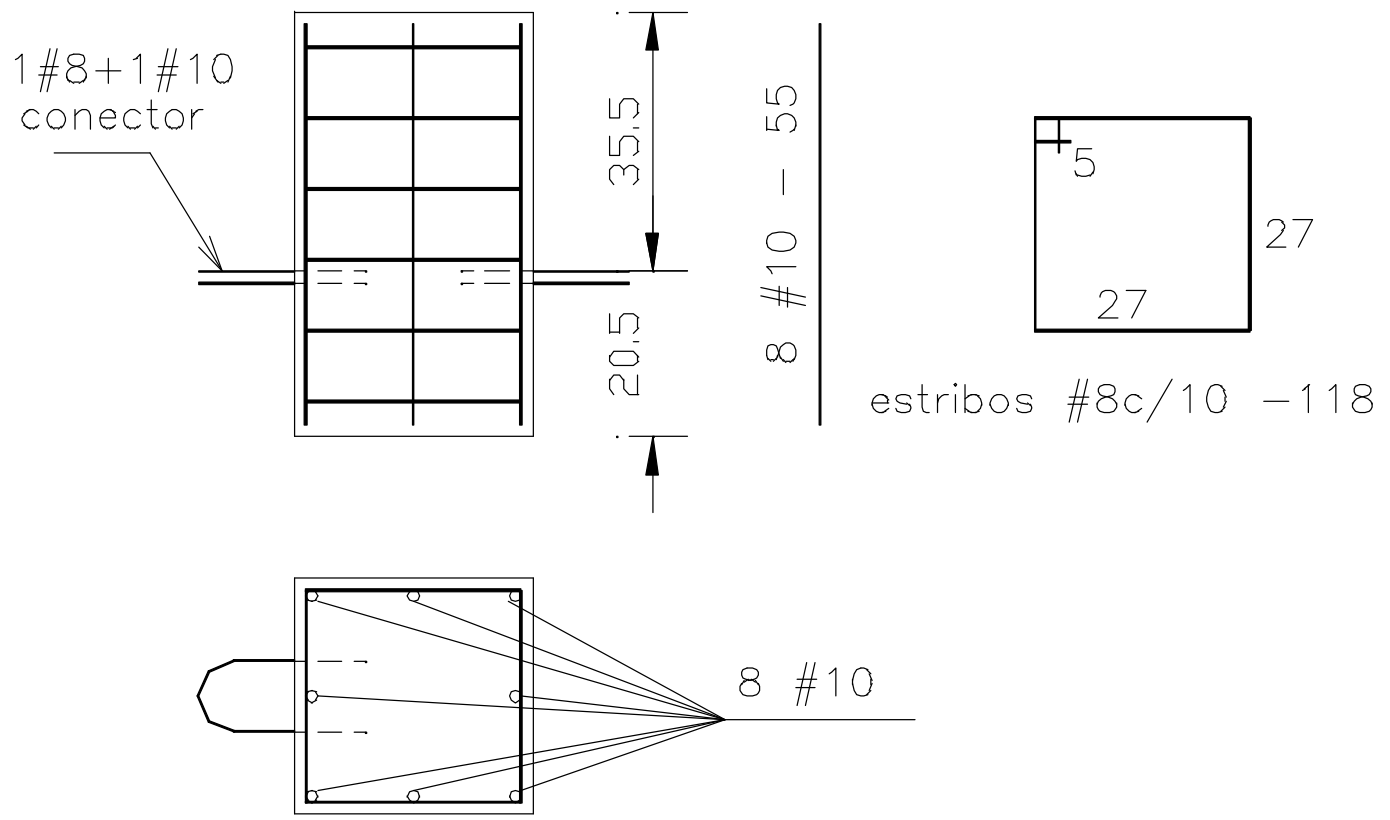

PARTE CENTRAL
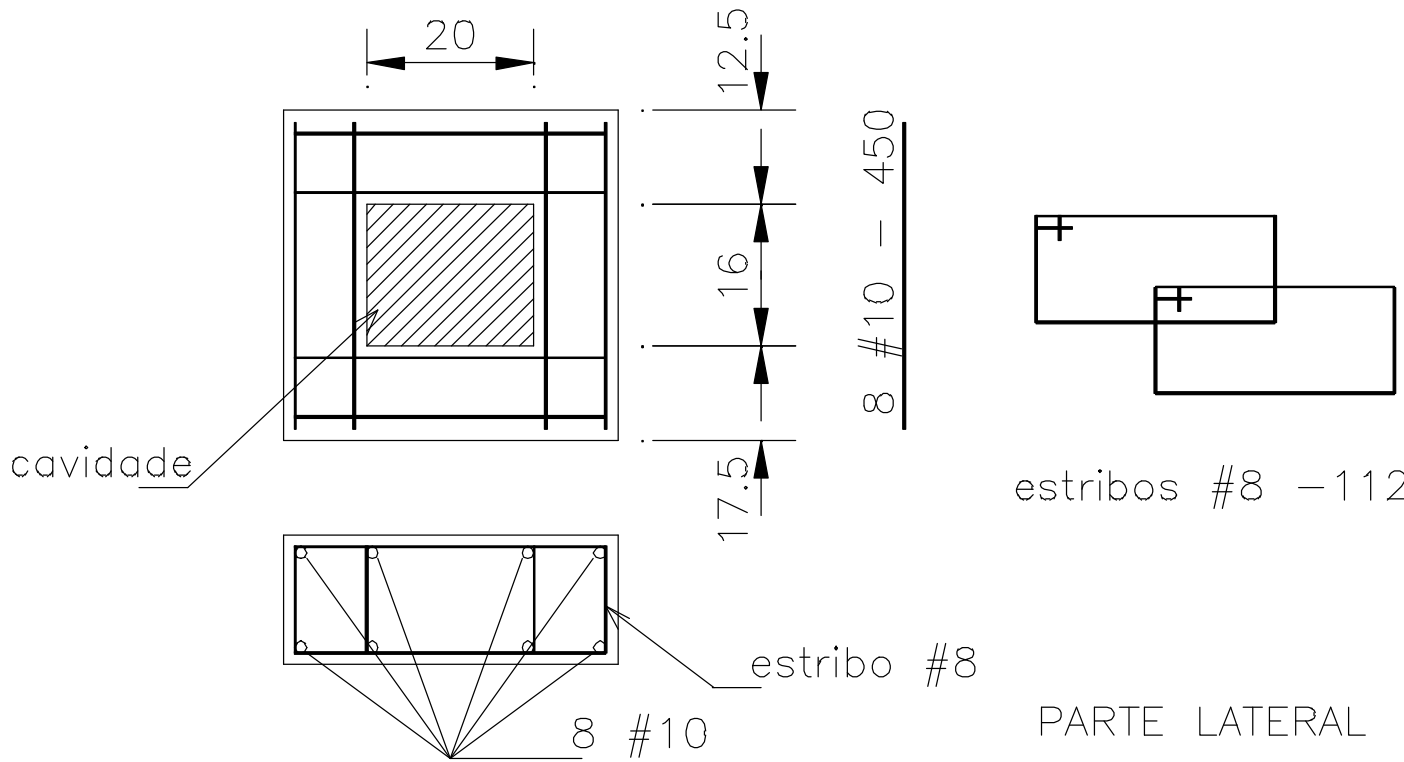

estribos \#8-112

PARTE LATERAL

Figura 4.6 - Armadura dos corpos-de-prova utilizados nos ensaios de ligação por conector 
Foram confeccionados seis corpos-de-prova, sendo três montados com superfície de contato lisa e três com superfície de contato apicoada visando uma maior resistência por aderência. A concretagem das cavidades foi feita em duas etapas, por dois dias consecutivos, sendo a cada dia feita a concretagem de um lado do corpo-de-prova. Não foram feitos ensaios para escolha do traço, sendo utilizado um traço disponível no laboratório ao qual foi adicionado microssílica. $O$ concreto das cavidades apresentou uma resistência média de $62 \mathrm{MPa}$ na data dos ensaios ( 7 dias ) e o aço utilizado nos conectores foi o CA-50 A ( $\left.f_{y k}=500 \mathrm{MPa}\right)$.

\subsubsection{Instrumentação e procedimentos de ensaio}

Os corpos-de-prova foram instrumentados com quatro transdutores de deslocamento, numerados de 1 a 4 , fixados na parte central e com a haste apoiada nas partes laterais, para avaliação do deslizamento relativo entre as partes. $\mathrm{Na}$ figura 4.7 são mostrados a numeração dos transdutores e o esquema geral do ensaio.

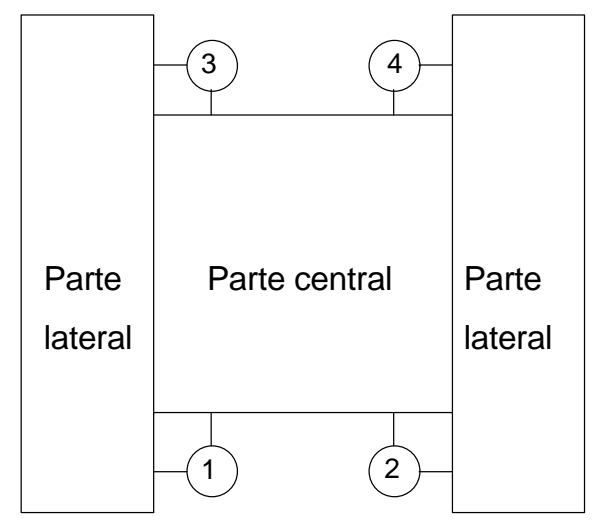

Vista superior

Figura 4.7(a) - Numeração dos transdutores de deslocamento 

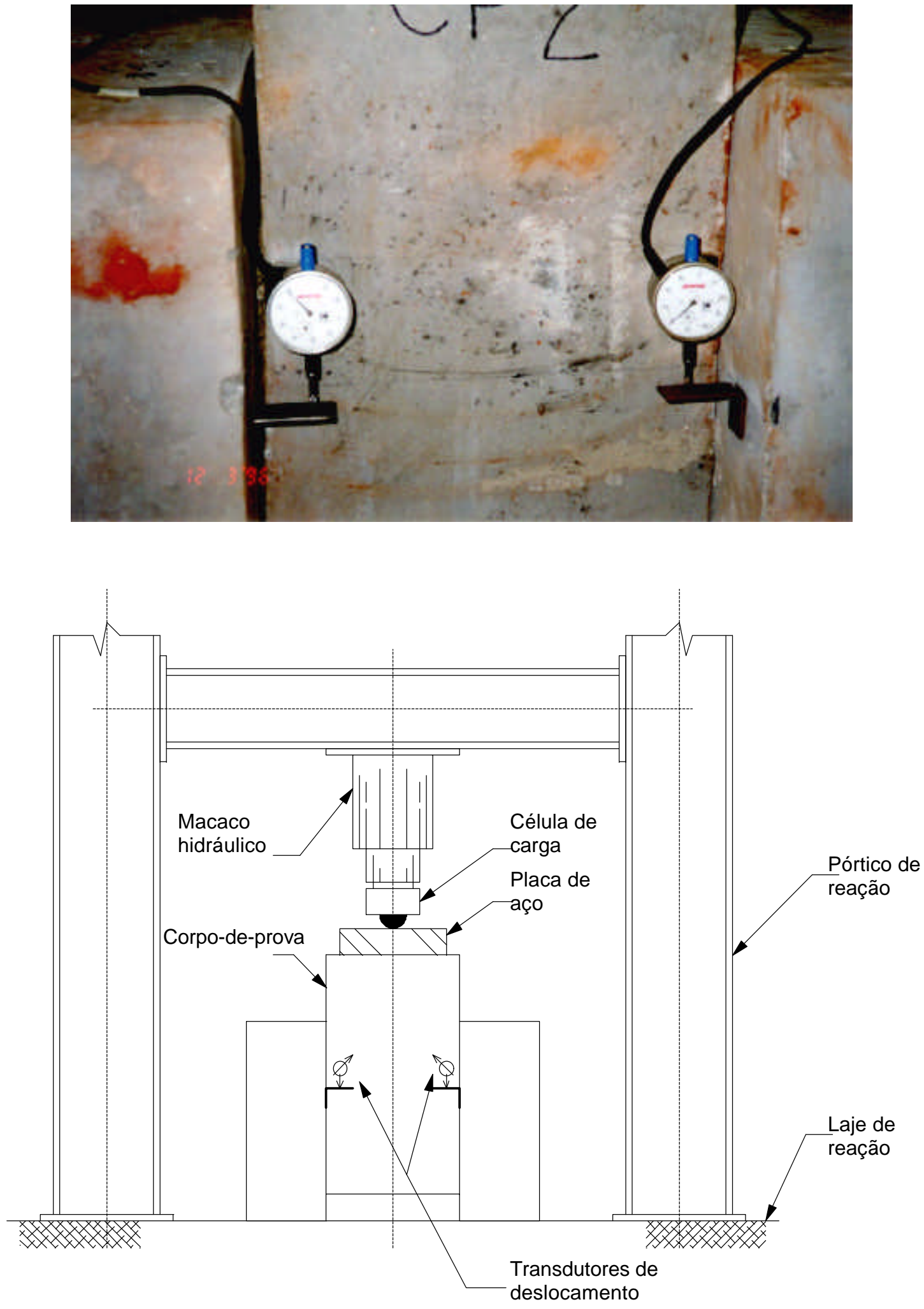

Figura 4.7(b) - Fixação dos transdutores e esquema geral do ensaio 


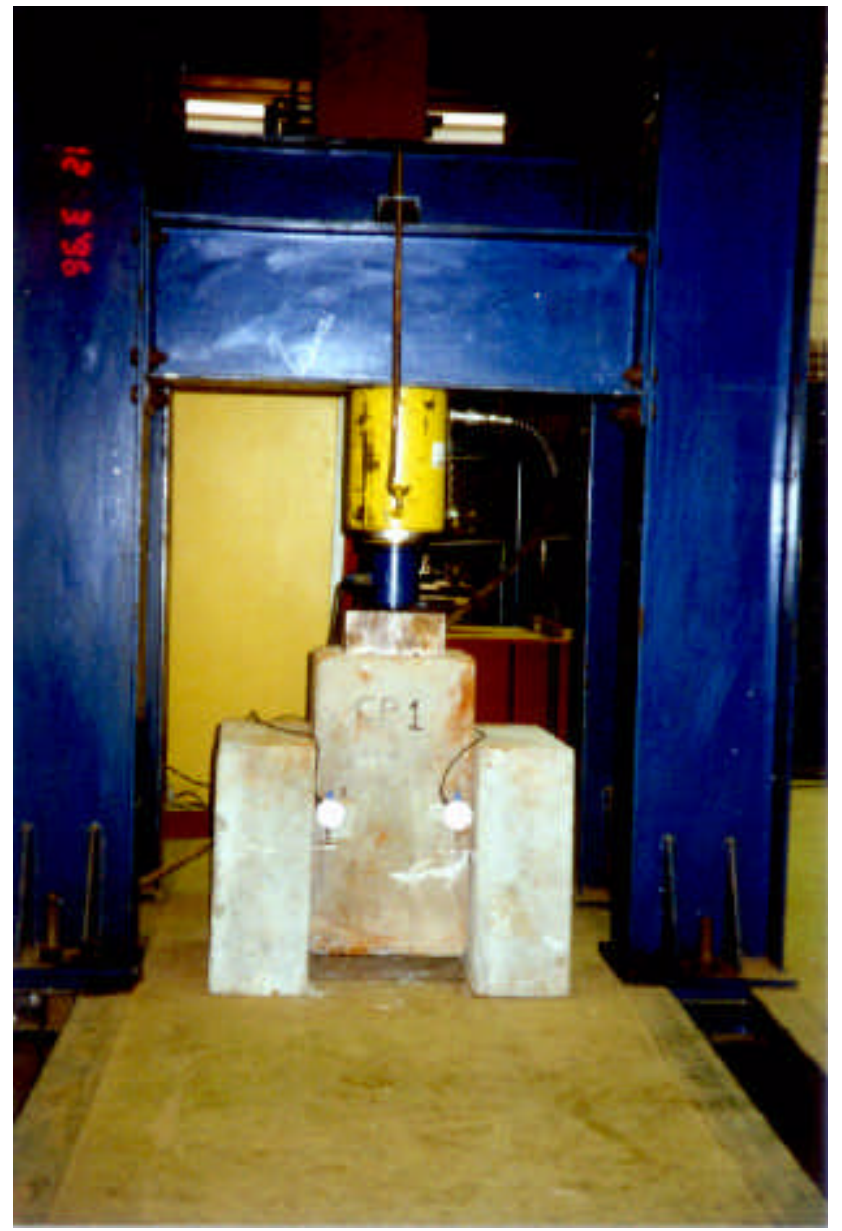

Figura 4.7(c) - Estrutura de reação e corpo-de-prova posicionado para ensaio

O ensaio foi realizado aplicando-se etapas de carregamento de $10 \mathrm{kN}$ até duas ou três etapas após a perda de aderência entre as duas superfícies de concreto. Após esse estágio, os transdutores foram retirados e a força incrementada continuamente até a ruptura total da ligação. Em cada etapa de carregamento, as leituras de força e deslocamento foram registradas após a estabilização da força aplicada. A figura 4.8 mostra a ruptura do conector do corpode-prova CP4 e o aspecto final da superfície do concreto. 

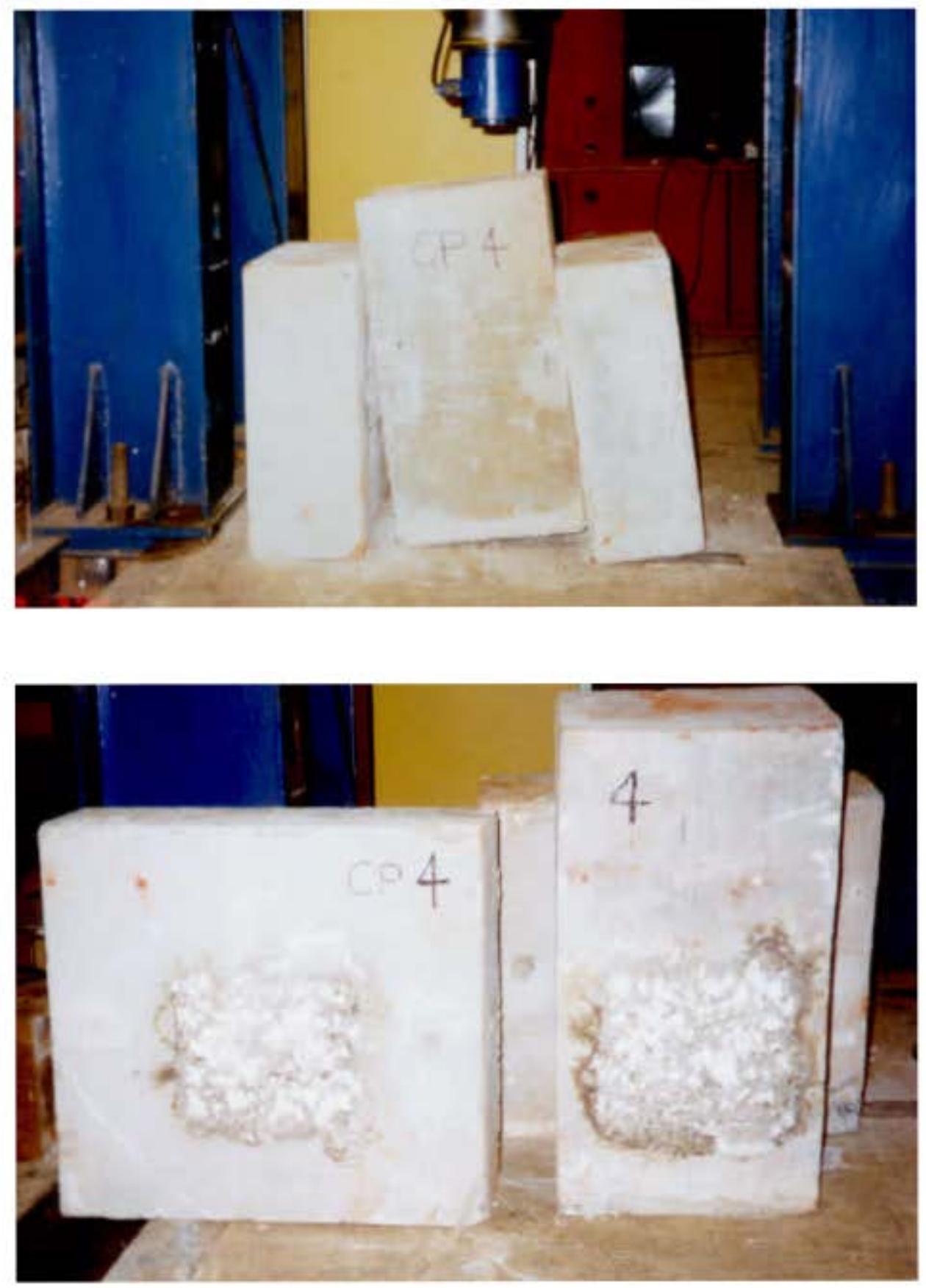

Figura 4.8 - Ruptura do corpo-de-prova CP4 e aspecto da superfície do concreto 


\subsubsection{Resultados dos ensaios e discussão}

Os resultados dos ensaios nos seis corpos-de-prova estão indicados nos gráficos da figura 4.10, cujos deslizamentos indicados pelos quatro transdutores são correspondentes à força total aplicada. Também estão indicados nos gráficos as curvas obtidas aplicando-se o modelo analítico de Tassios e Vintzeleou considerando a superfície de contato lisa. Na figura 4.9 estão ilustrados os valores estimados para a força total resistida pelo bloco quando aplica-se o modelo de Tassios e Vintzeleou com superfície lisa e superfície rugosa.

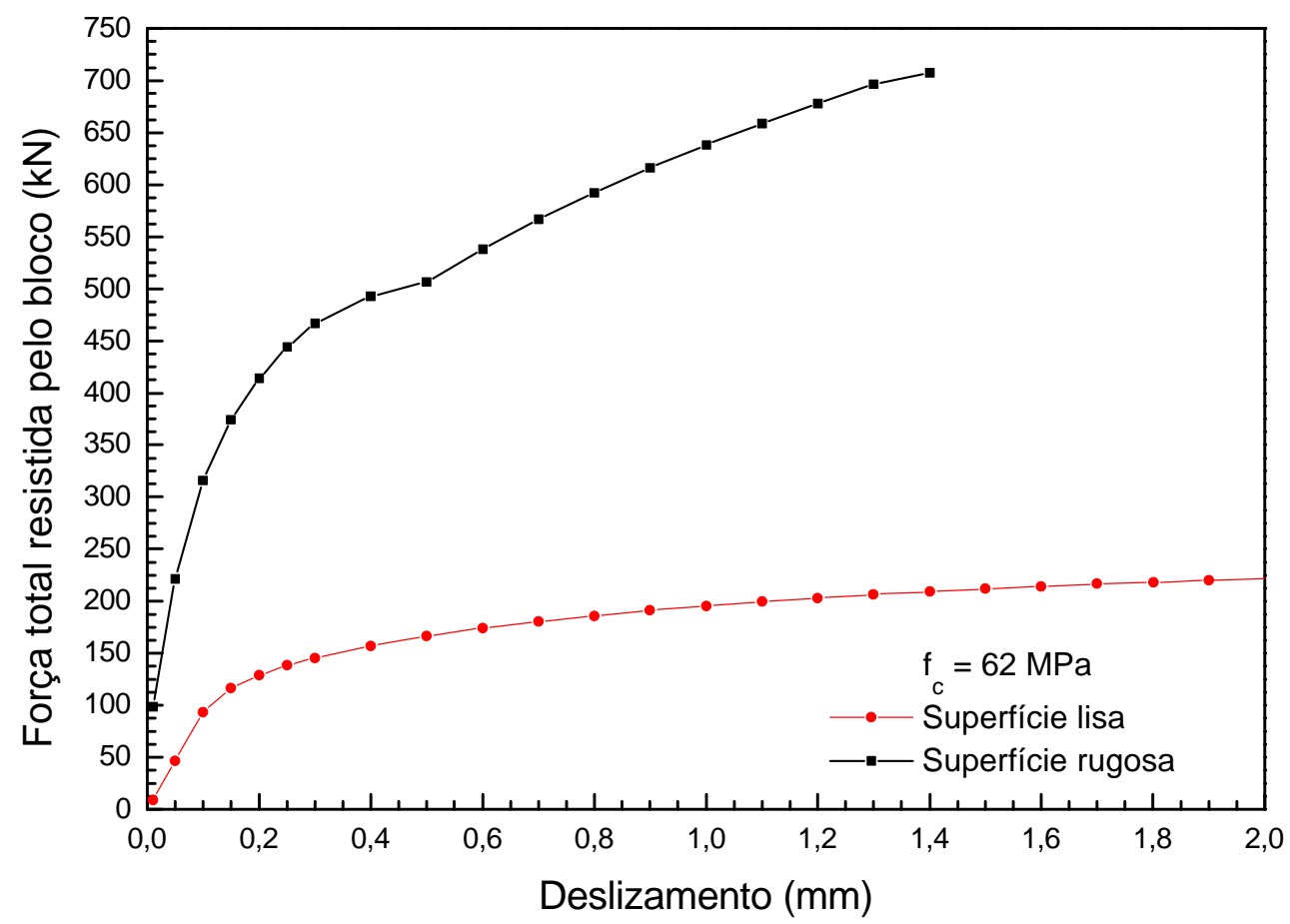

Figura 4.9 - Aplicação do modelo de Tassios; Vintzeleou aos corpos-de-prova considerando superfície lisa e rugosa 

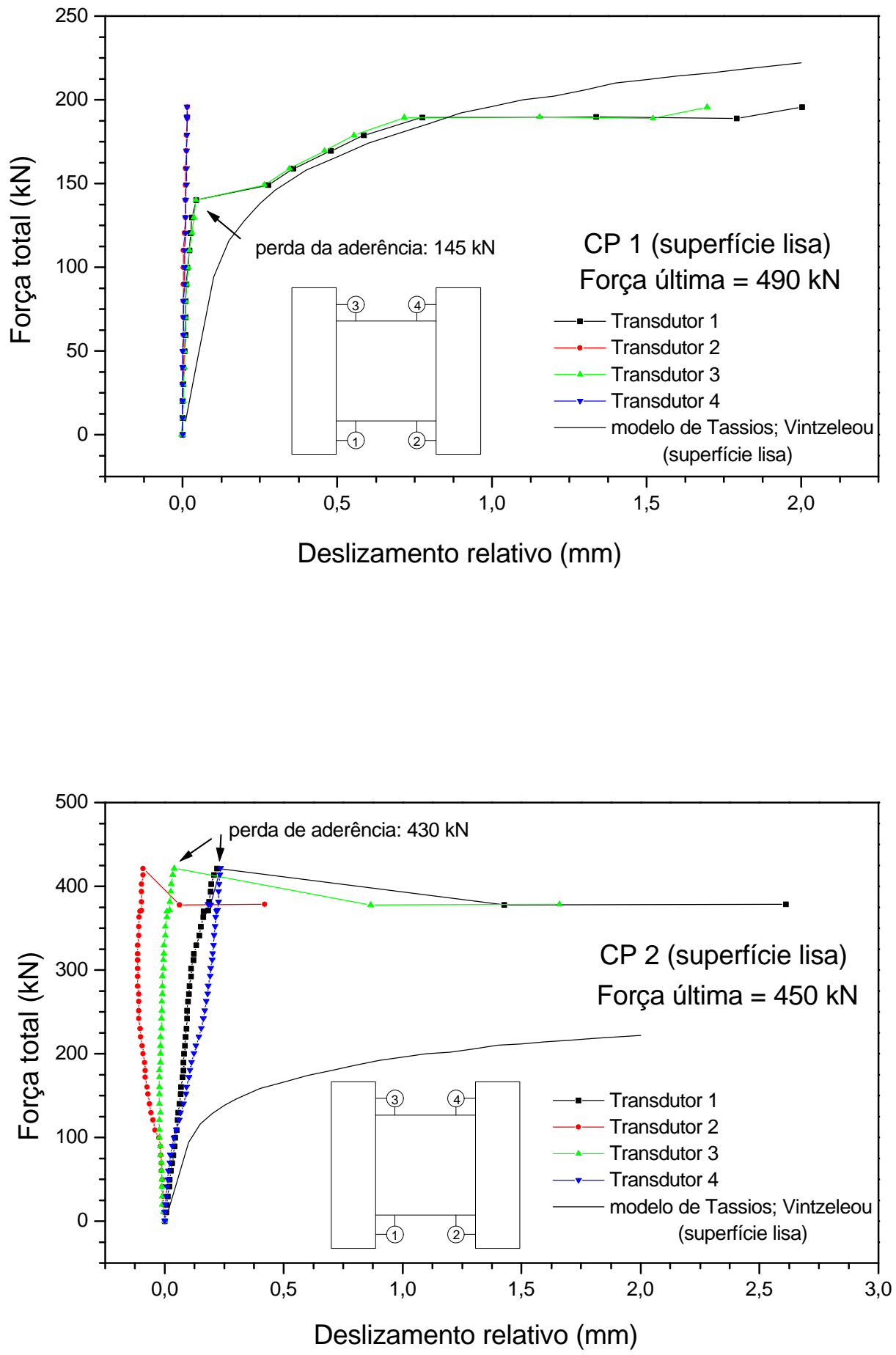

Figura 4.10 - Resultados dos ensaios da ligação por conector (continua) 

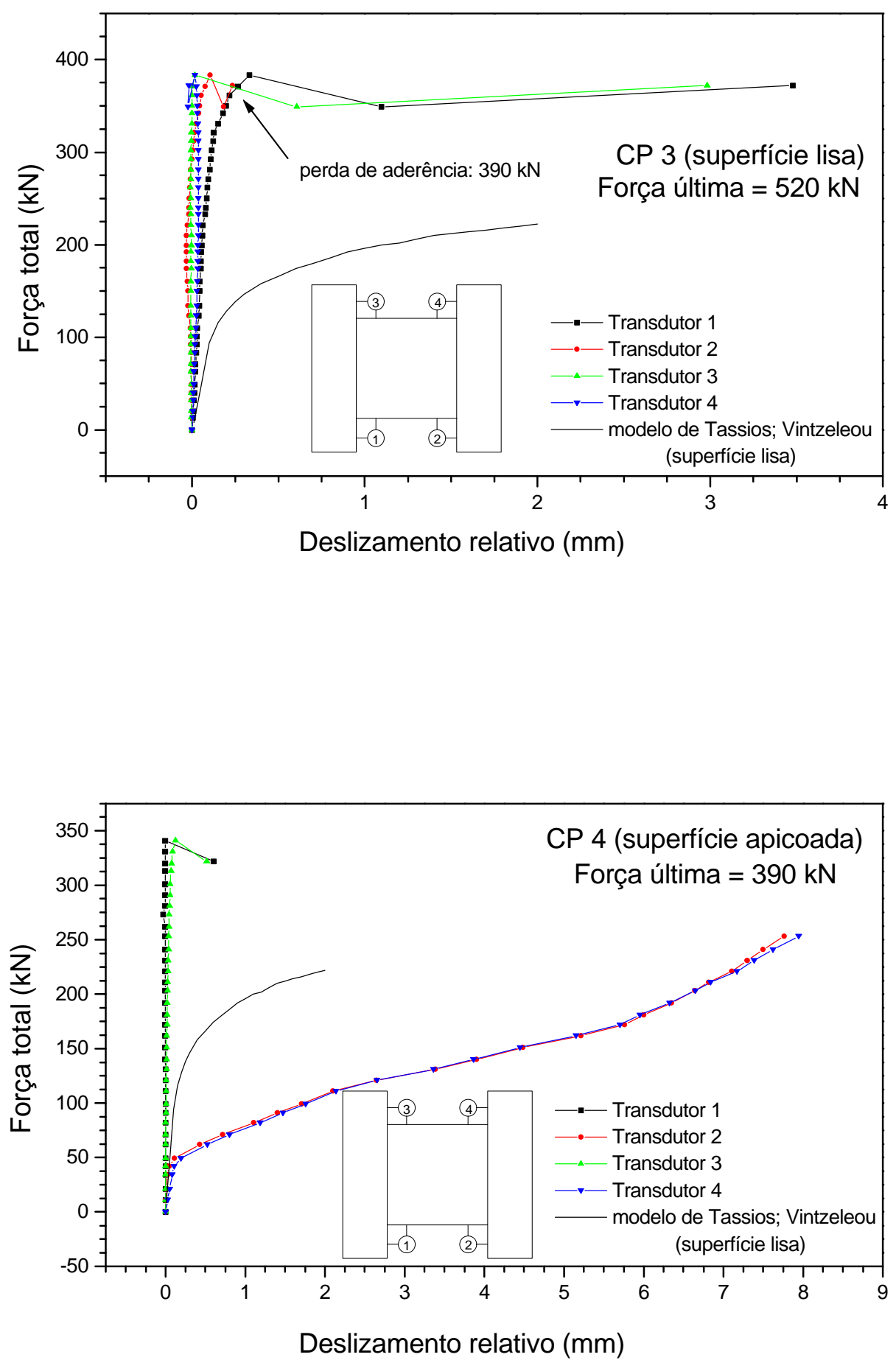

Figura 4.10 - Resultados dos ensaios da ligação por conector (continuação) 

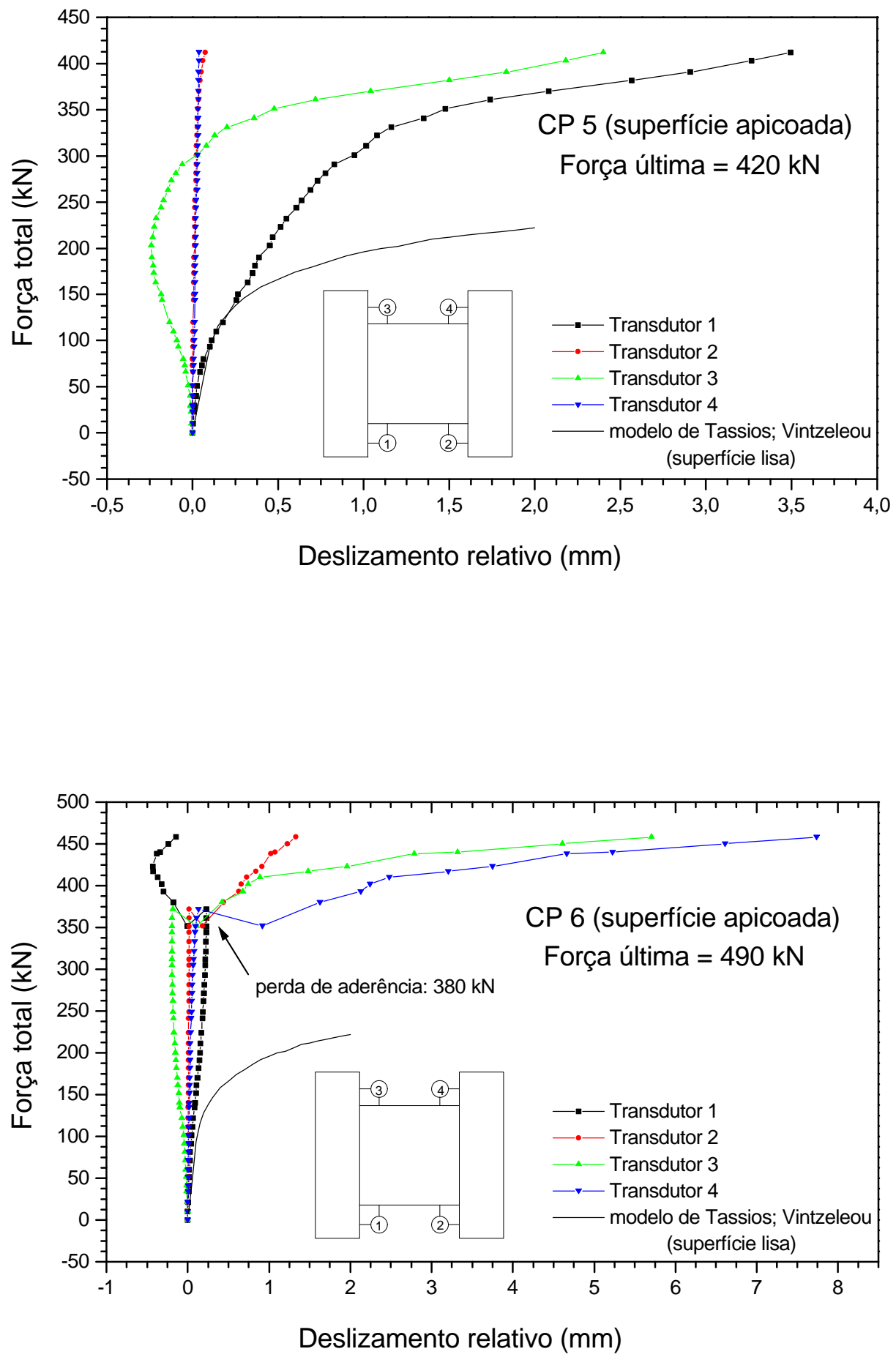

Figura 4.10 - Resultados dos ensaios da ligação por conector (continuação) 
Em alguns ensaios pode-se observar valores negativos de deslizamento, o que é proveniente da rotação do bloco central em relação ao seu eixo vertical. Tal efeito foi bastante significativo no corpo-de-prova CP5.

Dos gráficos observa-se grande influência da aderência entre o concreto velho e o concreto novo na resistência final ao cisalhamento. Este efeito pode ser explicado devido à taxa de armadura normal à interface $(0,8 \%)$ estar situada numa região onde a influência da aderência é significativa. Deve-se lembrar também que a alta resistência do concreto das cavidades (com presença de microssílica) também pode ter contribuído com o aumento da aderência.

Observando os resultados dos corpos-de-prova CP2 e CP3 nota-se que após vencida a resistência por aderência ocorreu um pequeno decréscimo da força aplicada enquanto o deslizamento relativo aumentava. Este comportamento sugere que a quantidade de armadura normal à interface não foi capaz de introduzir uma tensão normal, conforme a teoria atrito cisalhamento, capaz de aumentar a parcela de resistência por atrito. Comportamento diferente foi observado no corpo-de-prova CP1 onde ,devido à prematura perda de aderência da ligação, ocorreu acréscimos da força aplicada com acréscimos do deslizamento relativo. Portanto, parece razoável utilizar a teoria atrito-cisalhamento para descrever o fenômeno de transferência de tensões de cisalhamento deste tipo de ligação, devendo-se definir um limite mínimo para a taxa de armadura e incluir uma parcela de resistência devido à aderência entre as superfícies de concreto. Vale salientar que a resistência por aderência é uma parcela que após vencida não é mais recuperada.

Os corpos-de-prova que possuíam a superfície da parte central apicoada apresentaram grandes deslizamentos em uma das lajes para baixos valores de força aplicada. Contudo, a força última apresentou valor semelhante à dos corposde-prova com superfície lisa. Tal comportamento pode ser explicado pelo fato de apenas uma das lajes deslizar em relação à parte central enquanto a outra apresentou grande resistência por aderência. Tal comportamento indica que o apicoamento da superfície não foi suficiente para torná-la rugosa, mas apenas diminuir a aderência entre as peças. 
Comparando os resultados obtidos dos ensaios com os previstos pelo modelo analítico de Tassios e Vintzeleou, observa-se que ele apresentou valores inferiores aos do ensaio quando a superfície de contato foi considerada lisa, e valores superiores para superfície de contato rugosa. Apesar disso, observando novamente os resultados do corpo-de-prova CP1, nota-se que os resultados fornecidos por esse modelo, até seu limite máximo de deslizamento, aproximaramse bem dos resultados do ensaio. Ao que parece, o modelo de Tassios e Vintzeleou, baseado na teoria atrito-cisalhamento, representa bem 0 comportamento desse tipo de ligação e, caso o estado limite de ruptura da interface seja caracterizado pelo deslizamento excessivo, ele pode ser utilizado para avaliar a resistência ao cisalhamento da interface. Essas observações foram feitas em ensaios com baixa taxa de armadura e baseado no comportamento de apenas um modelo, de forma que são necessários mais ensaios variando a rugosidade da superfície de contato e a taxa de armadura para poder-se afirmar de forma conclusiva sobre a validade da utilização do modelo de Tassios e Vintzeleou na avaliação desse tipo de ligação.

Alguns modelos empíricos obtidos de ensaios de cisalhamento direto possuem uma parcela de resistência por aderência e outra parcela de resistência por atrito. Esses modelos, portanto, poderiam representar o comportamento da ligação por conector. Para verificar tal hipótese eles foram aplicados aos corposde-prova ensaiados, sendo os resultados mostrados na tabela 4.4.

Tendo em vista a variabilidade nos resultados dos ensaios, não é possível estabelecer, mediante seis ensaios, valores confiáveis da resistência da ligação para utilização em projetos, contudo é possível avaliar o comportamento geral da ligação. Seriam necessários novos ensaios variando a resistência do concreto da cavidade, a taxa de armadura da ligação e a rugosidade da superfície. Contudo, baseado nestes ensaios, parece razoável a utilização da equação proposta por Mattock (eq.(2.50)) para avaliação da resistência ao cisalhamento de ligações entre peças pré-moldadas através de conectores em forma de laço. Observa-se também que, conforme imaginado, este tipo de ligação possui comportamento semelhante ao dos ensaios de cisalhamento direto que possuem parcela de resistência por aderência como função da resistência à compressão do concreto. 
Tabela 4.4 - Aplicação dos modelos empíricos à ligação por conector

\begin{tabular}{|c|c|c|}
\hline Modelo empírico & $\tau_{\text {modelo }}(\mathrm{MPa})$ & $\mathrm{F}_{\text {u,modelo }}(\mathrm{kN})$ \\
\hline Mattock, 1974 (eq.(2.42))* & 6.00 & 383 \\
\hline Mattock, 1988 (eq,(2.50))* & 7.69 & $492^{+}$ \\
\hline Patnaik, 1992 (eq.(2.53))** & 9.68 & 620 \\
\hline Patnaik, 1994 (eq.(2.54)) & 7.97 & 510 \\
\hline Mattock, 1994 (eq.(2.55.c)) & 9.56 & 612 \\
\hline Mattock, 1994 (eq.(2.55.b)) & 9.11 & 583 \\
\hline \multicolumn{2}{|c|}{ Valor médio da força última obtido dos } \\
ensaios
\end{tabular}

* modelo obtido de ensaios de cisalhamento direto em interfaces pré-fissuradas.

** modelo obtido de ensaios em vigas com superfície rugosa.

+ a parcela de resistência por aderência é de 286 kN. 


\section{Programa experimental desenvolvido}

Neste capítulo são apresentados o detalhamento e os resultados dos ensaios de três vigas compostas biapoiadas realizados no Laboratório de Estruturas da EESC. O objetivo desses ensaios foi obter resultados próprios que proporcionassem uma maior sensibilidade na análise dos resultados experimentais disponíveis na literatura. Nessas vigas foi variada a forma da armadura transversal à interface para poder-se observar a influência do arranjo da armadura na resistência da interface das vigas aos esforços de cisalhamento horizontal.

\subsection{Introdução}

Foram ensaiadas três vigas biapoiadas com seção transversal em forma de $\mathrm{T}$ e carregadas com uma força concentrada no meio do vão (figura 5.1). As dimensões das vigas e as características da interface eram semelhantes às do programa experimental desenvolvido por Patnaik (PATNAIK (1992)). A variável estudada nos ensaios foi a forma da armadura transversal à interface, sendo utilizada armadura em forma de estribo fechado, em forma de estribo aberto com largura igual à largura dos estribos da alma e em forma de estribo aberto com largura reduzida. A largura do estribo foi reduzida para simular as características da ligação entre vigas pré-moldadas e laje moldada no local com a utilização de prélajes como fôrma. Nesse tipo de ligação, a armadura de costura possui largura inferior à largura da alma de forma a possibilitar o apoio das pré-lajes, sendo, portanto, a área de contato da interface entre a viga pré-moldada e a laje moldada no local reduzida.

A resistência do concreto prevista para as vigas era de $35 \mathrm{MPa}$ e a superfície da interface seria tornada naturalmente rugosa pela exposição dos 
agregados graúdos. Na tabela 5.1 são apresentados um resumo das principais características das vigas ensaiadas e as variáveis estudadas.

Tabela 5.1 - Resumo das principais características das vigas ensaiadas e variáveis estudadas.

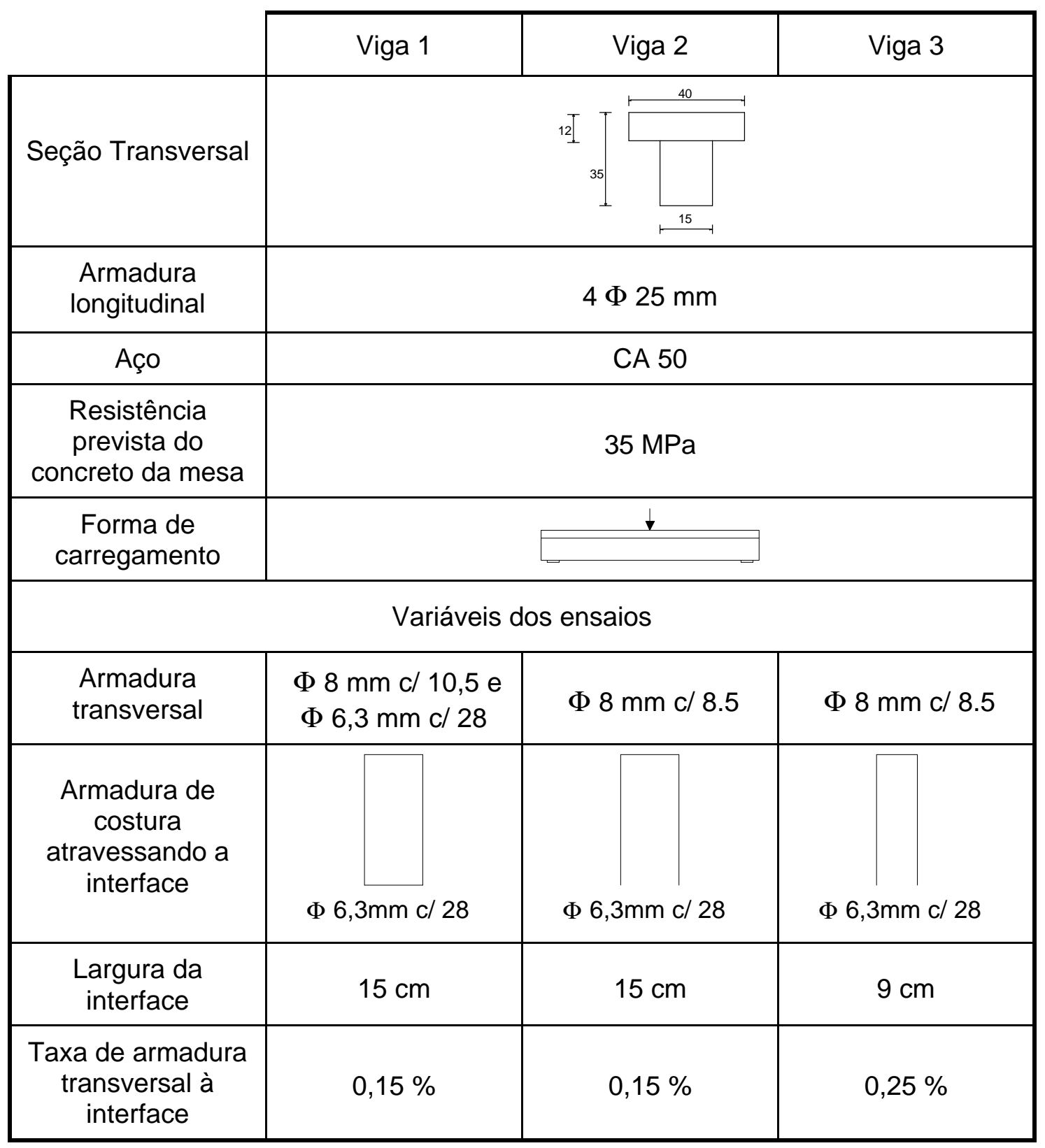

A definição da quantidade de armadura transversal à interface foi feita levando-se em consideração a quantidade mínima recomendada pelas normas e as vigas ensaiadas por Patnaik, de maneira que fosse possível levar as vigas à ruptura por cisalhamento horizontal com os equipamentos disponíveis no laboratório. 


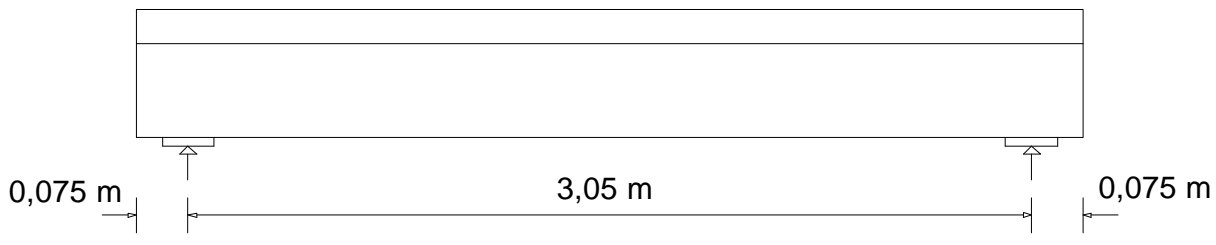

(a) elevação

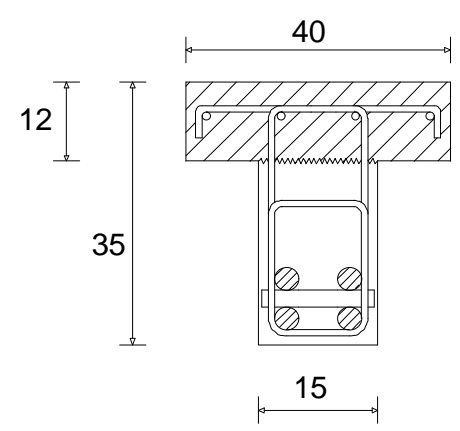

Viga 1

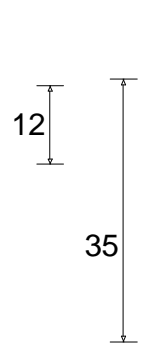

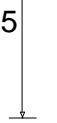

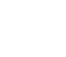

$$
\text { (1) }
$$

(
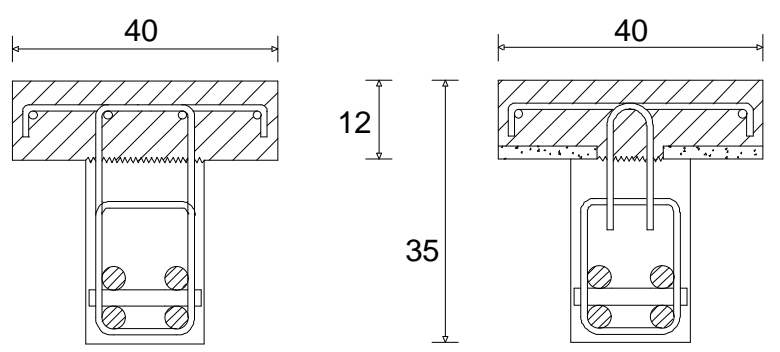

15

Viga 2

dimensões em cm

(b) seções transversais

Figura 5.1 - Dimensões das vigas compostas ensaiadas.

\subsection{Materiais}

\subsubsection{Concreto}

Os materiais utilizados na preparação do concreto foram obtidos na região. Após um estudo prévio de traços foi escolhido o traço 1:2,2:3,4 com fator água/cimento de 0,55. Para melhorar a trabalhabilidade do concreto e facilitar a concretagem das vigas foi adicionado $0,3 \%$, do peso do cimento, de superplastificante (Reax 1000) disponível no laboratório, tomando-se o cuidado de corrigir a quantidade de água. Essa correção foi feita multiplicando-se a quantidade em peso do superplastificante pela sua densidade e, admitindo uma presença de $70 \%$ de água na sua composição, subtraindo-se da quantidade de água. Utilizou-se cimento de alta resistência inicial, da marca Ciminas, de forma a permitir o ensaio das vigas sete dias após a concretagem da mesa. A resistência à compressão e a 
resistência à tração do concreto foram obtidas da ruptura de corpos-de-prova cilíndricos com $10 \mathrm{~cm}$ de diâmetro e $20 \mathrm{~cm}$ de altura.

Na tabela 5.2 é mostrada a quantidade de material para preparação de um metro cúbico de concreto e na tabela 5.3 são mostradas as principais características dos agregados utilizados. A resistência média à compressão e a resistência média à tração do concreto da alma e da mesa das vigas ensaiadas são mostradas na tabela 5.4 .

Tabela 5.2 - Quantidade de material para preparação de um metro cúbico de concreto.

\begin{tabular}{|c|c|}
\hline Material & Quantidade $(\mathrm{Kg})$ \\
\hline cimento ARI & 345 \\
\hline agregado miúdo & 759 \\
\hline agregado graúdo & 1173 \\
\hline água & 188,8 \\
\hline $\begin{array}{c}\text { superplastificante } \\
\left(\text { Reax } 1000-\gamma=1,245 \mathrm{Kg} / \mathrm{dm}^{3}\right)\end{array}$ & 1,289 \\
\hline
\end{tabular}

Tabela 5.3 - Principais características dos agregados.

\begin{tabular}{|c|c|c|}
\cline { 2 - 3 } \multicolumn{1}{c|}{} & Agregado graúdo & Agregado miúdo \\
\hline Diâmetro máximo & $19 \mathrm{~mm}$ & $2,4 \mathrm{~mm}$ \\
\hline Módulo de finura & 6,57 & 2,34 \\
\hline Massa unitária & $1,448 \mathrm{Kg} / \mathrm{dm}^{3}$ & $1,460 \mathrm{Kg} / \mathrm{dm}^{3}$ \\
\hline Massa específica real & $2,90 \mathrm{Kg} / \mathrm{dm}^{3}$ & $2,60 \mathrm{Kg} / \mathrm{dm}^{3}$ \\
\hline Índice de forma & 3,2 & - \\
\hline $\begin{array}{c}\text { Índice de material } \\
\text { pulverulento }\end{array}$ & $2,6 \%$ & - \\
\hline
\end{tabular}


Tabela 5.4 - Resistência média do concreto utilizado nas vigas ensaiadas.

\begin{tabular}{|c|c|c|c|c|c|c|c|}
\hline \multirow{2}{*}{ Viga } & \multicolumn{3}{|c|}{ Resistência média à compressão } & \multicolumn{3}{|c|}{ Resistência média à tração $\left(\mathrm{f}_{\mathrm{t}}\right)$} \\
& \multicolumn{4}{|c|}{$\left(\mathrm{f}_{\mathrm{c}}\right) \mathrm{MPa}$} & \multicolumn{3}{|c|}{$\mathrm{MPa}$} \\
\cline { 2 - 8 } & alma & $\mathrm{s}$ & mesa & $\mathrm{s}$ & alma & mesa & $\mathrm{s}$ \\
\hline 1 & 48,60 & 3,23 & 39,80 & 3,68 & - & 3,80 & 0,17 \\
\hline 2 & 42,84 & 3,08 & 41,50 & 2,97 & - & 3,64 & 0,89 \\
\hline 3 & 44,09 & 1,75 & 41,67 & 3,67 & - & 3,27 & 0,24 \\
\hline
\end{tabular}

$\mathrm{N}^{0}$ de corpos-de-prova ensaiados: compressão da alma: 4 compressão da mesa: 8 tração da mesa: 4

O módulo de elasticidade do concreto foi obtido da expressão recomendada pelo $\mathrm{ACl} 318-89$ :

$$
E_{c}=42,735 \cdot \gamma^{1,5} \cdot \sqrt{f_{c}}(M P a), \gamma=24 \mathrm{kN} / \mathrm{m}^{3}
$$

\subsubsection{Aço}

O aço utilizado na armação das vigas foi adquirido de comerciantes da região. Na figura 5.2 são mostradas as curvas de tensão-deformação das barras de 6,3 $\mathrm{mm}$ e $10 \mathrm{~mm}$. Para o ensaio de tração das barras de aço foram utilizados, para cada diâmetro, três corpos-de-prova com $40 \mathrm{~cm}$ de comprimento. Os resultados dos ensaios foram obtidos à partir do diagrama força-deslocamento traçado pelo equipamento. Para cálculo da tensão solicitante na interface, o aço foi admitido com módulo de elasticidade igual a $210.000 \mathrm{MPa}$.

As barras de $8 \mathrm{~mm}$ e $25 \mathrm{~mm}$ utilizadas nos estribos da alma e na armadura longitudinal, respectivamente, não foram ensaiadas por não serem objeto de estudo deste trabalho. 


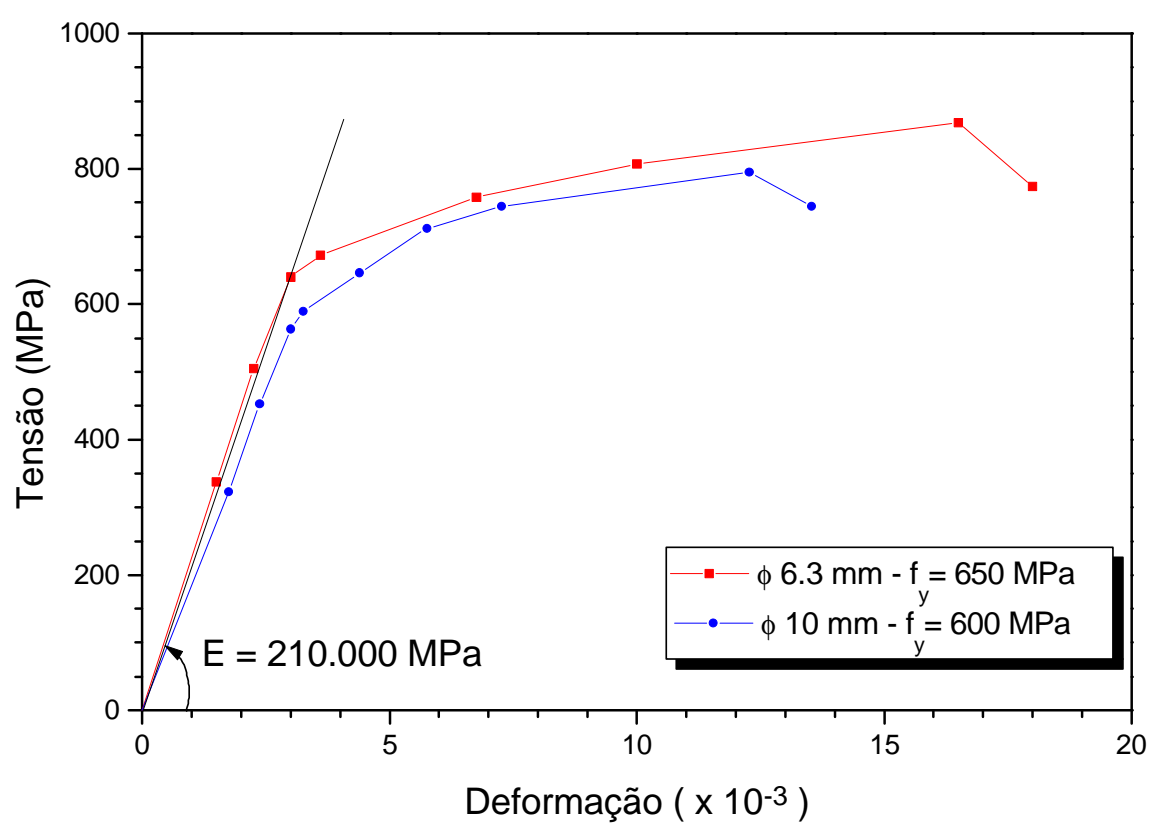

Figura 5.2 - Diagrama tensão-deformação do aço utilizado nas vigas.

\subsection{Execução das vigas}

\subsubsection{Fôrma}

Para possibilitar a moldagem das vigas foi confeccionada uma fôrma de madeira compensada de $15 \mathrm{~mm}$ reforçada com caibros de madeira e ligadas por parafusos. Na figura 5.3 é mostrada uma vista geral da fôrma e as principais dimensões. 

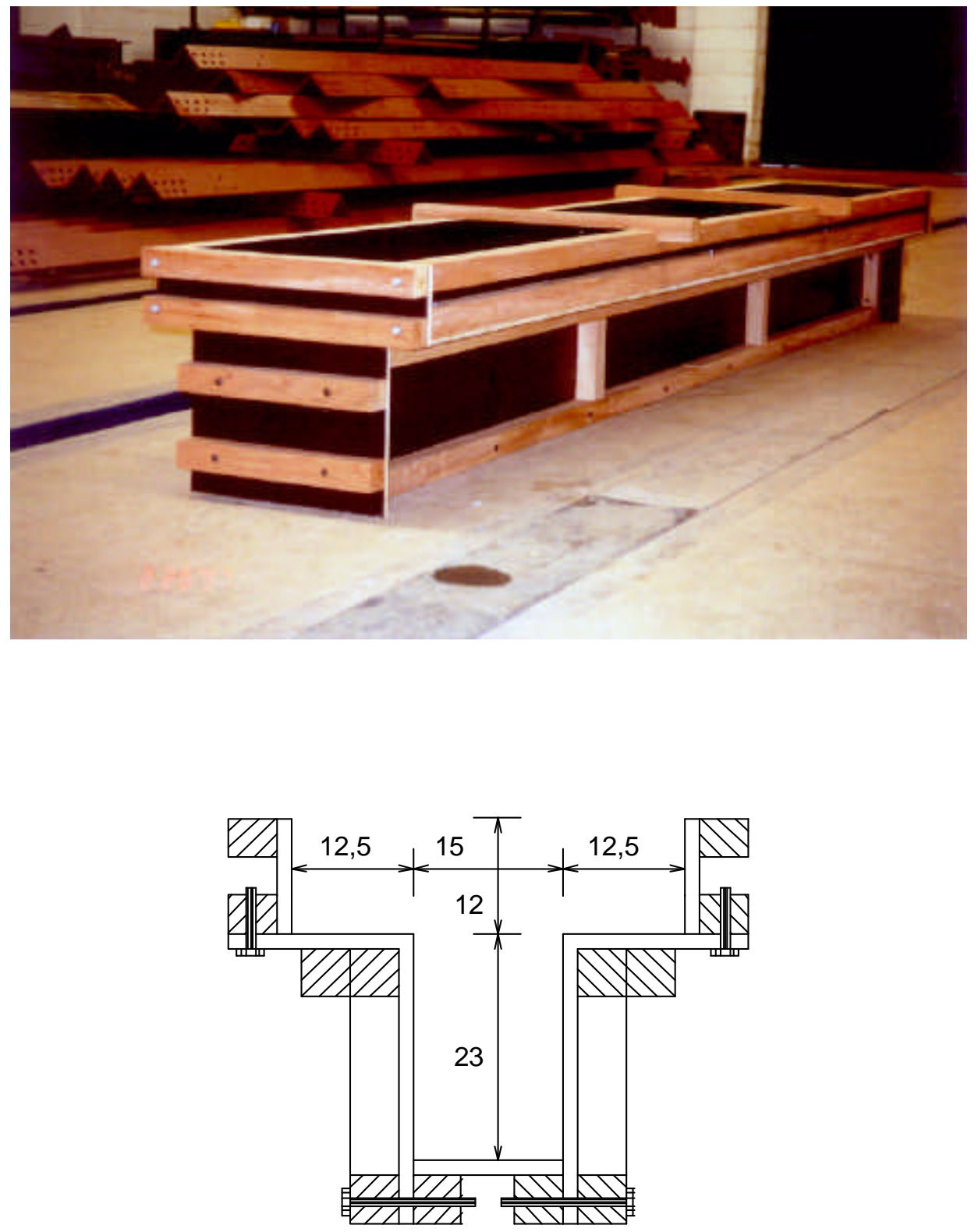

Figura 5.3 - Vista geral da fôrma e principais dimensões (cm).

\subsubsection{Armadura das vigas}

As vigas foram dimensionadas de forma que a ruptura ocorresse na interface entre a mesa e a alma. Dessa forma, tanto a armadura para resistir ao momento fletor quanto a armadura para resistir ao esforço cortante foram dimensionadas para resistir a duas vezes a força estimada para ruptura por cisalhamento da interface. Na figura 5.4 é mostrado o detalhamento da armadura das três vigas ensaiadas. Foram empregadas três formas de armadura de costura 
da interface: armadura em forma de estribo fechado (viga 1), em forma de estribo aberto com largura igual à largura dos estribos da alma (viga 2) e em forma de estribo aberto com largura reduzida (viga 3). Na figura 5.5 é mostrada uma vista da armadura da alma de cada viga ensaiada.
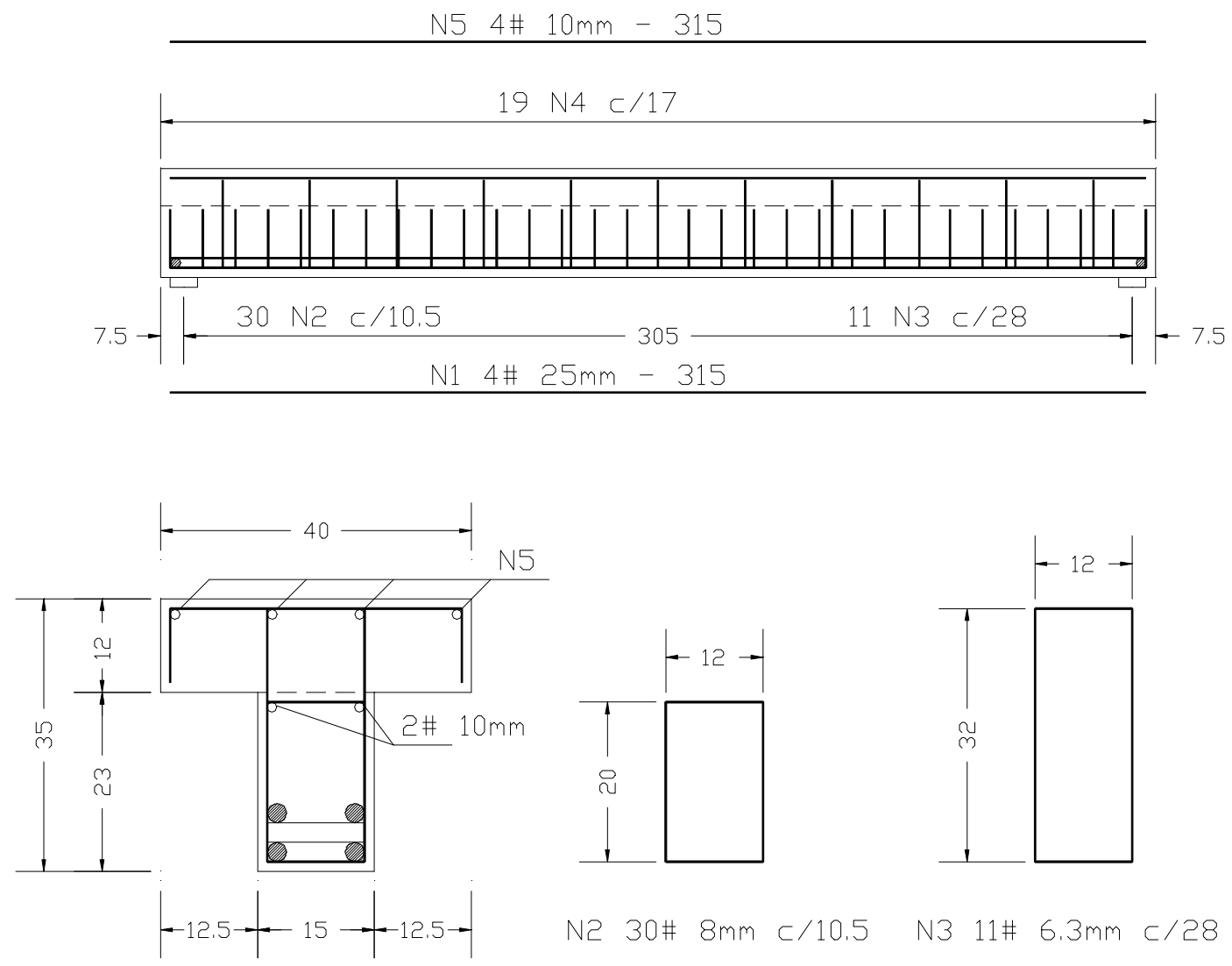

N2 $30 \#$ Bmm $\sqsubset / 10.5$

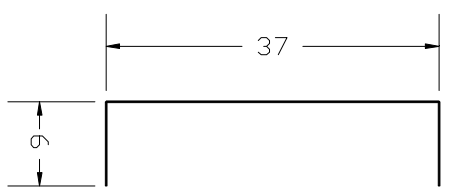

पbs: medidas em centimetro

N4 19\# 10mm c/17

Figura 5.4(a) - Detalhamento da viga 1. 

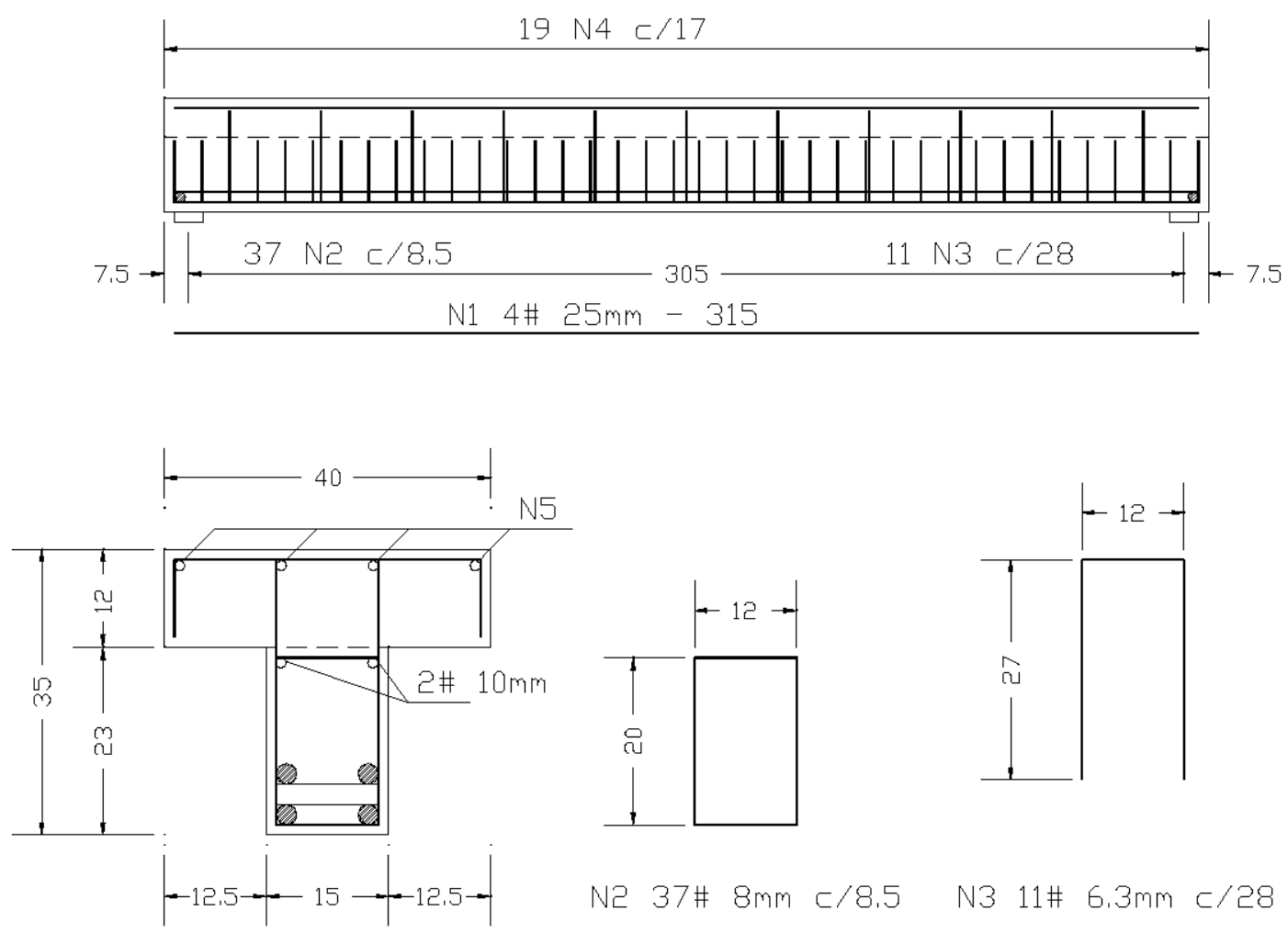

N2 $37 \# \quad 8 m m \quad \subset / 8.5$

N3 11\# $6.3 \mathrm{~mm} \subset / 28$

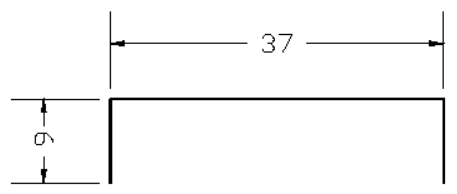

Dbsi medidas em centimetro

N4 19\# 10mm c/17

Figura 5.4(b) - Detalhamento da viga 2. 

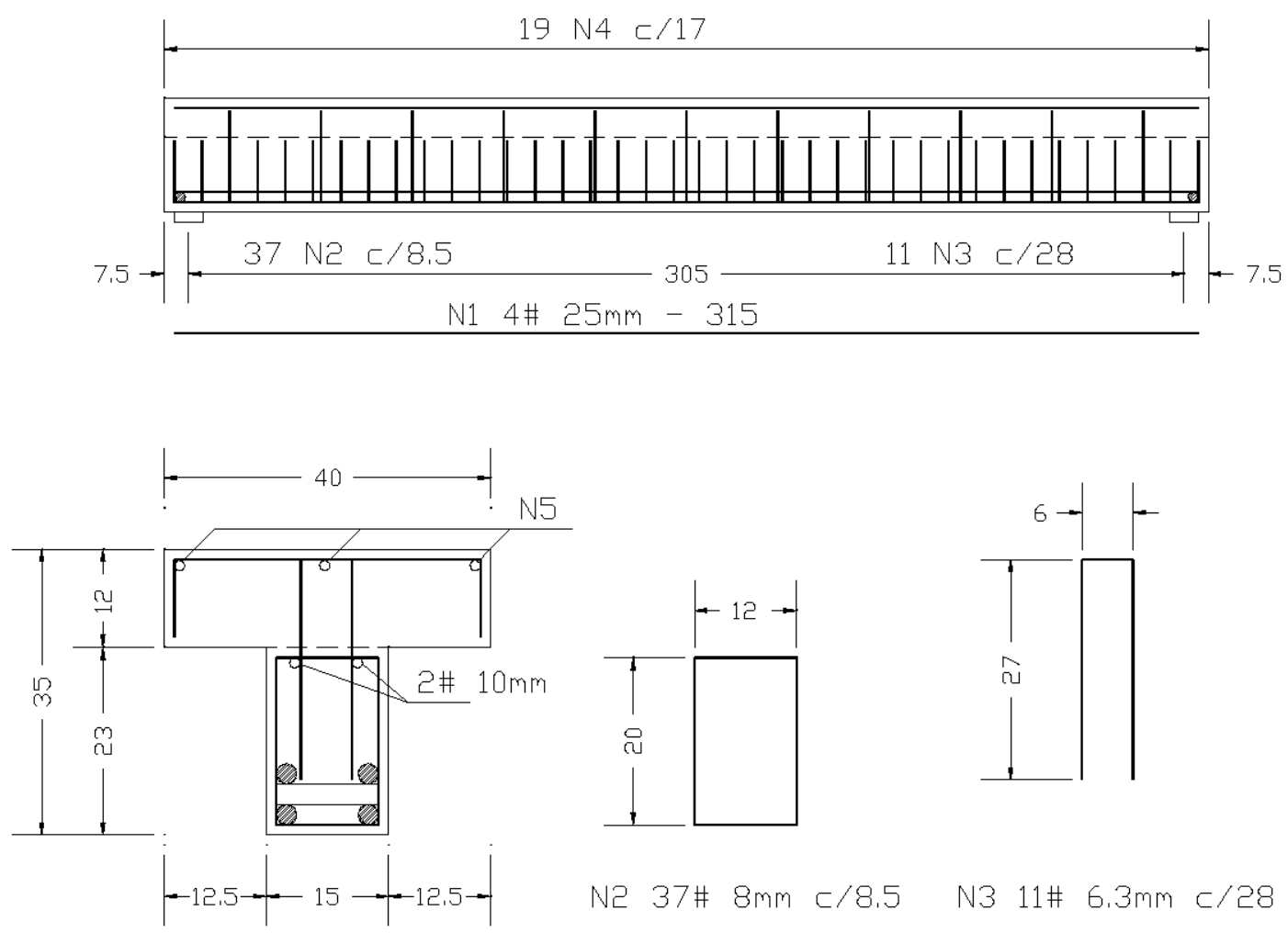

N2 $37 \# 8 \mathrm{~mm} \subset / 8.5 \quad$ N3 $11 \# 6.3 \mathrm{~mm} \quad c / 28$

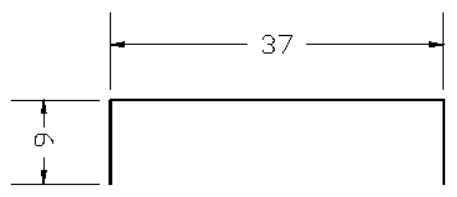

Dbsi medidas em centimetro

N4 19\# 10mm c/17

Figura 5.4(c) - Detalhamento da viga 3. 


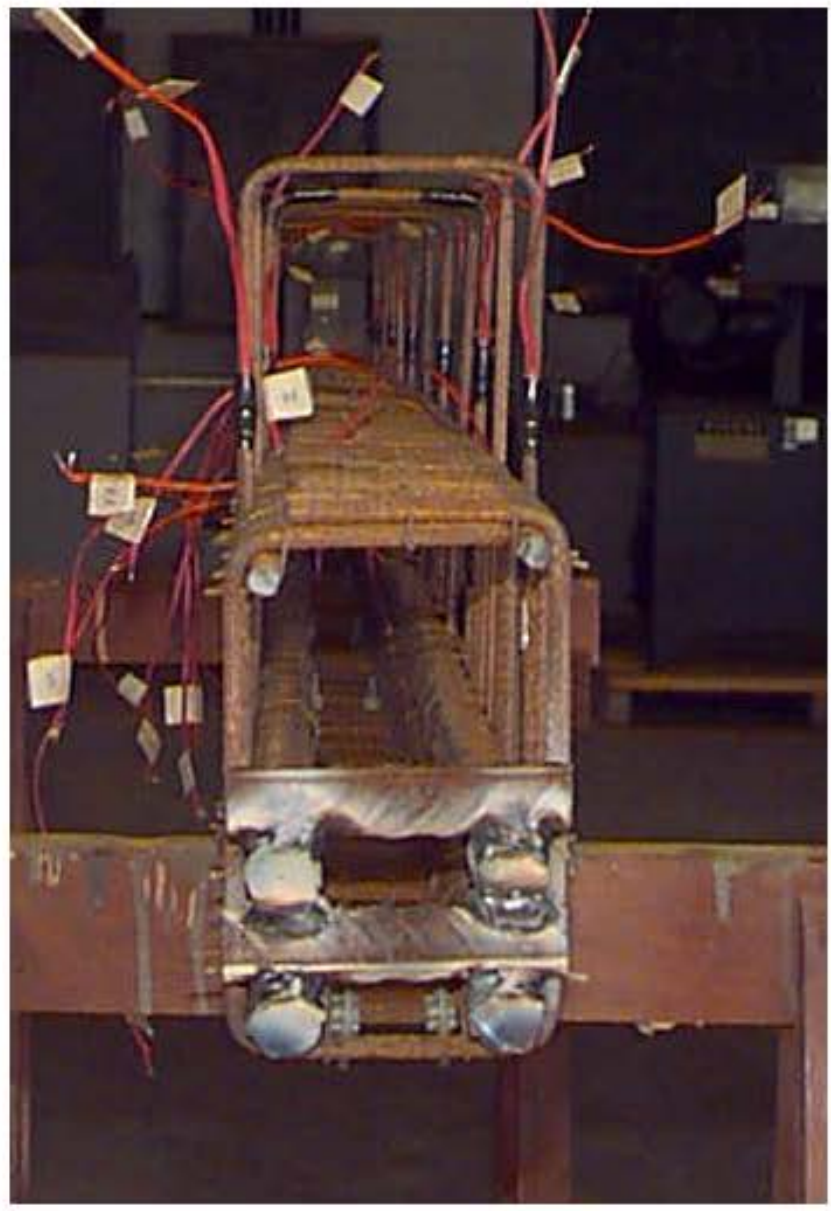

Figura 5.5(a) - Vista da armadura da alma da viga 1.

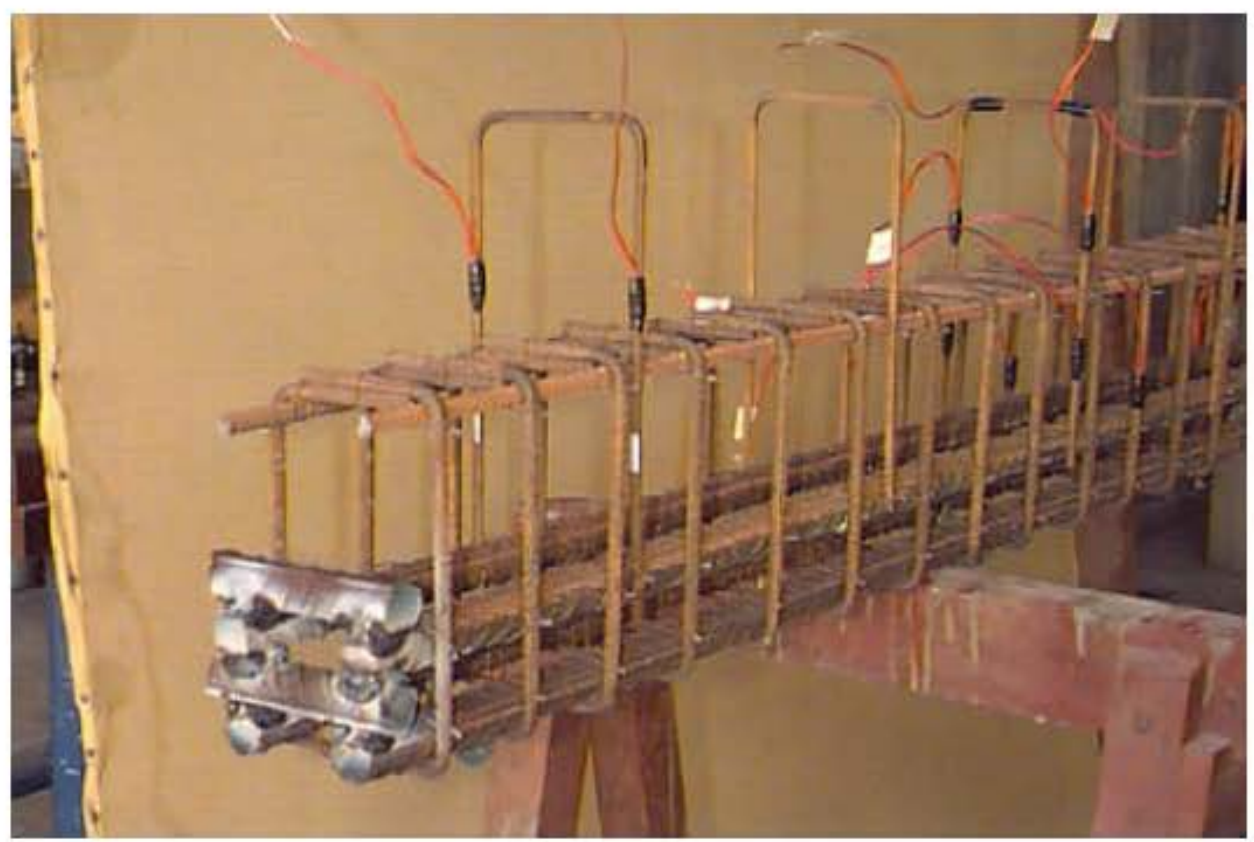

Figura 5.5(b) - Vista da armadura da alma da viga 2. 


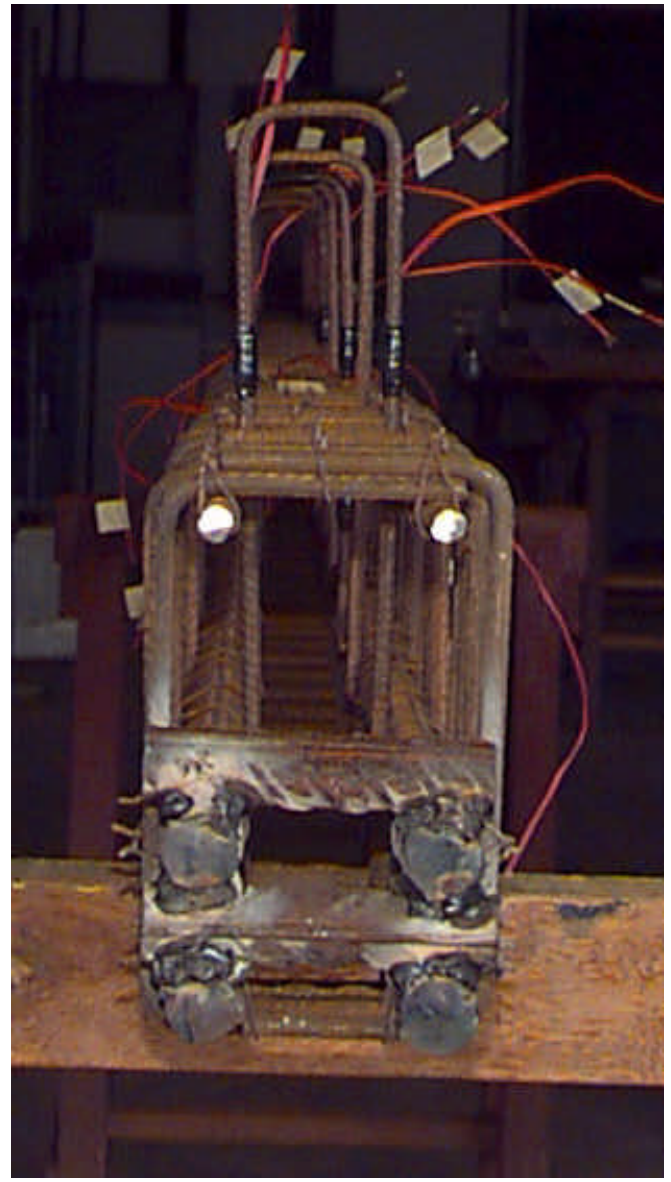

Figura 5.5(c) - Vista da armadura da alma da viga 3.

A armadura longitudinal foi estendida até o apoio e, nesta posição, foram soldadas duas barras $\left(\Phi_{\mathrm{s}}=25 \mathrm{~mm}\right)$ para garantir a ancoragem da armadura longitudinal e evitar a ruptura localizada por escorregamento da armadura (figura 5.6). Foram colocadas armaduras longitudinais próximas à interface $\left(\Phi_{\mathrm{s}}=10 \mathrm{~mm}\right)$ por ser essa uma situação comum em vigas pré-moldadas de forma a facilitar a montagem dos estribos. 


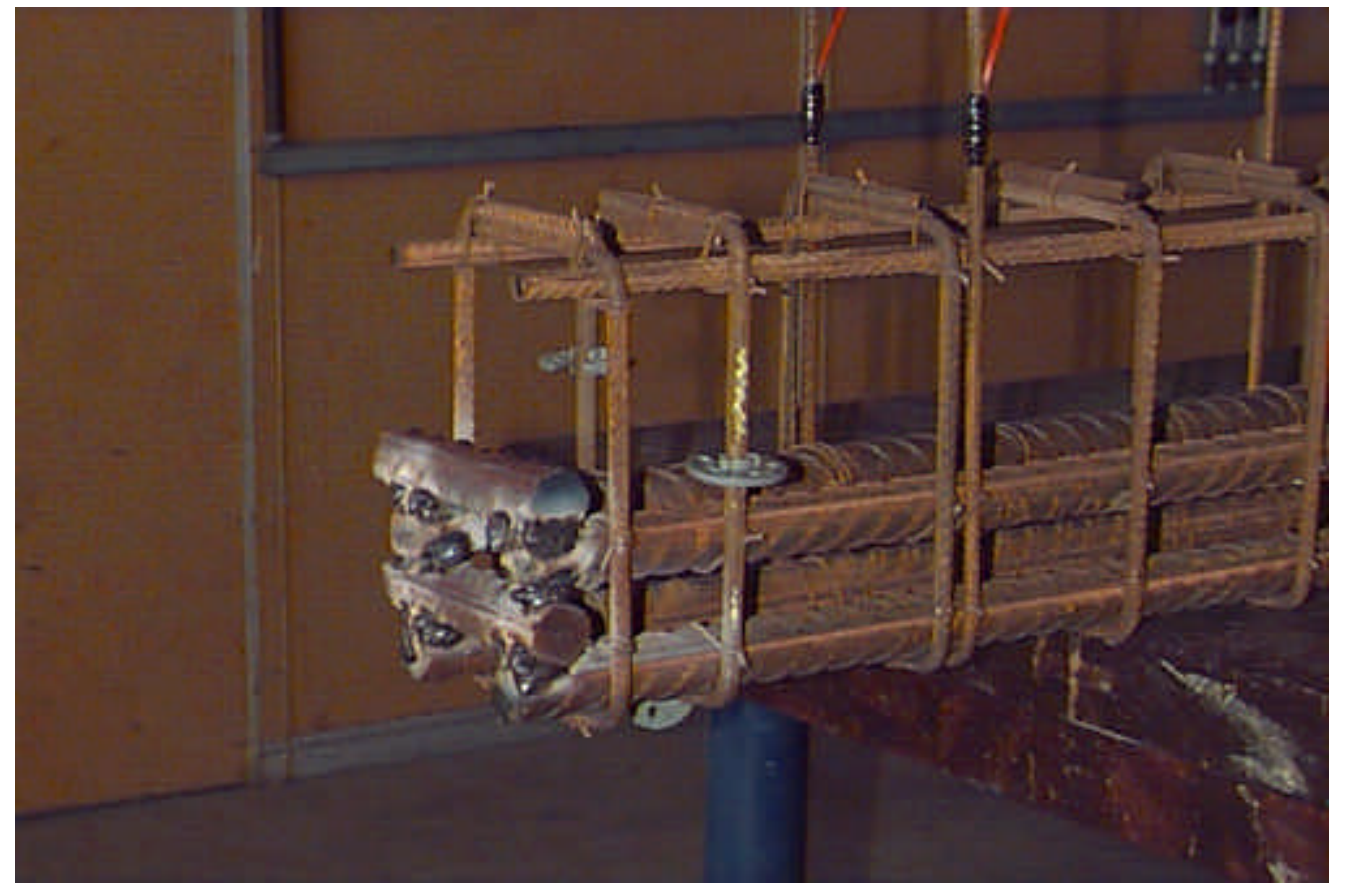

Figura 5.6 - Detalhe da ancoragem da armadura longitudinal no apoio.

\subsubsection{Moldagem das vigas}

As vigas foram moldadas em duas etapas com a finalidade de simular 0 comportamento de estruturas compostas formadas por vigas pré-moldadas e laje moldada no local. Na primeira etapa foi moldada a alma da viga deixando-se exposta parte da armadura de costura e, após quatro dias, foi moldada a mesa. $O$ cronograma típico de moldagem de uma viga é mostrado na figura 5.7.

\begin{tabular}{|c|l|l|l|l|l|l|l|l|l|l|l|l|}
\hline Dias & 1 & 2 & 3 & 4 & 5 & 6 & 7 & 8 & 9 & 10 & 11 & 12 \\
\hline $\begin{array}{c}\text { Moldagem da alma da viga e } \\
\text { corpos de prova }\end{array}$ & & & & & & & & & & & & \\
\hline $\begin{array}{c}\text { Moldagem da mesa da viga e } \\
\text { corpos de prova }\end{array}$ & & & & & & & & & & & & \\
\hline \begin{tabular}{c} 
Desmoldagem da viga \\
\hline $\begin{array}{c}\text { Ensaio da viga e ruptura dos } \\
\text { corpos de prova }\end{array}$
\end{tabular} & & & & & & & & & & & & \\
\hline
\end{tabular}

Figura 5.7 - Cronograma de moldagem de uma viga composta. 
Após montada a armação da alma, ela foi colocada na forma com espaçadores para garantir o cobrimento de concreto da armadura. A moldagem da alma foi feita em duas camadas. A primeira camada de concreto foi lançada de forma que, após vibrada, houvesse uma distância de aproximadamente $3 \mathrm{~cm}$ até a face superior da alma. Essa camada foi bem adensada com vibrador de agulha para que o concreto envolvesse toda a armadura e não houvesse a formação de vazios. A segunda camada de concreto foi lançada imediatamente a seguir, sendo rapidamente vibrada de forma que os agregados graúdos ficassem expostos, isto é, não surgisse grande quantidade de nata de cimento na superfície durante a vibração. Dessa forma, procurou-se obter uma superfície naturalmente rugosa que poderia ser reproduzida em obras civis correntes. O aspecto final da superfície é mostrado na figura 5.8 .

Após o início da pega do concreto da alma, sua superfície foi coberta com espuma encharcada com água e mantida nessas condições por dois dias. No terceiro dia as espumas foram retiradas e a armadura da mesa foi montada. No quarto dia procedeu-se a limpeza da superfície da interface com ar comprimido e aspirador para retirar impurezas e partículas soltas. Em seguida a superfície foi umedecida e efetuou-se a moldagem da mesa. Tomou-se o cuidado de evitar que houvesse água livre na superfície de contato pois poderia prejudicar a ligação entre o concreto velho e o concreto novo. A mesa foi moldada em uma única camada e sua superfície alisada. Após o início da pega, a superfície de concreto foi mantida úmida durante dois dias através de espuma encharcada com água.

A viga 3 apresentou um detalhe na interface diferente das outras duas vigas. Após a concretagem da alma, uma faixa de aproximadamente $3 \mathrm{~cm}$ de largura de cada lado da superfície da alma foi alisada de forma que o agregado graúdo não ficasse exposto. Um dia antes da concretagem da mesa foi colada fita isolante nessa faixa para impedir a transferência de tensões de cisalhamento por aderência entre a mesa e a alma nessa região (figura 5.9). Esse detalhe foi empregado para tentar simular a falta de aderência na superfície de contato entre as vigas pré-moldadas e as pré-lajes utilizadas em construções compostas. 

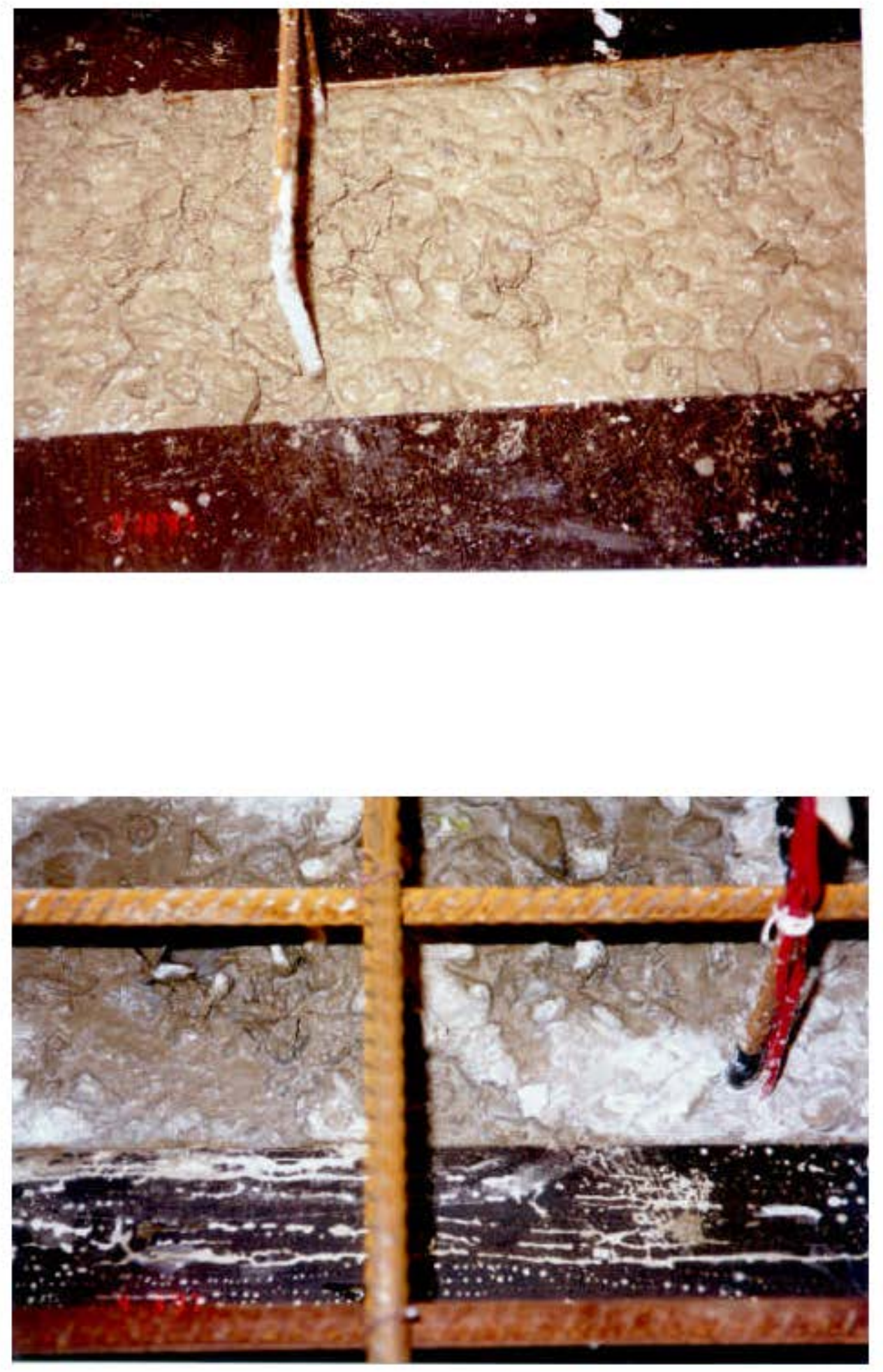

Figura 5.8 - Aspecto final da superfície da interface. 

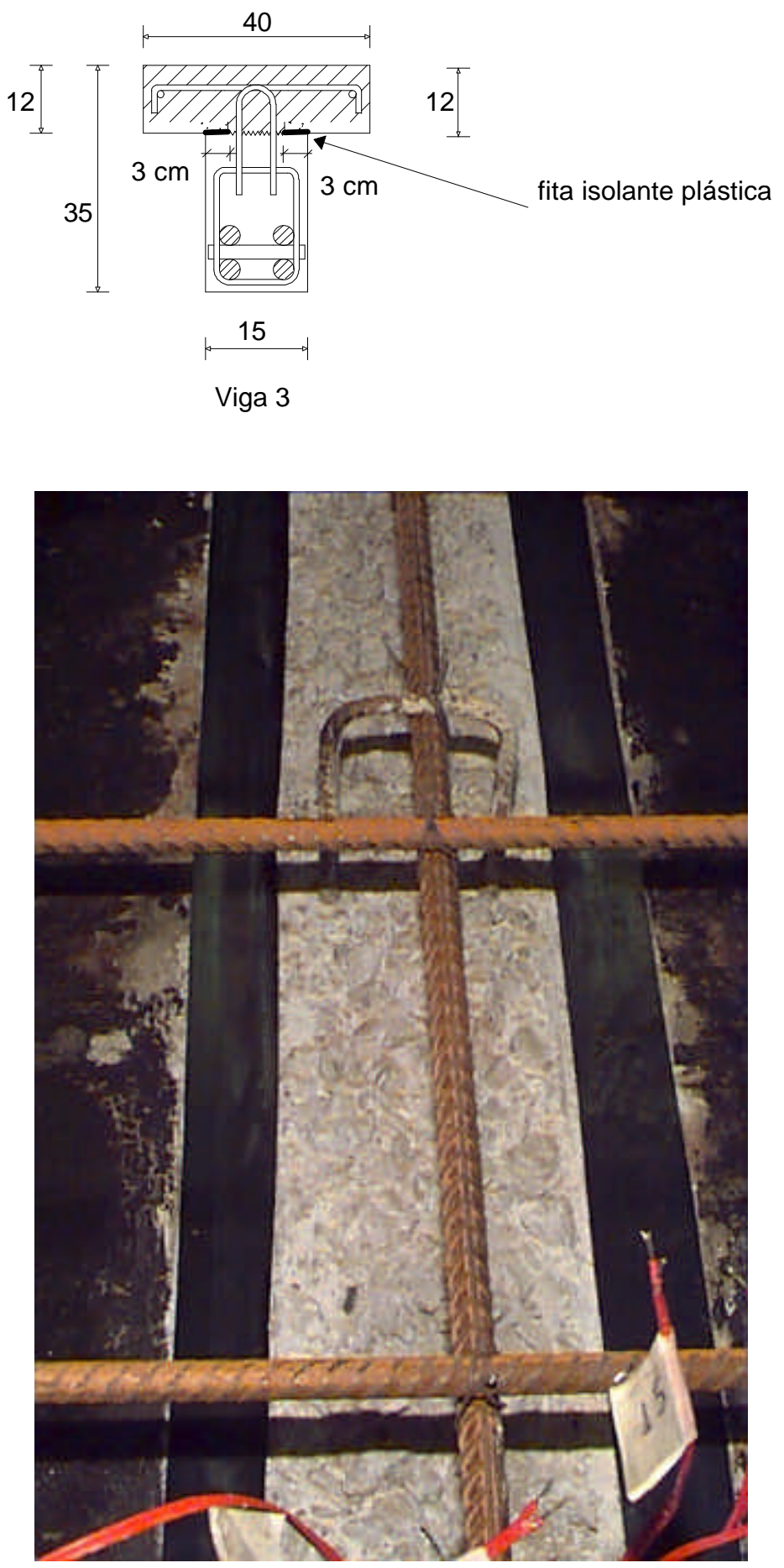

Figura 5.9 - Detalhe da interface da viga 3. 


\subsection{Instrumentação e execução dos ensaios}

No terceiro dia após a moldagem da mesa a viga foi desmoldada. Para tanto, ela foi tombada e colocada em posição invertida de maneira que as laterais da fôrma pudessem ser retiradas. Com ajuda da ponte rolante a viga foi içada e colocada no pórtico de ensaio em posição invertida, ou seja, com a face superior da mesa voltada para baixo. A figura 5.10 ilustra a posição da viga no pórtico e o esquema de carregamento.

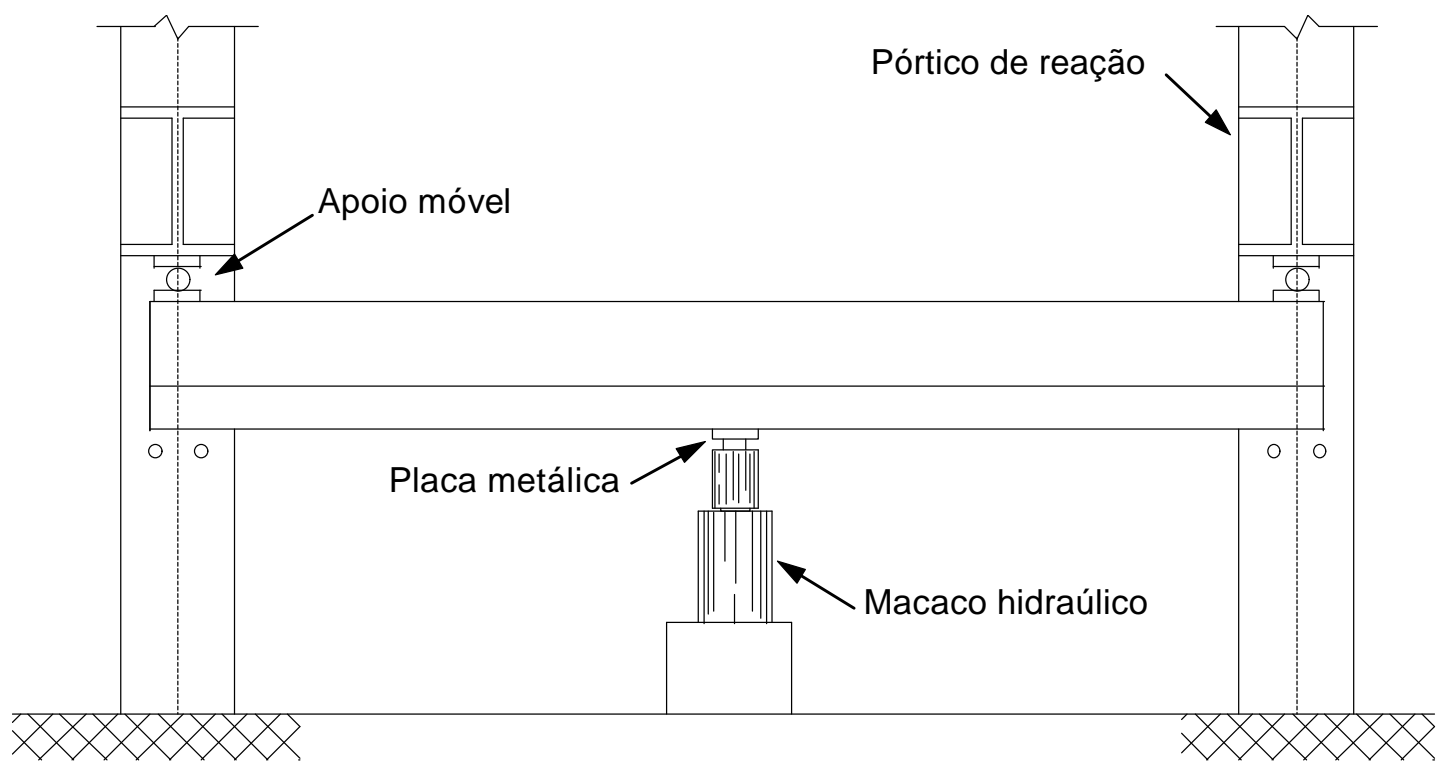

Figura 5.10 - Posição de ensaio das vigas e esquema de carregamento.

As vigas foram instrumentadas para a medição do deslizamento relativo entre a mesa e a alma, para medição de deslocamentos verticais e para medição da deformação da armadura. Na figura 5.11 é mostrada toda a instrumentação das vigas ensaiadas. O deslizamento relativo entre a mesa e a alma foi medido através de transdutores fixados à mesa, por meio de cantoneiras de alumínio, com a haste apoiada numa cantoneira fixada na alma (figura 5.11(g)). Esses transdutores foram colocados nos pontos onde esperava-se ocorrer os maiores deslizamentos. Próximos às extremidades e ao meio do vão foram colocados relógios mecânicos para medição do deslizamento em algumas etapas de carregamento. Os deslocamentos verticais foram medidos em três pontos: no meio do vão e na quarta parte de cada lado do vão. 
Para medição da deformação da armadura foram colados extensômetros elétricos de resistência. Eles foram colados no meio das barras da armadura longitudinal $\left(\Phi_{\mathrm{s}}=25 \mathrm{~mm}\right)$ para controle das deformações por momento fletor e em dois estribos contidos na alma para controle da deformação devido ao esforço cortante. A maior parte da instrumentação da armadura foi realizada na armadura de costura da interface. Em seis estribos foram colados extensômetros na altura da interface, sendo que em dois deles foram colados mais alguns extensômetros para analisar a distribuição de tensões ao longo da armadura de costura (figura 5.11(a)).

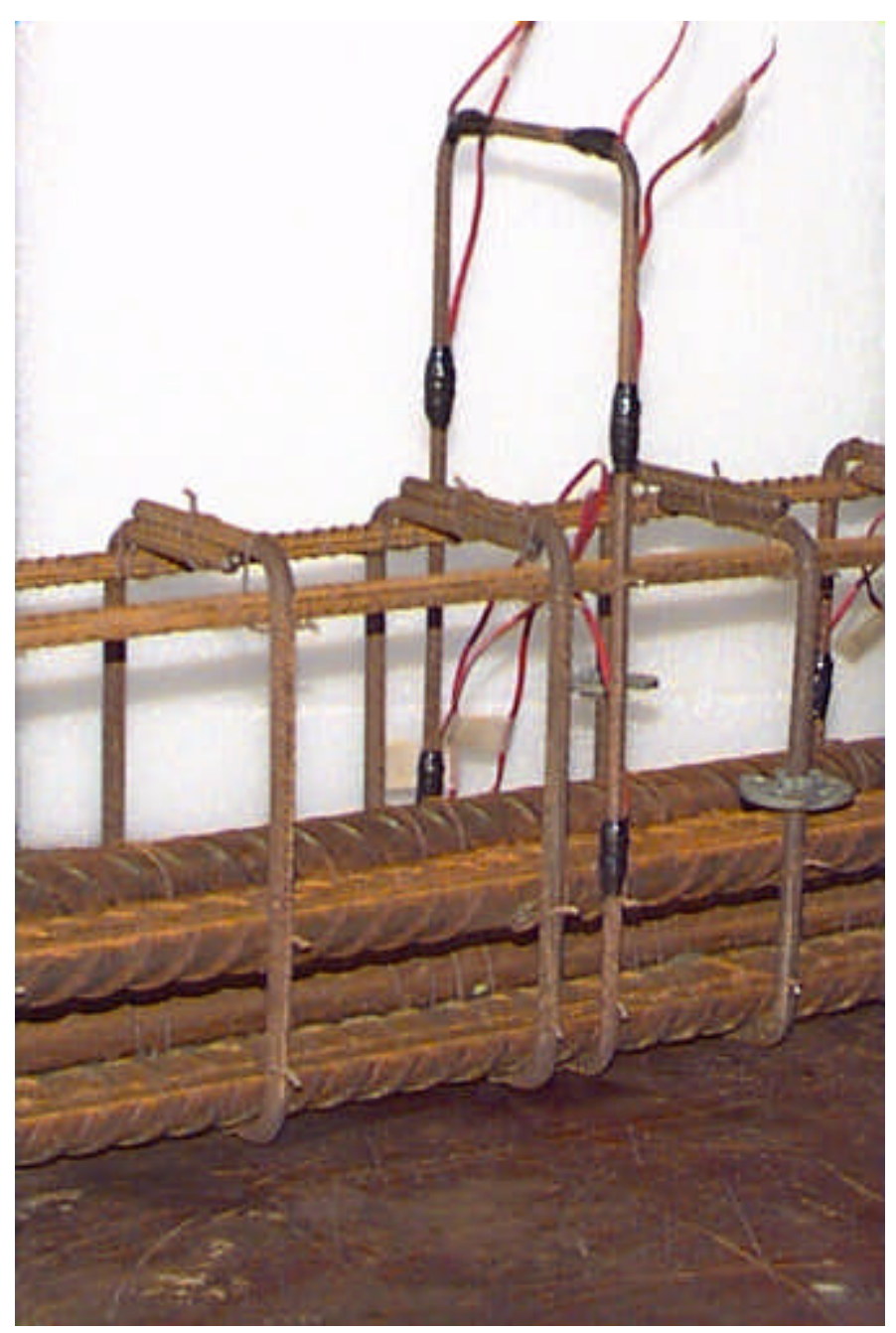

Figura 5.11(a) - Detalhe da instrumentação da armadura de costura da interface com extensômetros elétricos de resistência. 


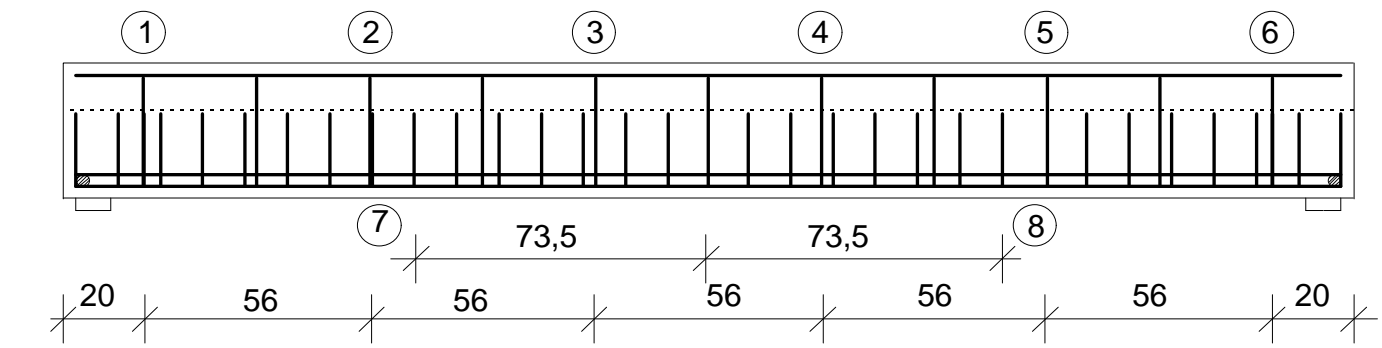

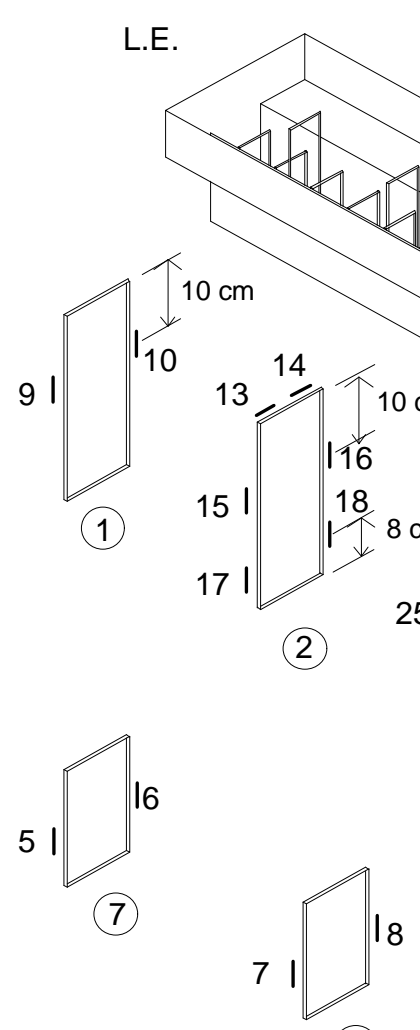

(8)

dimensões em cm

L.D.

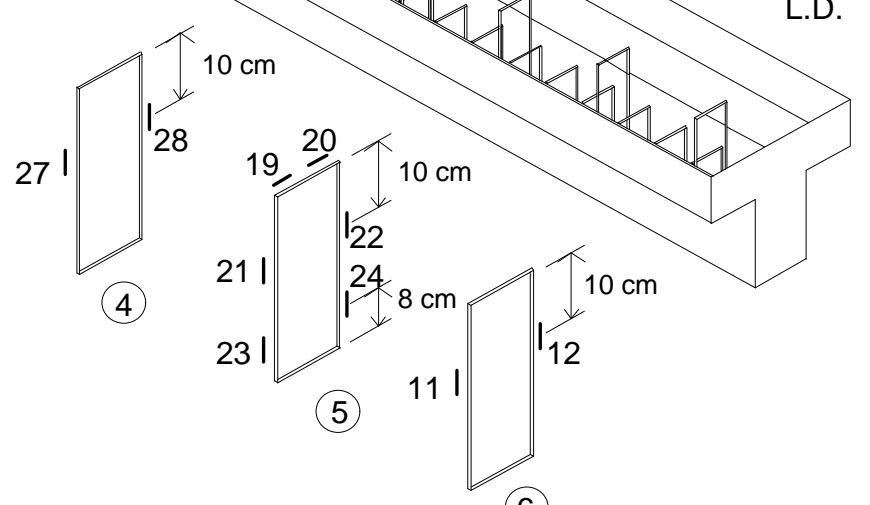

(6)

extensômetros da armadura transversal e do concreto

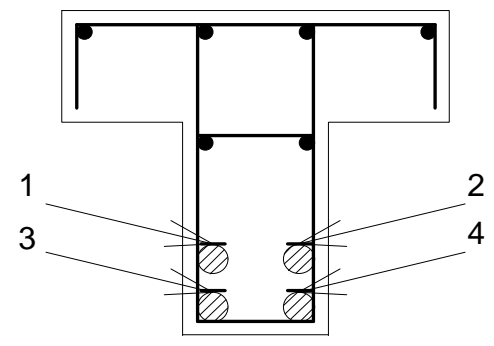

extensômetros da armadura longitudinal

Figura 5.11(b) - Instrumentação da viga 1: numeração dos extensômetros na armadura e no concreto. 


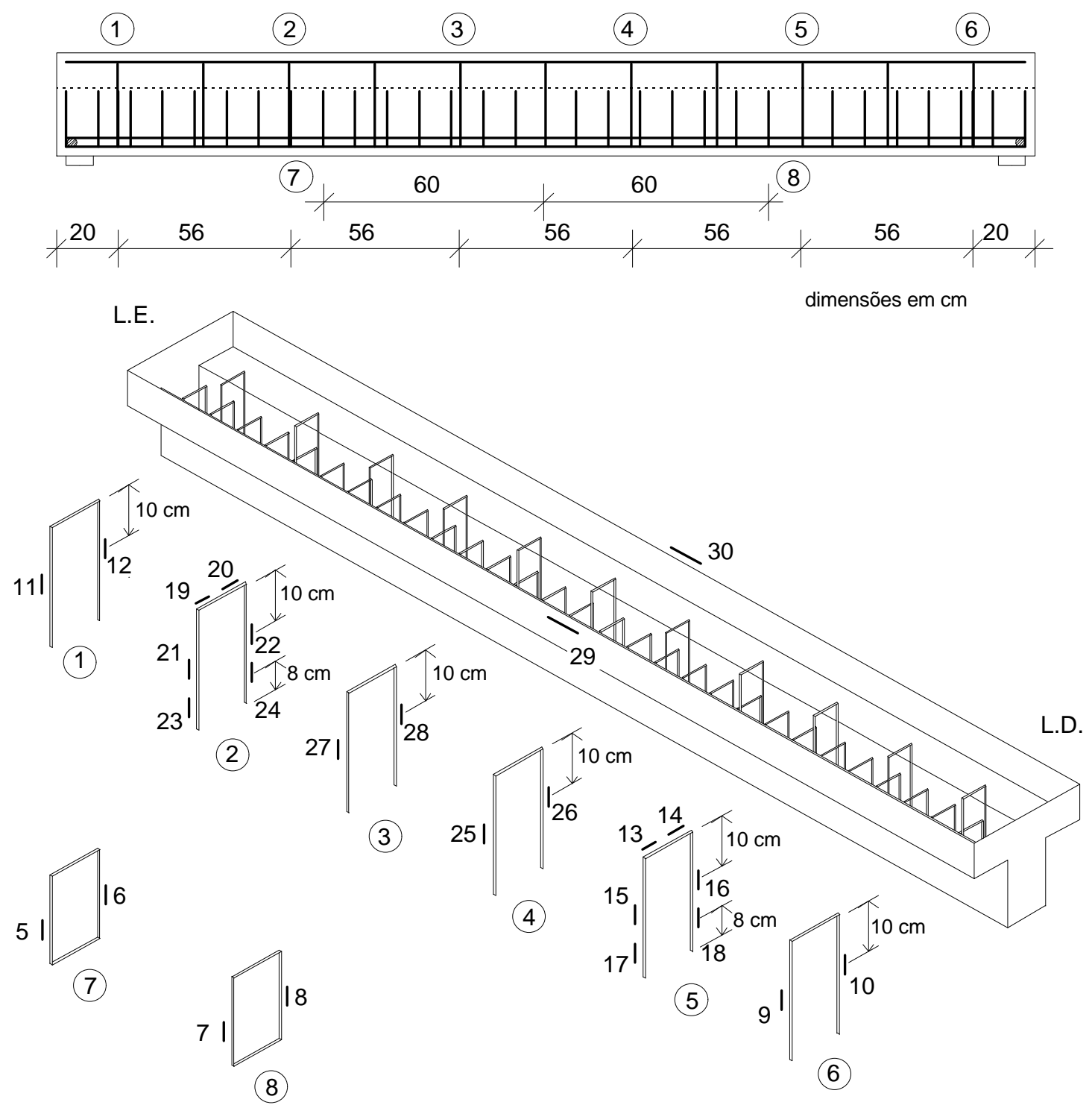

extensômetros da armadura transversal e do concreto

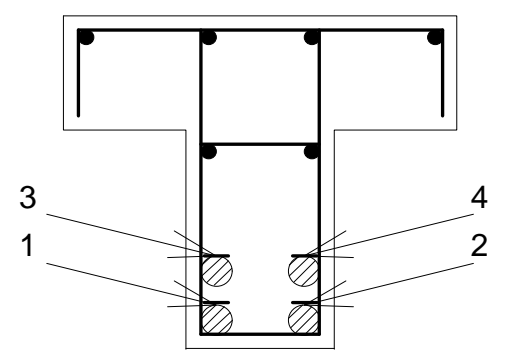

extensômetros da armadura longitudinal

Figura 5.11(c) - Instrumentação da viga 2: numeração dos extensômetros na armadura e no concreto. 

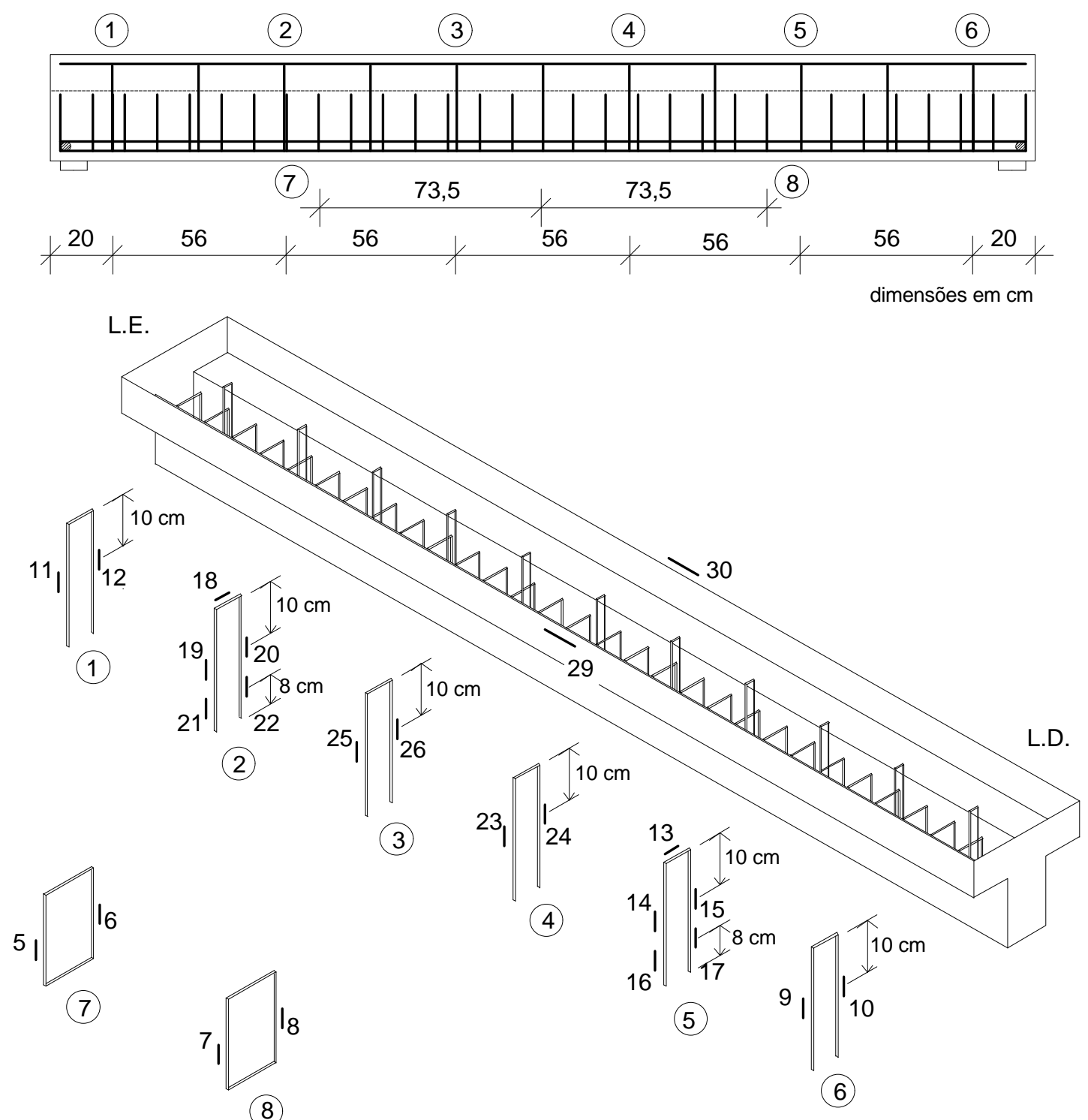

extensômetros da armadura transversal e do concreto

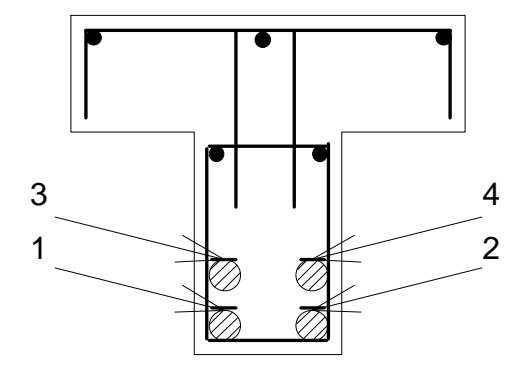

extensômetros da armadura longitudinal

Figura 5.11(d) - Instrumentação da viga 3: numeração dos extensômetros na armadura e no concreto. 


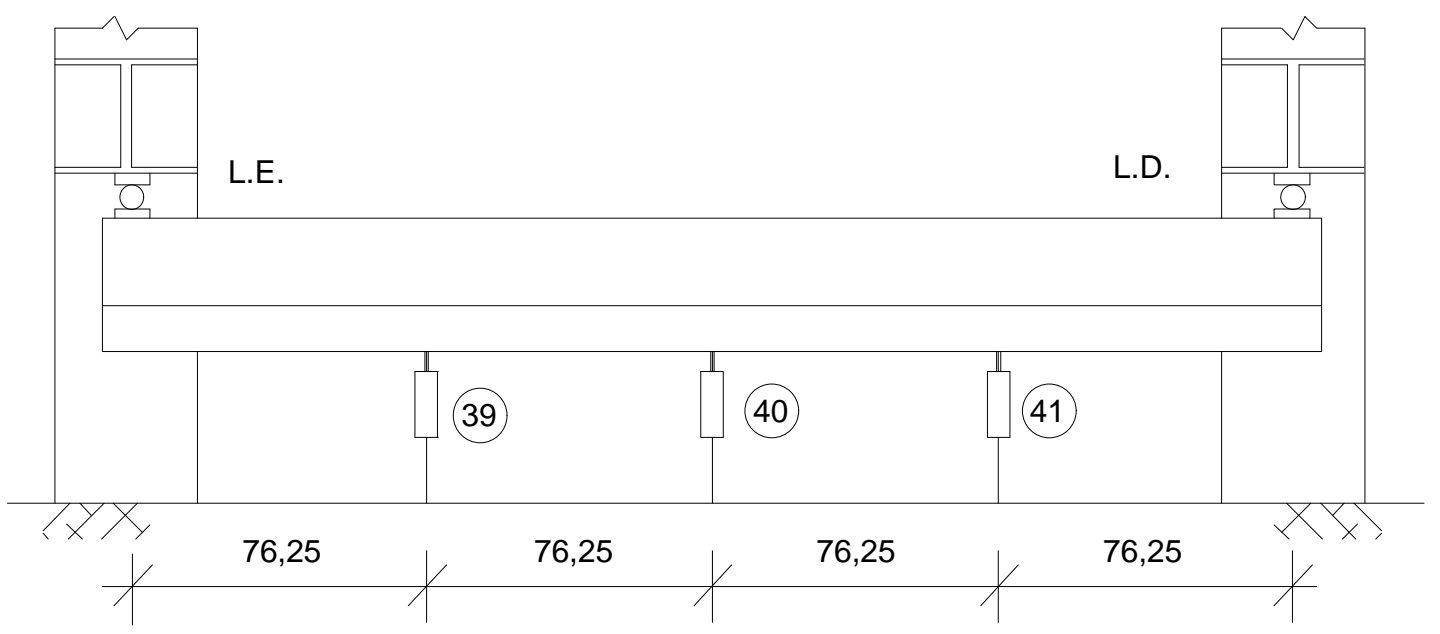

Posição dos transdutores para medição dos deslocamentos verticais

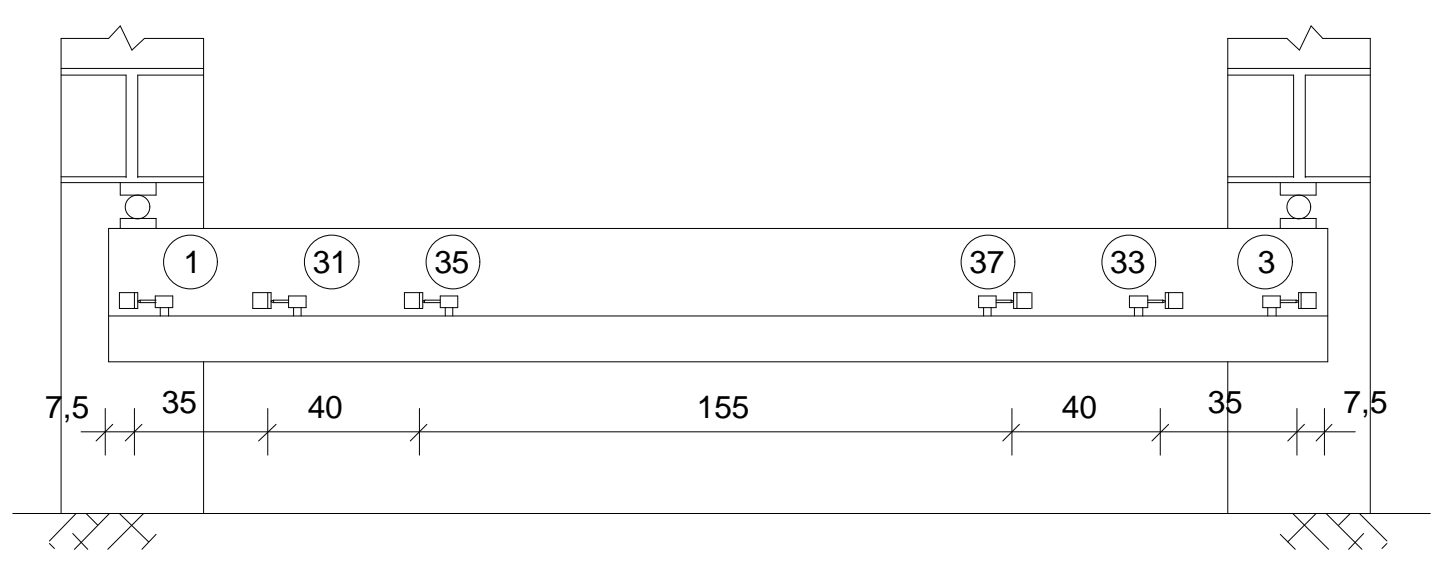

elevação

L.E. \begin{tabular}{cccccccccc}
2 & 32 & 36 & 38 & 34 \\
\hline
\end{tabular}

planta

Posição dos transdutores para medição do deslizamento relativo entre a mesa e a alma dimensões em cm

Figura 5.11(e) - Instrumentação da viga 1: numeração dos transdutores para medição do deslizamento da interface e deslocamentos verticais. 


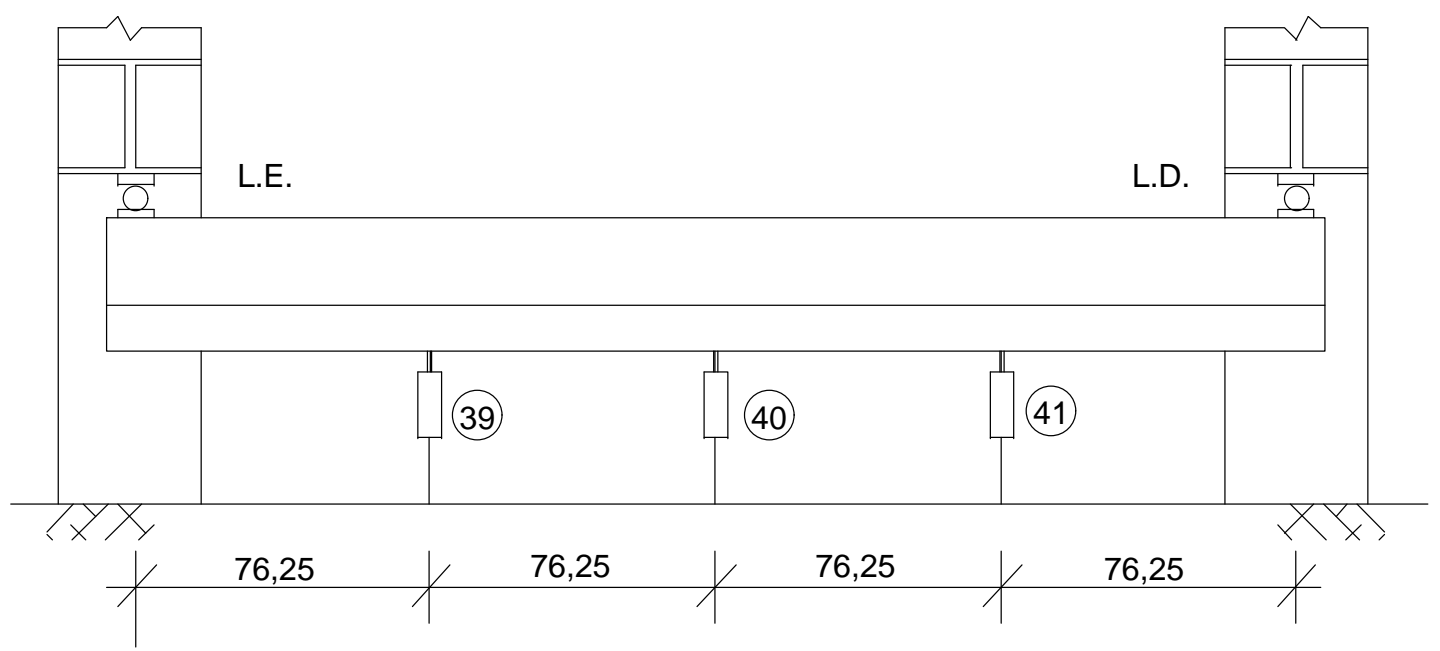

Posição dos transdutores para medição dos deslocamentos verticais
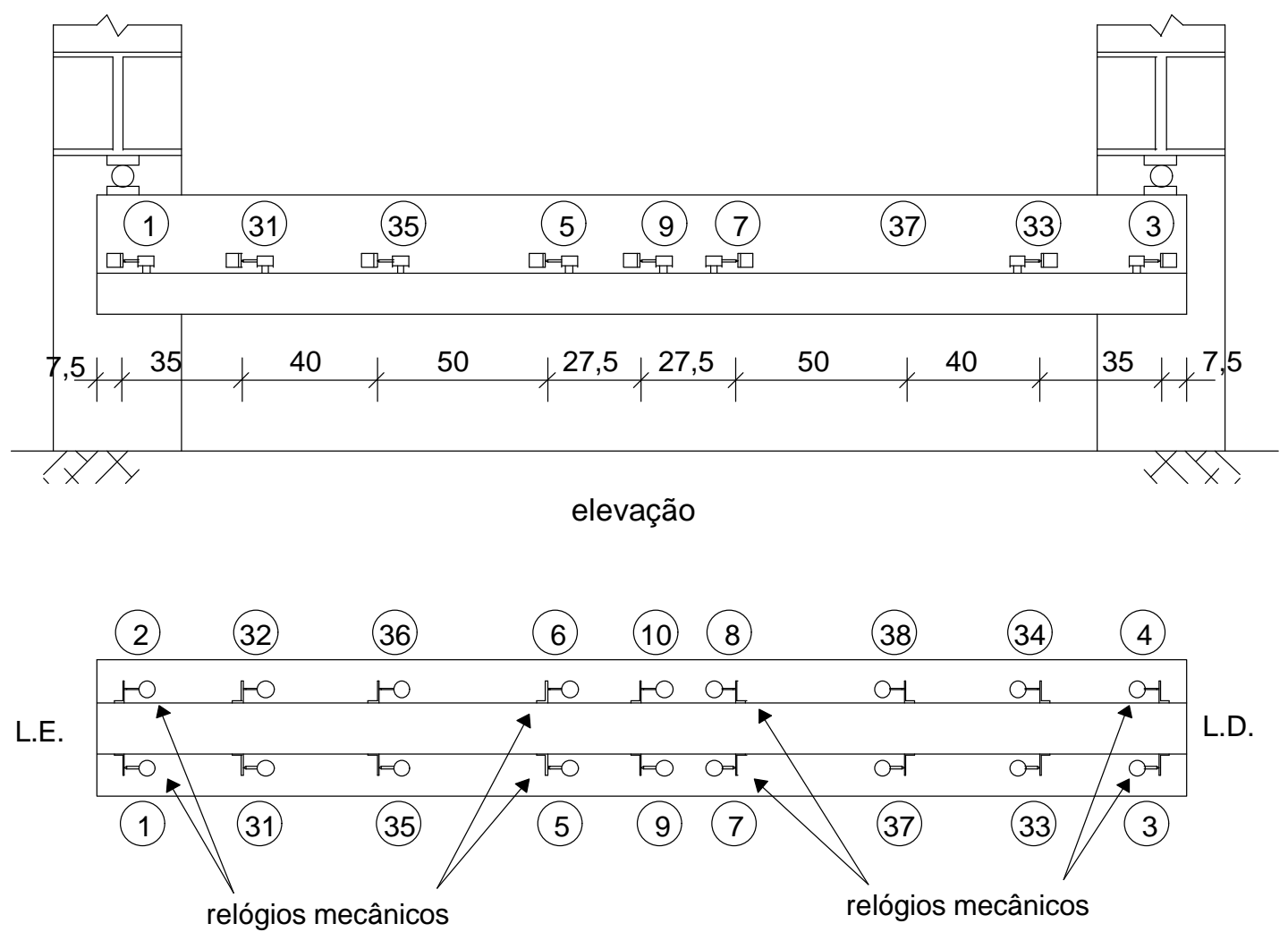

planta

Posição dos transdutores para medição do deslizamento relativo entre a mesa e a alma dimensões em cm

Figura 5.11(f) - Instrumentação das vigas 2 e 3: numeração dos transdutores para medição do deslizamento da interface e deslocamentos verticais. 


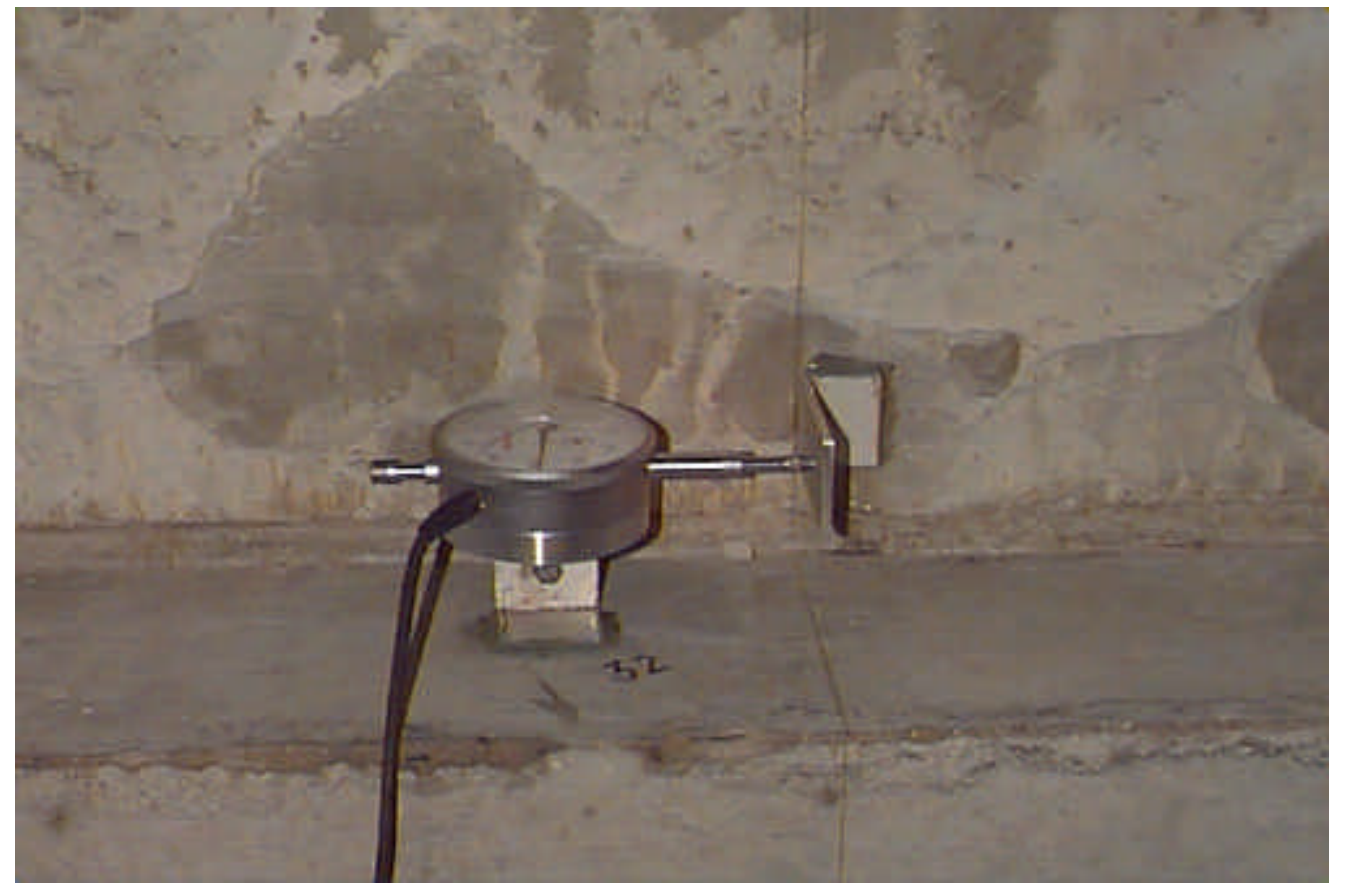

Figura 5.11(g) - Detalhe da fixação dos transdutores para medição do deslizamento relativo entre a mesa e a alma.

Procedeu-se o ensaio da viga após sete dias da moldagem da mesa. Foi colocada uma placa metálica entre o macaco hidráulico e a superfície da mesa para distribuir a força e evitar uma ruptura localizada no concreto. A força foi aplicada com incrementos de $5 \mathrm{kN}$ até a viga iniciar a fissuração por flexão. Nas três vigas ensaiadas, a força que provocou a fissuração variou de $65 \mathrm{kN}$ a $90 \mathrm{kN}$. A partir dessa etapa a força foi incrementada em $10 \mathrm{kN}$. Os dados sobre o deslizamento relativo da interface, sobre os deslocamentos verticais e sobre as deformações da armadura foram processados pelo sistema de aquisição de dados do laboratório.

As fissuras das vigas foram marcadas a cada incremento de $20 \mathrm{kN}$ na força. Nas vigas 2 e 3, após atingida a ruptura, observou-se o comportamento da fissuração da interface enquanto o valor da força decrescia. Em seguida ela foi incrementada de forma a observar o modo de ruptura das vigas. Os ensaios tiveram uma duração de 90 a 120 minutos, e no mesmo dia foram ensaiados os corpos-de-prova para obtenção da resistência à compressão e resistência à tração do concreto. 


\subsection{Resultados dos ensaios}

\subsubsection{Tensão de cisalhamento na interface}

A tensão de cisalhamento horizontal na interface foi calculada utilizando-se a equação elástica apresentada no capítulo 3 (eq.(3.1)), sendo, por comodidade, aqui novamente apresentada:

$$
\tau=\frac{\text { V.S }}{\text { I.b }}
$$

onde I é o momento de inércia e S o momento estático da área acima da interface em relação à linha neutra da seção transversal. Esta expressão é válida para materiais elásticos, mas pode ser utilizada para avaliação das tensões em seções de concreto no estádio II, desde que as características geométricas da seção sejam obtidas da seção fissurada. Dessa forma, calculou-se o momento de inércia da seção transversal considerando apenas a área de concreto comprimido e a área da seção transversal da armadura de flexão, e o momento estático considerando a área de concreto comprimido. Na tabela 5.5 são mostradas a altura da linha neutra da seção transversal do meio do vão $(x)$ e os valores de I e $S$ calculados para a seção fissurada das três vigas ensaiadas. A seção do meio do vão foi adotada por ser esta a que possui menor inércia fissurada (momento fletor máximo). Observase que nas três vigas a linha neutra está acima da interface, logo a tensão de cisalhamento na interface é igual à máxima tensão de cisalhamento da seção transversal obtida na fibra posicionada sobre a linha neutra.

$\mathrm{Na}$ tabela 5.6 são apresentadas as forças e tensões de cisalhamento na interface obtidas na ruptura das vigas e para os deslizamentos relativos da interface iguais a $0,13 \mathrm{~mm}$ e $0,5 \mathrm{~mm}$. $O$ valor de $0,13 \mathrm{~mm}$ para o deslizamento foi recomendado por Hanson para caracterizar a ruptura por cisalhamento de vigas compostas, enquanto o valor de $0,5 \mathrm{~mm}$ de deslizamento foi recomendado por Patnaik (PATNAIK (1992)). Também são apresentadas a resistência à compressão do concreto da mesa e a tensão normal à interface. 
Tabela 5.5 - Características geométricas da seção fissurada das vigas ensaiadas.

\begin{tabular}{|c|c|c|c|c|c|}
\hline Viga & $b(\mathrm{~cm})$ & $x(\mathrm{~cm})$ & $\mathrm{S} \times 10^{3}\left(\mathrm{~cm}^{3}\right)$ & $\mathrm{I} \times 10^{3}\left(\mathrm{~cm}^{4}\right)$ & $\frac{\mathrm{S}}{\mathrm{I} . \mathrm{b}} \times 10^{-1}\left(\mathrm{~cm}^{-2}\right)$ \\
\hline 1 & 15 & 11,07 & 2,451 & 63,121 & 0,0259 \\
\hline 2 & 15 & 11,06 & 2,446 & 62,495 & 0,0261 \\
\hline 3 & 9 & 10,96 & 2,402 & 62,378 & 0,0428 \\
\hline
\end{tabular}

Tabela 5.6 - Tensões de cisalhamento na interface das vigas ensaiadas.

\begin{tabular}{|c|c|c|c|c|c|c|c|c|}
\hline \multirow{2}{*}{ Viga } & \multirow{f_{c}}{*}{$\begin{array}{c}\rho . f_{y} \\
(\mathrm{MPa})\end{array}$} & \multicolumn{3}{|c|}{ Força $(\mathrm{kN})$} & \multicolumn{2}{|c|}{$\begin{array}{c}\text { Tensão de cisalhamento na } \\
\text { interface }-\tau(\mathrm{MPa})\end{array}$} \\
\cline { 4 - 9 } & & & $\begin{array}{c}\text { desliz. } \\
0,13 \mathrm{~mm}\end{array}$ & $\begin{array}{c}\text { desliz. } \\
0,5 \mathrm{~mm}\end{array}$ & ruptura & $\begin{array}{c}\text { desliz. } \\
0,13 \mathrm{~mm}\end{array}$ & $\begin{array}{c}\text { desliz. } \\
0,5 \mathrm{~mm}\end{array}$ & ruptura \\
\hline 1 & 39,80 & 0,91 & 241,0 & 375,0 & 420,0 & 3,12 & 4,86 & 5,44 \\
\hline 2 & 41,50 & 0,91 & 183,8 & 342,5 & 390,0 & 2,40 & 4,47 & 5,08 \\
\hline 3 & 41,67 & 1,50 & 210,8 & - & 250,0 & 4,51 & - & 5,35 \\
\hline
\end{tabular}

A tensão de cisalhamento na interface também pode ser avaliada pelo equilíbrio de forças horizontais na seção transversal mais solicitada (eq.(3.6)) ou pela equação aproximada baseada no esforço cortante (eq.(3.3)). Na tabela 5.7 são apresentados os resultados da avaliação da tensão na interface pelas três expressões apresentadas no capítulo 3. Observa-se que os resultados obtidos são próximos devido ao esforço cortante ser constante ao longo do vão a viga. No restante deste capítulo será utilizada a equação elástica para análise dos resultados dos ensaios. 
Tabela 5.7 - Avaliação da tensão de cisalhamento na interface por diferentes expressões.

\begin{tabular}{|c|c|c|c|c|}
\hline Viga & $\begin{array}{c}\text { Força de } \\
\text { ruptura (kN) }\end{array}$ & \multicolumn{3}{|c|}{ Tensão de cisalhamento na interface - $\tau$ (MPa) } \\
\cline { 3 - 5 } & & $\begin{array}{c}\text { Eq. elástica - } \\
\text { eq.(5.1) }\end{array}$ & $\begin{array}{c}\text { Eq. aproximada - } \\
\text { eq.(3.3) }\end{array}$ & $\begin{array}{c}\text { Equilíbrio de forças } \\
\text { horizontais - } \\
\text { eq.(3.6) }\end{array}$ \\
\hline 1 & 420 & 5,44 & 5,37 & 5,24 \\
\hline 2 & 392 & 5,08 & 4,89 & 5,46 \\
\hline 3 & 250 & 5,35 & 5,33 & 4,92 \\
\hline
\end{tabular}

\subsubsection{Configuração das fissuras e forma de ruptura das vigas}

Para pequenos valores de força aplicada às vigas, surgiram fissuras de flexão no meio do vão. Com o aumento da força novas fissuras inclinadas surgiram afastadas do meio do vão e as já existentes aumentaram sua extensão. Continuando a aumentar a força, as fissuras mais próximas das extremidades da viga atingiram a interface e prolongaram-se ao longo do vão. À partir desse estágio de carregamento a viga 3 apresentou comportamento diferente das vigas 1 e 2 .

As vigas 1 e 2 apresentaram pouca fissuração da interface. Nessas vigas, a força correspondente ao início da fissuração da interface representou, aproximadamente, $58 \%$ da força de ruptura. O deslizamento relativo da interface ocorreu de ambos os lados da viga, contudo, a ruptura aconteceu apenas em um dos lados pelo rápido acréscimo nos deslizamentos sem aumento da força aplicada (figuras 5.12(a) e 5.12(b)). Próximo à ruptura observou-se a formação de uma biela de compressão ligando a interface ao apoio (figura 5.12(c)), sem contudo haver uma separação da extremidade da viga em virtude dessa biela. A fissuração da interface estendeu-se da biela de compressão até próximo a região de aplicação da força, sem alcançar o meio do vão. $\mathrm{Na}$ viga 2 , do lado que houve a formação da biela de compressão, a fissura da interface estendeu-se até a extremidade, sem contudo causar grandes deslizamentos. 


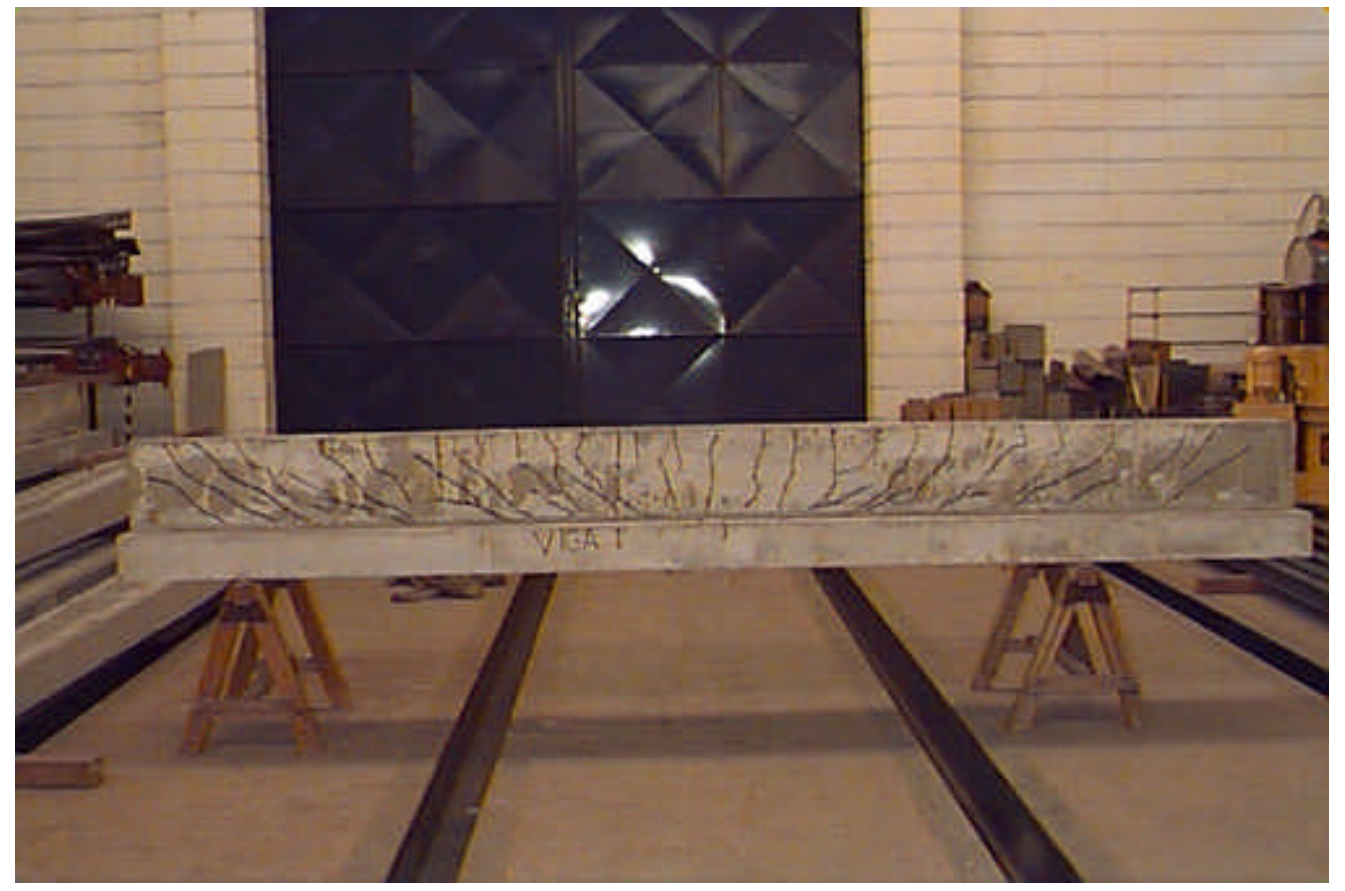

Figura 5.12(a) - Forma de ruptura da viga 1.

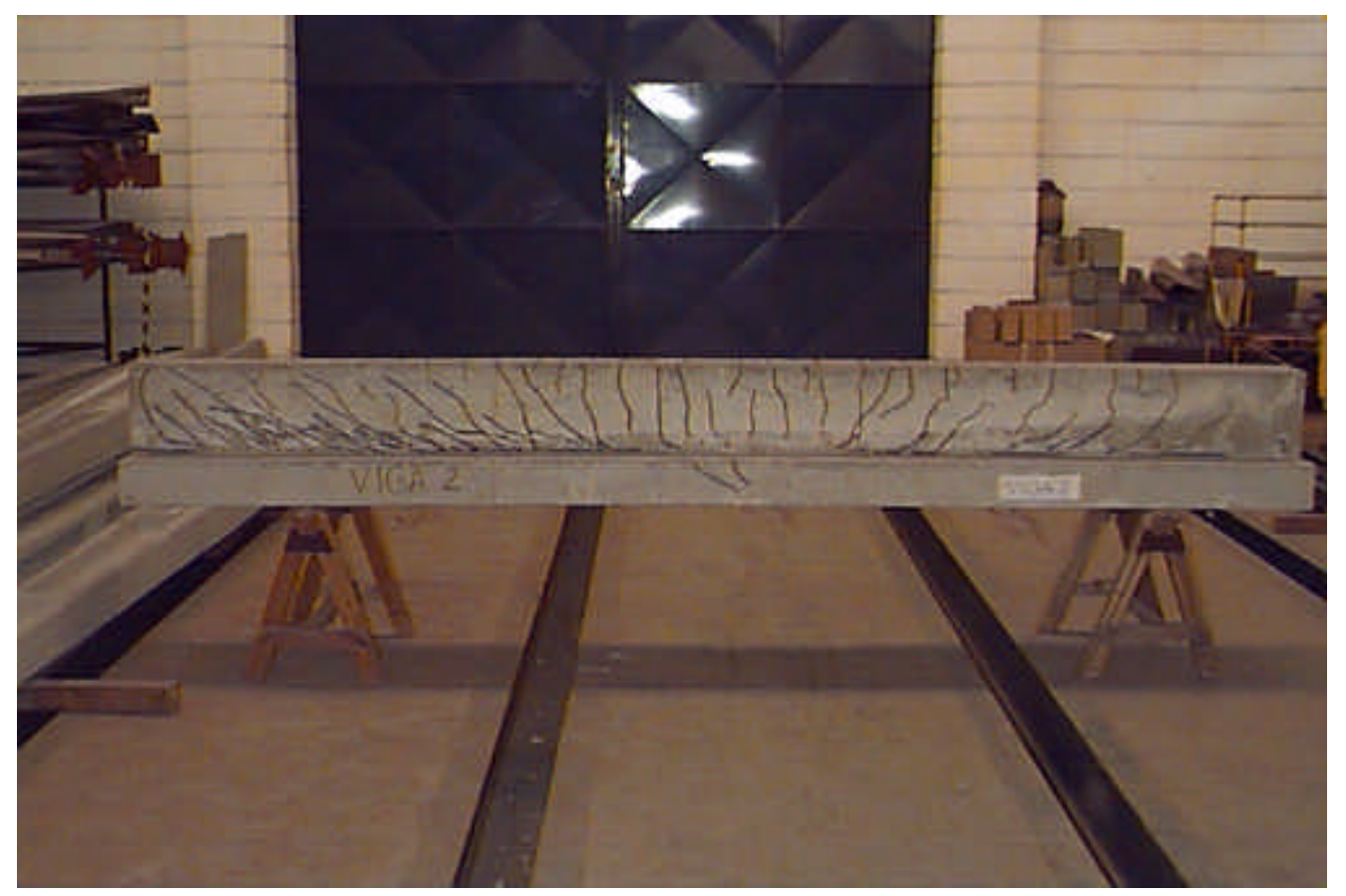

Figura 5.12(b) - Forma de ruptura da viga 2. 


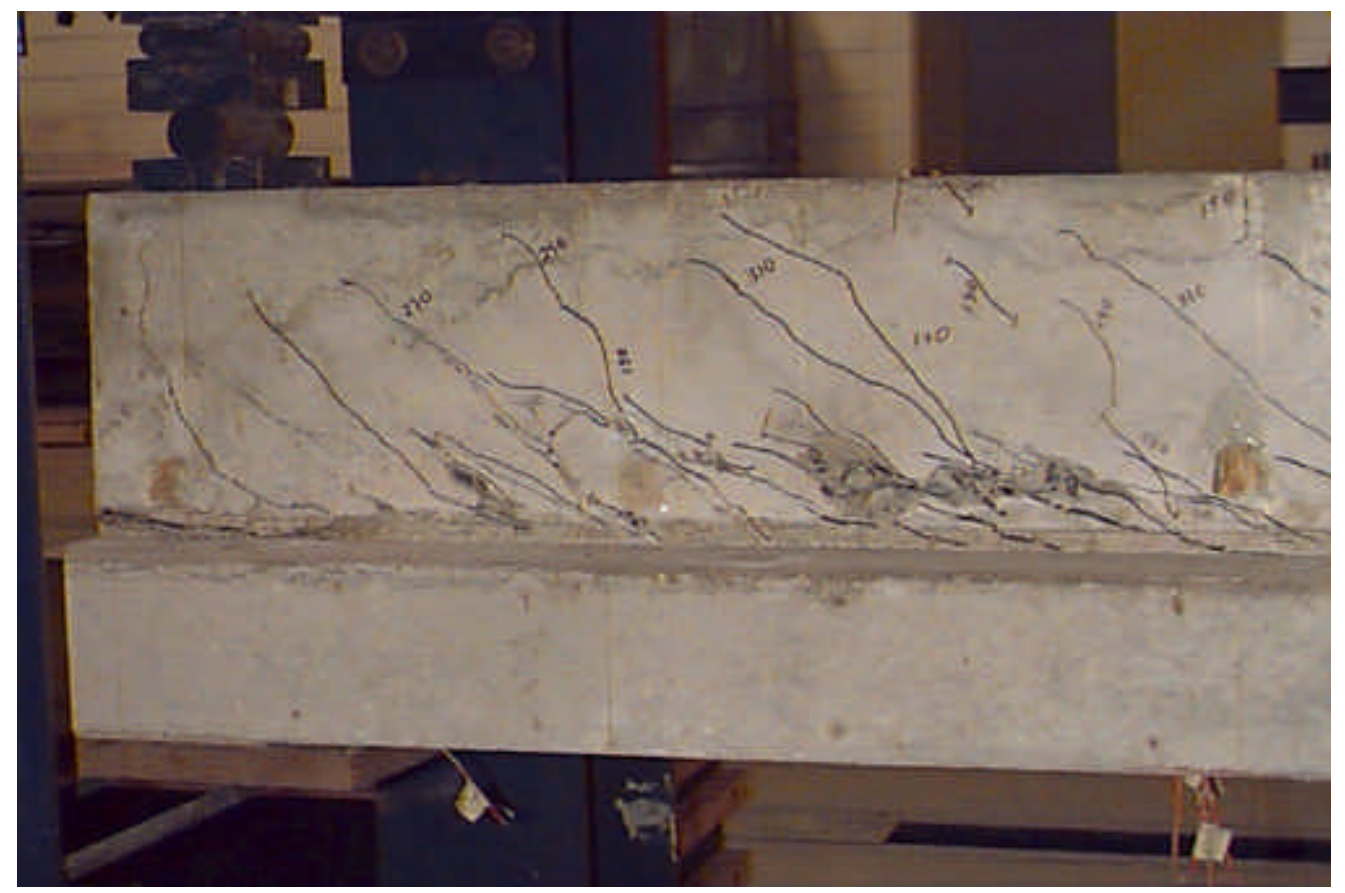

Figura 5.12(c) - Detalhe da biela de compressão, junto ao apoio, formada na ruptura da viga 2.

$\mathrm{Na}$ viga 3, a força correspondente ao início da fissuração da interface representou $88 \%$ da força de ruptura, apesar de seu valor ser próximo ao que provocou a fissuração nas vigas 1 e 2 . Nessa viga, logo após o início da fissuração da interface, houve a ruptura brusca da aderência de um dos lados e um grande deslizamento entre a mesa e a alma. À partir desse estágio de carregamento, observou-se acréscimos no deslizamento relativo entre a mesa e a alma sem, contudo, observar-se acréscimos na força aplicada. A fissura da interface estendeu-se da região próxima ao ponto de aplicação da força até a extremidade da viga, sendo que do outro lado do vão praticamente não houve fissuração (figura 5.12(d)). Na última etapa de carregamento observou-se deslizamentos da ordem de $4,5 \mathrm{~mm}$ entre a mesa e a alma e uma evidente separação entre elas (figura 5.12(f)). Não observou-se grande fissuração da alma e também não formou-se a biela de compressão observada nas vigas 1 e 2 . 


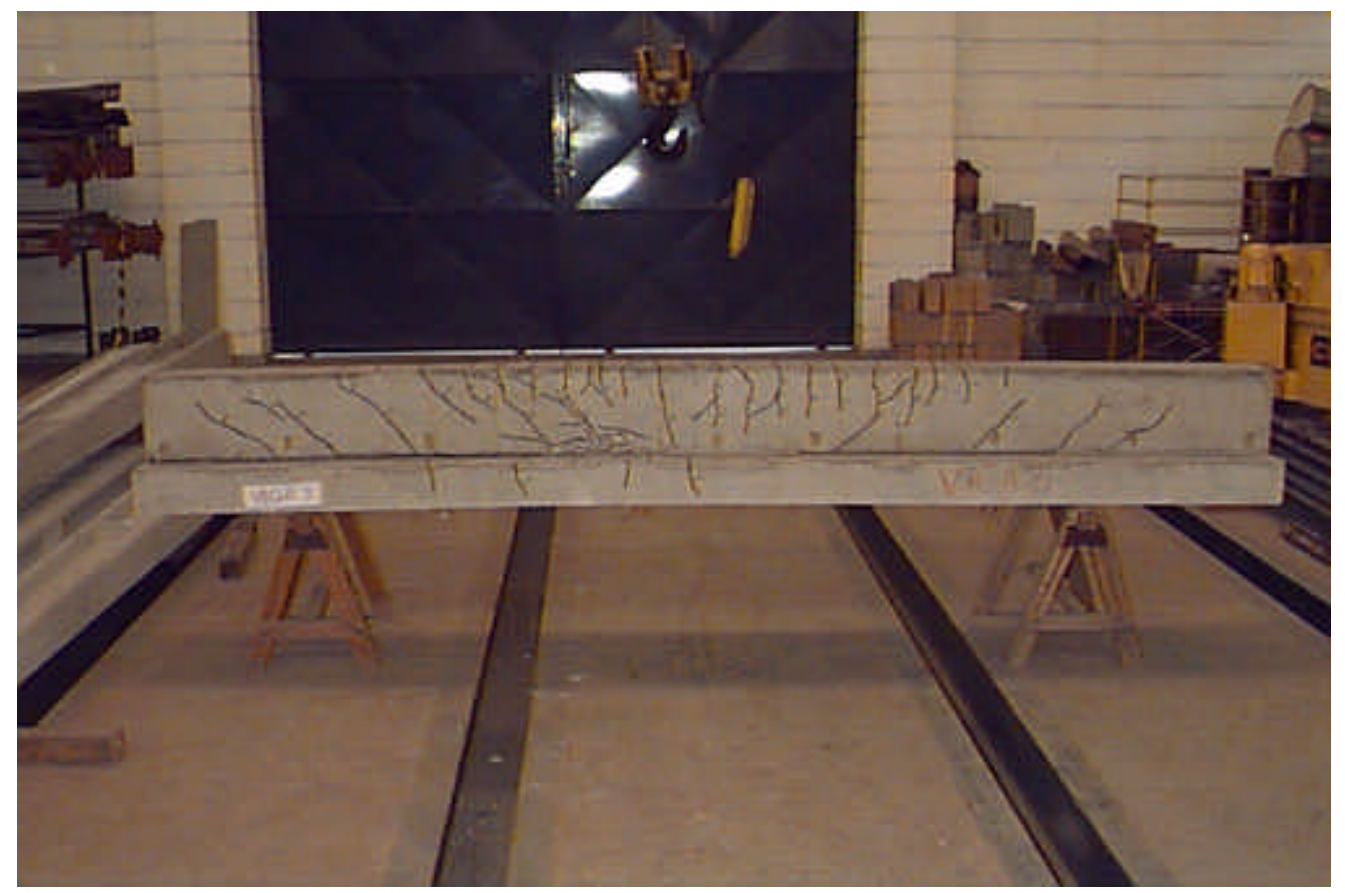

Figura 5.12(d) - Forma de ruptura da viga 3.

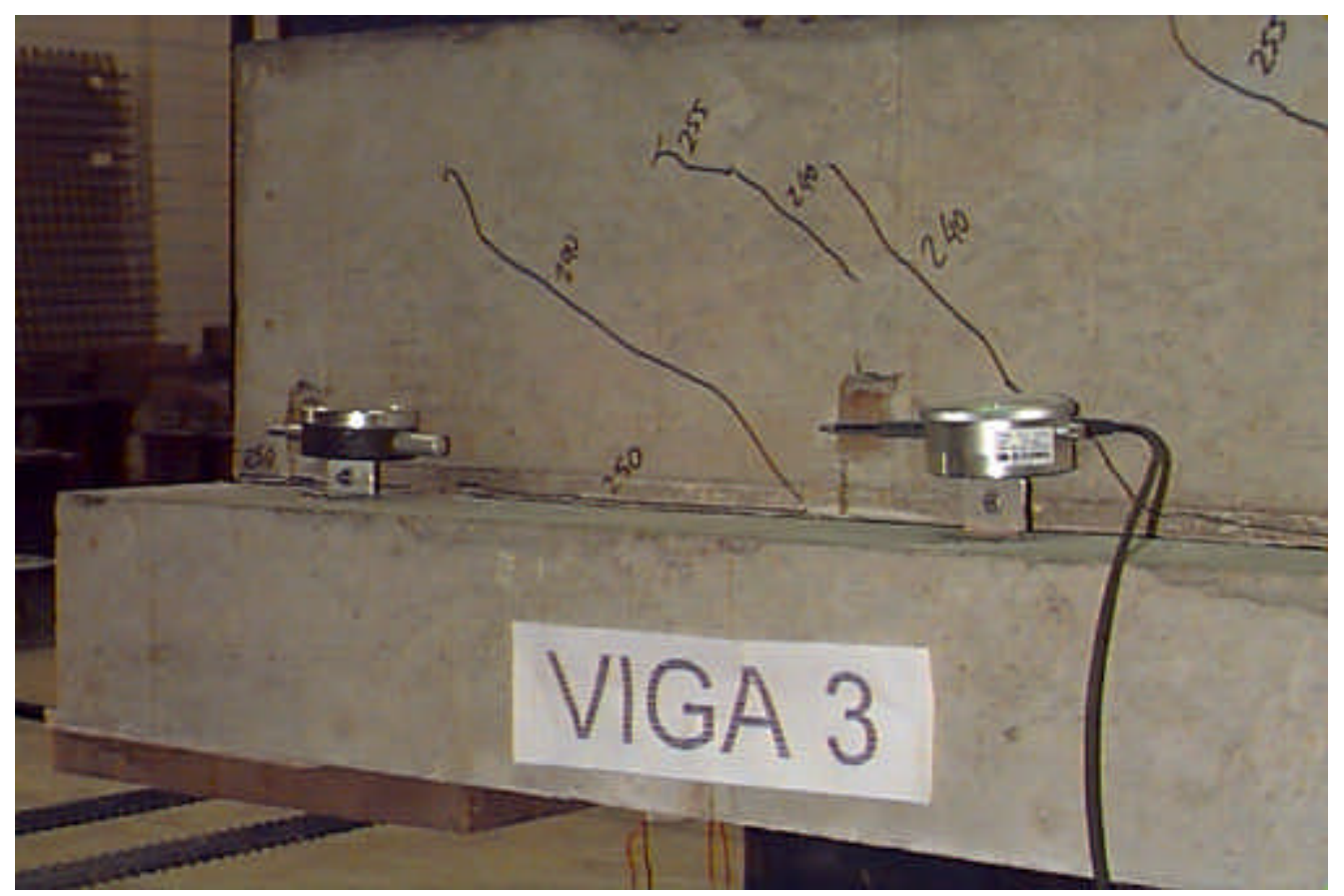

Figura 5.12(e) - Detalhe da fissuração da extremidade da viga 3. 


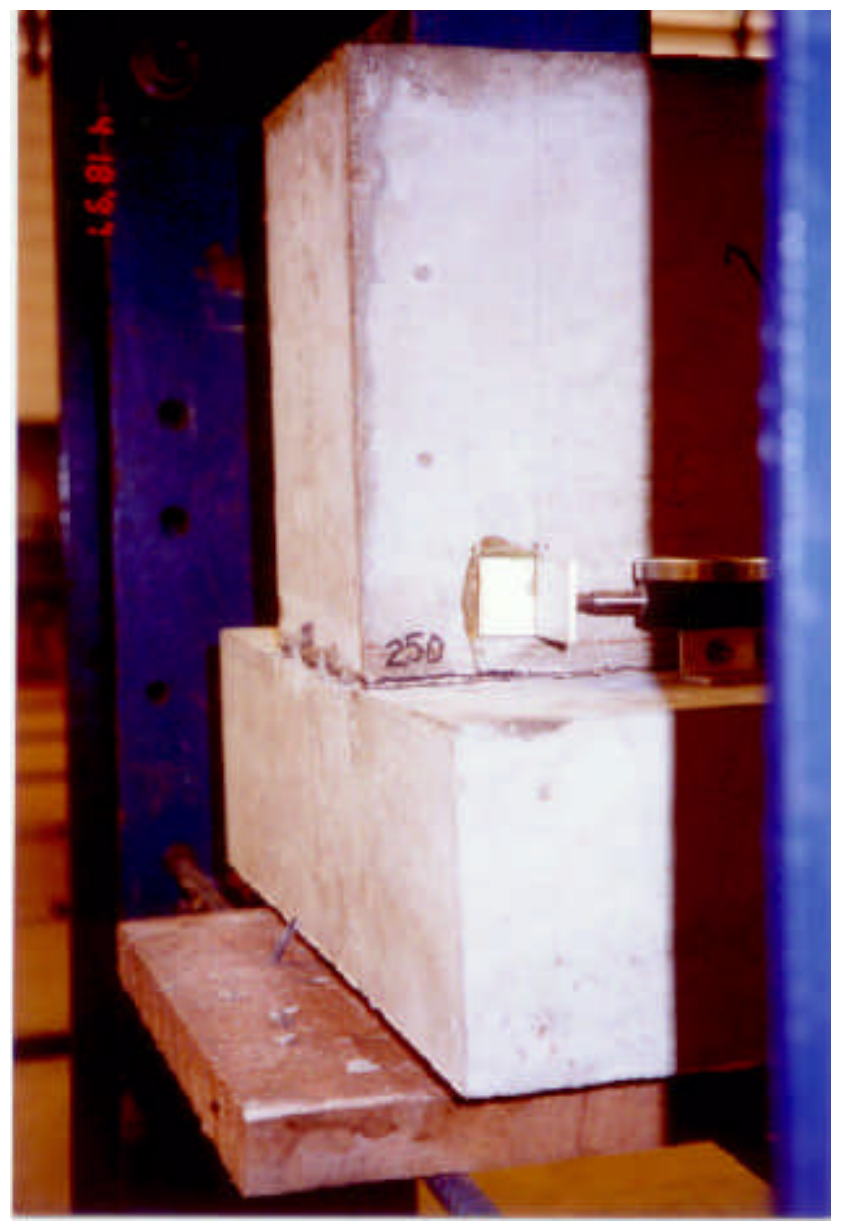

Figura 5.12(f) - Separação entre a mesa e a alma na extremidade da viga 3.

A ausência de formação da biela de compressão junto ao apoio da viga 3 talvez possa ser explicada pelo fato da largura da região de transferência de tensões de cisalhamento pela interface ser menor que a largura da alma, impossibilitando a transferência por arco das tensões de cisalhamento da interface ao apoio. Uma vez esgotada a resistência por aderência, os estribos não foram suficientes para absorver as forças horizontais, ocorrendo uma ruptura repentina e brusca da viga. 


\subsubsection{Deslizamento relativo da interface}

O deslizamento relativo entre a mesa e a alma das vigas foi observado durante 0 processo de carregamento. Na figura 5.13 são mostrados os deslizamentos relativos da interface em função da tensão de cisalhamento calculada pela eq.(5.1). Nessa figura cada gráfico representa os deslizamentos ocorridos na metade do vão de cada viga. Observou-se que até, aproximadamente, $2 \mathrm{MPa}$ de tensão de cisalhamento na interface não ocorreram deslizamentos na interface das viga 1 e 2 , sendo os esforços resistidos apenas pela aderência entre as superfícies de concreto. Acima desse nível de tensão os transdutores situados na quarta parte do vão indicaram o início do deslizamento relativo da interface. A ruptura ocorreu de um lado do vão pelo grande deslizamento da interface, sendo observado deslizamentos de até $1 \mathrm{~mm}$ do outro lado do vão.

Na viga 3 não observou-se deslizamentos relativos até níveis de tensão de cisalhamento da interface próximos a $4 \mathrm{MPa}$. À partir desse valor ocorreram pequenos deslizamentos da ordem de 0,2 $\mathrm{mm}$ e, quando as fissuras da alma atingiram a interface, houve uma ruptura repentina e brusca. $O$ deslizamento ocorreu de forma aproximadamente uniforme de um lado do vão e do outro lado observou-se pequena inversão no sentido do deslizamento. Ao contrário das vigas 1 e 2, do lado oposto ao que aconteceu a ruptura praticamente não ocorreram deslizamentos da interface.

Na figura 5.14 é mostrado o deslizamento relativo típico da interface das vigas ensaiadas. Observa-se a diferença de comportamento entre as vigas 1 e $2 \mathrm{e}$ a viga 3. As viga 1 e 2 apresentaram uma ruptura dúctil devido à formação da biela de compressão enquanto a viga 3 apresentou uma ruptura frágil. Quando o deslizamento relativo da interface das vigas 1 e 2 atingiu, em algum ponto, o valor de $0,5 \mathrm{~mm}$, a força aplicada representava, em média, $89 \%$ da força de ruptura das vigas. Esses resultados estão de acordo com as observações feitas por outros pesquisadores em ensaios de vigas compostas. 

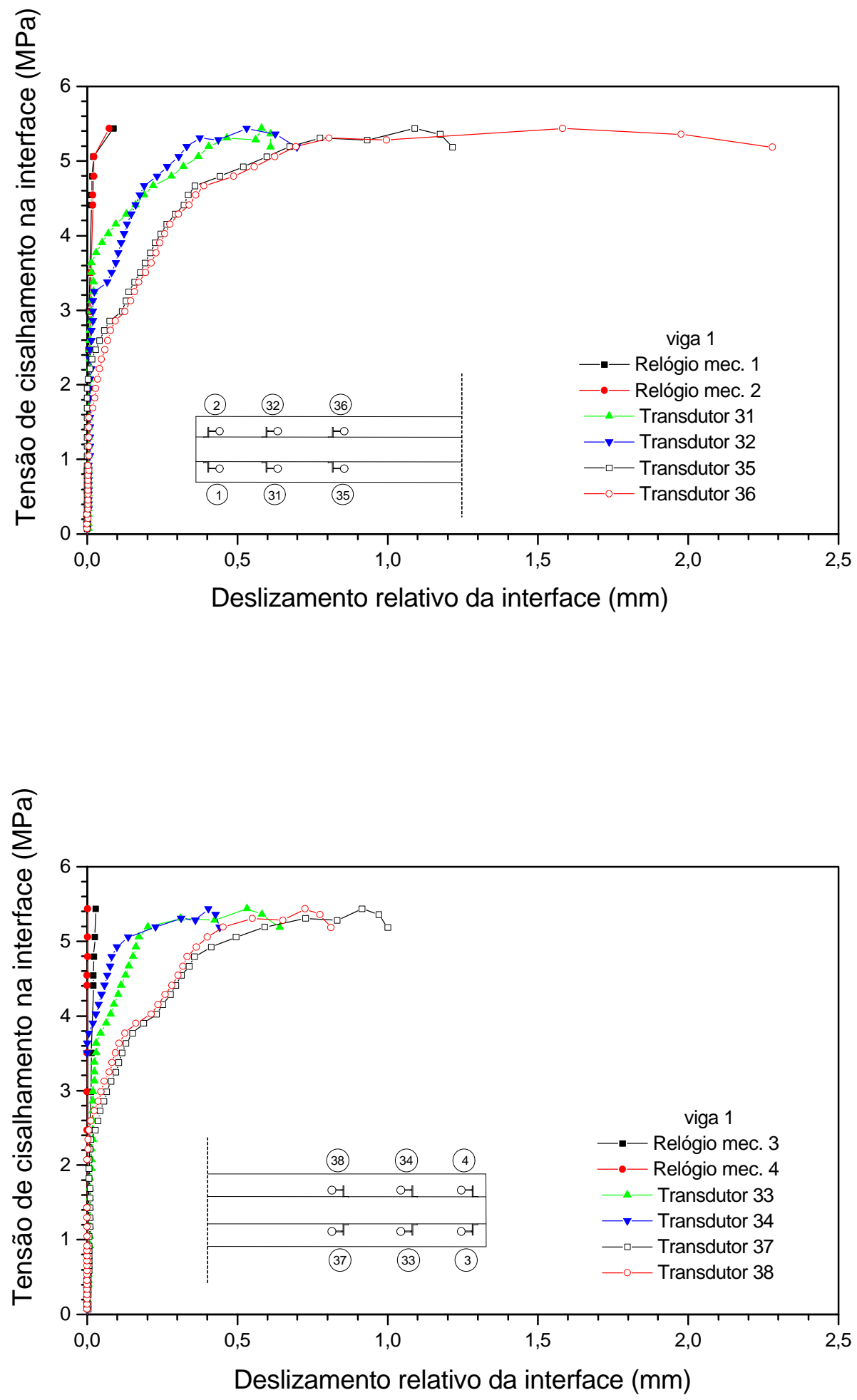

Figura 5.13(a) - Deslizamento relativo da interface da viga 1. 

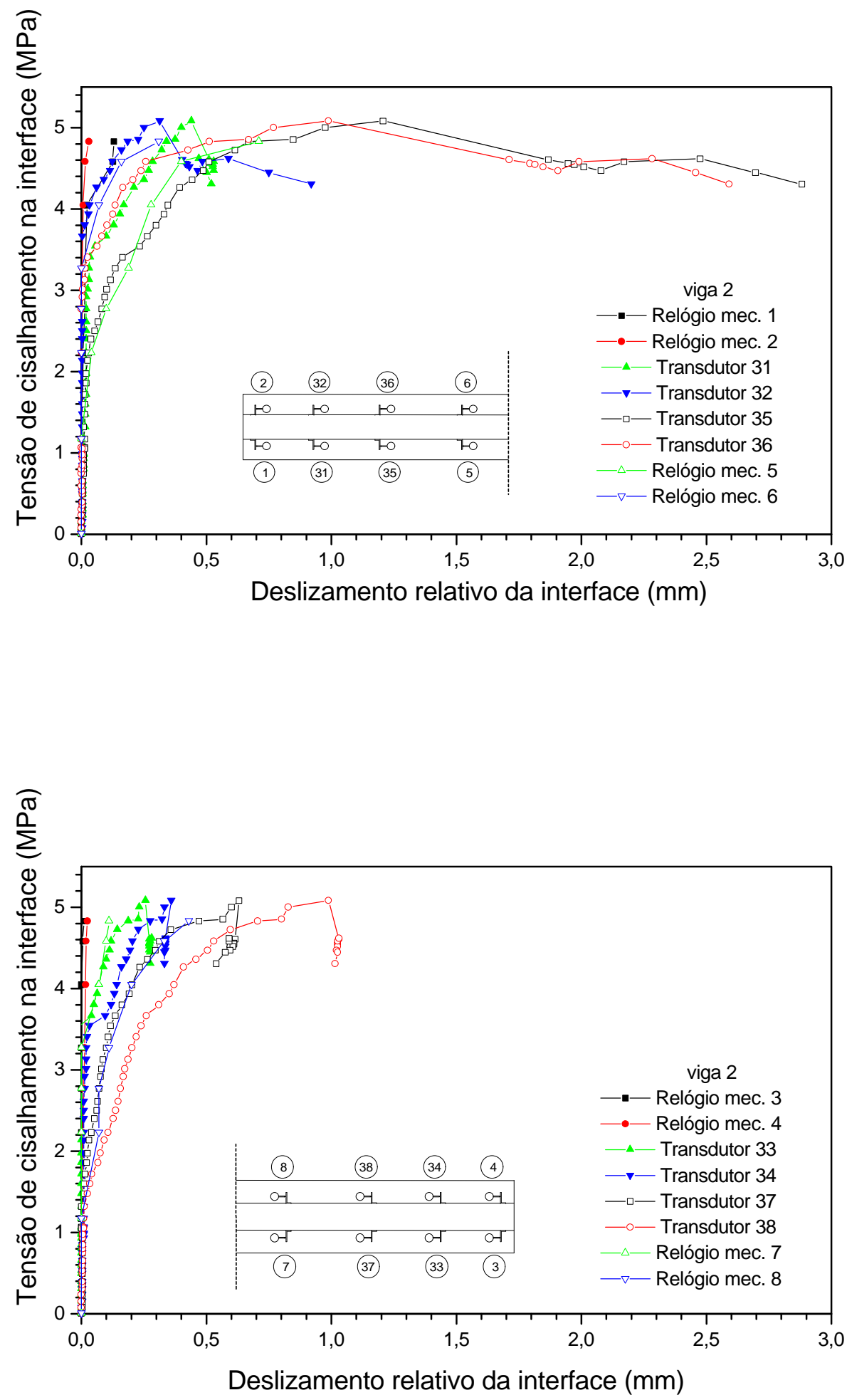

Figura 5.13(b) - Deslizamento relativo da interface da viga 2. 

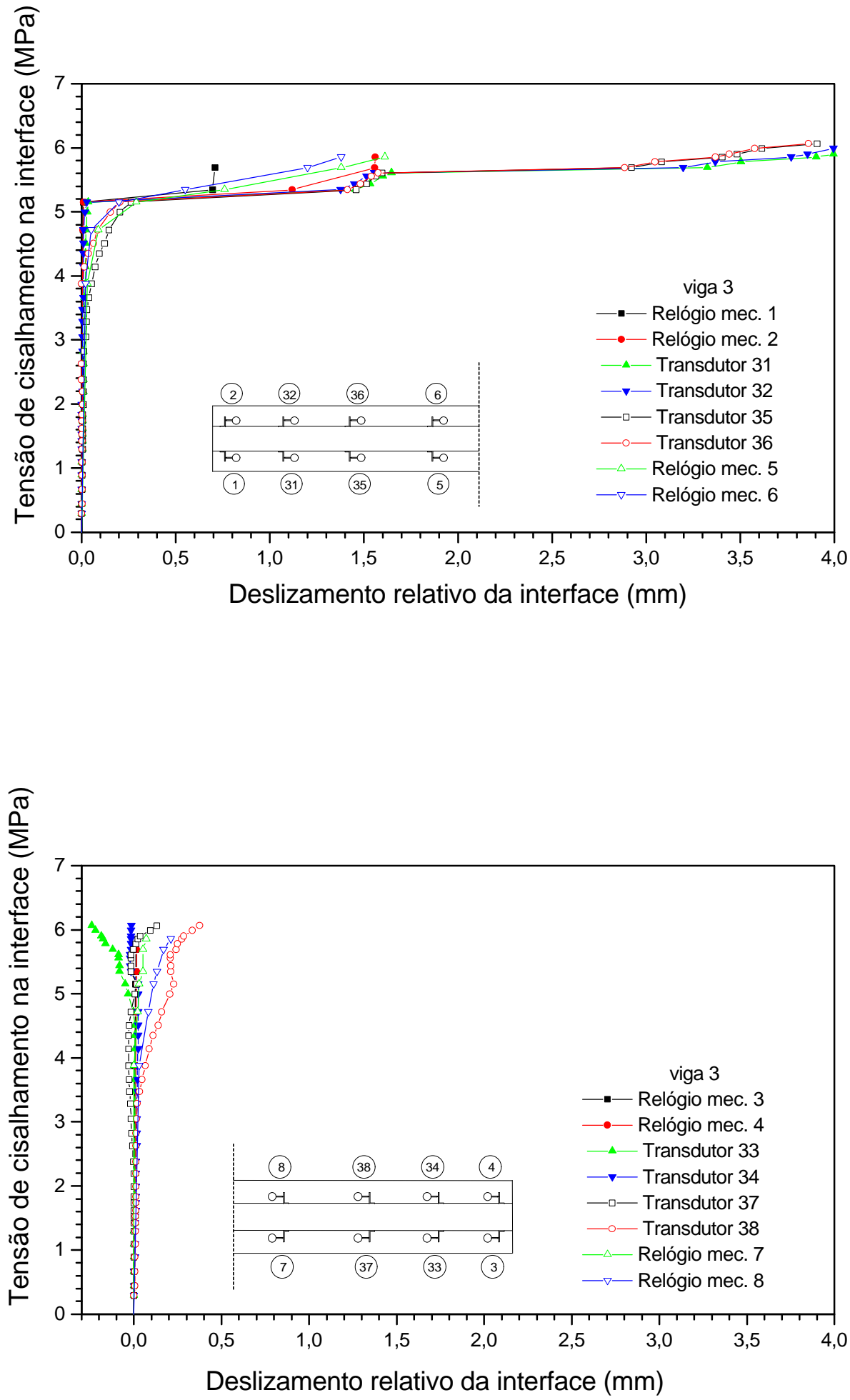

Figura 5.13(c) - Deslizamento relativo da interface da viga 3. 


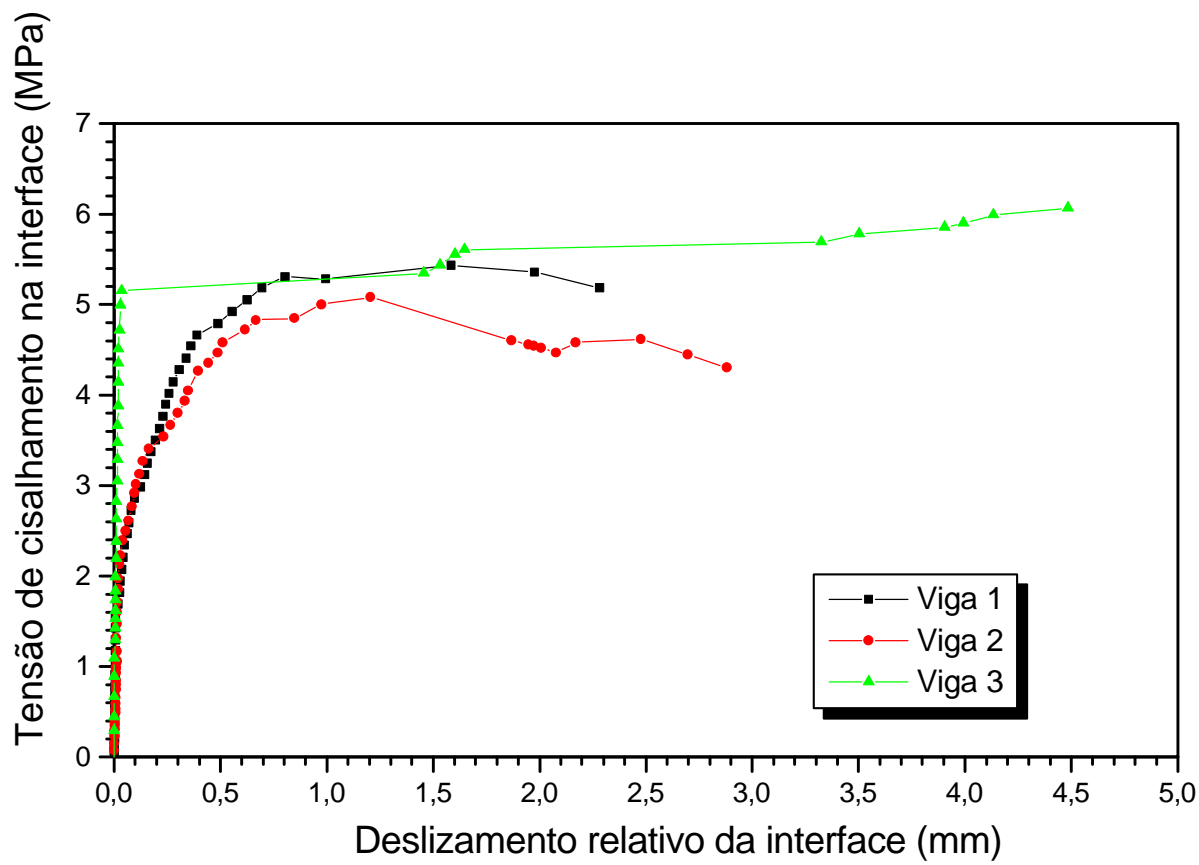

Figura 5.14 - Deslizamento relativo típico entre a mesa e a alma das vigas ensaiadas.

$\mathrm{Na}$ figura 5.15 são mostrados os deslizamentos relativos da interface ao longo do vão das vigas para alguns níveis de tensão na interface. Dessa figura observa-se que até próximo à ruptura o deslizamento da interface é praticamente igual em ambos os lados da viga, mas ao atingir a ruptura um dos lados sofre deslizamentos sensivelmente maiores. Na figura 5.16 é mostrado o máximo deslizamento relativo obtido durante os ensaios. Observa-se que nas vigas 1 e 2 o máximo deslizamento ocorreu na quarta parte do vão, ao contrário dos resultados obtidos por Patnaik que observou o máximo deslizamento a uma distância do apoio igual à altura útil da viga. Essa contradição pode ser explicada pelo fato da biela de compressão formada nas vigas ensaiadas não provocar a separação do apoio com o restante da viga, de forma que não houve uma acumulação dos deslizamentos ocorridos ao longo do vão. Nos ensaios realizados por Patnaik houve essa separação, sendo os deslizamentos por ele obtido maiores que os observados neste trabalho. Essa acumulação pôde ser observada na viga 3 que, por apresentar uma fissura até a extremidade, apresentou deslizamentos maiores próximo à extremidade da viga. 

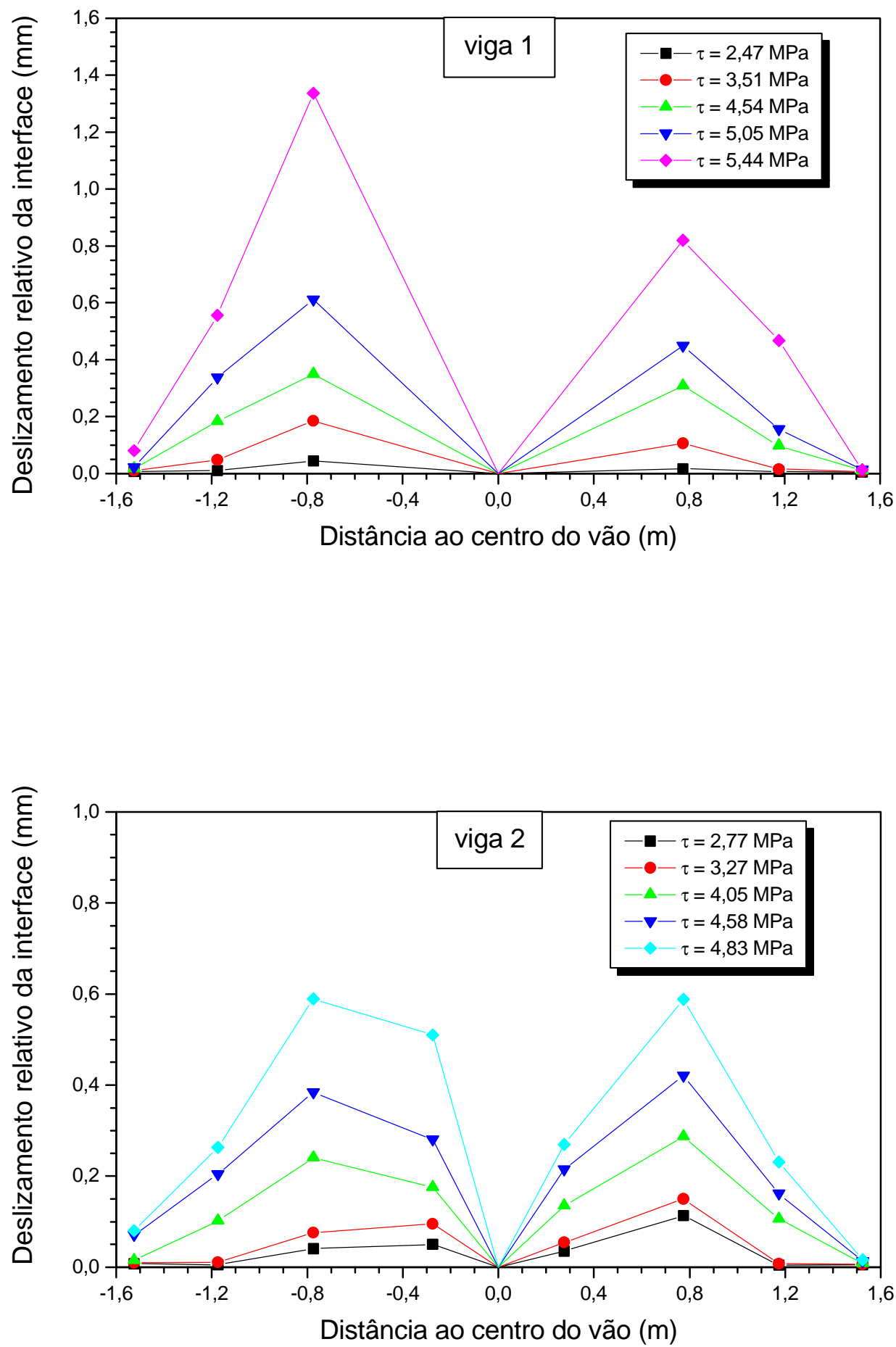

Figura 5.15 - Deslizamento da interface ao longo do vão das vigas ensaiadas. (continua) 


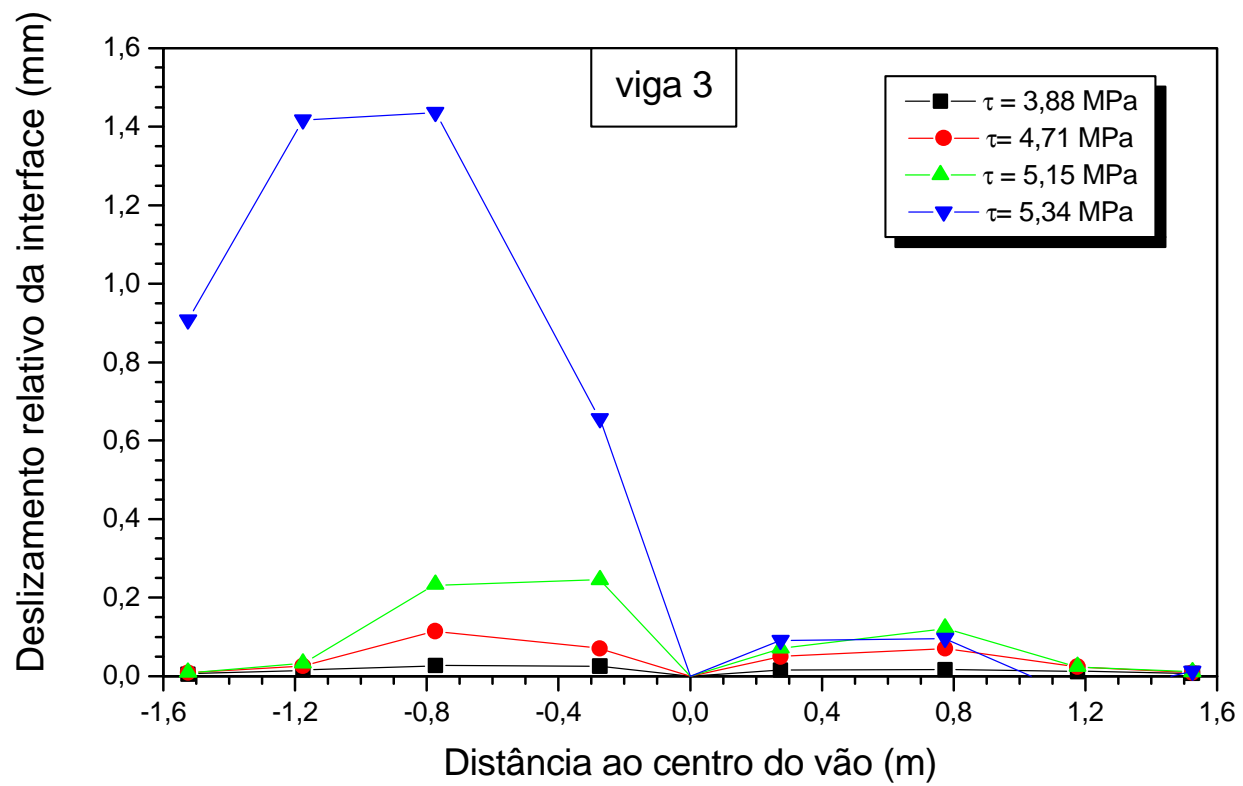

Figura 5.15 - Deslizamento da interface ao longo do vão das vigas ensaiadas. (continuação)

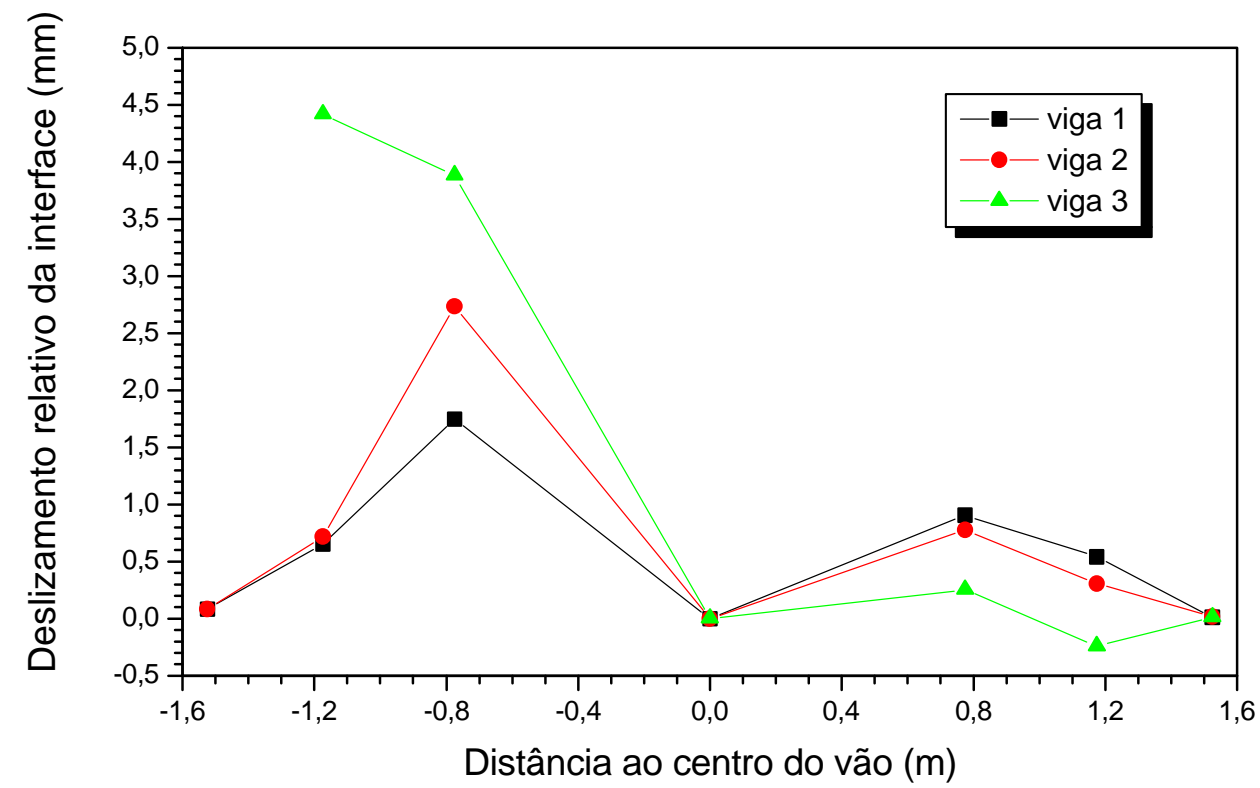

Figura 5.16 - Máximo deslizamento da interface nas vigas ensaiadas. 
A relação entre a deformação da armadura de costura da interface e o deslizamento relativo entre a mesa e a alma é mostrada na figura 5.17. A deformação da armadura foi medida na altura da interface e o deslizamento relativo medido no transdutor ou relógio mecânico mais próximo. Observa-se que nas vigas 1 e 2 a armadura atingiu a deformação de escoamento para deslizamentos relativos próximos de $0,5 \mathrm{~mm}$, sendo que a armadura que estava localizada do lado que sofreu os maiores deslizamentos na ruptura atingiu a deformação de escoamento com menores deslizamentos. Na viga 3 a ruptura da interface ocorreu para deslizamentos inferiores a $0,5 \mathrm{~mm}$, sendo que nesse instante a armadura transversal não havia alcançado a resistência de escoamento.

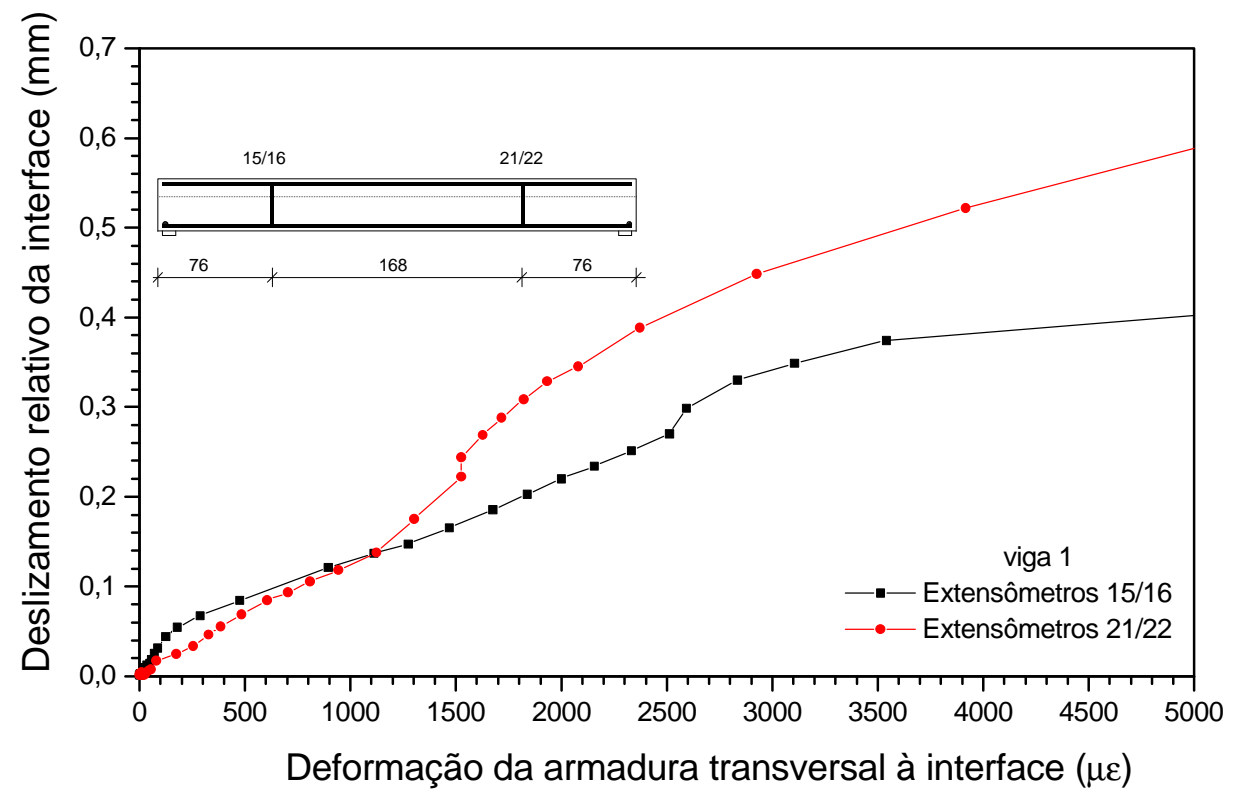

Figura 5.17 - Deformação da armadura de costura da interface em função do deslizamento relativo. (continua) 

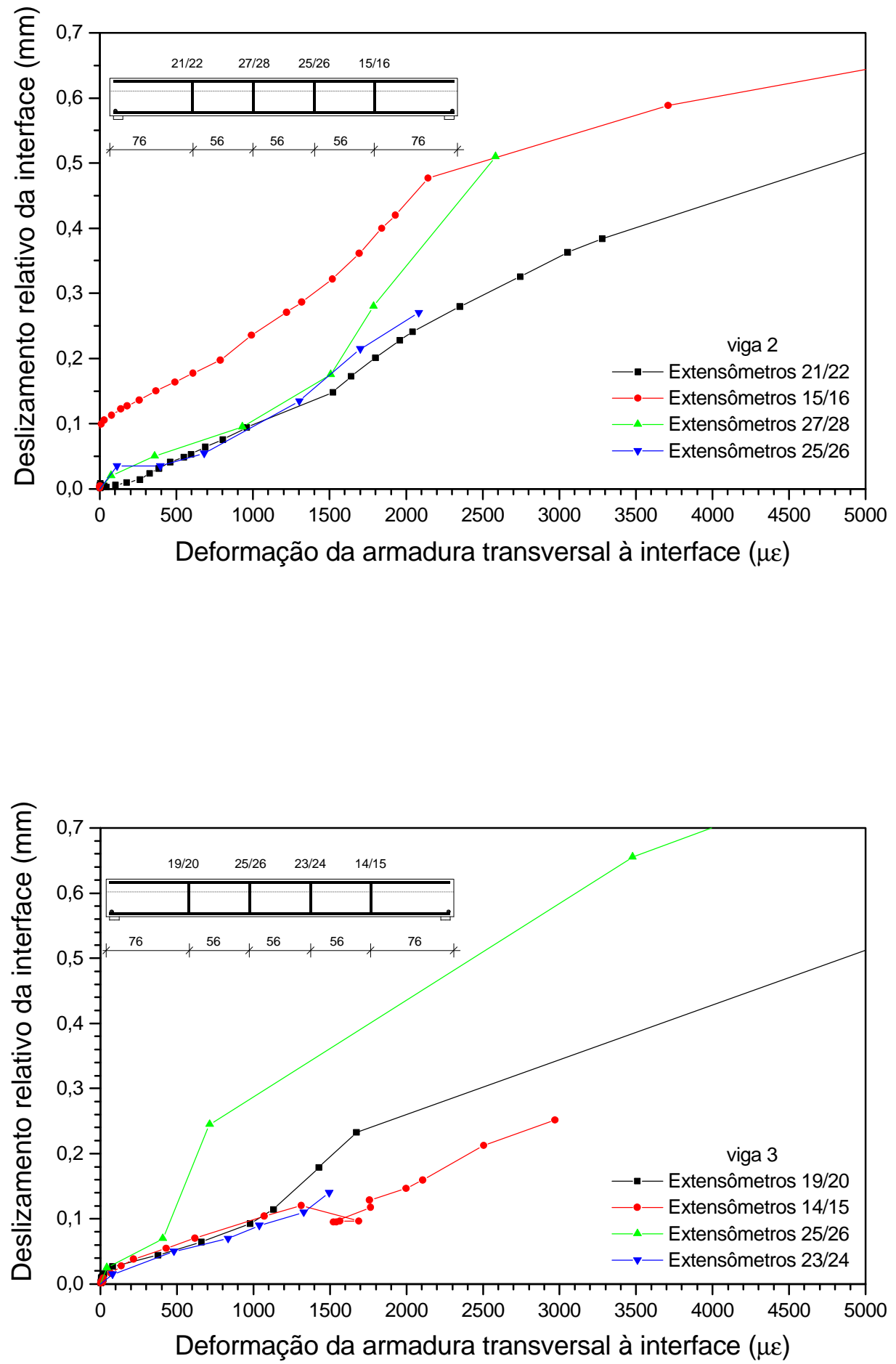

Figura 5.17 - Deformação da armadura de costura da interface em função do deslizamento relativo. (continuação) 


\subsubsection{Deformações da armadura de costura da interface}

As deformações da armadura ao nível da interface, em função da tensão de cisalhamento, são apresentadas na figura 5.18. Na figura 5.19 é feita a comparação, para um determinado estribo, da deformação ao nível da interface entre as vigas ensaiadas. Observa-se que nas vigas 1 e 2 praticamente não houve deformações na armadura até a tensão de cisalhamento na interface atingir $2 \mathrm{MPa}$. Até esse nível de tensão não houve deslizamentos da interface e as tensões foram transferidas apenas pela aderência entre as superfícies de concreto. Ao aproximarse da ruptura, os estribos alcançaram a resistência de escoamento com exceção daqueles localizados próximos às extremidades. Esses resultados mostram que os estribos localizados nas extremidades são pouco solicitados devido à formação da biela de compressão ligando a interface ao apoio. Apenas um dos estribos localizado na extremidade da viga atingiu a deformação de escoamento devido ao prolongamento da fissura da interface até a extremidade da viga após atingida a ruptura da interface.

$\mathrm{Na}$ viga 3 não houve deformações na armadura até a tensão de cisalhamento na interface atingir $4 \mathrm{MPa}$, sendo as tensões transferidas pela aderência entre as superfícies em contato. Pelos gráficos da figura 5.19 parece razoável admitir que se não houvesse ocorrido a ruptura prematura da interface essa viga teria suportado maiores carregamentos, uma vez que no momento da ruptura nenhum dos estribos transversais à interface haviam atingido a resistência de escoamento. Além disso, deve-se lembrar que essa viga possuía taxa de armadura maior que as vigas 1 e 2, o que por si só deveria aumentar a resistência final da viga aos esforços de cisalhamento horizontal. Após a ruptura da interface a força ainda foi incrementada e os estribos localizados do lado que sofreu menores deslizamentos também atingiram a resistência de escoamento. Observa-se também dos gráficos dessa figura o comportamento semelhante dos estribos das vigas 1 e 2 , independente de sua posição na viga. 


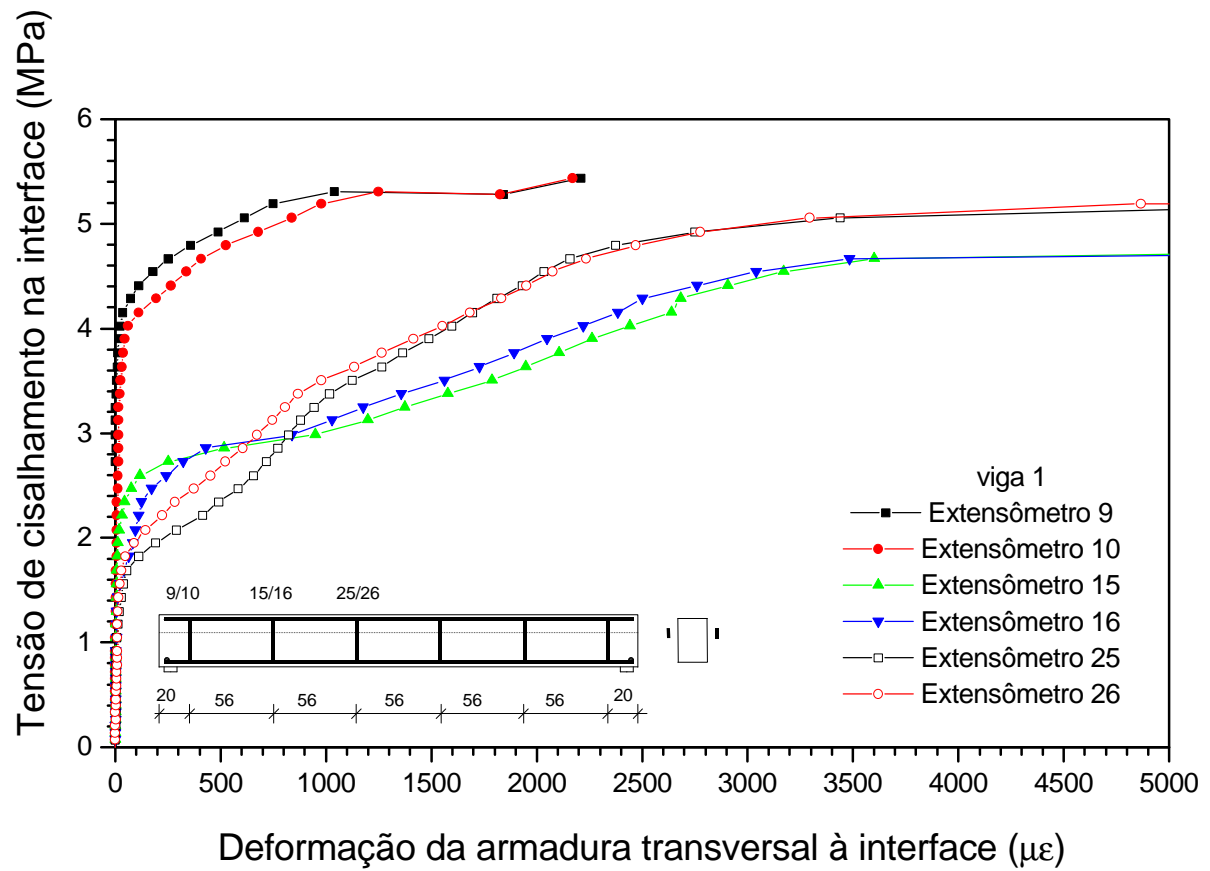

- Lado que sofreu maior deslizamento

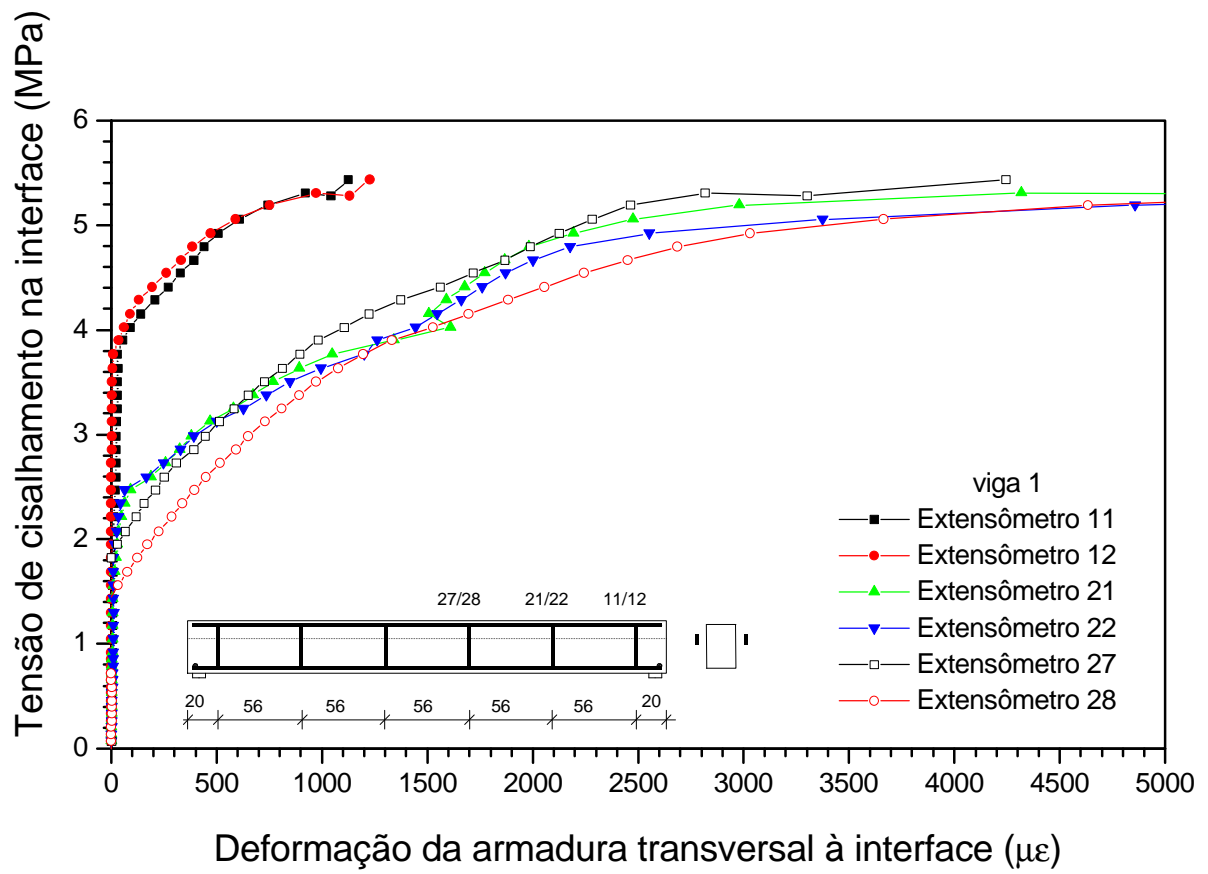

- Lado que sofreu menor deslizamento

Figura 5.18(a) - Deformação da armadura de costura ao nível da interface da viga 1. 


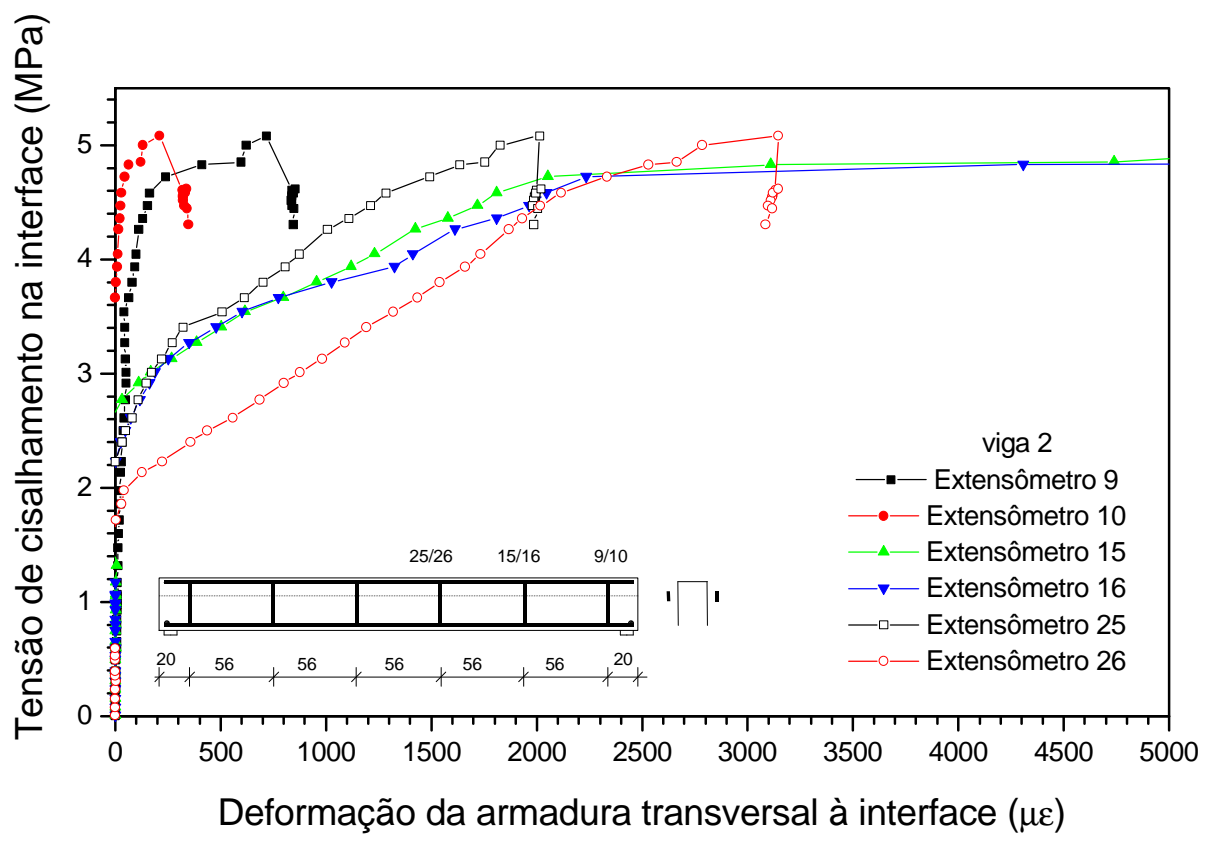

- Lado que sofreu menor deslizamento

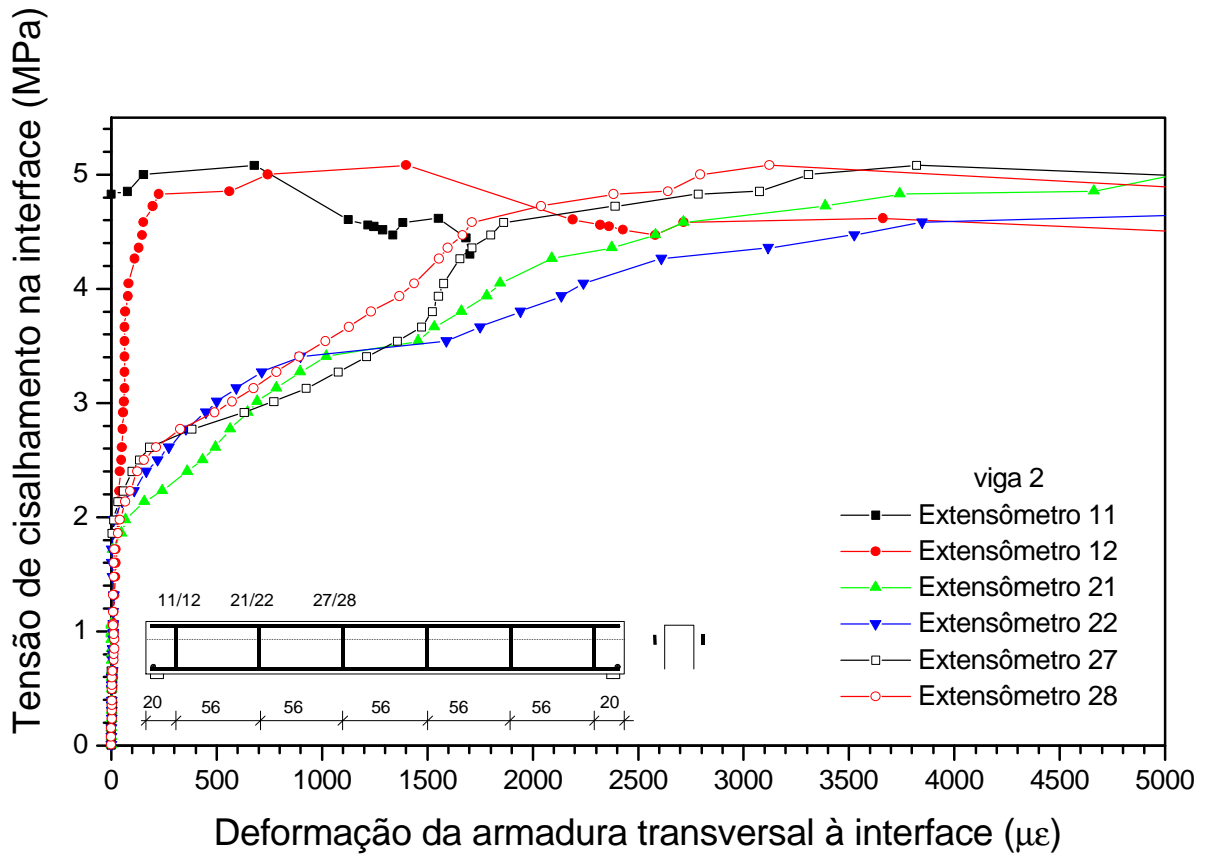

- Lado que sofreu maior deslizamento

Figura 5.18(b) - Deformação da armadura de costura ao nível da interface da viga 2. 


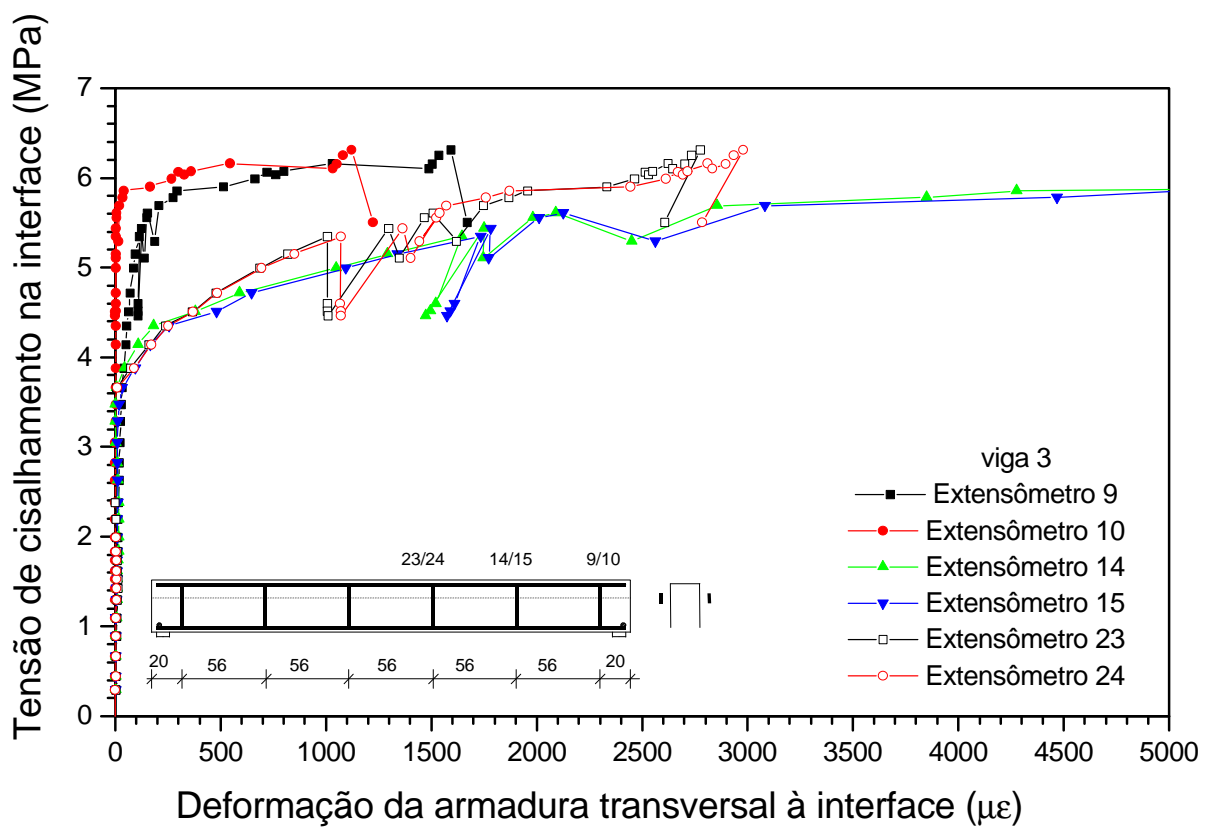

- Lado que sofreu menor deslizamento

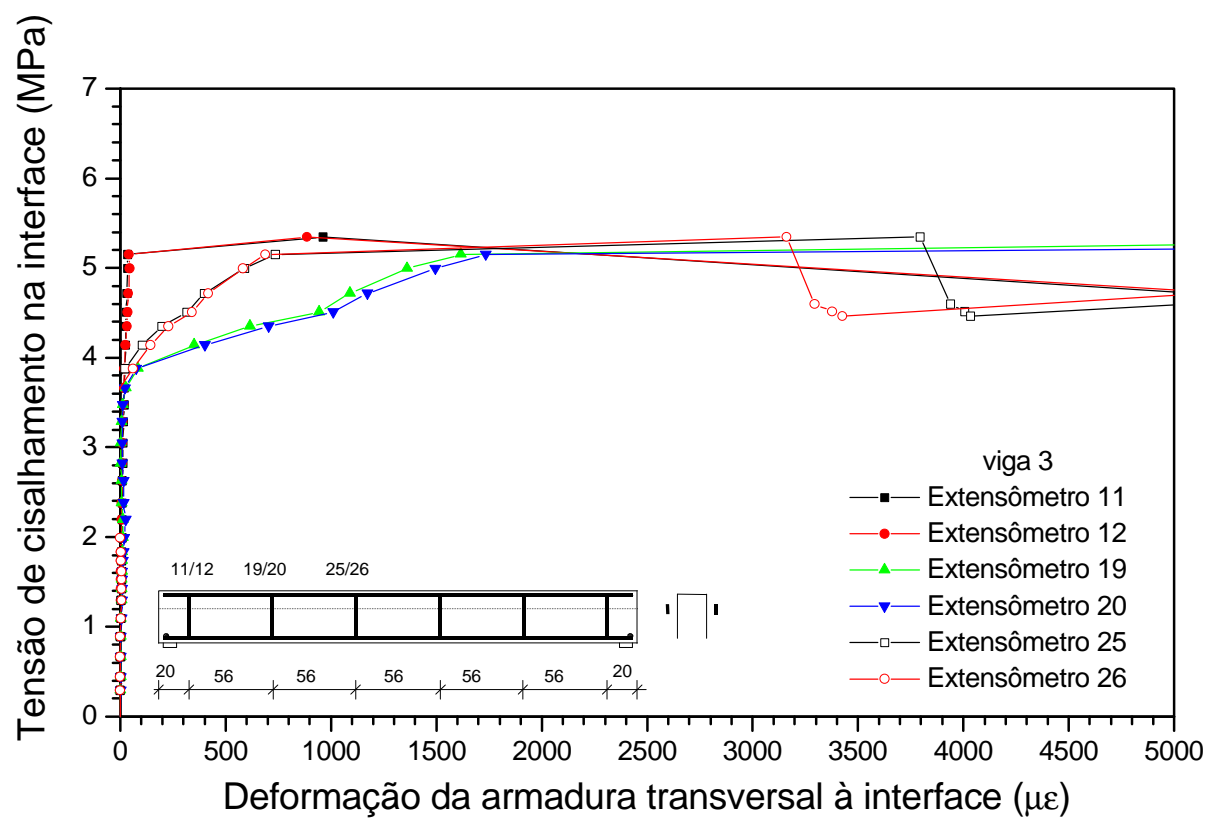

- Lado que sofreu maior deslizamento

Figura 5.18(c) - Deformação da armadura de costura ao nível da interface da viga 3. 

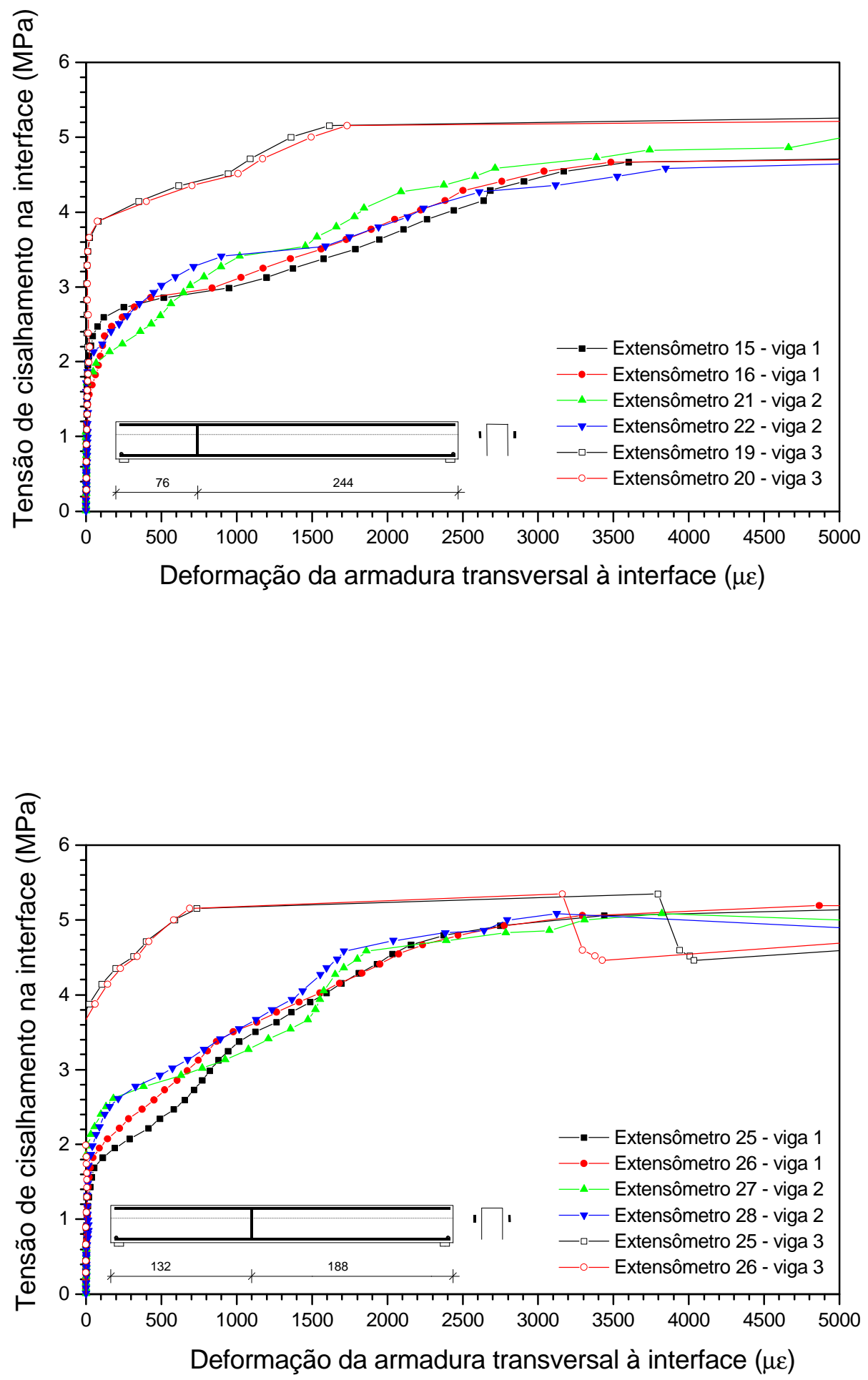

Figura 5.19 - Comparação, entre as vigas ensaiadas, da deformação da armadura de costura ao nível da interface. (continua) 

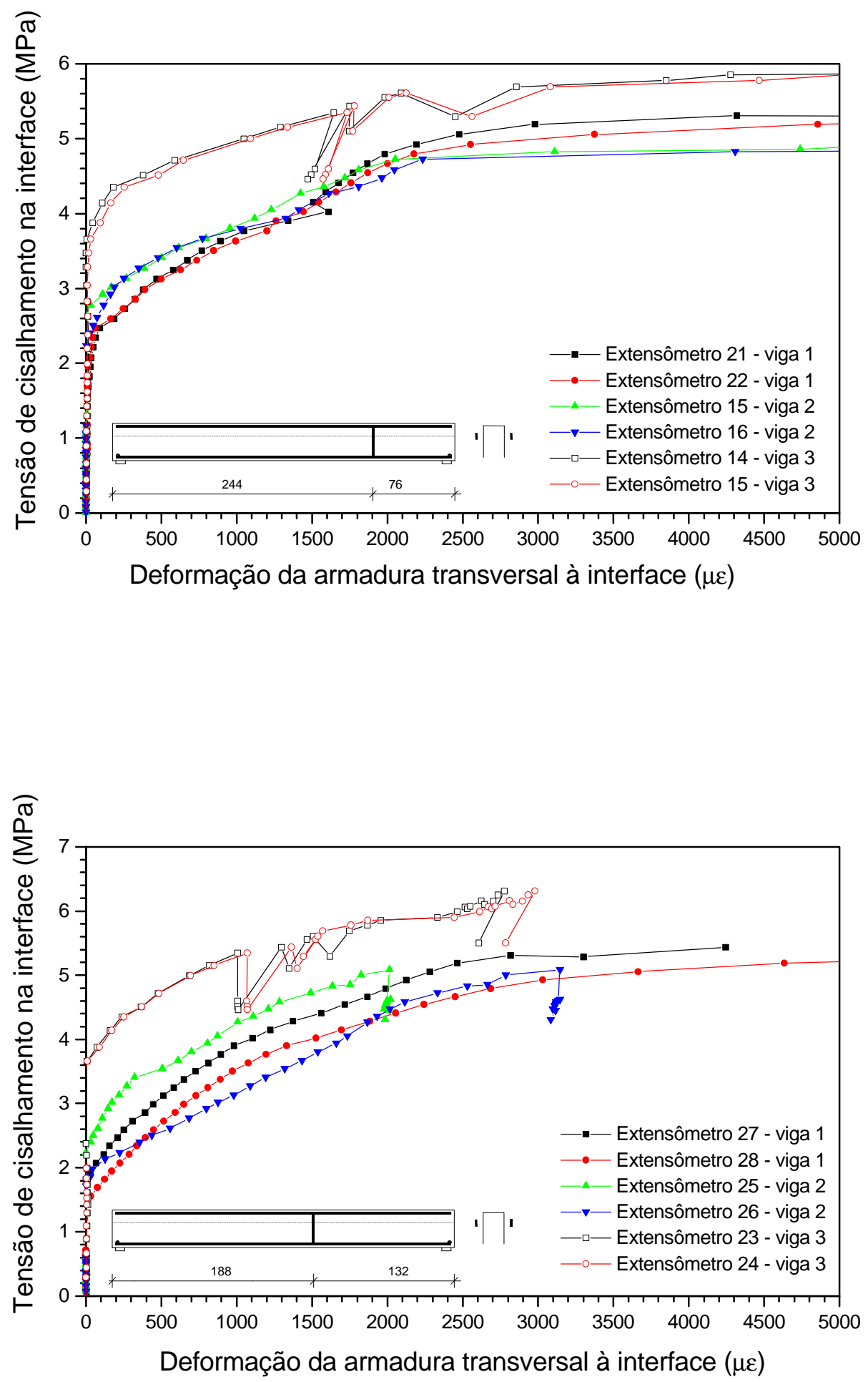

Figura 5.19 - Comparação, entre as vigas ensaiadas, da deformação da armadura de costura ao nível da interface. (continuação) 
Na figura 5.20 é mostrada a deformação ao longo da armadura de costura da interface em função da tensão de cisalhamento, e na figura 5.21 é feita a comparação da deformação desse estribo entre as vigas ensaiadas. Observa-se que a região da armadura ao nível da interface apresenta as maiores deformações. Este comportamento está de acordo com a teoria atrito-cisalhamento que propõe que a armadura transversal a uma junta de concreto é solicitada pela tendência de afastamento entre as superfícies em contato, aplicando forças normais à interface e garantindo a transferência de tensões de cisalhamento por atrito entre essas superfícies (item 2.4.1). A região da armadura de costura localizada no interior da alma apresenta comportamento semelhante entre as vigas ensaiadas, o que sugere não haver diferença na distribuição de tensões nessa região do estribo quando utilizado de forma fechada ou aberta, devendo-se apenas tomar o cuidado de projetar um comprimento adequado para garantir a transferência dos esforços da armadura ao nível da interface para a região de concreto da alma.

Em BRUGGELING; HUYGHE (1991) é proposto um mecanismo de transferência de tensões pela interface de vigas compostas baseado no modelo de biela e tirante (figura 5.22). A formação desse mecanismo pode ser entendido da seguinte forma: a resultante das forças de compressão na mesa é desviada pelo estribo, solicitando-o a esforços de tração e formando uma biela de compressão que cruza a interface segundo um ângulo $\alpha$. Essa biela inclinada introduz esforços normais à interface e aumenta sua resistência aos esforços de cisalhamento. Esse mecanismo talvez possa explicar a ruptura prematura da viga 3 , isto é, como o estribo era muito estreito não formou-se a biela comprimida inclinada. Ao que parece, com o aumento do deslizamento da interface, a armadura transversal é solicitada e deforma-se segundo a teoria atrito-cisalhamento. Num certo nível de deslizamento há a formação dessa biela inclinada que possibilita maiores deslizamentos e, consequentemente, maiores deformações da armadura. Na viga 3 ocorreram pequenos deslizamentos e alguma deformação da armadura, mas, como não houve a formação da biela cruzando a interface, não foi possível a armadura aumentar a resistência por atrito, provocando um deslizamento repentino e brusco que causou a ruptura da viga. A formação da biela cruzando a interface nas vigas 1 e 2 pode ser observada pelas deformações ocorridas no trecho horizontal dos estribos. 


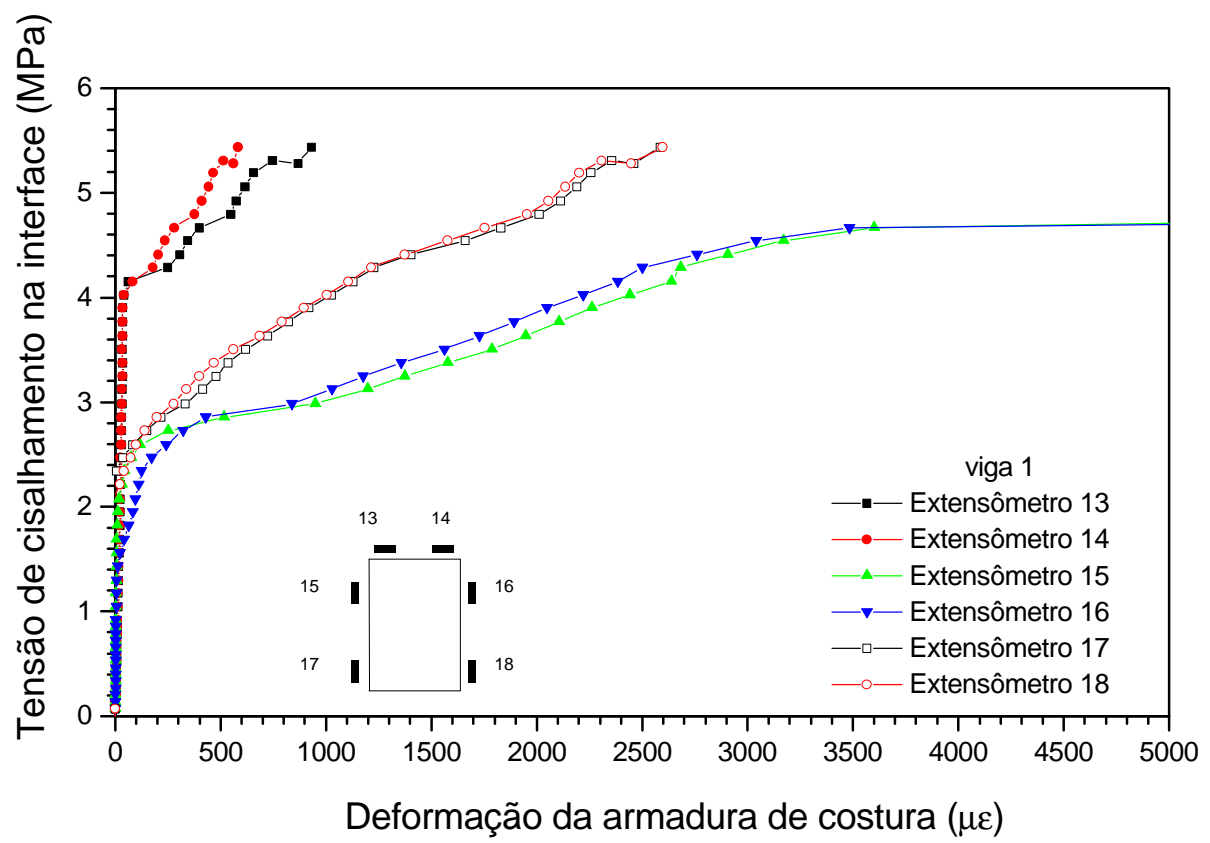

- Lado que sofreu maior deslizamento

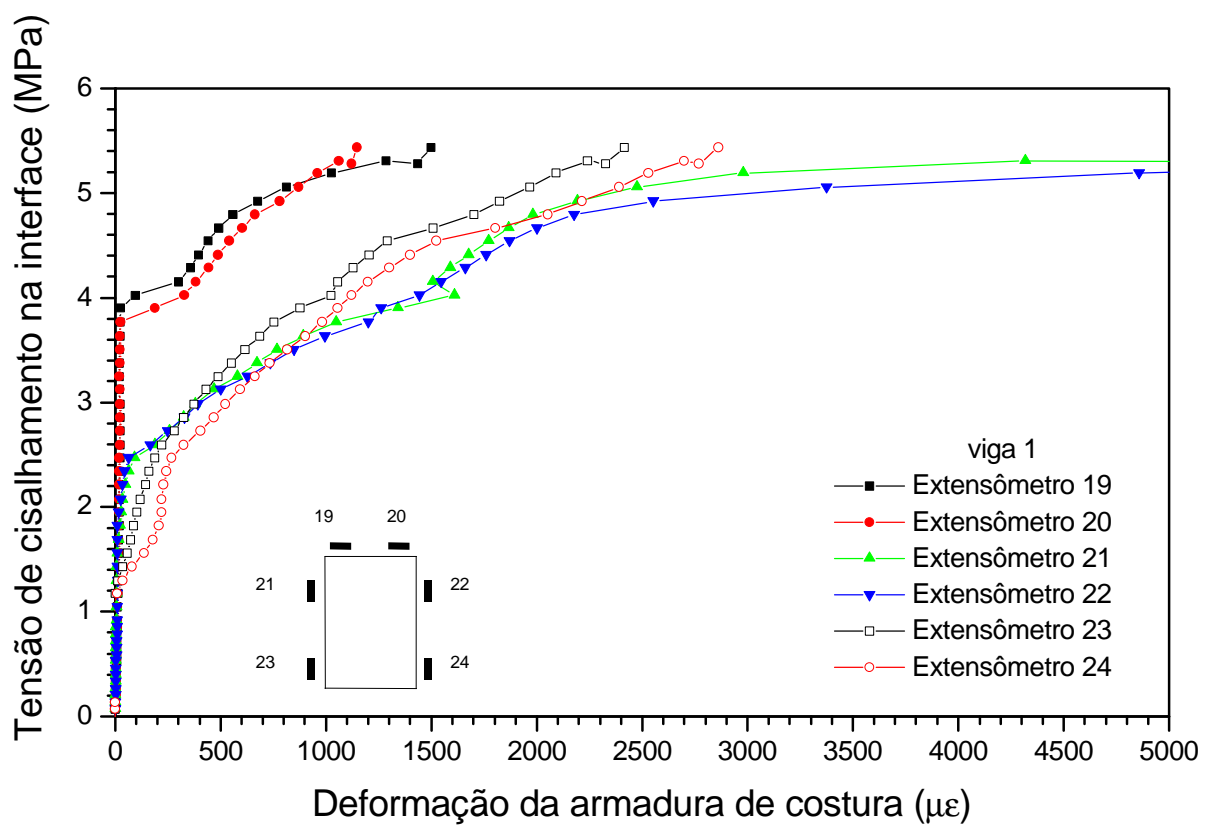

- Lado que sofreu menor deslizamento

Figura 5.20(a) - Deformação ao longo da armadura de costura da interface da viga 1. 


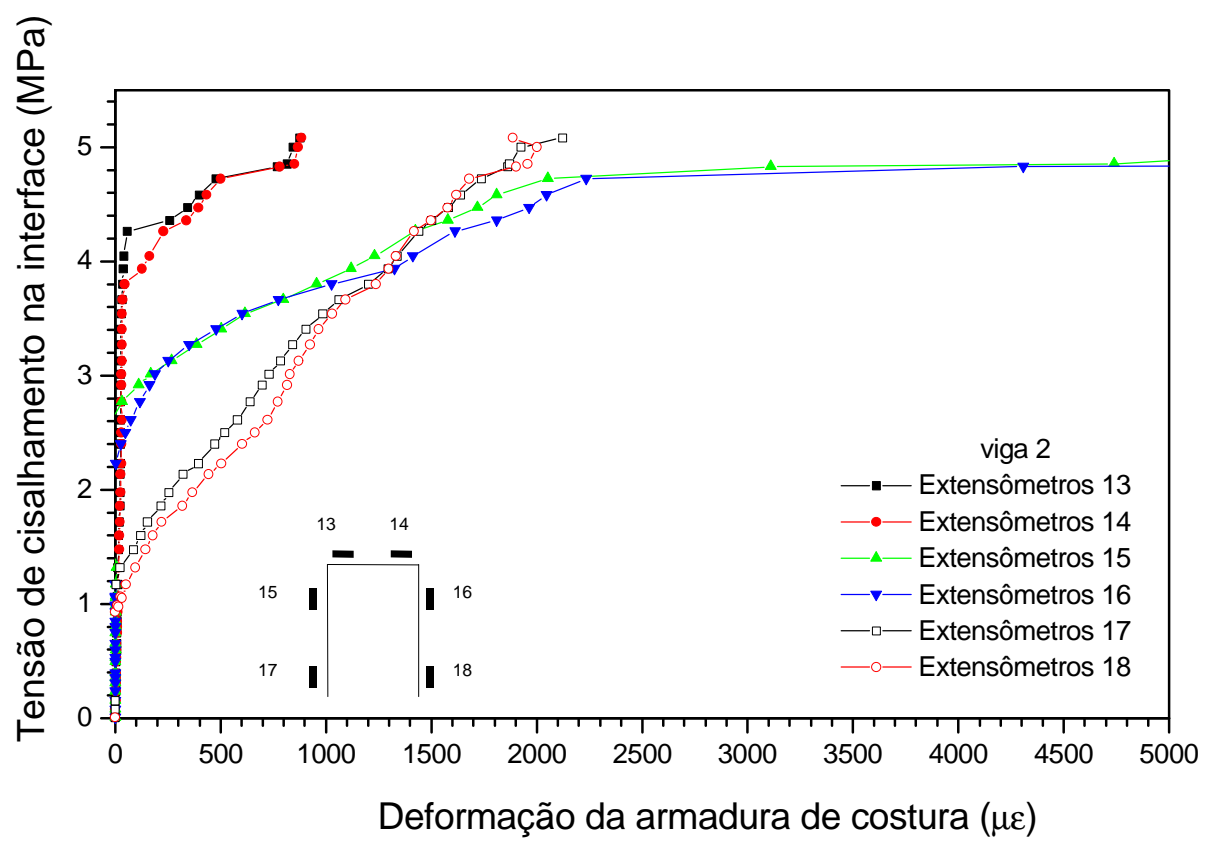

- Lado que sofreu menor deslizamento

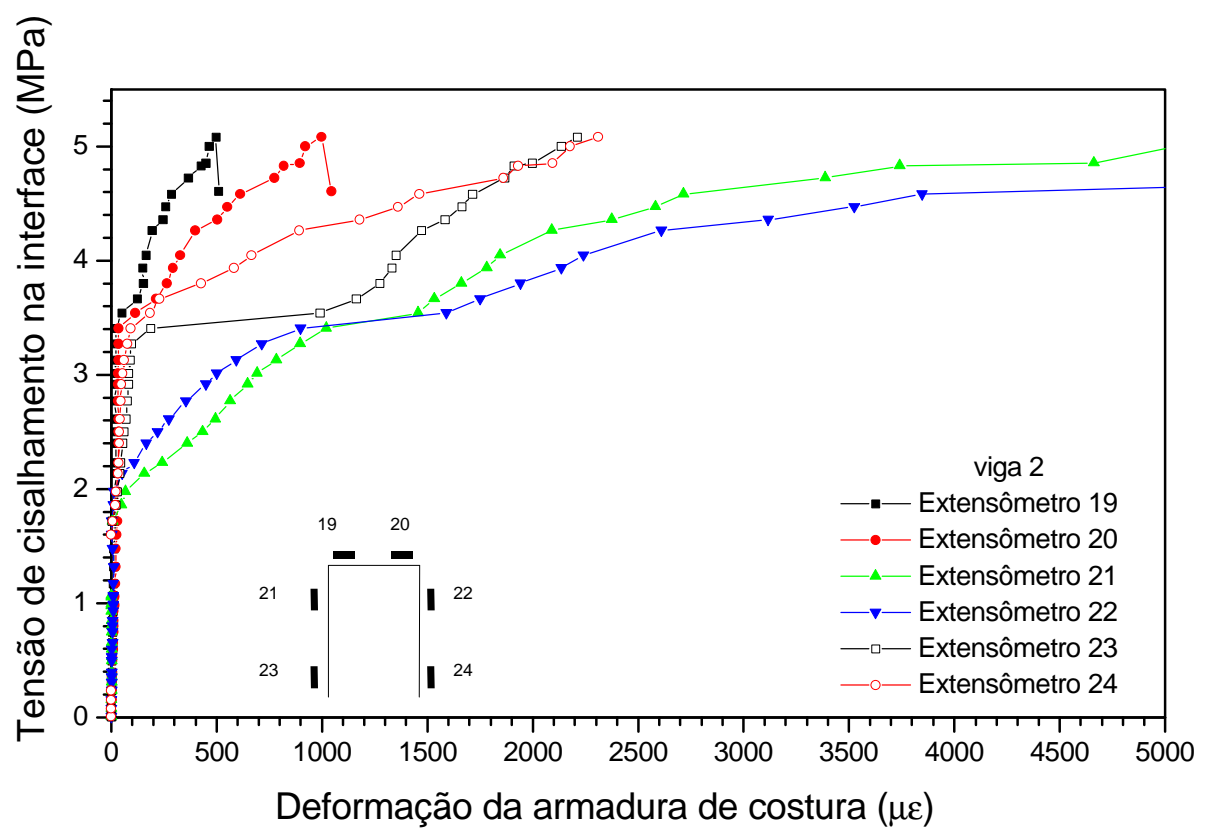

- Lado que sofreu maior deslizamento

Figura 5.20(b) - Deformação ao longo da armadura de costura da interface da viga 2. 


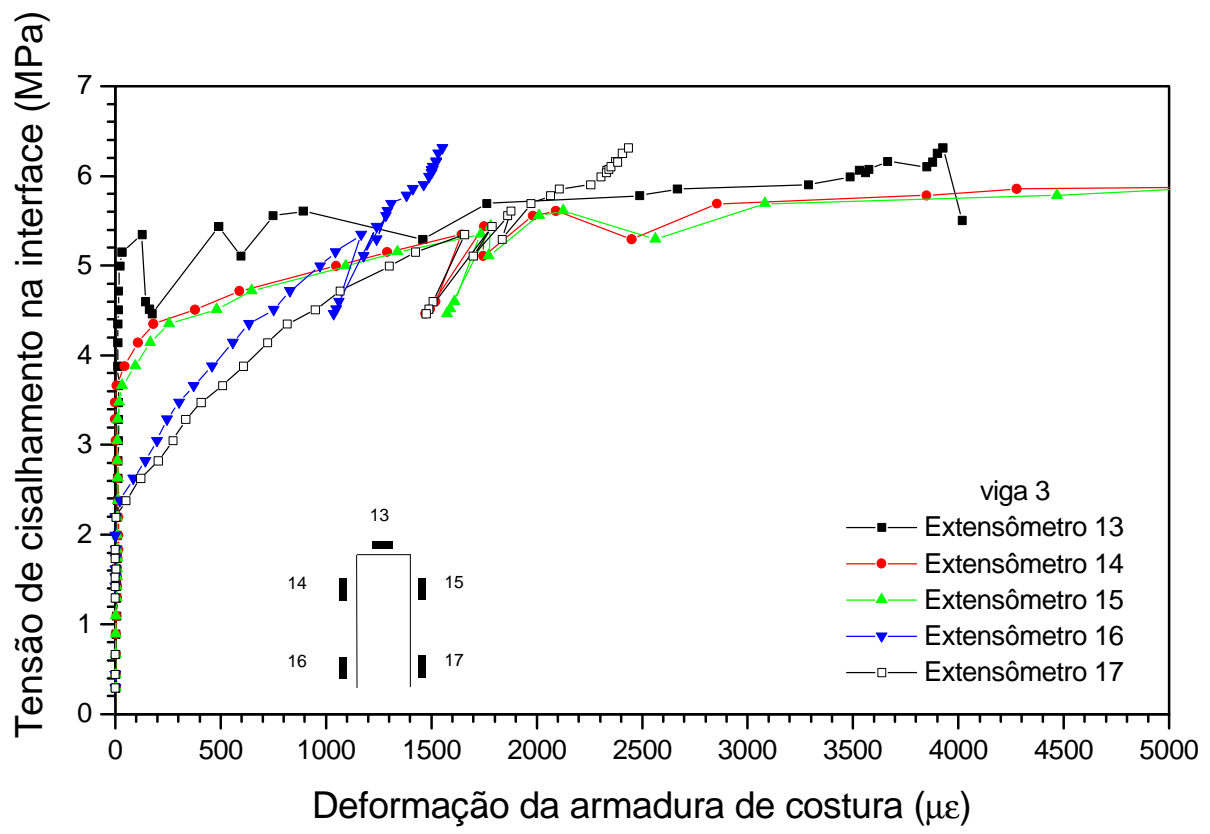

- Lado que sofreu menor deslizamento

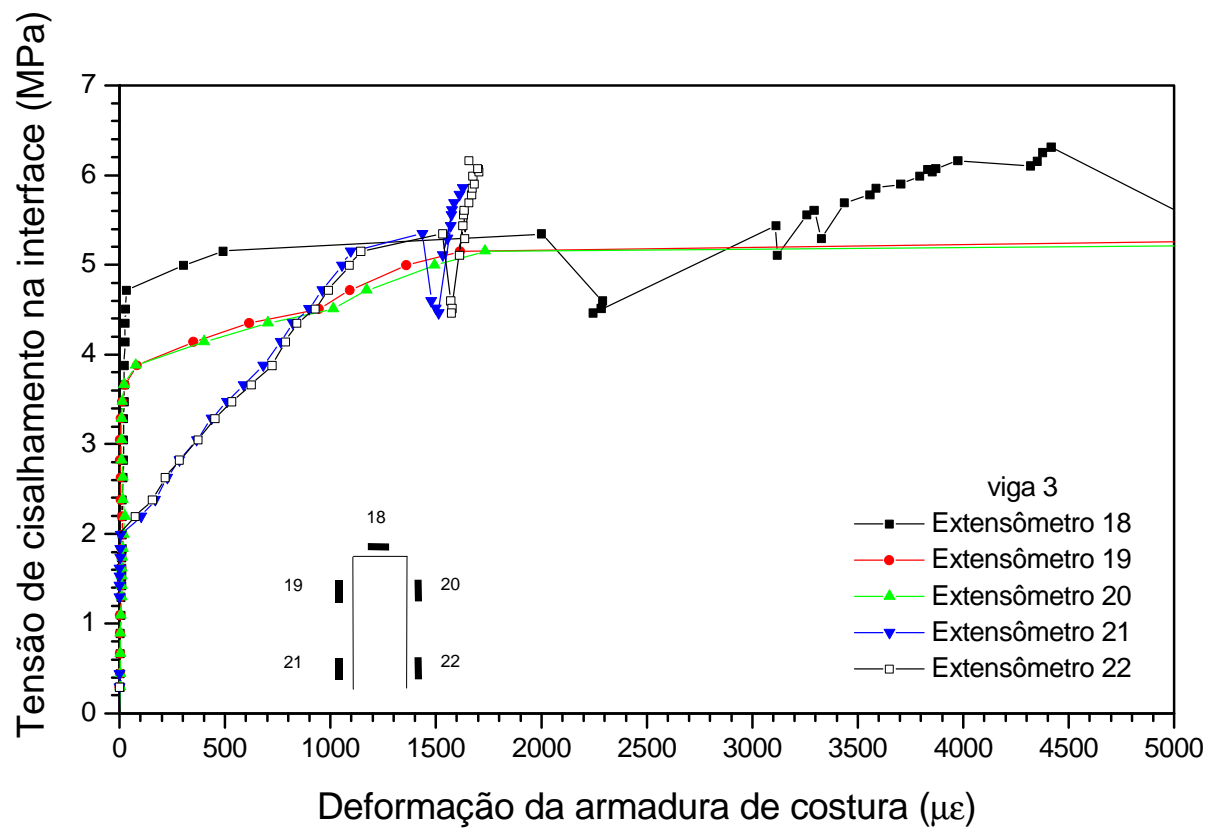

- Lado que sofreu maior deslizamento

Figura 5.20(c) - Deformação ao longo da armadura de costura da interface da viga 3. 


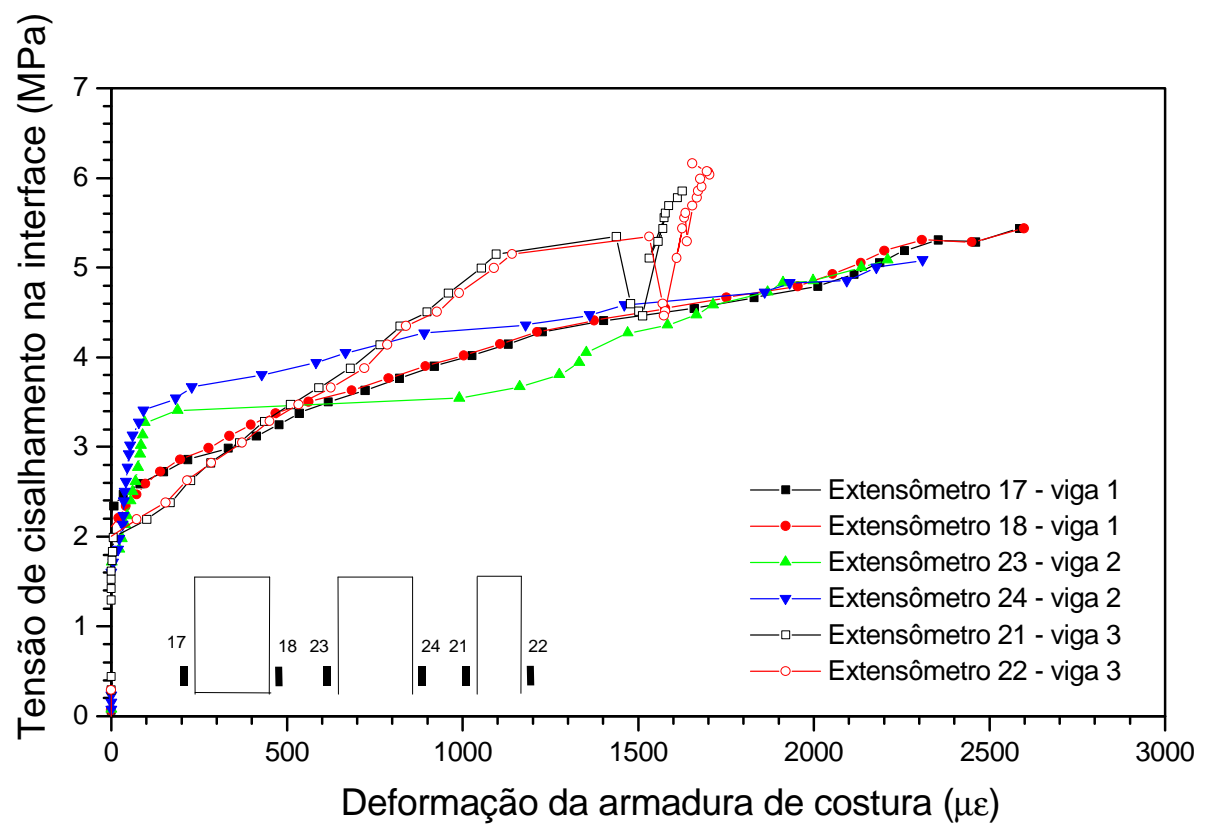

- Lado que sofreu maior deslizamento

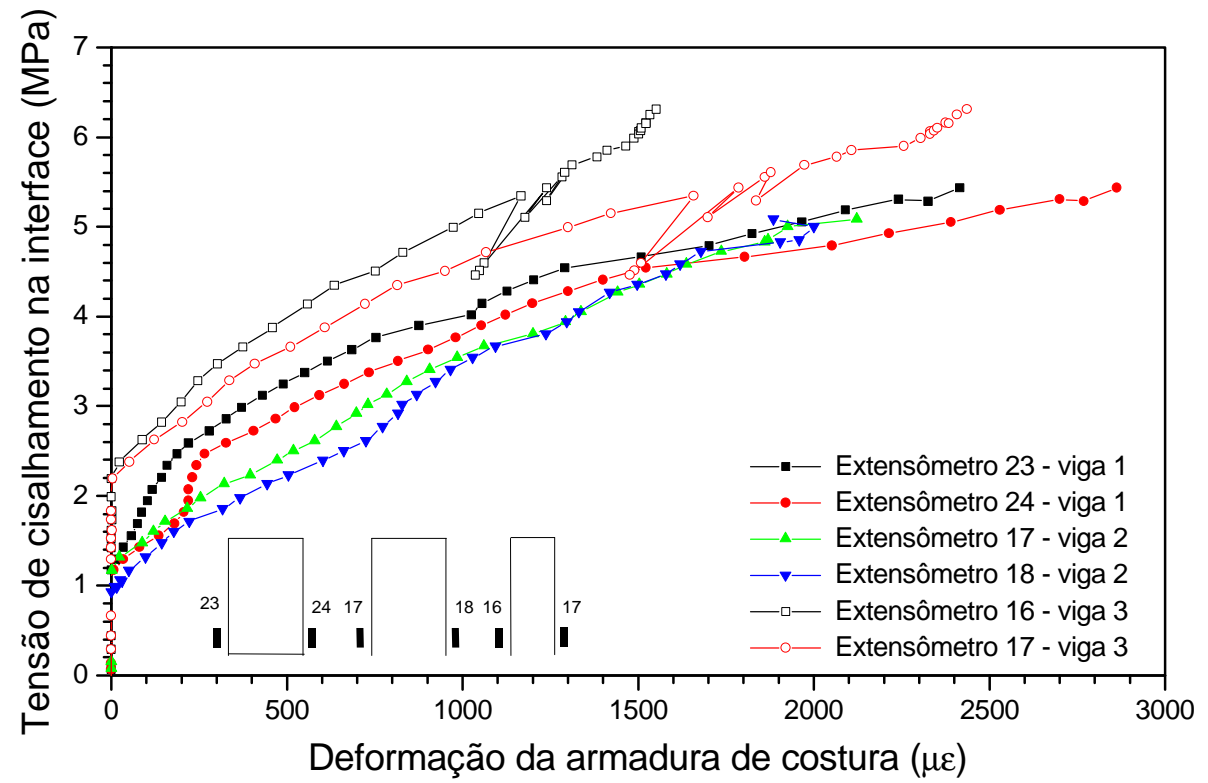

- Lado que sofreu menor deslizamento

Figura 5.21 - Comparação, entre as vigas, da deformação ao longo da armadura de costura da interface. (continua) 


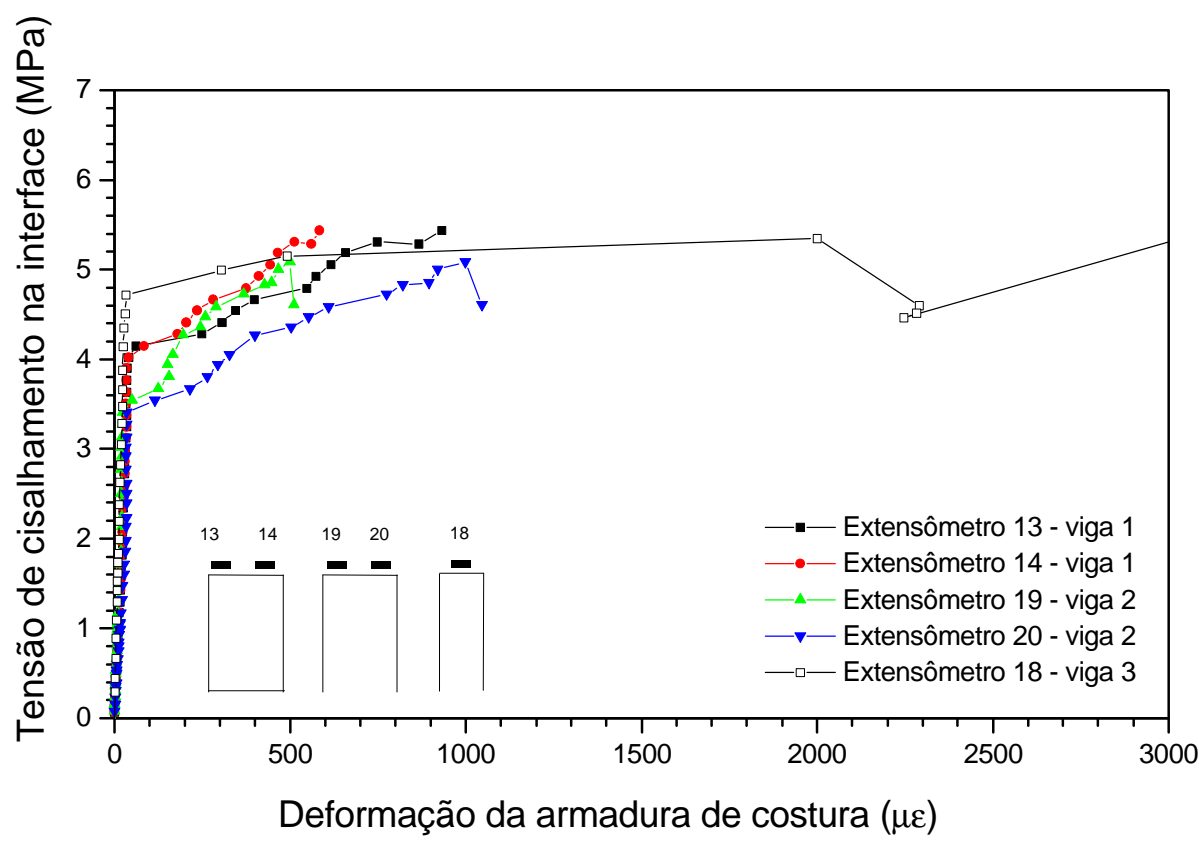

- Lado que sofreu o maior deslizamento

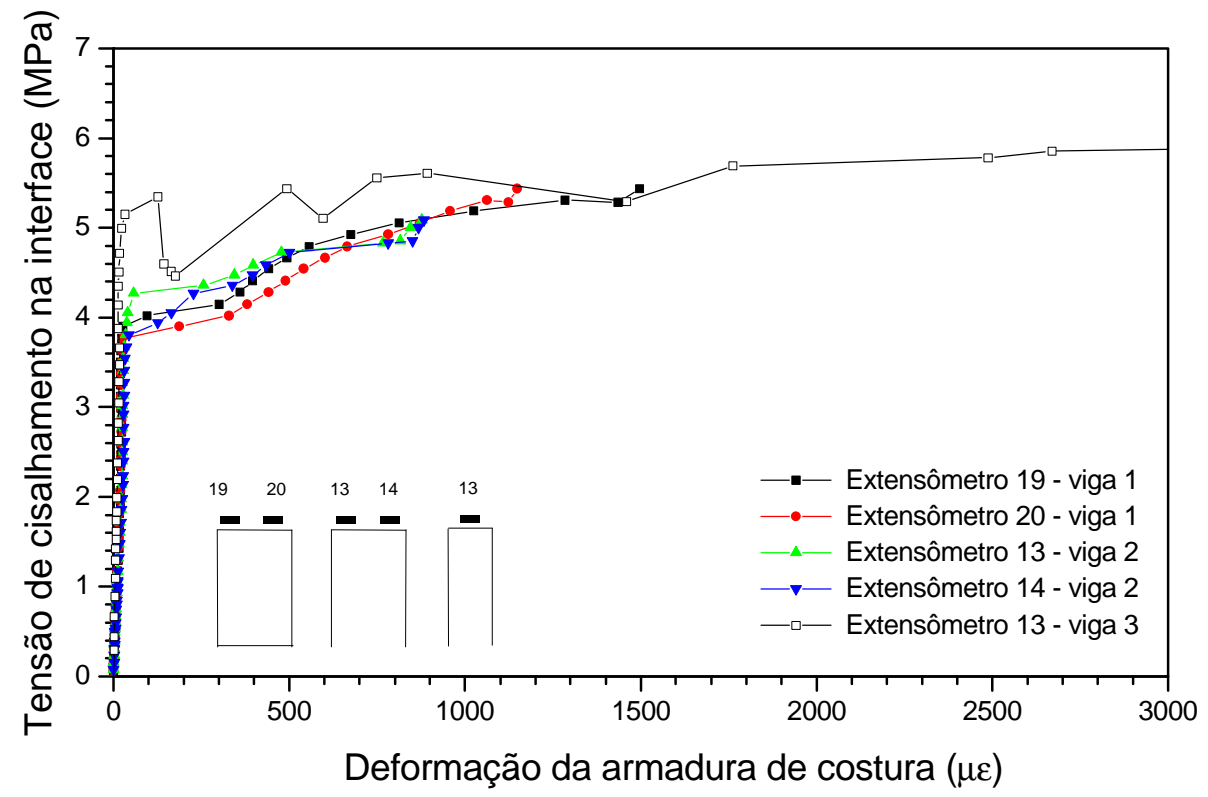

- Lado que sofreu o menor deslizamento

Figura 5.21 - Comparação, entre as vigas, da deformação ao longo da armadura de costura da interface. (continuação) 


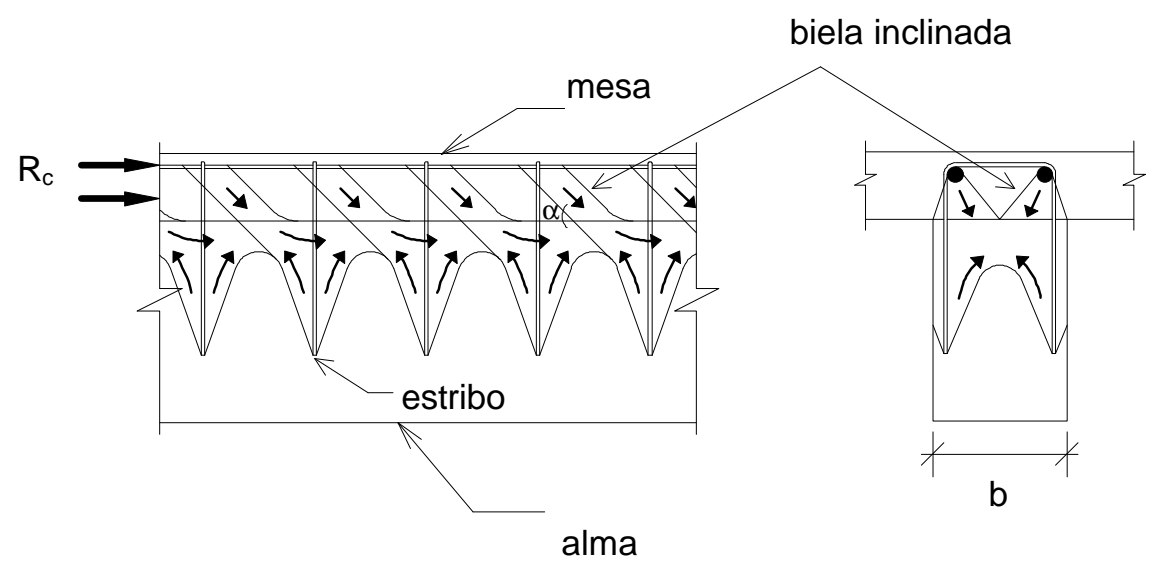

Figura 5.22 - Mecanismo de transferência de tensões em interface de vigas compostas (BRUGGELING; HUYGHE (1991)).

Estes resultados sugerem que deve existir uma relação mínima entre a largura da região de transferências de esforços da interface (e consequentemente a largura do estribo) e a largura da alma para que o estribo possa contribuir na transferência dos esforços de cisalhamento pela interface após ocorrido um certo deslizamento relativo entre a mesa e a alma.

\subsection{Comparação entre os resultados dos ensaios e os modelos analíticos e empíricos}

Os modelos analíticos e empíricos que apresentaram melhor aproximação com os resultados dos ensaios de Patnaik, conforme apresentado no capítulo 4, foram aplicados às vigas ensaiadas. Na tabela 5.8 são apresentados os resultados obtidos.

Tabela 5.8(a) - Avaliação da resistência ao cisalhamento da interface das vigas ensaiadas pelos modelos analíticos.

\begin{tabular}{|c|c|c|c|c|c|}
\hline Viga & $\begin{array}{c}\mathrm{f}_{\mathrm{c}} \\
(\mathrm{MPa})\end{array}$ & $\begin{array}{c}\rho . \mathrm{f}_{\mathrm{y}} \\
(\mathrm{MPa})\end{array}$ & $\begin{array}{c}\text { Ensaios } \\
(\mathrm{MPa})\end{array}$ & $\begin{array}{c}\text { Tassios e Vintzeleou } \\
\text { (item 2.4.3) }\end{array}$ & $\begin{array}{c}\text { Hsu, et al. } \\
\text { (item 2.4.5) }\end{array}$ \\
\hline 1 & 39,80 & 0,91 & 5,44 & 4,97 & 3,65 \\
\hline 2 & 41,50 & 0,91 & 5,08 & 5,11 & 3,69 \\
\hline 3 & 41,67 & 1,50 & 5,35 & 6,05 & 4,56 \\
\hline
\end{tabular}


Tabela 5.8(b) - Avaliação da resistência ao cisalhamento da interface das vigas ensaiadas pelos modelos empíricos.

\begin{tabular}{|c|c|c|c|c|c|c|c|}
\hline Viga & $\begin{array}{c}\text { Ensaios } \\
(\mathrm{MPa})\end{array}$ & $\begin{array}{c}\text { Loov } \\
\text { eq(2.46) }\end{array}$ & $\begin{array}{c}\text { Walraven, et } \\
\text { al. eq(2.49) }\end{array}$ & $\begin{array}{c}\text { Mattock } \\
\text { eq(2.50) }\end{array}$ & $\begin{array}{c}\text { Mau, Hsu } \\
\text { eq(2.51) }\end{array}$ & $\begin{array}{c}\text { Patnaik } \\
\text { eq(2.53) }\end{array}$ & $\begin{array}{c}\text { Mattock } \\
\text { eq(2.55.a) }\end{array}$ \\
\hline 1 & 5,44 & 3,60 & 3,73 & 4,20 & 4,00 & 3,80 & 3,70 \\
\hline 2 & 5,08 & 3,69 & 3,80 & 4,29 & 4,06 & 3,88 & 3,79 \\
\hline 3 & 5,35 & 4,74 & 4,91 & 4,76 & 5,21 & 4,89 & 4,87 \\
\hline
\end{tabular}

Observa-se que, de forma geral, os modelos forneceram resultados sensivelmente inferiores aos obtidos da ruptura das vigas. O modelo analítico de Tassios e Vintzeleou, admitindo o deslizamento da interface igual a 1,4 mm, apresentou a melhor aproximação com os resultados experimentais. Comportamento semelhante foi observado no capítulo 4 para as vigas ensaiadas por Patnaik que possuíam baixa taxa de armadura transversal. Ao que parece, esse modelo, baseado na transferência de esforços por atrito e por ação de pino da armadura, fornece resultados superiores aos outros modelos quando há baixa taxa de armadura transversal à interface. Analisando a contribuição de cada mecanismo desse modelo na transferência dos esforços pela interface das vigas ensaiadas, nota-se que a ação de pino da armadura representa apenas $10 \%$ da resistência total da interface, ou seja, a grande contribuição da armadura é proporcionar uma tensão normal à interface que garanta uma boa transferência por atrito. Outra observação importante é o fato da armadura transversal, segundo o modelo, atingir a resistência de escoamento para deslizamentos da ordem de 0,5 mm. Nessa configuração, que pode ser admitida como uma configuração de ruptura, a resistência fornecida pelo modelo é muito próxima da resistência fornecida pelos modelos empíricos. Contudo, mesmo após a armadura atingir a resistência de escoamento, a resistência da interface, pode continuar aumentando até o deslizamento atingir 1,4 mm. Nesse momento, a resistência da interface é dada pela eq.(2.13), que pode ser escrita como:

$$
\tau=0,44 \cdot \mathrm{f}_{\mathrm{c}}{ }^{0,67} \cdot \sigma_{\mathrm{n}}{ }^{0,33}
$$


Dessa equação observa-se que o expoente da resistência do concreto $\left(\mathrm{f}_{\mathrm{c}}\right)$ é maior que os encontrados nos modelos empíricos, enquanto o expoente da tensão normal $\left(\sigma_{n}\right)$ é menor. Isso justifica porque o modelo fornece valores superiores aos dos modelos empíricos para baixas taxas de armadura e valores inferiores para altas taxas de armadura, desde que o deslizamento da interface seja levado até o limite de $1,4 \mathrm{~mm}$.

Do exposto acima, parece que, em razão da pouca confiança na resistência por aderência, os modelos adotam valores conservadores para essa parcela da resistência (eq.(2.50)), ou simplesmente desprezam sua contribuição, adotando coeficientes de atrito aparente de forma a computar parte da resistência por aderência.

A aderência apresenta parcela importante da resistência da interface apenas quando há baixa taxa de armadura. Na viga 3, onde aumentou-se a taxa de armadura, todos os modelos empíricos forneceram resultados semelhantes e mais próximos dos resultados dos ensaios do que nas vigas 1 e 2 . Contudo, essa viga sofreu uma ruptura prematura que pode ter reduzido sua resistência final.

\subsection{Verificação das vigas pelos procedimentos de normas e regulamentos}

A resistência da interface das vigas ao cisalhamento horizontal foi avaliada pelos procedimentos de normas e regulamentos apresentados no capítulo 3 . Desconsiderando os coeficientes de segurança, os coeficientes de minoração da resistência dos materiais e utilizando a resistência média do concreto e do aço obtido dos ensaios, obteve-se os valores mostrados na tabela 5.9.

Observa-se que os resultados fornecidos pelas normas e regulamentos são sensivelmente inferiores aos resultados obtidos dos ensaios, havendo grande divergência quando compara-se, para a mesma viga, diferentes procedimentos. Essa divergência, em parte, deve-se ao fato da taxa de armadura das vigas encontrar-se próxima à armadura mínima requerida pelas normas, situação em que há grande influência da aderência. 
Tabela 5.9 - Avaliação da interface das vigas pelas normas e regulamentos.

\begin{tabular}{|c|c|c|c|c|c|}
\hline Viga & $\begin{array}{c}\text { Ensaios } \\
\text { (MPa) }\end{array}$ & $\begin{array}{c}\text { FIP } \\
\text { eq.(3.8) }\end{array}$ & $\begin{array}{c}\text { PCI } \\
\text { eq.(3.12) }\end{array}$ & $\begin{array}{c}\text { NBR-9062 } \\
\text { eq.(3.15) }\end{array}$ & $\begin{array}{c}\text { CAN3-A23.3-M84 } \\
\text { eq.(3.19) }\end{array}$ \\
\hline 1 & 5,44 & 1,52 & 2,50 & 0,93 & 0,82 \\
\hline 2 & 5,08 & 1,54 & 2,50 & 0,96 & 0,82 \\
\hline 3 & 5,35 & 2,07 & 3,21 & 1,19 & 1,35 \\
\hline
\end{tabular}

Tabela 5.9 - Avaliação da interface das vigas pelas normas e regulamentos (continuação).

\begin{tabular}{|c|c|c|c|c|}
\hline Viga & $\begin{array}{c}\text { Ensaios } \\
(\mathrm{MPa})\end{array}$ & $\begin{array}{c}\text { JSCE:SP1 } \\
\text { eq.(3.20.a) }\end{array}$ & $\begin{array}{c}\text { BS8110 } \\
\text { eq.(3.21) }\end{array}$ & $\begin{array}{c}\text { DS411 } \\
\text { eq.(3.22) }\end{array}$ \\
\hline 1 & 5,44 & 2,20 & 2,50 & 3,00 \\
\hline 2 & 5,08 & 2,23 & 2,50 & 3,13 \\
\hline 3 & 5,35 & 3,67 & 2,50 & 3,55 \\
\hline
\end{tabular}

As normas japonesa (JSCE:SP1) e dinamarquesa (DS411), que possuem como variável em sua expressão a resistência a compressão do concreto, são as que fornecem os valores mais altos de resistência da interface. As normas brasileira (NBR-9062) e canadense (CAN3-A23.3-M84) são muito conservadoras com relação às outras normas quando há baixa taxa de armadura transversal à interface.

Para uma melhor análise deveriam ser aplicados coeficientes de minoração para levar em consideração a dispersão de resultados, o que reduziria a resistência nominal das vigas. Contudo, como o objetivo desses ensaios era uma avaliação qualitativa do comportamento das vigas na ruptura e não uma avaliação quantitativa, não aplicou-se esses coeficientes. 


\subsection{Considerações finais}

Foram ensaiadas três vigas compostas à flexão com o objetivo de obter resultados próprios que proporcionassem uma maior sensibilidade na análise dos resultados experimentais disponíveis na literatura. Os modelos analíticos e empíricos apresentaram resultados semelhantes e sensivelmente inferiores aos obtidos dos ensaios. A aderência na interface apresentou uma parcela importante da resistência final, o que justifica a diferença observada, uma vez que os modelos desprezam a parcela de aderência ou avaliam-na de forma conservadora. A influência da aderência em vigas com taxa de armadura superior à mínima mostrou-se ser menos significativa.

Os procedimentos de normas e regulamentos forneceram resultados inferiores aos dos ensaios, sendo que as normas brasileira e canadense mostraram-se muito conservadoras quando há baixa taxa de armadura transversal à interface.

Observou-se que a utilização de armadura de costura em forma de estribo fechado ou aberto não influenciou na resistência final da viga. Nesse caso a ruptura ocorreu pelo deslizamento gradual da interface e formação de uma biela de compressão ligando a interface ao apoio. Os estribos transversais à interface atingiram a resistência de escoamento, com exceção dos estribos localizados nas extremidades da viga. A viga 3 apresentou uma ruptura brusca da interface, a qual, aparentemente, acarretou uma diminuição de sua resistência final. Isso sugere que deve haver uma relação mínima entre a largura da alma e a largura da região de transferência de esforços da interface, ou largura dos estribos, de forma a possibilitar a formação, na mesa, de uma biela inclinada à interface que garanta a deformação dos estribos e possibilite a transferência por arco das tensões da interface ao apoio. Portanto, cuidados devem ser tomados na utilização de prélajes que reduzam a largura da interface. 


\section{Considerações finais e conclusão}

Neste trabalho foi estudado o cisalhamento na interface entre concreto prémoldado e concreto moldado no local em elementos submetidos à flexão, tendo sido enfocadas as vigas compostas formadas por alma pré-moldada e mesa moldada no local com armadura de costura atravessando a interface.

No capítulo 2 foi apresentado o mecanismo de transferência de esforços de cisalhamento através de juntas de concreto, sendo as tensões transferidas pela superfície de contato (aderência, atrito e engrenamento dos agregados) e pela ação de pino da armadura transversal à interface. Alguns ensaios encontrados na literatura para avaliação da resistência da interface de peças compostas também foram apresentados. Foram estudados dois modelos analíticos baseados na transferência por atrito entre as superfícies em contato e na transferência pela ação de pino da armadura transversal. Um terceiro modelo analítico, baseado no modelo de bielas e tirantes, foi apresentado para representar o comportamento de interfaces de peças compostas sem fissuração inicial. Ao final foram apresentados vários modelos empíricos encontrados na literatura.

No terceiro capítulo foram apresentados alguns critérios de projeto e algumas indicações de normas para o dimensionamento da interface de vigas e lajes compostas submetidas à flexão, com e sem armadura transversal. $\mathrm{Na}$ seqüência foram apresentadas algumas recomendações para execução de peças compostas.

No capítulo 4, os modelos analíticos e empíricos estudados foram utilizados para avaliar a resistência da interface de algumas vigas compostas disponíveis na literatura, com ênfase nos ensaios de Patnaik. Esses modelos também foram utilizados para avaliar a resistência da ligação entre peças pré-moldadas através de 
conectores formados por barras dobradas em laço. Ao final do estudo foram indicados os modelos que forneceram os resultados mais próximos aos obtidos dos ensaios nas vigas compostas e nas peças ligadas por conector.

No capítulo 5 foram apresentados os resultados dos ensaios de três vigas compostas biapoiadas. As vigas possuíam seção $\mathrm{T}$, sendo que a alma e a mesa foram moldadas em idades diferentes para representar a interface formada pela ligação de vigas pré-moldadas e laje moldada no local. Os resultados dos ensaios foram comparados com os modelos analíticos e empíricos e com os procedimentos de normas. Também foram feitas algumas observações sobre a influência da forma da armadura transversal à interface na resistência final das vigas aos esforços de cisalhamento horizontal.

\subsection{Conclusões}

Observou-se que os modelos analíticos de Tassios; Vintzeleou (TASSIOS; VINTZELEOU, (1990)) e Hsu; Mau; Chen (HSU, et al., (1987)) apresentaram boa aproximação com os resultados de ruptura de vigas compostas relatados na literatura. Contudo, a resistência segundo o modelo de Tassios; Vintzeleou foi obtida para deslizamentos da interface da ordem de 1,4 mm, situação em que a armadura de costura, segundo o modelo, já havia atingido a resistência de escoamento. Quando comparou-se a resistência fornecida por esse modelo, para um determinado valor de deslizamento, com a resistência das vigas compostas para o mesmo valor de deslizamento, observou-se que o modelo forneceu, sistematicamente, resultados inferiores aos dos ensaios. Ao que parece a expressão que fornece a resistência última desse modelo (eq.(2.13)) aproxima-se bem dos resultados de ruptura das vigas, entretanto ele não descreve bem a relação entre o deslizamento e a resistência da interface. Outra observação interessante foi que, em quase todas as comparações, a armadura atingiu a resistência de escoamento, tanto no modelo quanto nos ensaios, para o mesmo valor de deslizamento. Portanto, parece razoável utilizar esse modelo em vigas compostas apenas quando for interessante verificar se, para uma determinada resistência de concreto, a armadura transversal à interface pode atingir a sua resistência de escoamento. O modelo de Hsu; Mau; Chen apresentou uma melhor 
aproximação com os resultados experimentais de vigas compostas, entretanto, ele mostrou-se mais difícil de ser utilizado.

Os modelos empíricos que apresentaram melhor aproximação com os resultados dos ensaios de vigas compostas, além, evidentemente, da equação proposta por Patnaik, foram Loov (eq.(2.46)), Walraven, et al. (eq.(2.49)), Mattock (eq.(2.50) e eq.(2.55.a)) e Mau; Hsu (eq.(2.51)). Esses modelos possuem expressões relativamente simples apresentando-se mais adequados para utilização em projetos de vigas compostas com armadura de costura do que os modelos analíticos. Vale salientar que desses modelos apenas a equação proposta por Patnaik foi obtida de ensaios em vigas compostas.

Alguns modelos não apresentam um limite máximo para a resistência ao cisalhamento da interface, fornecendo valores superiores aos obtidos dos ensaios quando as vigas possuem altas taxas de armadura. O limite proposto por Patnaik de $0,25 . f_{c}$ parece razoável uma vez que fornece um limite seguro e coincide com o limite máximo proposto pela FIP.

Quando há baixa taxa de armadura atravessando a interface, a parcela de resistência por aderência entre as superfícies é significativa e os resultados fornecidos pelos modelos, de forma geral, são inferiores aos obtidos dos ensaios. Isso sugere que, em virtude da grande variabilidade da aderência, os modelos não consideram ou avaliam de forma conservadora sua contribuição.

Os modelos analíticos e empíricos apresentados foram comparados com resultados de ensaios de vigas compostas com armadura de costura atravessando a interface em forma de estribo, não podendo-se afirmar nada sobre a eficiência desses modelos em outros tipos de peças compostas submetidas à flexão.

Dos ensaios de cisalhamento direto das peças pré-moldadas ligadas por conector observou-se que a aderência entre as peças representou parcela importante da resistência final, sendo que a equação proposta por Mattock (eq.(2.50)) mostrou-se mais adequada para avaliação da resistência desse tipo de ligação. O modelo analítico de Tassios e Vintzeleou forneceu valores de resistência inferiores aos dos ensaios quando adotou-se superfície de contato lisa. Apesar disso, quando houve a ruptura prematura da aderência e ocorreram acréscimos no 
deslizamento com incrementos na força aplicada, observou-se que os resultados fornecidos por esse modelo, até seu limite máximo de deslizamento, aproximaramse bem dos resultados do ensaio. Ao que parece, o modelo de Tassios e Vintzeleou representa bem o comportamento desse tipo de ligação e, caso o estado limite de ruptura da interface seja caracterizado pelo deslizamento excessivo, ele pode ser utilizado para avaliar a resistência ao cisalhamento da interface. Essas observações foram feitas em ensaios com baixa taxa de armadura e baseado no comportamento de apenas um modelo, de forma que são necessários mais ensaios variando a rugosidade da superfície de contato e a taxa de armadura para poder-se afirmar de forma conclusiva sobre a validade da utilização do modelo de Tassios e Vintzeleou na avaliação desse tipo de ligação.

Dos ensaios das vigas compostas realizados no laboratório observou-se que os modelos empíricos e o modelo de Hsu; Mau e Chen apresentaram resultados semelhantes e sensivelmente inferiores aos obtidos dos ensaios. $O$ modelo de Tassios; Vintzeleou (adotando deslizamentos da ordem de 1,4 mm) apresentou melhor aproximação por considerar uma grande contribuição da resistência do concreto na resistência da interface para baixas taxas de armadura transversal à interface. A aderência na interface apresentou uma parcela importante da resistência final, o que justifica a diferença observada entre os resultados dos ensaios e os fornecidos pelos modelos, uma vez que estes últimos desprezam a parcela de aderência ou avaliam-na de forma conservadora. A influência da aderência em vigas com taxa de armadura superior à mínima mostrou-se ser menos significativa. Esses resultados estão de acordo com os observados em outros ensaios relatados na literatura.

As indicações de normas e regulamentos forneceram resultados inferiores aos dos ensaios, sendo que as normas brasileira e canadense mostraram-se muito conservadoras quando há baixa taxa de armadura transversal à interface.

Destes ensaios observou-se também que a utilização de armadura de costura em forma de estribo fechado ou aberto, com largura igual à largura dos estribos da alma, não influenciou na resistência final da viga. Neste caso a ruptura ocorreu pelo deslizamento gradual da interface e formação de uma biela de compressão ligando a interface ao apoio. Contudo, a diminuição da largura da 
região de transferência de esforços da viga, com conseqüente redução da largura dos estribos, provocou uma ruptura brusca da interface, acarretando uma diminuição da resistência final da viga. Isso sugere que deve haver uma relação mínima entre a largura da alma e a largura da região de transferência de esforços da interface de forma a possibilitar a transferência por arco das tensões da interface ao apoio. Portanto, cuidados devem ser tomados na utilização de prélajes que reduzam a largura da interface.

A norma brasileira, em todas as comparações, forneceu valores muito inferiores aos observados nos ensaios de vigas quando a taxa de armadura transversal a interface era inferior a 0,5\%. Entretanto, para altas taxas de armadura, ela tende a fornecer resultados superiores aos observados em ensaios. Isso sugere que deve ser proposto um limite máximo ao valor da resistência calculada pela norma para adequa-la aos resultados experimentais.

O procedimento do $\mathrm{PCl}$ mostrou-se mais adequado para utilização em projetos de vigas compostas com armadura de costura em forma de estribo, uma vez que ele forneceu resultados mais próximos aos obtidos dos ensaios. Contudo, ele apresentou um limite muito baixo para a resistência ao cisalhamento. Dessa forma, atingido esse limite, parece razoável verificar a resistência pelo procedimento da FIP e, se encontrado valor superior ao do $\mathrm{PCl}$, adotá-lo como a resistência da interface. Deve-se observar com atenção as características mínimas requeridas por cada procedimento para a caracterização da superfície de contato como rugosa.

\subsection{Recomendações para trabalhos futuros}

Alguns aspectos da transferência de esforços pela interface de peças compostas continuam obscuros. Algumas sugestões para trabalhos futuros são:

- Novos ensaios variando a largura do estribo e a rugosidade da interface de vigas compostas para definir uma relação mínima entre a largura da região de transferência de esforços pela interface e a largura da alma. Também é necessário verificar o comportamento dessa ligação para outros tipos de carregamento na viga. 
- Novos ensaios com maior variação dos valores da resistência do concreto e da taxa de armadura transversal à interface.

- Estudar a resistência da interface para vigas sujeitas a carregamentos cíclicos, situação típica de pontes.

- Realizar outros ensaios de cisalhamento direto variando a taxa de armadura e a rugosidade da superfície de contato.

- Realizar outros ensaios de cisalhamento direto variando a taxa de armadura e a rugosidade da superfície de contato. 


\section{Referências bibliográficas}

AMERICAN CONCRETE INSTITUTE - ACI (1989). Building code requirements for reinforced concrete (ACI 318M-89). Detroit, American Concrete Institute.

ASSOCIAÇÃO BRASILEIRA DE NORMAS TÉCNICAS - ABNT (1985). NBR 9062 Projeto e execução de estruturas de concreto pré-moldado. Rio de Janeiro.

ASSOCIAÇÃO BRASILEIRA DE NORMAS TÉCNICAS - ABNT (1978). NBR 6118 Projeto e execução de obras de concreto armado. Rio de Janeiro.

BIRKELAND, P.W.; BIRKELAND, H.W. (1966). Connections in precast concrete construction. Journal of American Concrete Institute, Proceedings, v.63, n.3, p.345-367, March.

BRUGGELING, A.S.G. ; HUYGHE, G.F. (1991). Prefabrication with concrete, p.106-113. Rotterdam, A. A. Balkema.

CALAVERA, J. (1989). Some anomalies in the shear at the interface design of composite members. Betonwerk und Fertigteil-Technik, v.55, n.5, p.51-52, May.

CARREIRA, D.J.; CHU, K. (1985). Stress-strain relationship for plain concrete in compression. Journal of the American Concrete Institute, Proceedings, v.82, n.6, p.797-804, November-December.

CASTRO, L.A. (1997). Análise da segurança no projeto de estruturas: método dos estados limites. São Carlos. Dissertação (Mestrado) - Escola de Engenharia de São Carlos - Universidade de São Paulo.

CNR-10025 (1984). La normativa sui prefabbricati. Milano, ITEC / La prefabricazione.

DIVAKAR, M.P.; FAFITIS, A. (1992). Micromechanics-based constitutive model for interface shear. Journal of Engineering Mechanics, ASCE, v.118, n.7, p.13171337, July.

EF-88 (1988). Instrucción para el proyecto y la ejecución de forjados unidireccionales de hormigón armado o pretensado. Madrid, Comisión permanente del hormigón. 
FEDERATION INTERNATIONALE DE LA PRECONTRAINTE - FIP (1982). Shear at the interface of precast and in situ concrete: guide to good practice.

HERMANSEN, B.R.; COWAN, J. (1974). Modified shear-friction theory for bracket design. Journal of the American Concrete Institute, Proceedings, v.71, p.5560 .

HOFBECK, J.A.; IBRAHIM, I.O.; MATTOCK, A.H. (1969). Shear transfer in reinforced concrete. Journal of the American Concrete Institute, Proceedings, v.66, n.2, p.119-128, February.

HSU, T.T.C.; MAU, S.T.; CHEN, B. (1987). Theory of shear transfer strength of reinforced concrete. ACl Structural Journal, v.84, n.2, p.149-160, March-April.

JONSSON, E. (1996). Design on the basis of testes. Betonwerk und FertigteilTechnik, v.62, n.1, p.162-174, January.

KRAUTHAMMER, T. (1992). Minimum shear reinforcement based on interface shear transfer. ACI Structural Journal, v.89, n.1, p.99-105, January-February.

LEONHARDT, F. (1977). Construções de concreto. Rio de Janeiro, Interciência. v.1-3.

MALITE, M. ; TAKEYA, T. (1996). Ensaios em conectores de cisalhamento viga-laje para tabuleiro de pontes (construtora MARNA Ltda). São Carlos, Departamento de Engenharia de Estruturas. EESC-USP. (Relatório técnico)

MAU, S.T.; HSU, T.T.C. (1988). Comments of "Influence of concrete strength and load history on the shear friction capacity of concrete members". PCI Journal, v.33, n.1, p.166-168, January-February. /paper by J. Walraven, et al., PCl Journal, v.32, n.1, p.66-84, January-February.

MAST, R.F. (1968). Auxiliary reinforcement in concrete connections. Journal of the Structural Division, ASCE, v.94, n.ST6, p.1485-1504, June.

MATTOCK, A.H. (1987). Anchorage of stirrups in a thin cast-in-place topping. PCI Journal, v.32, n.6 , p.70-85, November-December.

MATTOCK, A.H. (1988). Comments of "Influence of concrete strength and load history on the shear friction capacity of concrete members". PCI Journal, v.33, n.1, p.166-168, January-February. /paper by J. Walraven, et al., PCl Journal, v.32, n.1, p.66-84, January-February.

MATTOCK, A.H. (1994). Comments of "Horizontal shear strength of composite concrete beams with a rough interface". PCl Journal, v.39, n.5, p.106-108, September-October. /paper by R.E. Loov. A.K. Patnaik, PCl Journal, v.39, n.1, p.48-69, January-February.

PATNAIK, A.H. (1992). Horizontal shear strength of composite concrete beams with a rough interface. Ph.D Thesis, University of Calgary, Calgary, Canada. 
PRESTRESSED/ PRECAST CONCRETE INSTITUTE - PCI (1992). PCI design handbook: precast and Prestressed concrete. 4.ed. Chicago, $\mathrm{PCl}$.

SAEMANN, J.C.; WASHA, G.W. (1964). Horizontal shear connections between precast beams and cast-in-place slabs. Journal of the American Concrete Institute, Proceedings, v.61, n.11, p.1383-1408, November.

SANTOS, S.P. (1985). Ligações de estruturas prefabricadas de betão. Lisboa, Laboratório Nacional de Engenharia Civil.

SERNA ROS, P. et al. (1994). Experimental research on prestressed hollow core slabs floor with in situ concrete topping. In: INTERNATIONAL CONGRESS OF FEDERATION INTERNATIONALE DE LA PRECONTRAINTE, 12.,Washington, May. Proceedings. p.C33-C41.

SOLAS, A. (1988). Armaduras de cosido entre hormigones prefabricados y ejecutados in situ. Informes de la Construcion, v.39, n.394, p.33-48, marzo.

TASSIOS,T.P.; VINTZELEOU, E.N. (1987). Concrete-to-concrete friction. Journal of Structural Engineering, ASCE, v.113, n.4, p.832-849, April.

TASSIOS, T.P. ; VINTZELEOU,E.N. (1990). Shear crack stability along a precast reinforced concrete joint. In: CARPINTERI, A.,ed. Applications of fracture mechanics to reinforced concrete. Essex, Elsevier Applied Science. p.365486.

TIMOSHENKO, S.P.; GERE, J.E. (1983). Mecânica dos sólidos. Rio de Janeiro, LTC - :Livros Técnicos e Científicos editora. v.1.

TSOUKANTAS, S.G. ; TASSIOS, T.P. (1989). Shear resistance of connections between reinforced concrete linear precast elements. ACI Structural Journal, v.86, n.3, p.242-249, May-June.

UNIVERSIDADE DE SÃO PAULO. Escola de Engenharia de São Carlos. Serviço de Biblioteca (1997). Diretrizes para elaboração de dissertações e teses na EESC-USP. 2.ed.rev.ampl. São Carlos. 58p.

VECCHIO, F.J. ; COLLINS, M.P. (1986). The modified compression-field theory for reinforced concrete elements subjected to shear. Journal of the American Concrete Institute, Proceedings, v.83, n.2, p.219-231, March-April.

WALRAVEN, J. ; FRÉNAY, J. ; PRUIJSSERS, A. (1987). Influence of concrete strength and load history on the shear friction capacity of concrete members. PCI Journal, v.32, n.1, p.66-84, January-February. 


\section{Anexo A : Coeficientes de minoração a serem aplicados aos modelos.}

As comparações feitas no capítulo 4 tiveram como objetivo determinar os modelos que melhor representavam o comportamento da interface de vigas compostas. As normas recomendam que sejam aplicados coeficientes de majoração aos carregamentos externos e coeficientes de minoração às resistências nominais dos materiais para evitar que as estruturas atinjam o estado limite de ruptura. Outras normas minoram a resistência nominal da peça ao invés de majorar o carregamento. Independentemente desses coeficientes, quando a resistência de uma peça é obtida por equações empíricas, deve-se também aplicar outro coeficiente de minoração de forma a obter a resistência característica. Este coeficiente avalia a dispersão dos resultados empíricos em relação a sua média, de forma que é garantido uma margem de segurança das equações empíricas. A determinação numérica deste coeficiente pode ser feita por métodos estatísticos.

$\mathrm{Na}$ tabela 4.1 e na tabela 4.3 foram registradas as relações entre os resultados fornecidos pelos modelos e os resultados dos ensaios de Patnaik. Supondo que esses resultados obedeçam a uma curva normal de distribuição de freqüências é possível definir uma probabilidade de falha $\left(p_{f}\right)$ que representa a probabilidade de um evento não acontecer. Este método é utilizado, por exemplo, na determinação da resistência característica do concreto à compressão. Ensaiado um lote de concreto, a resistência característica $\left(f_{c k}\right)$ é aquela abaixo da qual só corresponde um total de $5 \%$ dos resultados obtidos, ou seja, um valor (ou evento) com $95 \%$ de probabilidade de ocorrência ou com $5 \%$ de probabilidade de falha (figura A.1(a)). 


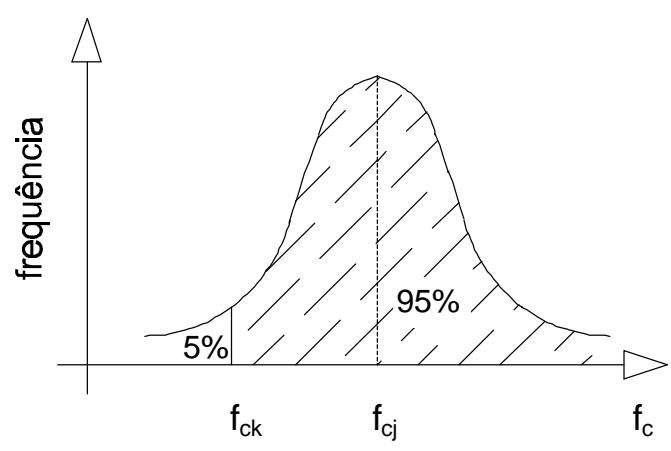

(a) curva normal para determinação da resistência característica do concreto à compressão

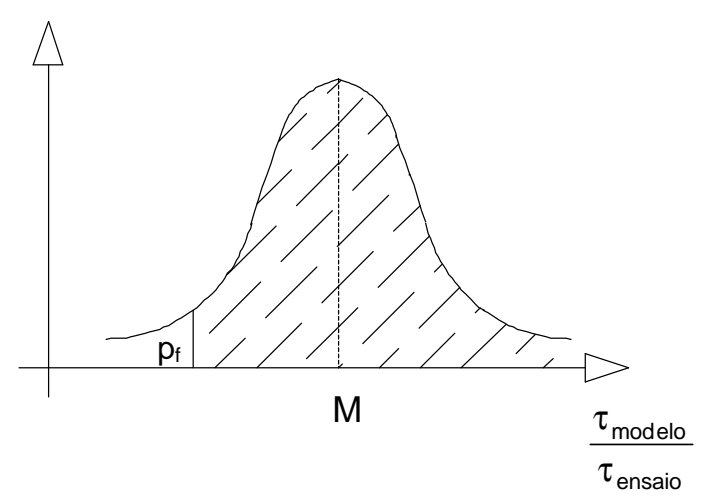

(b) curva normal para determinação de coeficientes de minoração

Figura A.1 - Curva normal de distribuição de freqüências.

É possível calcular um índice de confiabilidade $(\beta)$ em função da probabilidade de falha do evento, ou seja, da probabilidade da resistência fornecida pelos modelos ser maior que a resistência obtida dos ensaios. Esta hipótese foi adotada em função da maioria dos eventos que ocorrem na engenharia possuírem distribuição normal. $O$ índice de confiabilidade representa a margem de segurança de um evento ter sucesso, ou seja, indica quão longe determinada configuração de carregamento ou resistência de uma estrutura está de seu estado limite (CASTRO (1997)). Na tabela A.1 estão mostrados os valores do índice de confiabilidade em função da probabilidade de falha assumida (figura A.1(b)).

Tabela A.1 - índices de confiabilidade $(\beta)$

\begin{tabular}{|c|c|}
\hline $\begin{array}{c}\text { probabilidade de } \\
\text { falha assumida }\left(\mathrm{p}_{\mathrm{f}}\right)\end{array}$ & $\begin{array}{c}\text { índice de } \\
\text { confiabilidade }(\beta)\end{array}$ \\
\hline $10 \%$ & 1.28 \\
\hline $5 \%$ & 1.65 \\
\hline $1 \%$ & 2.33 \\
\hline $0.1 \%$ & 3.10 \\
\hline
\end{tabular}

Admitindo que a resistência da interface obtida pelos modelos analíticos e empíricos tenha uma probabilidade de $95 \%$ de ser inferior aos valores reais obtidos 
de ensaios $\left(\mathrm{p}_{\mathrm{f}}=5 \%\right)$, o coeficiente de minoração da resistência a ser aplicado aos modelos é calculado por:

$$
\phi=1-\beta . \delta
$$

$\beta=1,65\left(p_{\mathrm{f}}=5 \%\right)$

$\delta=\frac{S}{M}:$ coeficiente de variação;

S,M : desvio padrão e média, respectivamente, da relação entre a resistência calculada pelos modelos e os resultados obtidos dos ensaios (tabelas $4.1 \mathrm{e}$ 4.3).

Na figura A.2 estão ilustradas as curvas fornecidas pelos modelos analíticos e empíricos já multiplicadas pelos coeficientes de minoração e as curvas fornecidas pelos procedimentos e normas (sem coeficientes de minoração) aplicadas às vigas compostas ensaiadas por Patnaik com $\mathrm{f}_{\mathrm{c}}=35 \mathrm{MPa}$. Na tabela A.2 são mostrados os respectivos coeficientes de minoração para $p_{\mathrm{f}}=5 \%$. Observa-se da figura A.2 que essas curvas fornecem resultados próximos dos indicados pelos procedimentos e normas. Além disso, os valores de $\phi$ da tabela A.2 estão próximos do valor recomendado pela norma norueguesa $(\phi=0,83)$ para obter a resistência característica de peças de concreto ensaiadas em laboratório. Este valor pode ser obtido pela eq.(A.1) usando $\delta=0,1$ e $\beta=1,7$ (JONSSON (1996)). Portanto, parece razoável utilizar esses coeficientes de forma a permitir a aplicação dos modelos ao projeto de estruturas correntes. Vale ressaltar que, além disso, também devem ser aplicados coeficientes de minoração à resistência da estrutura e às resistências dos materiais de acordo com a norma utilizada no projeto. 


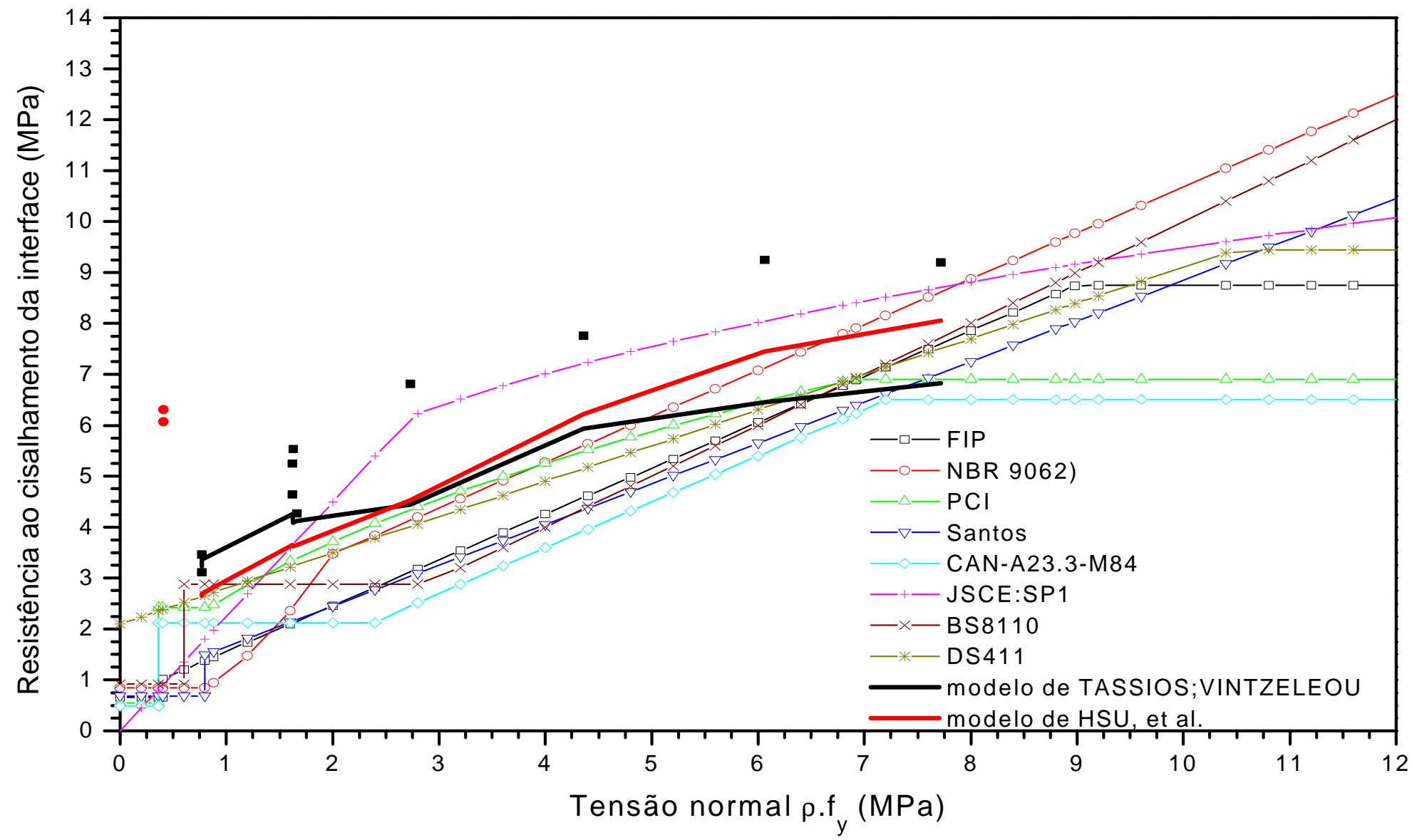

Figura A.2 - Comparação entre as curvas dos modelos analíticos e as curvas dos procedimentos de normas e regulamentos. (continua) 


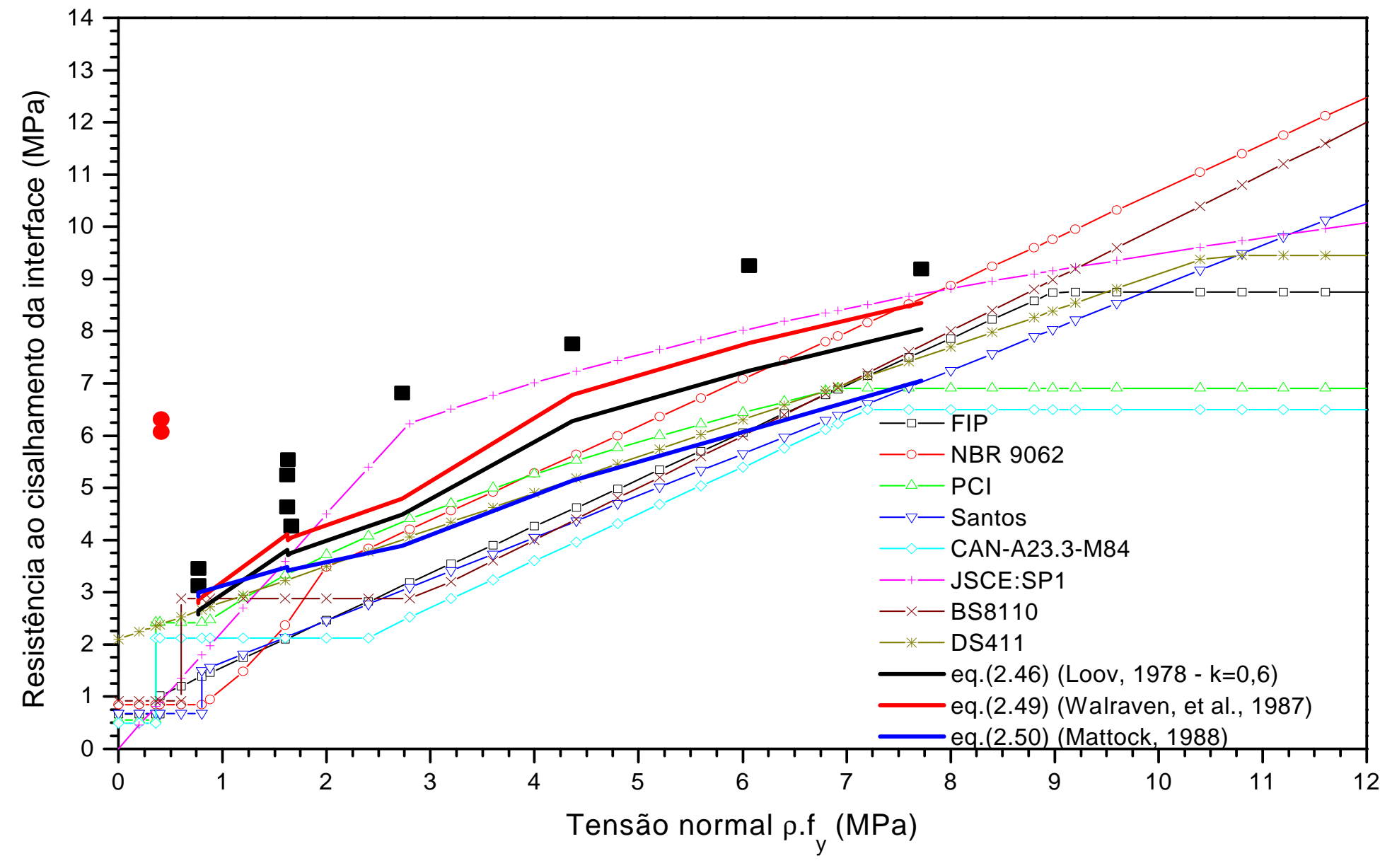

Figura A.2 - Comparação entre as curvas dos modelos empíricos e as curvas dos procedimentos de normas e regulamentos. (continuação) 


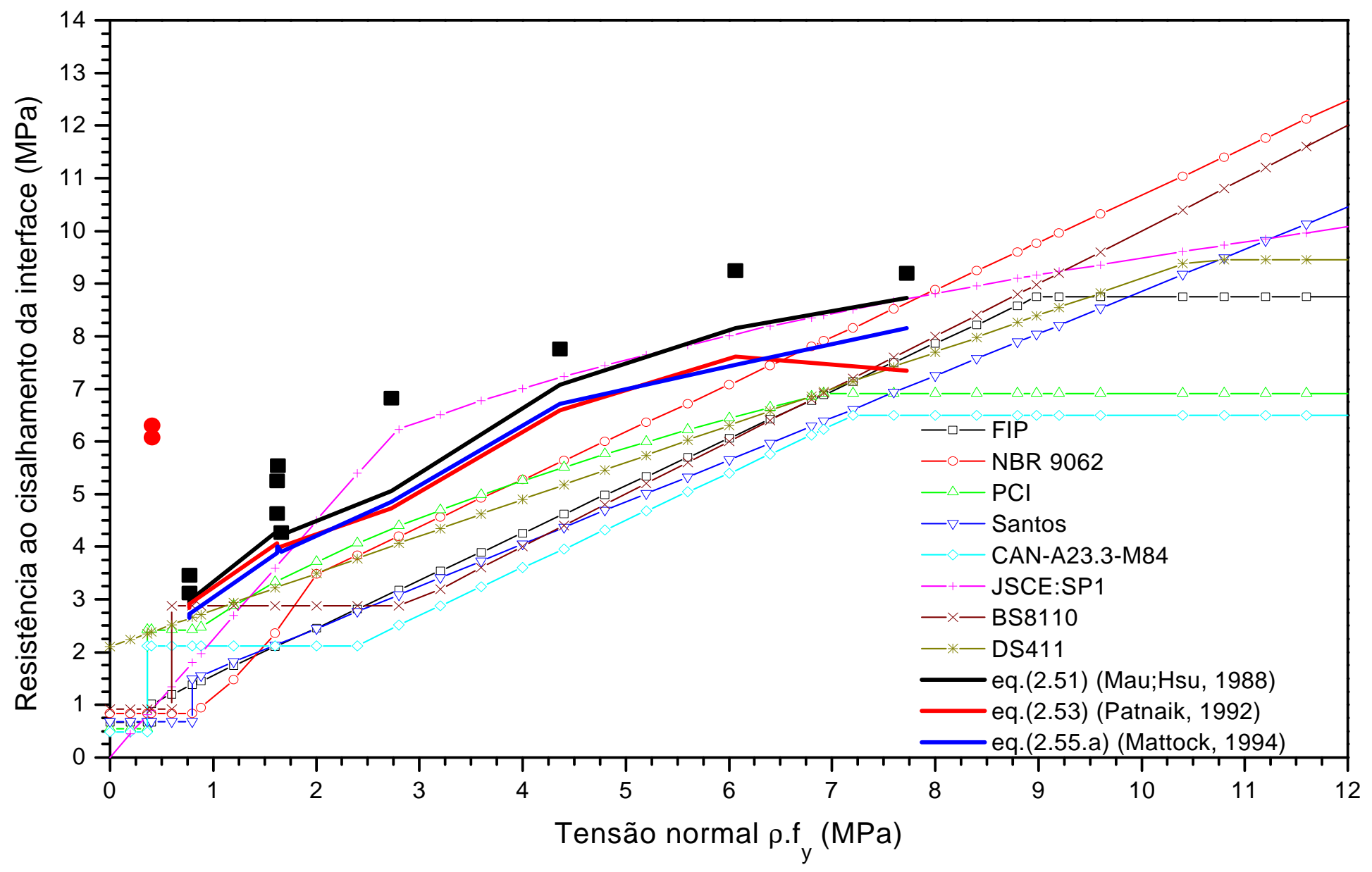

Figura A.2 - Comparação entre as curvas dos modelos empíricos e as curvas dos procedimentos de normas e regulamentos. (continuação) 
Tabela A.2 - Coeficientes de minoração dos modelos analíticos e empíricos

\begin{tabular}{|c|c|}
\hline modelo & $\begin{array}{c}\text { coeficiente de } \\
\text { minoração }(\phi)\end{array}$ \\
\hline TASSIOS; VINTZELEOU (1990) & 0.74 \\
\hline HSU, et al., (1987) & 0.84 \\
\hline Loov (eq.(2.46)) & 0.82 \\
\hline WALRAVEN, et al.,(1987) (eq.(2.49)) & 0.85 \\
\hline MATTOCK (1988) (eq.(2.50)) & 0.75 \\
\hline MAU; HSU (1988) (eq.(2.51)) & 0.84 \\
\hline PATNAIK (1992) (eq.(2.53)) & 0.85 \\
\hline MATTOCK (1994) (eq.(2.55.a)) & 0.83 \\
\hline
\end{tabular}

Vale registrar aqui que, num estudo mais detalhado, talvez seja mais conveniente utilizar coeficientes diferentes para baixas e altas taxas de armadura atravessando a interface. Essa observação está embasada no fato da relação entre os resultados fornecidos pelos modelos e os resultados dos ensaios apresentar comportamento diferente em função da quantidade de armadura de costura. 


\section{Apêndice I: Complementação dos resultados do programa experimental desenvolvido}

Neste apêndice são apresentados alguns resultados dos ensaios das vigas compostas que não foram analisados no texto.

\section{I.1. Deformação na armadura longitudinal}

A armadura longitudinal das vigas foi instrumentada para acompanhamento das deformações. Na figura I.1 são mostrados os resultados obtidos dos ensaios das três vigas.

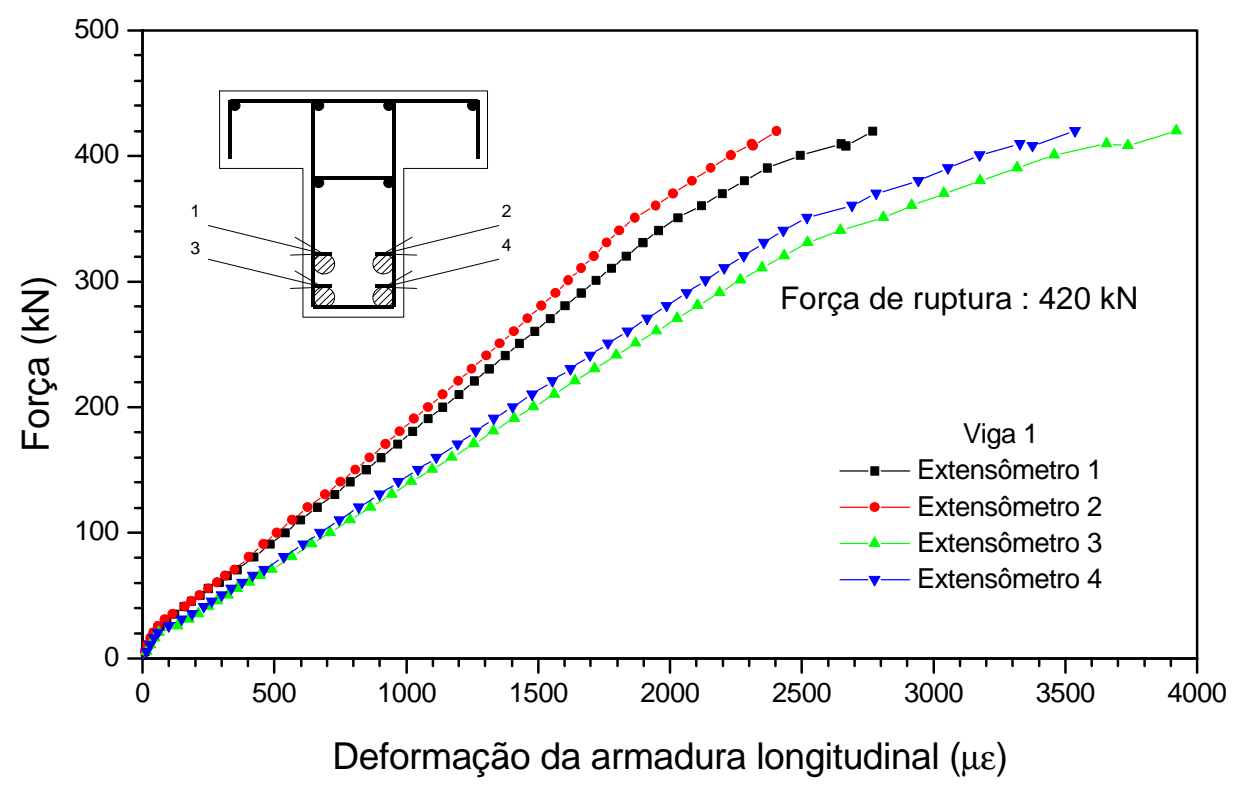

Figura I.1 - Deformação da armadura longitudinal das vigas ensaiadas. (continua) 

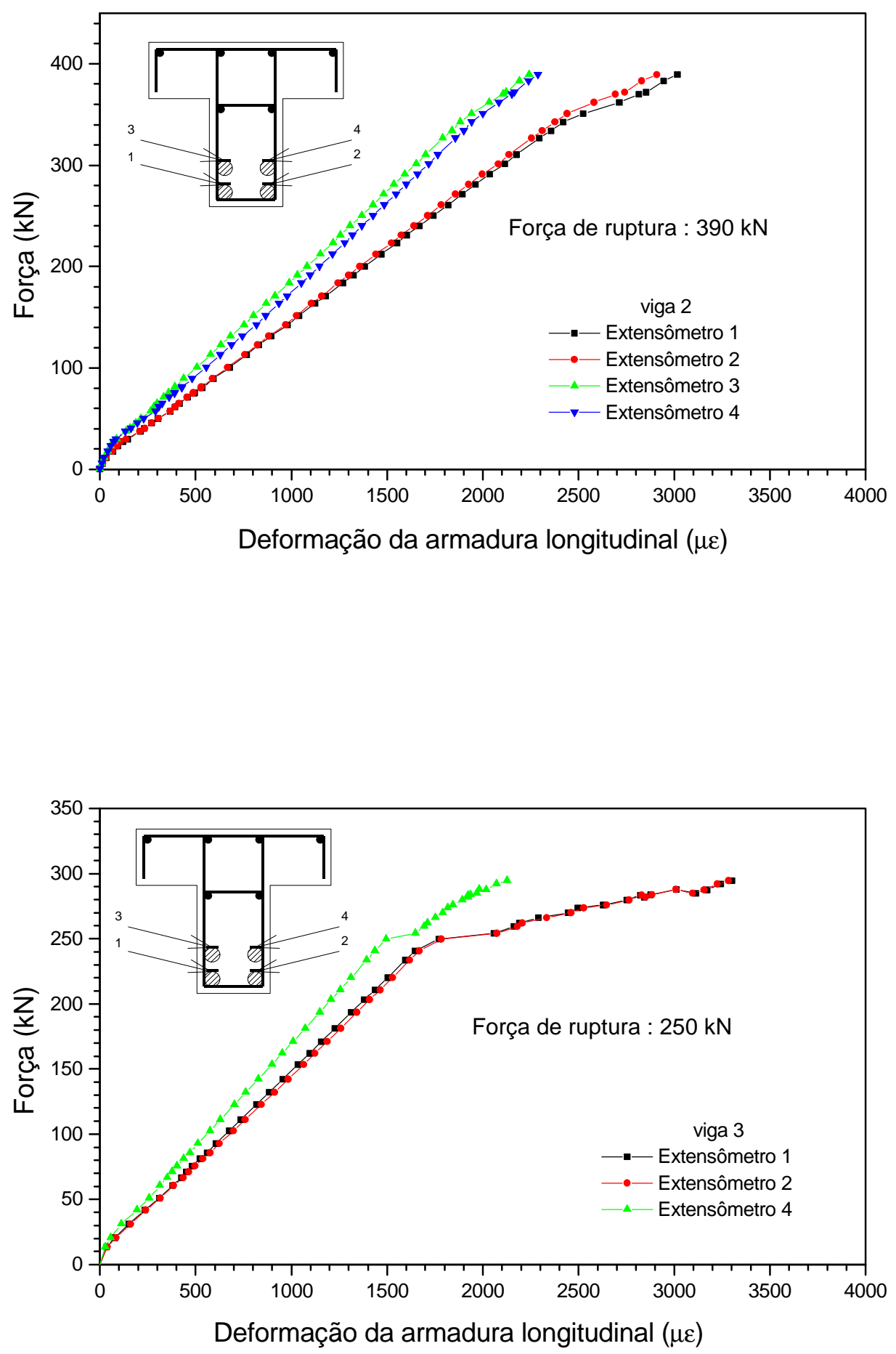

Figura I.1 - Deformação da armadura longitudinal das vigas ensaiadas. (continuação) 
Observa-se na viga 3 um rápido incremento na deformação da armadura após atingida a ruptura da viga. Estes resultados indicam que houve uma separação entre a mesa e alma que passaram a comportar-se de forma independente, ou seja, sem transferência de tensões pela interface.

\section{I.2. Deformação no concreto}

Foram colados extensômetros elétricos de resistência na superfície superior da mesa para acompanhamento, durante os ensaios, das deformações de compressão no meio do vão. Os resultados obtidos estão mostrados na figura I.2.

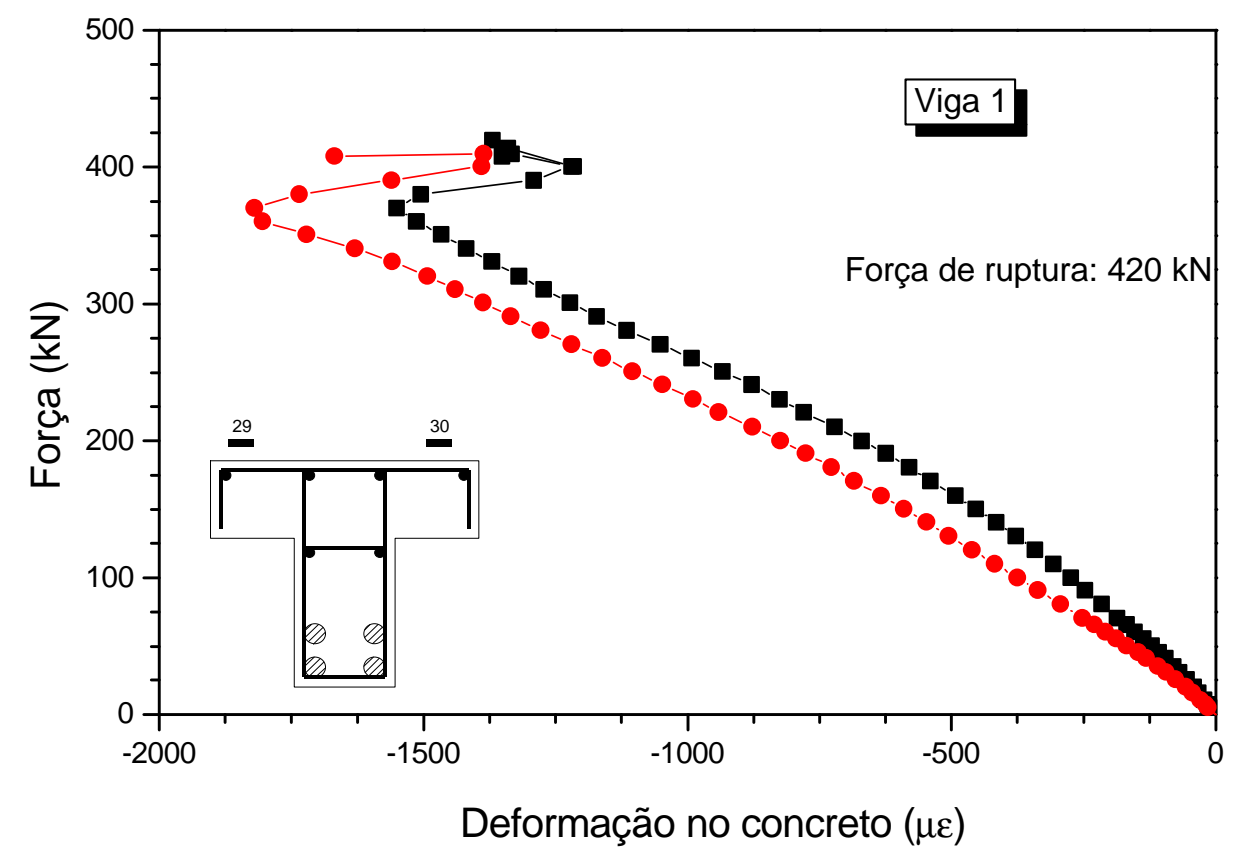

Figura I.2 - Deformação no concreto das vigas ensaiadas. (continua) 

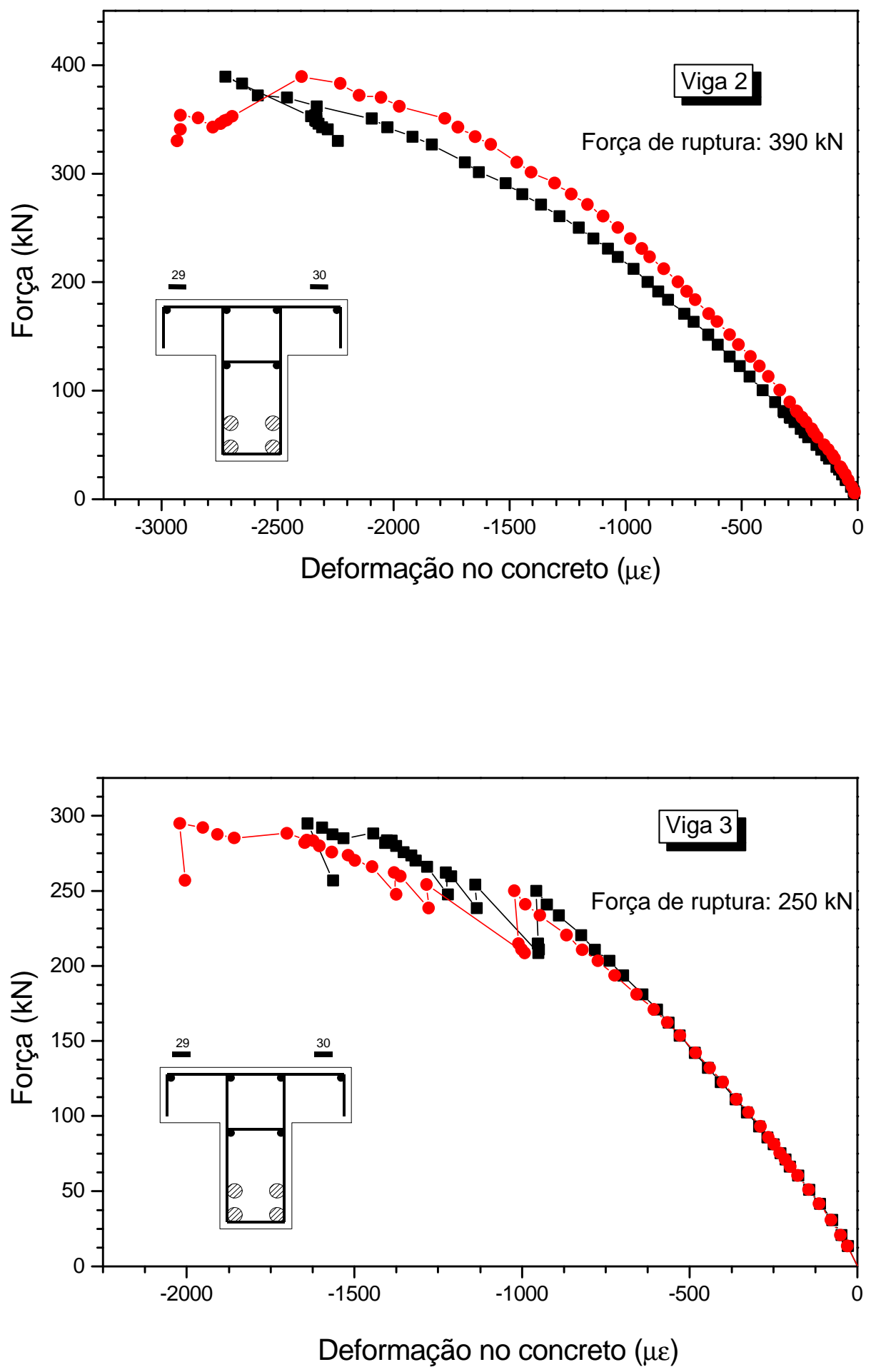

Figura I.2 - Deformação no concreto das vigas ensaiadas. (continuação) 


\section{I.3. Deformação nos estribos da alma}

Os estribos da alma das vigas foram instrumentados para acompanhamento das deformações devido ao esforço cortante. Na figura I.3 são mostrados os resultados obtidos dos ensaios das três vigas.

\section{I.4. Deslocamentos verticais}

Os deslocamentos verticais das vigas foram medidos em três pontos por transdutores de deslocamentos. Os resultados obtidos das três vigas ensaiadas são mostrados na figura I.4. Na tabela I.1 são mostradas as flechas das vigas no momento da ruptura.

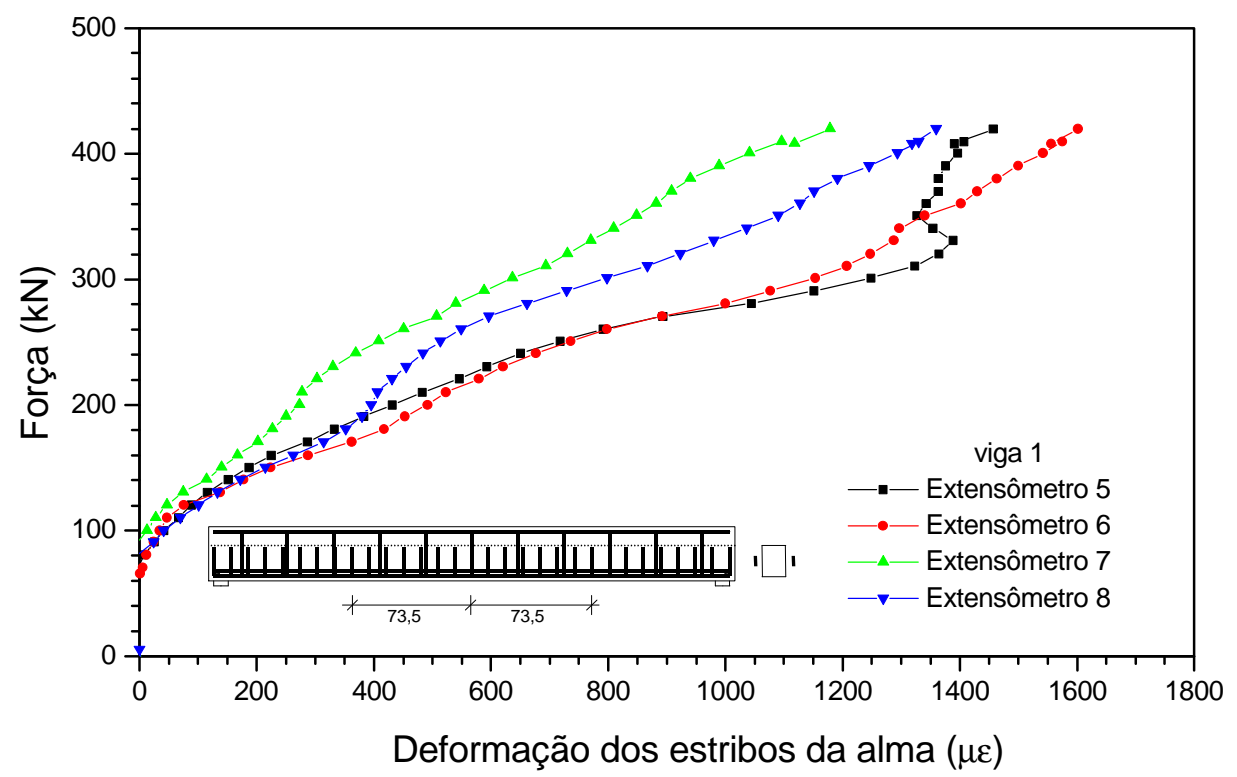

Figura I.3 - Deformação nos estribos da alma. (continua) 


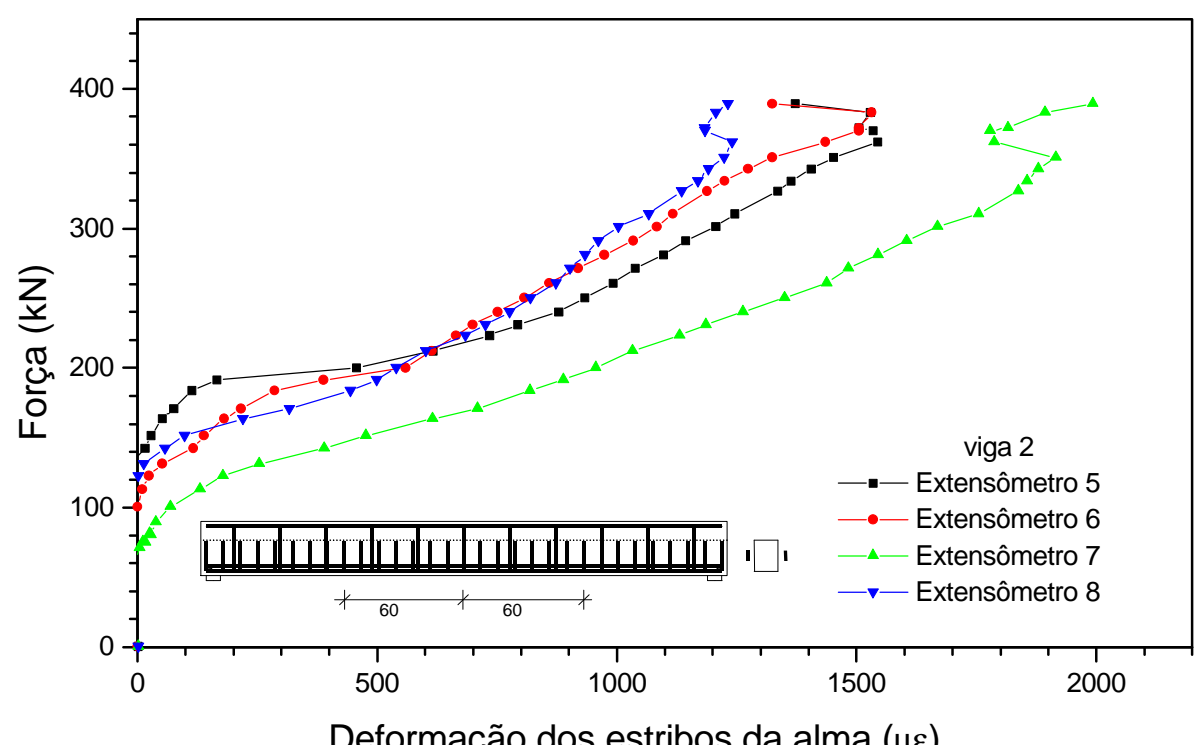

Deformação dos estribos da alma $(\mu \varepsilon)$

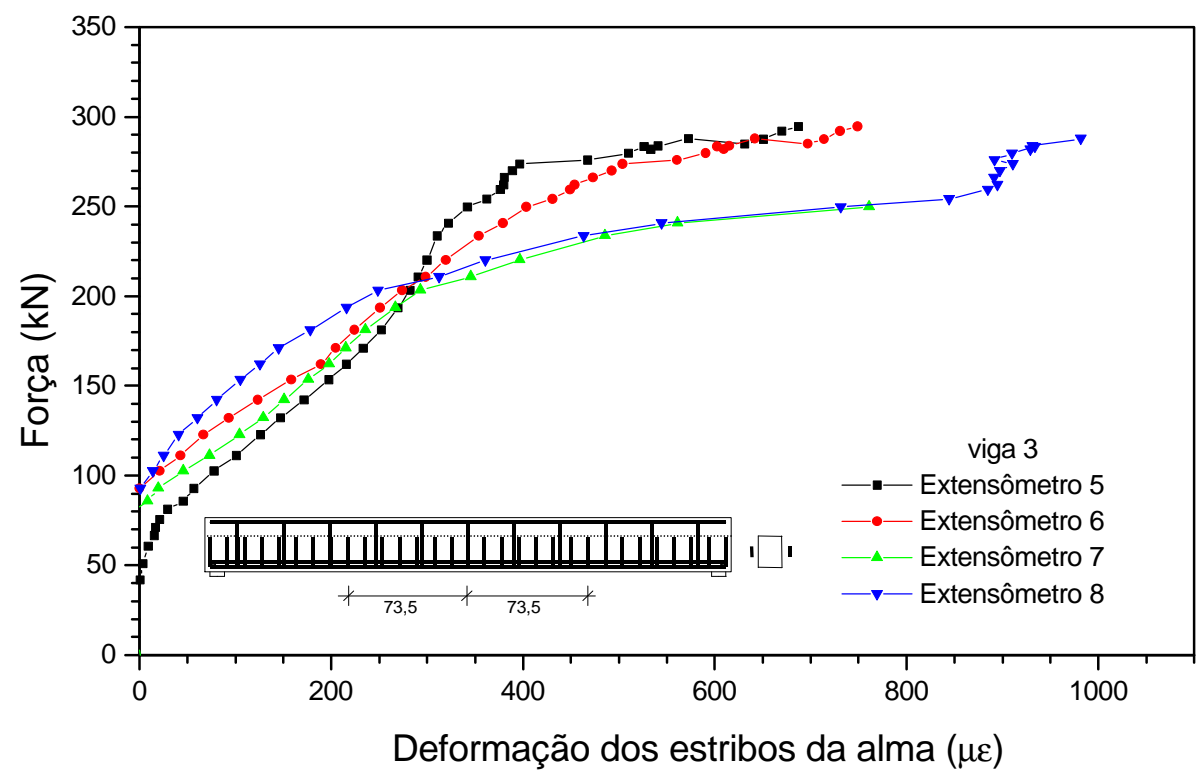

Figura I.3 - Deformação nos estribos da alma. (continuação) 

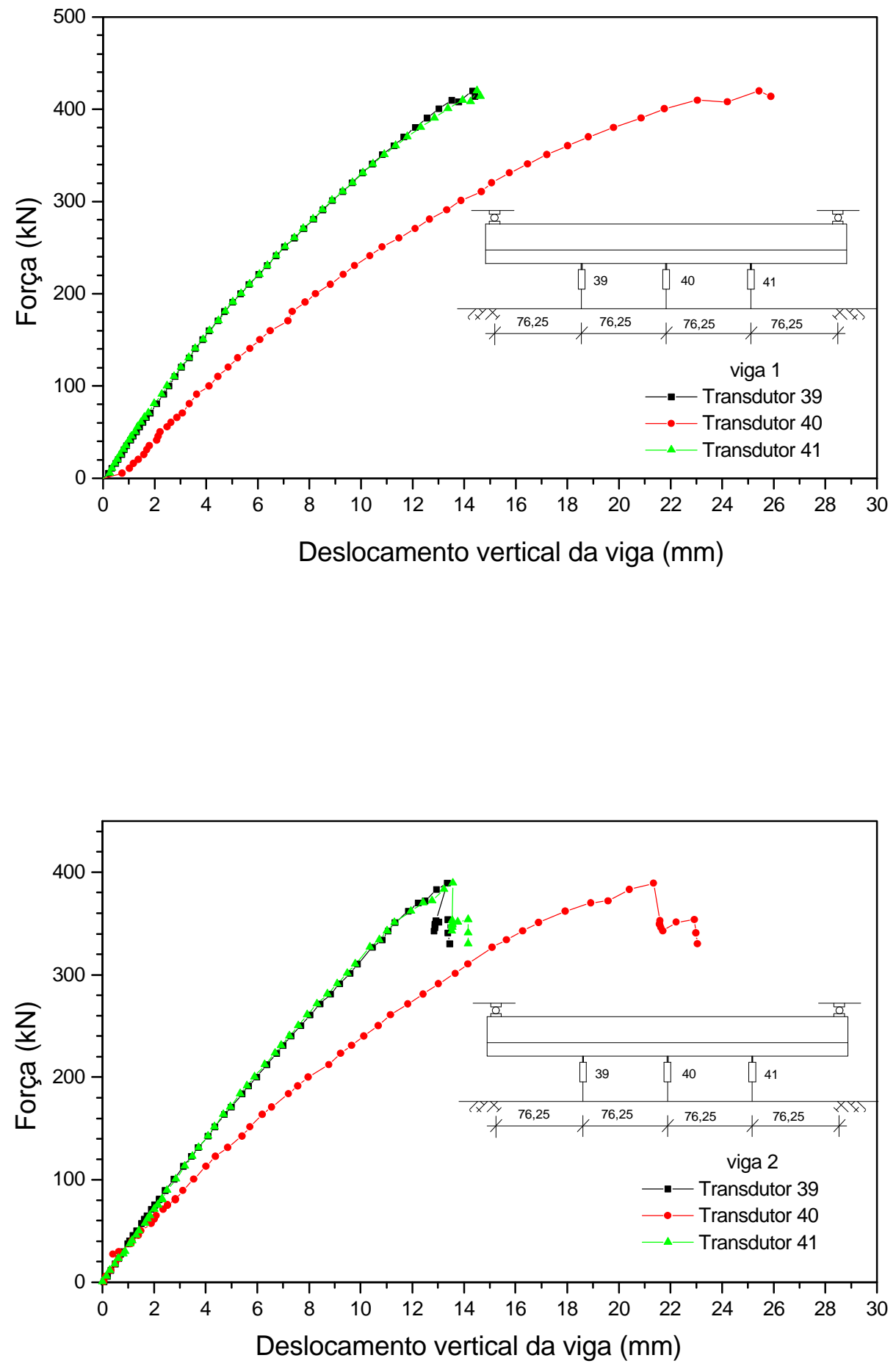

Figura I.4 - Deslocamentos verticais das vigas. (continua) 


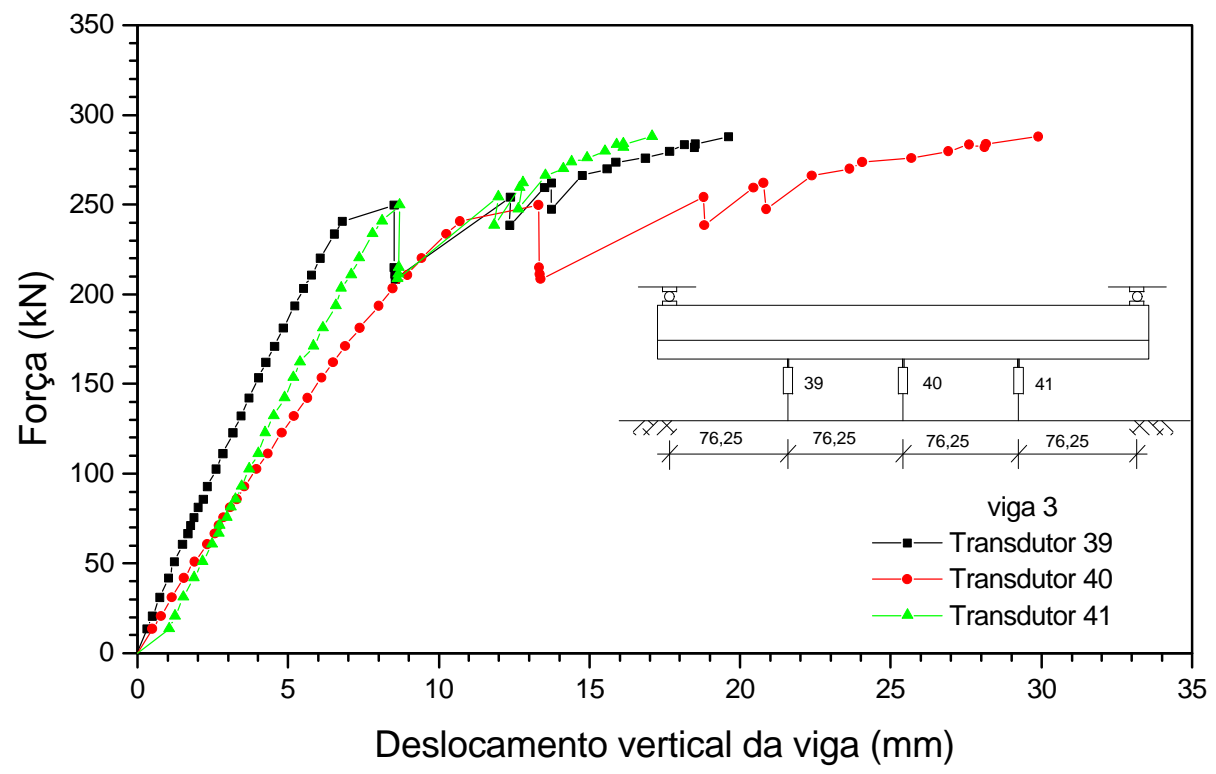

Figura I.4 - Deslocamentos verticais das vigas. (continuação)

Tabela I.1 - Flecha no meio do vão das vigas ensaiadas no momento da ruptura.

\begin{tabular}{|c|c|c|}
\hline Viga & Força de ruptura $(\mathrm{kN})$ & Flecha no meio do vão $(\mathrm{mm})$ \\
\hline 1 & 420 & 25,43 \\
\hline 2 & 390 & 21,33 \\
\hline 3 & 250 & 13,31 \\
\hline
\end{tabular}

